
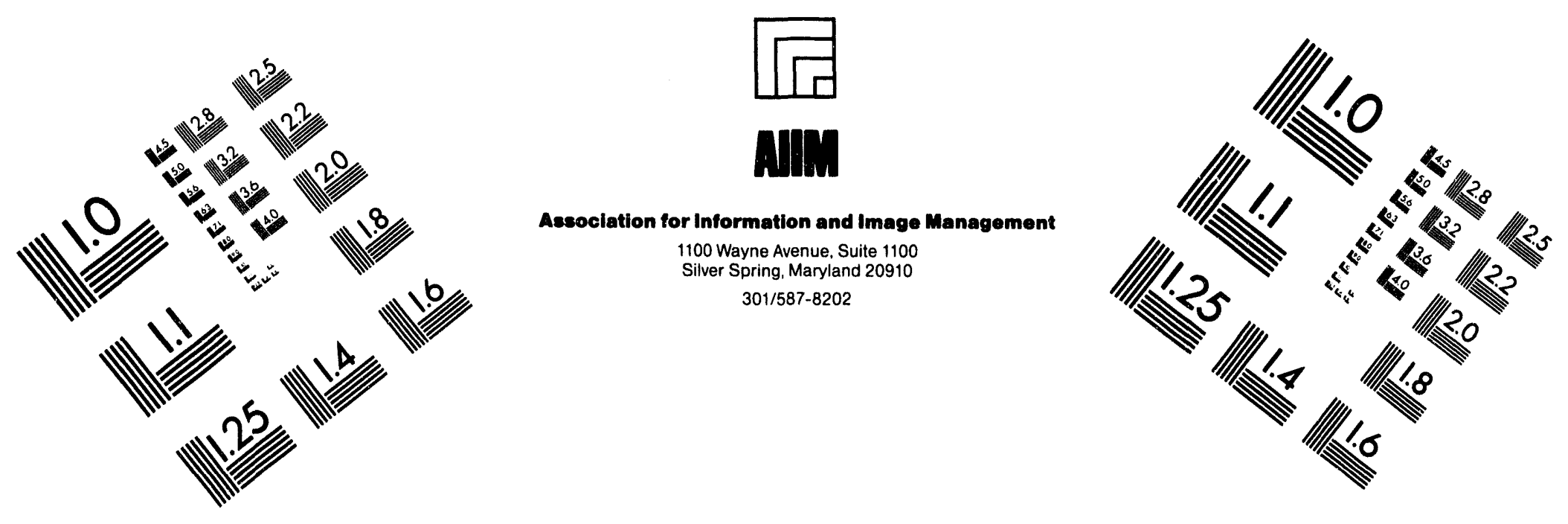

\title{
Centimeter
}

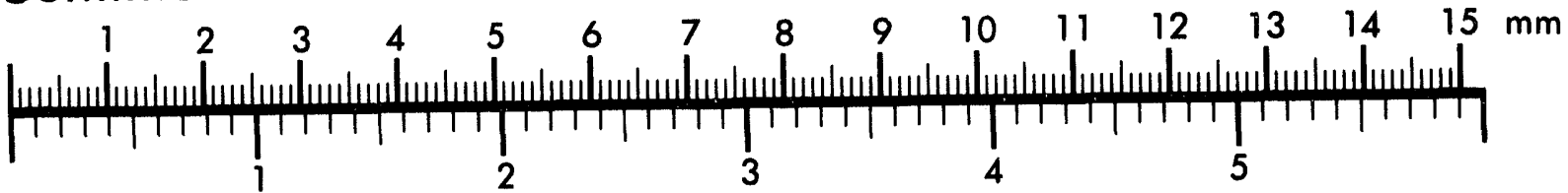
Inches
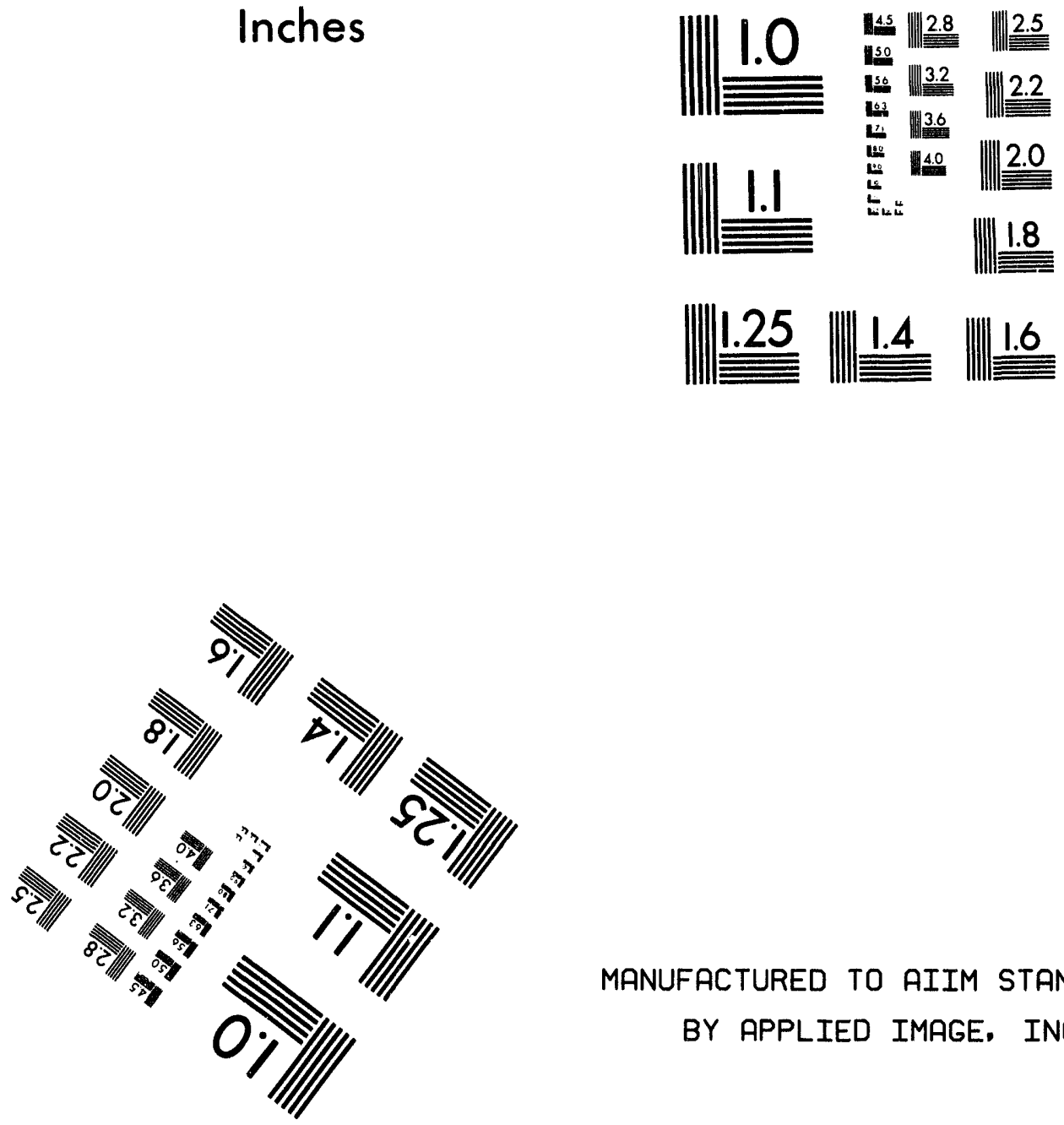

MANUFACTURED TO AIIM STANDARDS BY APPLIED IMAGE, INC.

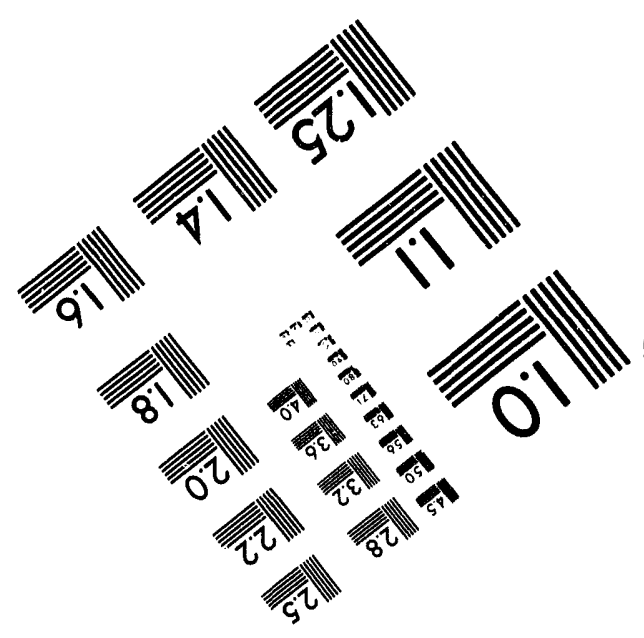





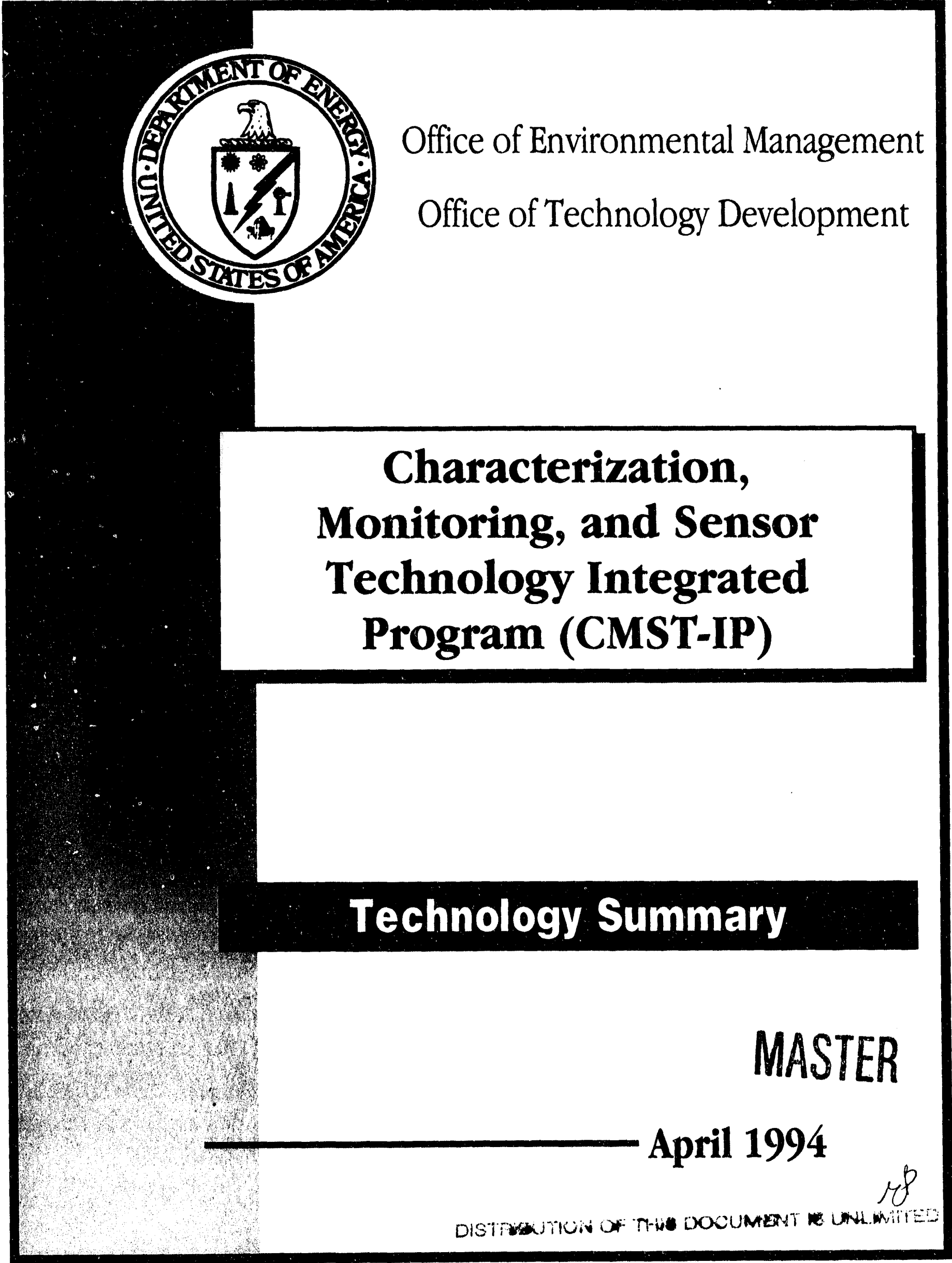




\section{CHARACTERIZATION, MONITORING, AND SENSOR \\ TECHNOLOGY INTEGRATED PROGRAM \\ TECHNOLOGY SUMMARY}

\section{CONTENTS}

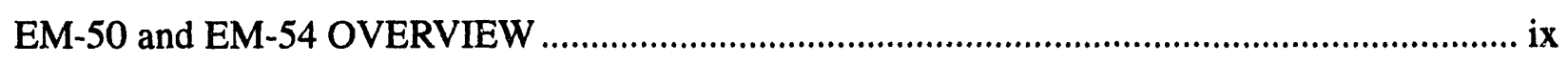

Characterization, Monitoring, and Sensor Technology Integrated Program Overview .............. xiii

1.0 Contaminants in Soils and Groundwater ................................................................... 1

1.1 Expedited Site Characterization at DOE Facilities ................................................... 3

1.2 Ames Laboratory Expedited Site Characterization Project ……………………….... 5

2.0 Sensors and Field Analysis Equipment …………...................................................... 9

$2.1 \quad$ Ames Mobile Laboratory Project ........................................................................ 11

2.2 Site Characterization and Penetrometer System ................................................... 13

2.3 Time Domain Reflectometry and Fiber-Optic Probes for the Cone

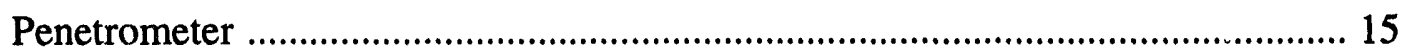

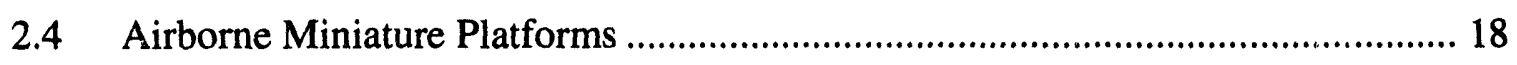

2.5 Development of Screening and Quantitative Field Methods Coupled to the

Cone Penetrometer ……………………............................................................ 21

2.6 Secondary Ion-Mass Spectrometry Analysis: Development and Evaluation ......... 24

2.7 Miniaturized Chemical Flow Probe Sensor Development ...................................... 27

2.8 Multi-analyte, Single-Fiber Optical Sensor …………........................................... 30

2.9 Sol-Gel Indicator Program ................................................................................ 32

2.10 Portable, Real-Time Monitoring Systems for Volatile Organics ............................ 35

2.11 Chlorinated and Aromatic Hydrocarbon Thin Film Chemical Sensors ................. 38

2.12 Air Quality Site Boundary Monitoring for Volatile Organic Compounds ............. 42

2.13 Direct Sarnpling Ion Trap Mass Spectrometry Instrumentation ............................. 45 
2.14 Multisorbent Arrayed Sampler for Collection of Vadoze Zone Organic Contaminants 48

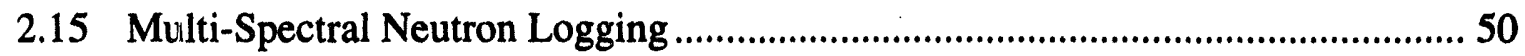

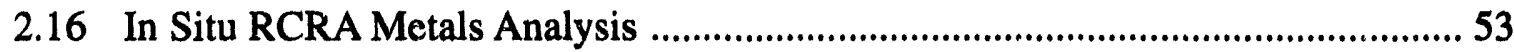

2.17 Air-Quality Monitoring for Alpha Contamination - Long Range Alpha

Detector 56

2.18 Direct Measurement of Strontium-90 in Surface Soils in Real-Time ................... 59

2.19 LA-ICP-AES Using a High-Resolution Fiber-Optic Interferometer .................... 62

2.20 Characterization and Monitoring Support for the Savañnah River Integrated Demonstration Program 65

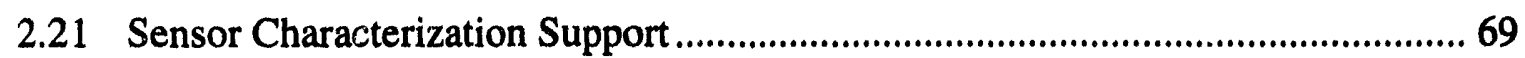

2.22 Technology Performance Specifications .......................................................... 71

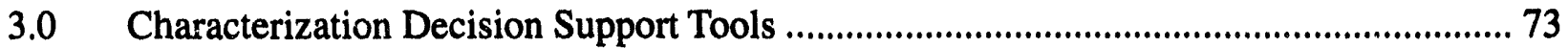

3.1 Data Fusion for Characterization and Monitoring ....................................... 75

4.0 Geophysical and Hydrogeologic Measurements ........................................................ 79

4.1 Three-Dimensional/Three-Component Reflection Seismic for Site

Characterization

4.2 Crosshole Compressional and Shear-Wave Seismic Tomography ....................... 84

4.3 Zero-Tension Lysimeters: An Improved Design to Monitor Colloid-Facilitated

Contaminant Transport in the Vadoze Zone ....................................................... 87

4.4 Analog Site for Characterization of Fractured Rock ........................................ 90

4.5 Rabbit Valley Geophysics Performance Evaluation Range .............................. 92

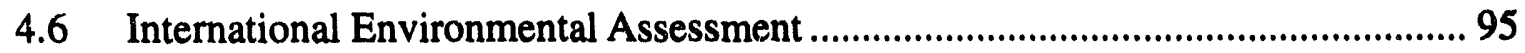

4.7 Contaminant Transport Studies of Russian Sites ............................................ 96

4.8 Electrical Resistance Tomography for Subsurface Imaging ............................... 99

$5.0 \quad$ High-Level Waste Tanks ............................................................................. 103

5.1 Moisture Measurement by Electromagnetic Induction .................................... 105 
5.2 In-Tank Interface Detection Using Time Domain Reflectometry ...................... 108

5.3 Transuranic Elements and Moisture Measurement in High-Level Waste Tanks by Neutron Activation

5.4 Sensing of Head Space Gases: Continuous In Situ Monitoring of Gaseous Components in Underground Storage Tanks Using Piezoelectric Thin Film Resonator Sensors

5.5 Raman Probe Radiation Study 116

5.6 Infrared Analysis of Wastes: Novel Laboratory and On-Line Measurements by Photoacoustic and Transient Infrared Spectroscopies

5.7 Laser Ablation Mass Spectrometry Scanning of Waste Tank Core Samples ....... 121

5.8 Imaging Through Obscuration During Sluicing Operations .............................. 124

5.9 Problem-Directed Rapid Chemical Characterization ...................................... 126

6.0 Characterization, Treatment, and Disposal of Mixed Waste ...................................... 129

6.1 Contiruous Emission Monitor for Incinerations ....................................... 131

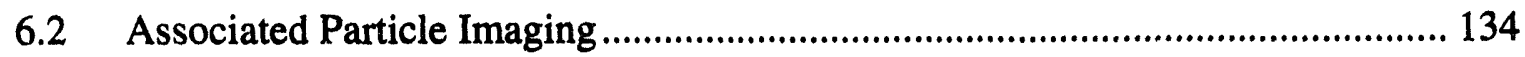

6.3 Defining Requirements for Evaluation and Testing of Characterization

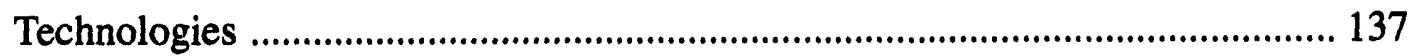

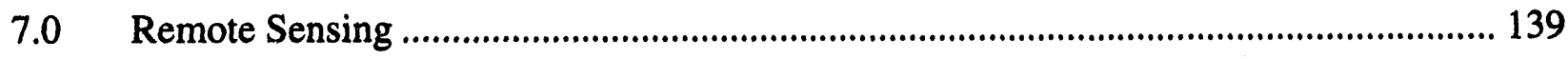

7.1 Remote Sensing Systems Development .................................................... 141

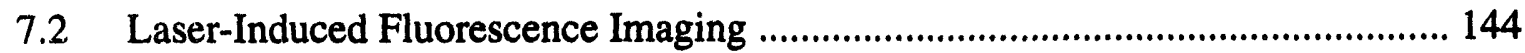

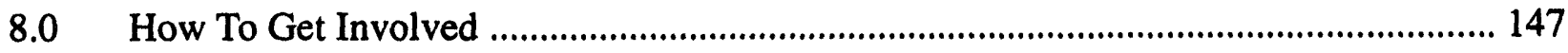

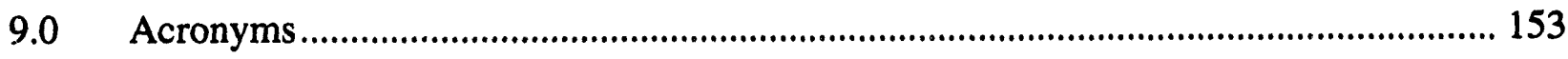




\section{Figures}

A DOE Organizational Structure as of June 1993 ......................................................... ix

B. Office of Technology Development Organizational Structure as of June 1993 .............. X.

1.1a. Expedited Site Characterization. ............................................................................. 3

1.1b. A general map of the Pantex Site showing the locations of current work zones. ............ 4

1.2. Iowa State University Center for Advanced Technology Development Model applied to Expedited Site Characterization. ............................................................. 5

2.1. The Mobile Demonstration Laboratory for Environmental Screening Technologies. ..... 11

2.2. Site Characterization and Analysis Penetrometer System description. ........................ 13

2.3. Cone Penetrometer Tip for Hydrologic Investigations. .......................................... 15

2.4a. The "Droop Snoop," a plane designed to carry a 35mm camera. .............................. 18

2.4b. Out-dated aerial photograph of Solid Waste Storage Area 6 on the Oak Ridge

Reservation

2.4c. Photograph taken from the "Droop Snoop," rectified and substituted for the same area in the out-dated photograph.

2.6a. Secondary ion mass spectrometry particle bombardment and sputtering of salt species from tank waste.

2.6b. Schematic diagram of transportable SIMS instrument applied to the analysis of salt particulate from underground storage tanks.

2.6c. Direct SIMS analysis of basalt chips contaminated with tributyl phosphate.

2.7. Schematic representation of functional blocks for the flow probe in a possible device arrangement.

2.8. Photo-micrograph of the distal end of a single 500 micron diameter imaging fiber. ...... 30

2.9a. Diagram of fiber optic diode array spectrophotometers system with sol-gel probe........ 32

2.9b. Response of bromophenol blue sol-gel pH probe. .............................................. 33

2.10a. Schematic of a surface acoustic wave sensor. ...................................................... 35 
2.10b. Deployment of a down hole portable acoustic wave sensor system at the Hanford site in Washington State.

2.10c. Real-time monitoring of contamination at the Hanford site using a down hole portable acoustic wave sensor system for in situ analysis.

2.11a. Fourier-transform infrared-attenuated total reflection (FTIR-ATR) spectras. 38

2.11b. Linear concentration dependent SAW response of various analytes.

2.11c. Comparisons of the responses of the self-assembled a-cyclodextrin monolayer.

2.12. The Los Alamos transportable gas chromatograph ion trap mass spectrometer used for the field analysis of volatile organic compounds in the environment.

2.13a. Direct sampling ion trap mass spectrometry modular inlet system. 45

2.13b. Fieldable direct sampling ion trap mass spectrometry instrumentation. 46

2.14a. Multisorbent arrayed sampler. 48

2.14b. Field deployment of prototype arrayed sampler at 'Savannah River Site.

2.15a. Small portion of a simulated gamma-ray energy spectrum. 50

2.15b. Cross-section of contaminant-doped concrete test facility setting on an existing borehole calibration model at the Grand Junction Projects Office.

2.16a. Schematic representation of a basic laser-induced breakdown spectroscopy instrument. 53

2.16b. Calibration curve for Los Alamos soil spiked with lead. 54

2.17a. Schematic of a long range alpha detector, technology-based air-quality monitor. 56

$2.17 \mathrm{~b}$. Radon response of two long range alpha detector, technology-based detectors, HM-1 and HM-2. 57

2.17c. An overlay of the particulate-corrected HM-2 and Grand Junction Project Office data. 57

2.18a. Schematic cross-section of improved Strontium-90 sensor showing discrimination capabilities. 60

2.18b. Simplified diagram of the custom-designed sensor circuitry. 61 
2.19a. Schematic of the acousto-optic tunable filter, fiber-optic Fabry-Perot interferometer system.

2.19b. Illustration of overlapping bandwidths of acousto-optic tunable filter and fiber-optic Fabry-Perot devices leading to high resolution of combined system.

2.19c. Spectrum of uranium solution in an inductively coupled plasma, using the bulk optics Fabry-Perot

2.20. Three-dimensional image showing the distribution of tetrachloroethylene at concentrations of greater than $0.25 \mathrm{mg} / \mathrm{kg}$ in sediments at the Integrated

Demonstration Site. 68

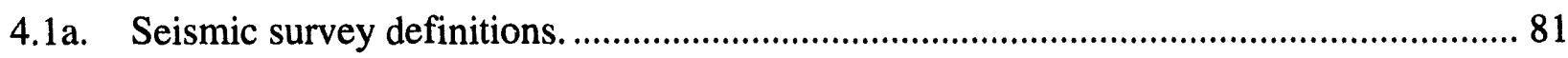

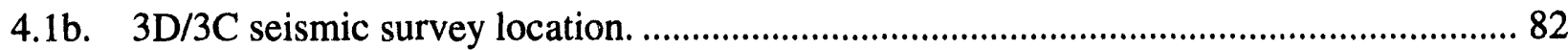

4.2a. Down hole equipment used in preliminary test at Hanford site. ....................................... 84

4.2b: Example of cross hole data collected with Bolt airgun at Hanford site............................ 85

4.3a. Sampling and maintenance of the zero-tension lysimeter. ............................................. 88

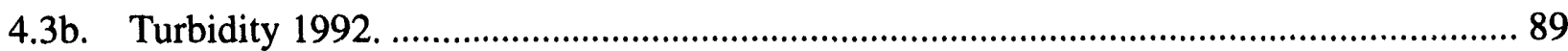

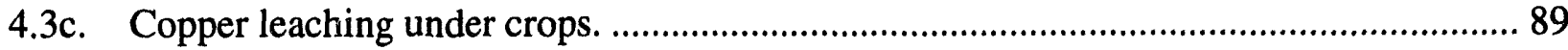

4.5. Contour presentation of electrical conductivity data collected over the Geophysics Performance Evaluation Range.

4.8a. Schematic representation of electrical resistance tomography to delineate leaks from an underground storage tank 99

4.8b. Computer simulation of electrical resistance tomography below a steel tank with a conductive plume of $250 \mathrm{ohm}-\mathrm{m}$ beneath the tank center. 101

5.1. Magnitude of complex impedance plotted vs.percent moisture 106

5.2a. Twin lead laboratory probe data collected with cathetometer. 109

5.2b. Waste liquid level/sludge-salt cake characterization using time domain reflectometry. 110

5.3c. Time domain reflectometry liquid level monitoring system using a twin lead probe. ... 110 


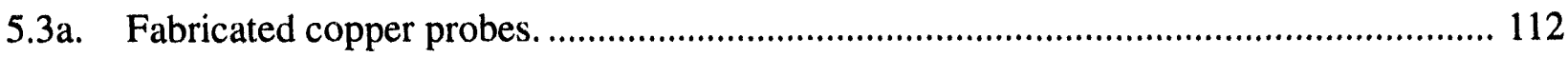

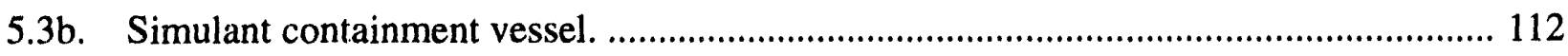

5.4a. Two thin film resonators and a custom integrated circuit epoxied to a chip carrier...... 113

5.4b. Response of quartz crystal microbalances with a coating of nickel-palladium alloy as a function of hydrogen concentration. ....................................................... 114

5.4c. Thin film resonators are used as the frequency control elements in oscillator circuits. . 115

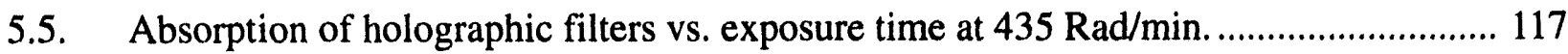

5.6a. Schematic of a transient infrared spectroscopy unit on the waste encapsulation line.... 118

5.6b. Fourier-transform infrared photoacoustic spectroscopy spectra of three sludge surrogates containing differing amounts of nitrate.

5.6c. Typical correlation between nitrate peak heights observed by Fourier-transform infrared photoacoustic spectroscopy and the actual nitrate concentration in the sample.

5.7a. Laser-ablation/mass spectrometry sampling analysis..................................... 121

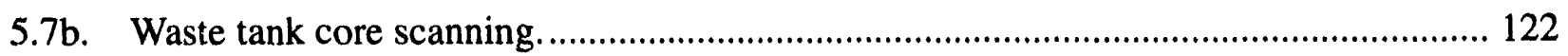

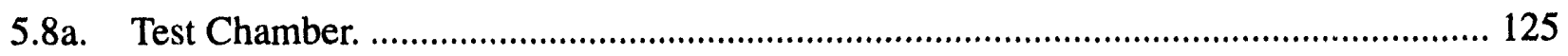

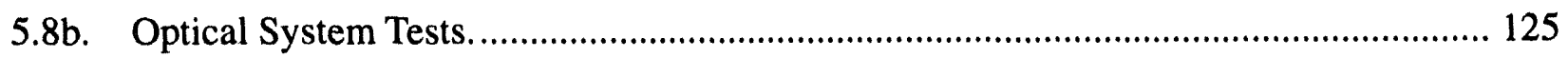

5.9. Comparison of chromatograms of extract of unknown fuel spill on Oak Ridge Reservation soil with standard diesel fuel, confirming that the unknown soil is actually diesel fuel from a ruptured storage drum.

6.1a. The Toxic Substances Control Act Incinerator at K-25, Oak Ridge, Tennessee. .......... 131

6.1b. Comparison of stack gas samples with and without methane present......................... 133

6.2a. Associated Particle Imaging schematic. ............................................................. 134

6.2b. Three-dimensional images of salt and water from real associate particle imaging data. 134

6.2c. Three-dimensional images of salt and water from simulated associated particle imaging data. 
7.1. Comparison of aerial photo with Daedalus Multispectral Scanner channel 10............ 142

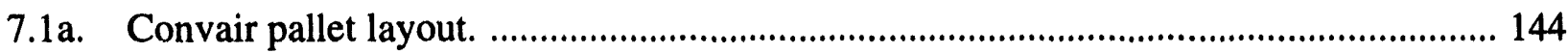

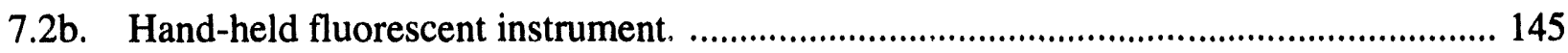

\section{TABLES}

6.2. Data showing how spatial gating improves sig.7al to noise ratios ........................... 135

7.1. Table comparing the root mean squared error of two standard image registration algorithms with the newly developed multiquadric algorithm. The registration error in the multiquadric method is less

142 


\section{EM-50 and EM-54 OVERVIEW}

The Department of Energy (DOE) established the Office of Technology Development (EM-50) (OTD) as an element of Environmental Restoration and Waste Management (EM) in November, 1989 (see Figure A). The organizational structure of EM-50 is shown in Figure B.

EM manages remediation of all DOE sites as well as wastes from current operations. The goal of the EM program is to minimize risks to human health, safety and the environment, and to bring all DOE sites into compliance with Federal, state, and local regulations by 2019.

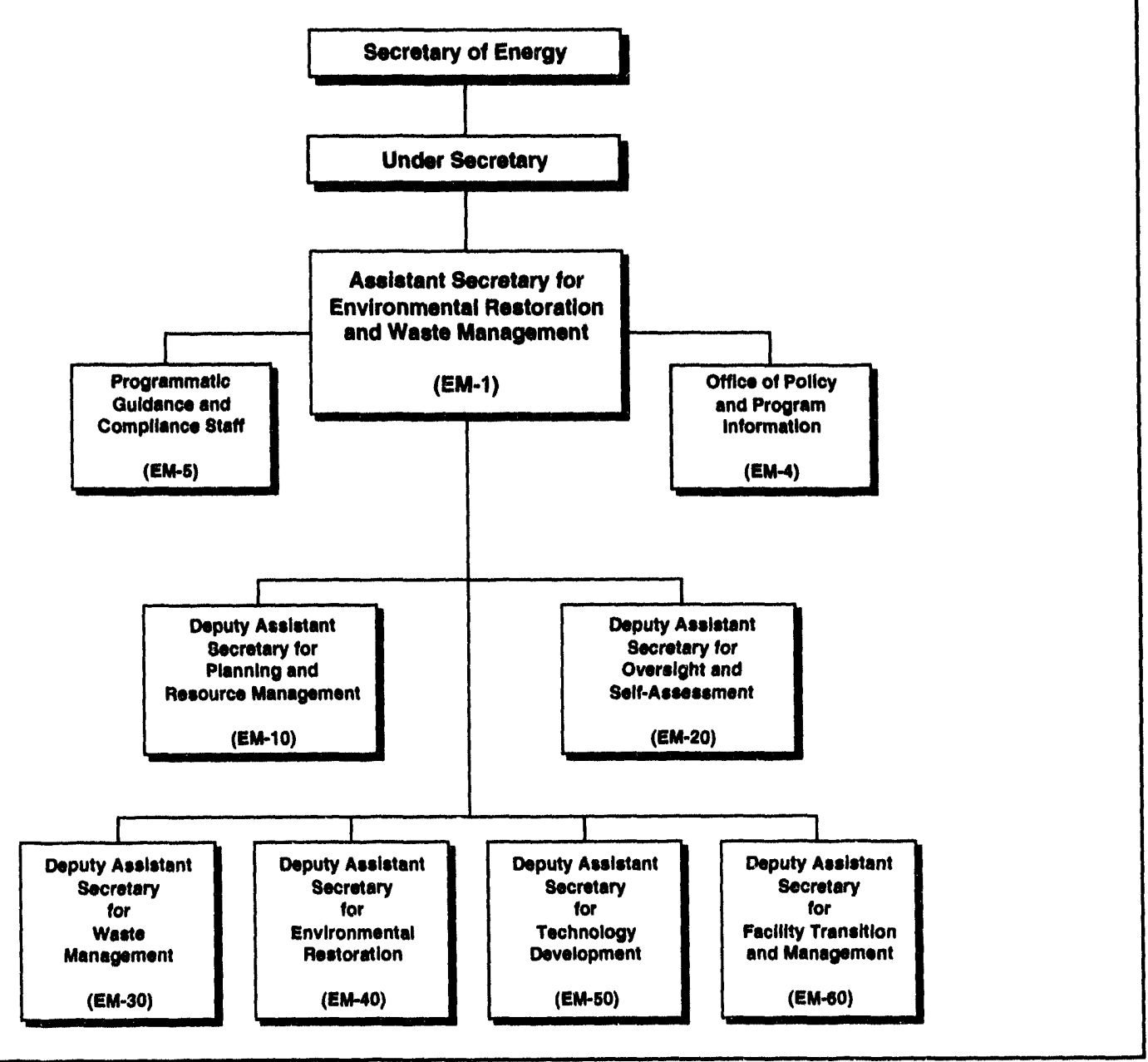

Figure A. DOE Organizational Structure as of June 1993.

EM-50 is charged with developing new technologies that are safer, faster, more effective and less expensive than current methods.

In an effort to focus resources and address opportunities, EM-50 has developed Integrated Programs (IP) and Integrated Demonstrations (ID). 
An Integrated Program focuses on technologies to solve a specific a spect of a waste management or environmental problem and it can be either unique to a site or conmon to many sites. An Integrated Program supports applied research to develop innovative technologies in key application areas organized around specific activities required in each stage of the remediation process (e.g., characterization, treatment, and disposal).

An Integrated Demonstration is the cost-effective mechanism that assembles a group of related and synergistic technologies to evaluate their performance individually or as a complete system in correcting waste management and environmental problems from cradle to grave.

The Characterization, Monitoring, and Sensor Technology Integrated Program (the subject of this report) is part of EM-541, the Environmental Restoration Division of EM-54. Figure B shows the EM-50 Organizational Structure as of June 1993.

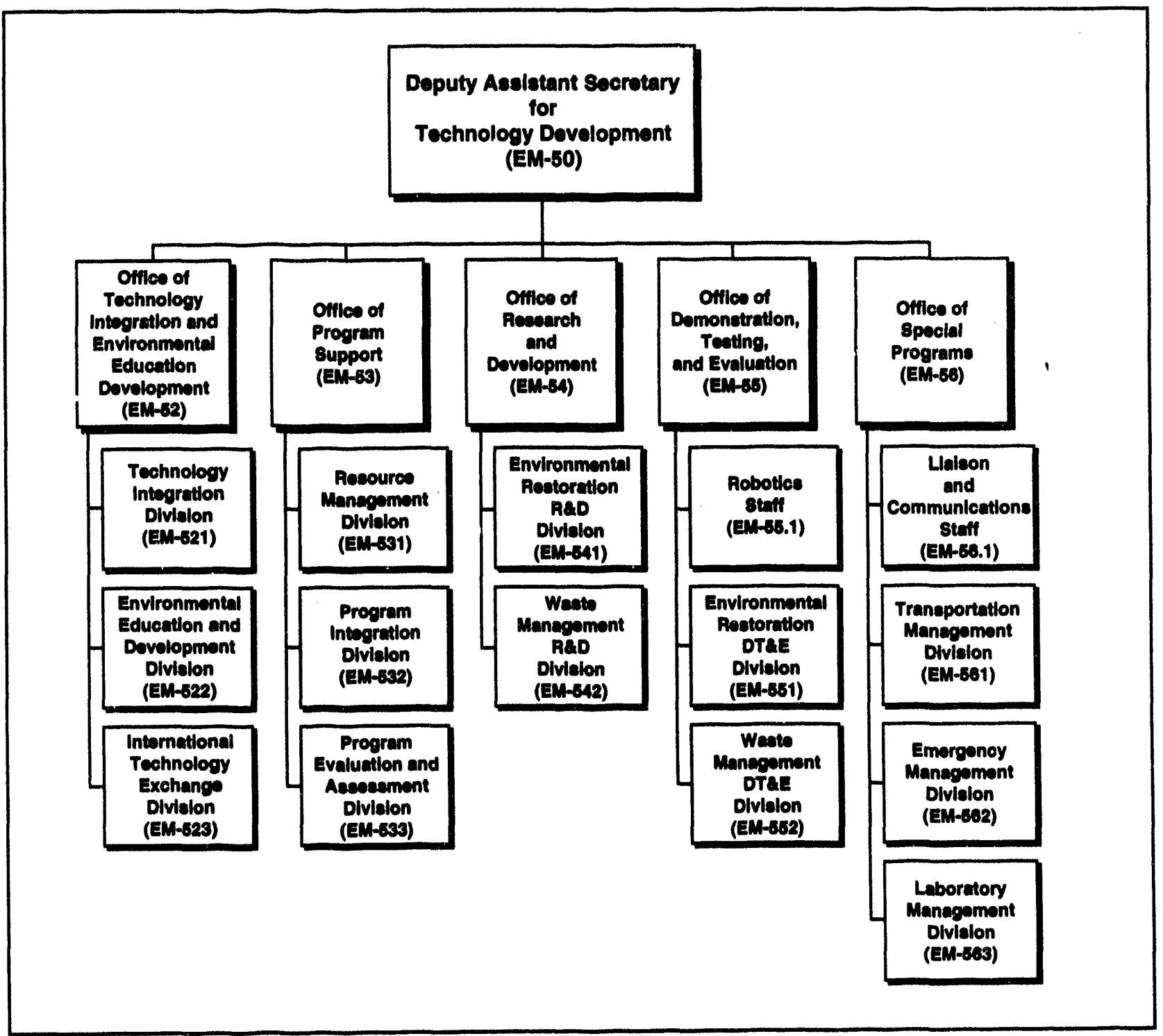

Figure B. Office of Technology Development Organizational Structure as of June 1993. 


\section{CHARACTERIZATION, MONITORING, AND SENSOR TECHNOLOGY INTEGRATED PROGRAM OVERVIEW}

\section{PURPOSE}

The Characterization, Monitoring, and Sensor Technology Integrated Program seeks to deliver needed technologies, timely and costeffectively, to the Office of Waste Management (EM-30), the Office of Envirosimental Restoration (EM-40), and the Ciffice of Facility Transition and Management (EM-60). The scope of characterization, monitoring, and sensor technology needs that are required by those organizations encompass:

- initial location and characterization of wastes and waste environments prior to treatment;

- monitoring of waste retrieval, remediation and treatment processes;

- characterization of the co-position of final waste treatment forms to evaluate the performance of waste treatments processes; and

- site closure and compliance monitoring.

Wherever possible, the CMST-IP fosters technology transfer and commercialization of technologies that it sponsors.

\section{TECHNOLOGY NEEDS}

Validated CMST needs submitted by the Office of Waste Management, the Office of Environmental Restoration, and the Office of Technology Development were reviewed by teams of technical experts who compared these needs against their knowledge of existing
CMST. This comparison led to the generation of CMST development needs, written primarily by the technical experts, that formed the core of the CMST portion of the FY95 Calls for Proposals, the Research Opportunity Announcement (ROA), and the 1994 DOE EM Small Business Innovative Research (SBIR) Solicitation. Two draft characterization technology need statements were prepared as part of the Tank Waste Remediation System (TWRS) FY94 Technology Development Plan.

\section{WINDOWS OF OPPORTUNITY FOR CMST-IP}

CMST is needed throughout the EM process from site characterization to final site closure monitoring. The priorities of the CMST-IP will change to anticipate the priority needs of EM-30, EM-40, and EM-60 as those programs' priorities evolve.

\section{ACCOMPLISHMENTS}

Over 280 technical task proposals submitted by DOE and other federal proposers were evaluated by the technical experts cited earlier (see Technology Needs) as members of the CMST-IP Technology Focus Groups as well as by representatives of EM-30 and EM-40 organizations. Copies of the evaluations were distributed to the proposers' site organizations. 
CMST-IP staff also coordinated the review of 117 SBIR grant applications in chemical and radiochemical sensors by over 50 technical experts; CMST-IP staff participated in the review of ROA proposals.

Two topical reports were distributed: Chemical Sensors Technology Development Planning Workshop and Dense Non-Aqueous Phase Liquid (DNAPLs) at DOE Sites: Background and Assessment of Characterization Technologies. Another report, Technologies for the Determination of Radionuclides and Heavy Metals is expected to be completed in FY94.

Other publications include the FY94 CMSTIP midyear booklet and Technology Data Sheets on new and emerging CMST. A paper, "CMST-IP: An Overview of Emerging Technologies in Site/Waste Characterization and Waste Trea:ment Monitoring," was submitted for publication in the Proceedings of Waste Management '94. Another paper, "Development of the Characterization Technologies within the CMST-IP," was submitted to Spectrum ' 94.

The CMST-IP staff participated in the Characterization Technical Support Group activities for all but one of the EM-50 Integrated Demonstrations; the Characterization Architecture Group of the Hanford TWRS activity; Hanford Single-Shell Tank Instrumentation Program Revicw; Hanford Tank Vapor activities; and the EM-40 Field Area Technology Representatives group in support of the Technology Information Exchange workshops. These activities contribute to the effective coordination and integration of CMST applications and Research and Development/Demonstration: Testing, and Evaluation (RD/ DT\&E) efforts and help the CMST-IP team and others stay up to date regarding EM needs and lessons learned.
The CMST-IP Monthly Progress Report, a comprehensive summary of CMST-IP technical progress, has been distributed to over 130 interested parties each month since November 1993.

CMST-IP staff, working closely with the Technology Integration Program Manager and the EM Technology Transfer Network Points-ofContact, devised a focused approach to address technology transfer/commercialization planning for each FY94 CMST-IP project. This approach was presented to CMST-IP principal investigators during the CMST-IP meeting in Denver, CO in February 1994.

\section{FUTURE DIRECTIONS}

A CMST-IP Strategic Plan has been written that considers appropriate mechanisms for CMST-IP interactions with new organizations formed in the reorganization of EM described in the document, A New Approach to Environmental Research and Technology Development at the U.S. Department of Energy released on January 25,1994 . The document explored ways the CMST-IP could provide important links between the characterization organizations of the five focus areas and also broaden involvement with CMST activities of other Federal agencies.

This booklet contains summary sheets that describe FY94 Characterization, Monitoring, and Sensor Technology Integrated Program (CMST-IP) projects. More detailed information regarding these projects can be obtained by contacting the Principal Investigator (PI). 
Contact information is included in each project summary sheet.

\section{For further information, please contact:}

\section{Caroline Purdy}

Program Manager, CMST-IP

U.S. Department of Energy

Treviol. II Building 12800 Middlebrook Road Germantown, MD 20874 (301) 903-7672

\section{Eric Lightner}

Project Manager, CMST-IP

U.S. Department of Energy

Trevion II Building 12800 Middlebrook Road Germantown, MD 20874 (301) 903-7935

\section{Al Tardiff}

Project Manager, CMST-IP

U.S. Department of Energy

Trevion II Building 12800 Middlebrook Road Germantown, MD 20874 (301) 903-7670

\section{Paul Wang}

Integrated Program Coordinator, CMST-IP

Ames Laboratory 106 Spedding Hall Ames, IA 50011-3020 (515) 294-6773 


\section{Contaminants in Soils and Groundwater}

\section{Section 1.0}




\subsection{EXPEDITED SITE CHARACTERIZATION AT DOE FACILITIES}

\section{TASK DESCRIPTION}

A technically innovative approach to environmental site characterization has been developed that integrates all appropriate scientific disciplines to provide a more cost- and timeefficient answer for DOE's site characterization needs. The Expedited Site Characterization (ESC) process, developed by Argonne National Laboratory (ANL), emphasizes the use of a variety of non-intrusive or mininally-intrusive technologies (surface geophysics, cone penetrometer, HydroPunch sampling, vegetation sampling, etc.) to optimize sampling locations and minimize monitoring well installation. Technologies are selected on the basis of site-specific problems and requirements. The results of these technologies are often analyzed, interpreted, and integrated on-site by a full team of scientists through the use of a dynamic work plan. Decisions on sampling and analysis requirements

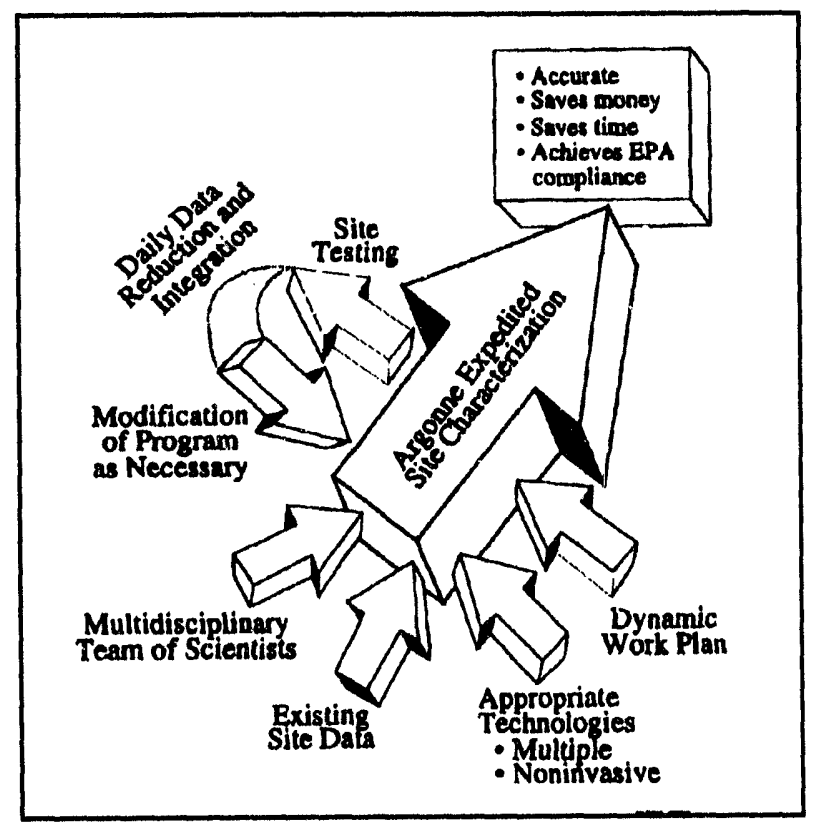

Figure 1.1a. Expedited Site Characterization. are made daily and used for planning the next day's program. This approach has cut the time necessary for full site characterization from programs lasting many months or years, to a matter of a few weeks (see Figure 1.1a).

\section{TECHNOLOGY NEEDS}

With the increased pressure on Federal agencies and regulators to accelerate the remedial activities and final cleanup of Federal facilities across the nation, there is a growing need to broaden the approach to characterize entire facilities, rather than proceeding one-by-one through the evaluation of the thousands of smaller Comprehensive Environmental Response, Compensation, and Liability Act (CERCLA) sites or Resource Conservation and Recovery Act (RCRA) -defined waste units. In response, DOE has identified the need for new site characterization technology and approaches as one of its highest priorities. The objective of the ESC process is to provide a more efficient, scientific, innovative, and integrated approach to solving DOE's site characterization needs, and ultimately to clean up sites and facilities across the DOE Complex.

\section{ACCOMPLISHMENTS}

During FY93, a demonstration of the ESC process was performed by ANL at a former facility site of the Commodity Credit Corporation, U.S. Department of Agriculture, in York, Nebraska. Prior to field demonstration of the methodology, an ESC work plan spe- 
cific to the chosen site was developed. The program emphasized the maximum use of non-intrusive technologies, field analytical procedures, and daily integration of data via various computer programs. Private industry and universities participated in the demonstration as needed, providing certain services, such as cone penetrometer, auger drilling, and field analytic capabilities. More than 100 representatives from private industry, DOE, and other government agencies attended the field demonstration. The field demonstration lasted approximately three weeks and included three separate demonstration sessions.

On the basis of the successful completion of the field demonstration, discussions have been held during the first half of FY94 with representatives from EM-50, EM-40, and their contractors to select a site for implementation of the ESC process at a DOE facility. The Pantex Plant has been tentatively selected as the first DOE site. Appropriate documents related to previous investigations are being reviewed as a prerequisite to development of the technical work plan for the Zone 12 Groundwater ESC.

\section{COLLABORATION/TECHNOLOGY} TRANSFER

The ESC process will be transferred to DOE sites for application in the ongoing environmental restoration programs. During the first phase of the transfer process, a pilot program will be implemented at a selected portion of the Pantex Site in Amarillo, Texas.

In addition, as a second phase of the technology transfer activities, training, guidance, and oversight of a selected industry partner at an additional DOE site will be provided. The private company will be responsible for actual implementation and ANL will provide appropriate technologies and the scientific approach of the ESC process.

\section{For further information, please contact:}

\section{Jacqueline C. Burton}

Argonne National Laboratory

9700 S. Cass Avenue

Argonne, IL 60439-4843

(708) $252-8795$

\section{James Helt}

Technical Program Manager

Argonne National Laboratory 9700 S. Cass Avenue

Argonne, IL 60439-4843 (708)

252-7335

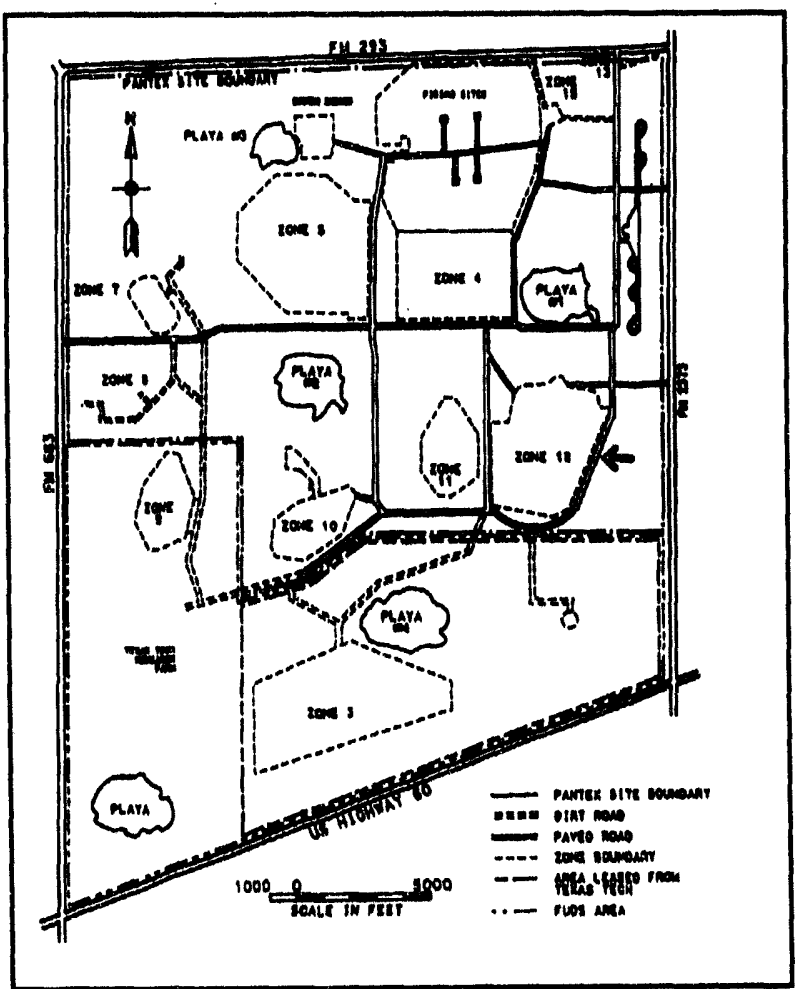

Figure 1.1b. A general map of the Pantex Site showing the locations of current work zones. 


\section{TASK DESCRIPTION}

The mission of the Ames Technology Integration Program (TIP) was conceived in 1990 as a way for the DOE OTD to exploit the existing Iowa State University (ISU) capability for novel university/national laboratory technology derisking and transfer embodied in the ISU Center for Advanced Technology Development (CATD). "Derisking" is the classic period in the development cycle lying in time between laboratory demonstration (bench-top, test tube, working model) and field (breadboard, prototype, pilot-plant) demonstrations. Scale-up issues can be critical. Technical issues, cost, performance, repeatability, and utility are all issues that may surface. This is especially true in the environmental marketplace where regulations are the dominant market driver. This technology transfer method was recently recognized by the Atlantic Council as one that ought to be used nation wide (see Figure 1.2).

The other major component of this proposal is grounded in ESC, which has several distinctive features. An intensive site investigation occurs over a period of several months that includes a comprehensive search for all existing site documentation and interviews with site personnel. This is the first of several steps that gathers, evaluates and integrates all site information and culminates into a daily integration of field data as a powerful decision making tool based on the human expert analysis of the dynamic site model. Field instruments capable of satisfying the United States Environmental Protection Agency (EPA) Level III data quality objectives are required for this process to succeed. Multiple, minimally intrusive, hydrogeological techniques are important tools. Careful planning by qualified experts who manage the field activities is at the core of this process from start to finish. The goal is to sufficiently understand the hydrogeologic media as well as the contaminants, so that expensive monitoring/extraction wells can be effectively positioned and successful remediation accomplished.

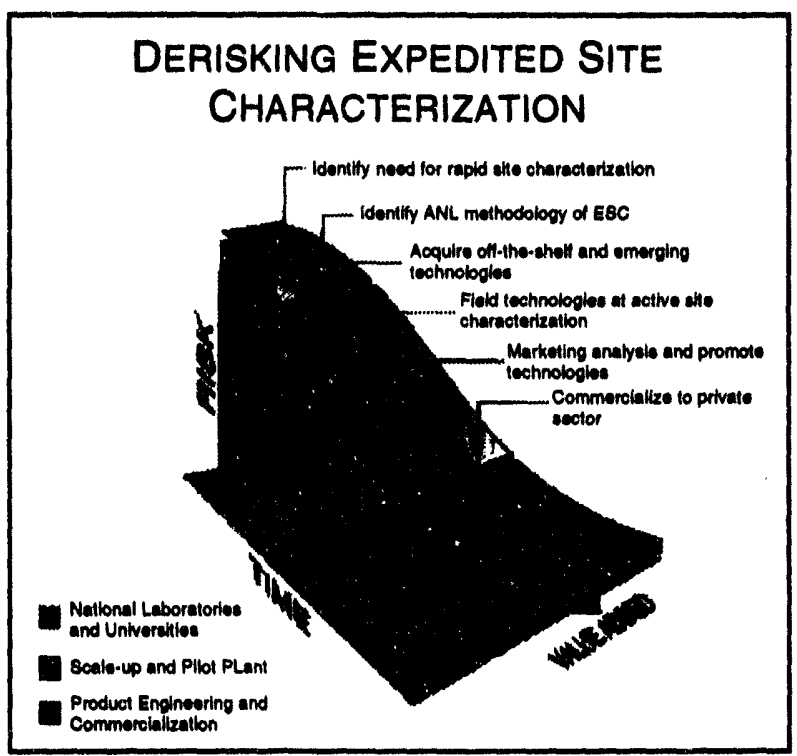

Figure 1.2. Lowa State University Center for Advanced Technology Development Model applied to Expedited Site Characterization.

\section{TECHNOLOGY NEEDS}

The objective of this project is to use the ESC methodology as an effective engine for accelerated transfer of site characterization technologies. To do this, actual contaminated sites must be characterized using both stateof-the-practice technologies (SOPT) and 
emerging technologies (ET) simultaneously. A guiding principle of this task will be to engage the private sector in the fielding of the SOPTs and to seek out the ETs wherever they can be found, whether in the private sector, inside DOE or other Federal agencies, or in university laboratories. Three technology areas are to be fielded and evaluated. Data fusion takes all the site historical information and integrates it with the field hydrogeologic and analytical data into an evolving conceptual site model. A spectrum of two-dimensional (including Site Planner used by ANL) and three-dimensional Geographical Information Systems packages on both a personal computer and a workstation will be fielded in a mobile command center to delineate their relative market niches as a function of site complexity. Choices of analytical and hydrogeologic technologies are site dependent.

\section{ACCOMPLISHMENTS}

Both sites planned for FY94 have been selected: a coal tar type, state lead site at Marshalltown, lowa, and the radiologically contaminated St. Louis Airport site (SLAPS), a DOE Superfund Formerly Utilized Sites Remedial Action Program (FUSRAP) site. Site access has been successfully negotiated for both. Requests for proposals for the site work at Marshalltown have been issued and a high-level statement of work has been agreed upon at SLAPS. Recommendations of the Marshalltown advisory teams have been incorporated into the detailed work plan. Within the organic arena at Marshalltown, SOPTs will consist of gas chromatographic (GC) systems in a mobile laboratory that are tuned to EPA methods (i.e., sonic solvent extraction) while quantitative ET extraction methods (e.g., thermal desorption, supercritical fluid extrac- tion and microextraction) will be fielded. Various immunoassay techniques and passive sorber materials for polycyclic aromatic hy. drocarbon (PAH) will be evaluated as organic screening techniques. Hydrogeological technologies include both geophysical and well/ borehole techniques as well as a cone penetrometer truck (CPT) equipped with tip/sleeve resistance, four probe resistivity and LaserInduced Fluorescence (LIF) sensors. An innovative reflection seismic technique and new down-hole instrumented probe have been identified for consideration. Preliminary site activity, such as nonintrusive geophysical and PAH screening, is scheduled for mid-March 1994 and the mobile laboratory intensive site characterization is scheduled for the second half of April and early May 1994.

\section{COLLABORATION/TECHNOLOGY TRANSFER}

A Ph.D. student and his advisor will be involved with the analysis and interpretation of the CPT information. Since successful bidders for the Marshalltown site field work have not yet been awarded, it is premature to cite collaborators. However, discussions have taken place with more than one potential private sector entity in each of the technical areas and their site-specific subtasks. National experts have been consulted on various aspects of the technology selection process. Cooperation from the property owner, IES Industries Inc., has been outstanding, both on the issue of coordination for the field work that has permitted the Ames Laboratory to meet its schedule to date, but especially in the more difficult promotion tasks of this project. 
Technology transfer is at the heart of this project. State and Federal regulators, technology providers, DOE problem holders, and other stakeholders will be invited to witness both site characterizations in FY94. The site reports will contain recommendations on technology status. But well beyond the reports themselves, brokering of those successful technologies will be an active part of this project after the site characterization work has been finished. The ultimate goal is to enhance the adoption, diffusion and transfer of innovative environmental characterization and monitoring technologies throughout DOE.

\section{For further information, please contact:}

\section{Albert Bevolo}

\section{Tom Noble}

TIP Office 125 S. 3rd St. Ames. IA 50010

(515) 294-5414/(515) 294-3910

\section{Jim Corones}

Technical Program Manager

(515) 294-9636 
- 


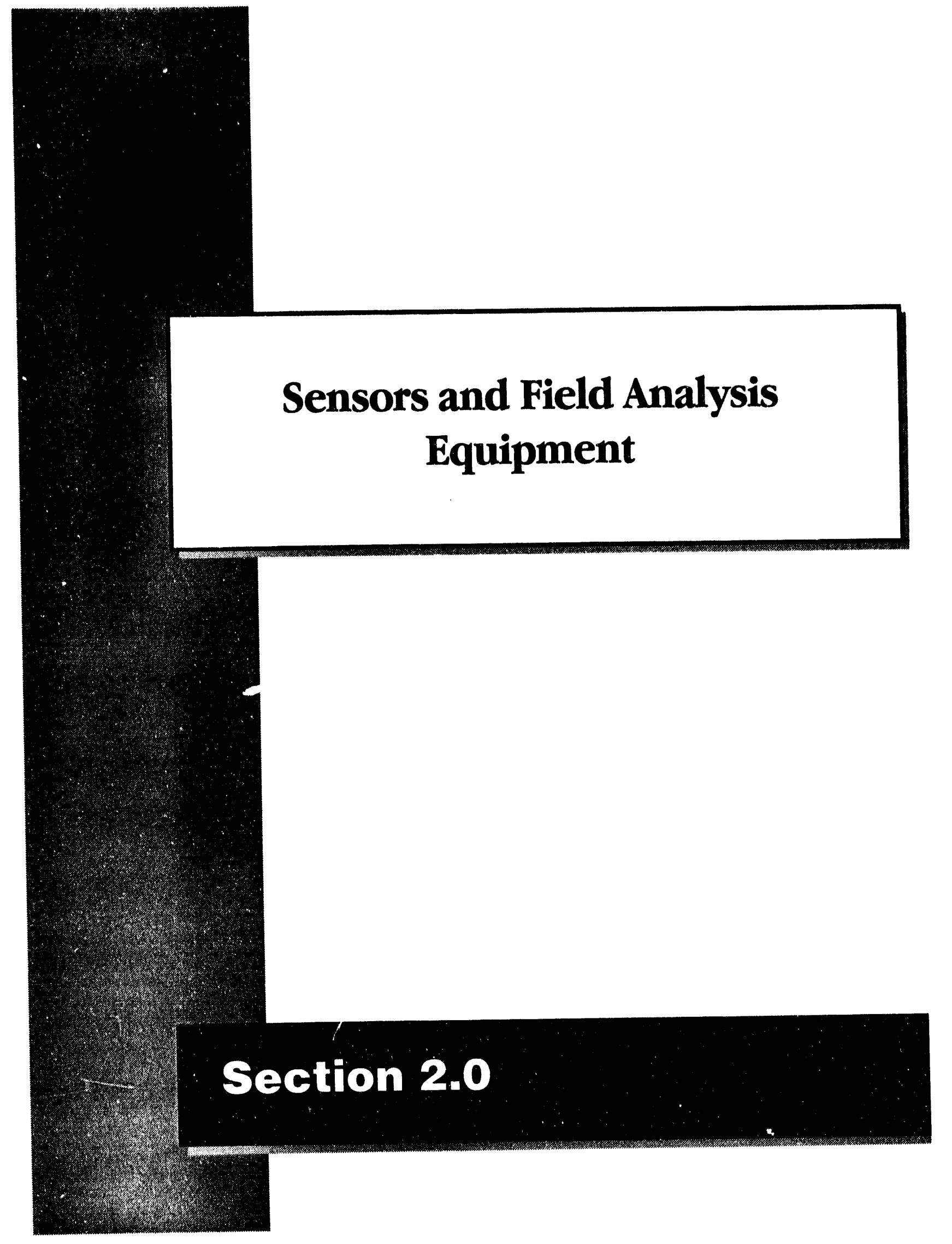




\subsection{AMES MOBILE LABORATORY PROJECT}

\section{TASK DESCRIPTION}

The rapid analysis of soil to determine $230 \mathrm{Th}$ activity levels using an on-site mobile laboratory at a uranium mill tailing remediation action (UMTRA) site will speed the remediation task by supplying the needed results required to make remediation decisions in a matter of 20 minutes, instead of the several weeks usually required to obtain the same information using off-site conventional laboratories. The goal of this task is to develop state-of-the-art technologies into prototype instruments that can help DOE cleanup hazardous waste at the Nuclear Weapons Complex better, safer, faster, and cheaper. The mobile demonstration laboratory for environmental screening technologies (MDLEST) is a completely self-contained mobile laboratory (see Figure 2.1).

Computers and control systems, electrical power, water, gases, and other utilities required to operate instrumentation are supplied by the MDLEST. An inductively coupled plasma-mass spectrometer (ICP-MS) coupled

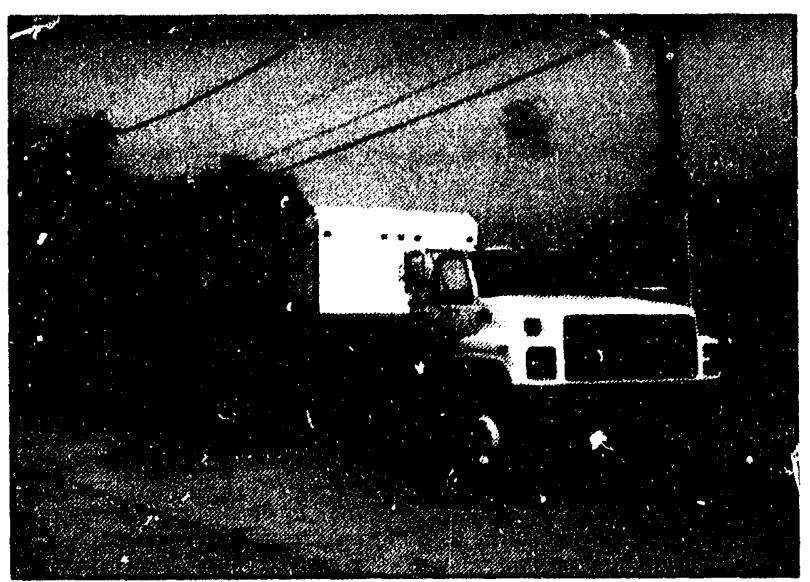

Figure 2.1. The Mobile Demonstration Laboratory for Environmental Screening Technologies. to a laser ablation (LA) sampling system is the current analytical instrumentation installed in the MDLEST for the soil screening demonstration at the Gunnison, Colorado, UMTRA site.

\section{TECHNOLOGY NEEDS}

The current methor. Eor determining heavy metals and radioisotopes in soil at the remediation level, as defined by the EPA and the Nuclear Regulatory Commission (NRC) agreements, is to collect a large number of samples and then analyze them using conventional laboratory methodologies at an off-site contract laboratory. Sample turnaround using this method can take several weeks to months, depending on the methodology of analysis used. Moreover, this approach can be extremely costly, not only due to the analysis, but the delays in making decisions on the amount of remediation still required. The rapid analysis instrumentation, LA-ICP-MS, mounted in a mobile laboratory and operated on-site where results are needed for timely remediation decisions, has been shown feaible by the successful demonstration at the Gunnison, Colorado, UMTRA site.

\section{ACCOMPLISHMENTS}

The LA-ICP-MS instrumentation has the sensitivity necessary to determine the $230 \mathrm{Th}$ activity at the remediation level, $15 \mathrm{pCi} / \mathrm{g}(0.8$ ppb (ng/g)), required by the UMTRA program. Direct analysis of soil samples by LAICP-MS in a mobile laboratory on-site allows 
a few samples per hour to be analyzed to determine the 230Th activity level, which is a more rapid sample turnaround than is currently being achieved using conventional offsite laboratory analyses. While only the 230-isotope of thorium was quantitated at the Gunnison site, the ICP-MS is capable of rapidly detecting trace amounts, sub-ppb, of radioisotopes or other heavy metals in the presence of large amounts of other radioisotopes or heavy metals that might be in the sample and would cause interferences for other measurement techniques.

This demonstration showed that a standard production-model ICP-MS is sufficiently rugged to be installed in a completely self-contained mobile laboratory, be transported across the country, and after arrival at the site, be operationally ready to acquire data in several hours. The system operated in the field for nine days, during winter conditions (as low as $-40^{\circ} \mathrm{F}$ ), without a catastrophic failure.

In summary, this demonstration shows the viability of performing rapid, on-site analysis of soil for radioisotopes using LA-ICP-MS as an alternative to current analytical approaches that require several weeks using an off-site laboratory. Given the constraints and severe weather conditions under which this demonstration was performed, the results are promising. Future effort will be directed to the development of sample preparation methods that will enhance the laser ablation particle generation to increase and stabilize the sample particle stream to the ICP-MS, and sampling methodology to increase operational efficiencies. These developments are suggested to provide a state-of-the-art analytical system, with rapid analysis capabilities, to help UMTRA and other DOE programs effectively fulfill their remediation requirements.

\section{COLLABORATION/TECHNOLOGY TRANSFER}

The ICP-MS instrument used for sample analysis during this demonstration was on loan from the Perkin-Elmer Corporation. In addition, a Perkin-Elmer Principal Scientist in ICP-MS spent 10 days on the site observing the operation of the ICP-MS in the mobile configuration. The demonstration schedule coincided with the year-end UMTRA meetings at the Gunnison site. Forty UMTRA managers and site personnel were given a tour of the MDLEST system with the LA-ICP-MS in operation. Additional visitors to the site during the demonstration included other instrument manufacturers, contractors, and equipment manufacturers that may be interested in future commercial development of the LA-ICP-MS technology.

\section{For further information, please} contact:

\section{Marvin S. Anderson \\ Tom Noble}

Ames Laboratory

TIP Office $125 \mathrm{~S}$. 3rd St.

Ames, IA 50010-6739

(515) 294-6404

Jim Corones

Technical Program Manager

(515) 294-9636 


\subsection{SITE CHARACTERIZATION AND PENETROMETER SYSTEM}

\section{TASK DESCRIPTION}

DOE is seeking new technologies to assist in their efforts to characterize and remediate hazardous waste sites under their control. It is DOE's goal to use technologies that will reduce costs and improve quality and timeliness of both site characterization and remediation. To help meet this goal, DOE has purchased a cone penetrometer truck to be used to conduct research and investigations at various sites throughout the country. This system is re- cost-effective tool for implementation in site characterization investigations at hazardous waste sites throughout the country.

This program will assist DOE in the integration of the SCAPS operations with other facets of OTD's technology development program. Argonne National Laboratory will be responsible for negotiating a contract with a company for the operation and maintenance of the cone penetrometer as well as manage the execution of the subcontract. Technical oversight of the subcontractor will also be provided.

Argonne will be responsible for technical evaluations of all sensors, samplers, and in situ analyses developed. The technology will be evaluated by comparison of the performance to the functional and operating requirements of the potential users of the technology. Once selected, the sensor or sampler de-

Figure 2.2. Site Characterization and Analysis Penetrometer System description.

ferred to as a Site Characterization and Analysis Penetrometer System (SCAPS). Figure 2.2 is a diagram of the SCAPS system.

DOE's major objective is to operate the SCAPS for evaluation and for further technology improvements to both the vehicle and its components. In addition, it is also DOE's objective to ensure that this technology is then transferred to industry, thus providing a rapid and vice will be interfaced to the cone penetrometer.

\section{TECHNOLOGY NEEDS}

The SCAPS, and technology associated with its operation, is expected to provide an improved rapid and cost-effective tool to be used in site characterization investigations at haz- 
ardous waste sites. The technique will allow in situ measurements of geophysical and physical properties of soils and stratigraphic units, as well as the determination of the presence of contaminants at a site without the extensive use of drilling and monitoring well installation. The SCAPS will also be used to collect soil and water data that will provide better definition of the zones of contamination enabling more accurate placement of remediation systems and monitoring wells.

An added benefit of the SCAPS is that the potential exposure of site personnel to hazardous materials is greatly reduced because no wastes are brought to the surface. This also reduces the amount of hazardous material that must be controlled and discarded.

\section{ACCOMPLISHMENTS}

A technical evaluation team met and reviewed the Request For Proposal responses for the SCAPS operation and maintenance contract. All respondents were evaluated on technical merit, which included experience operating CPT vehicles and equipment and experience with DOE and other government contracts. The team ranked each respondent independently and the technically superior company was selected. The financial office performed a budget analysis on all respondents. A conflict of interest review is being conducted by DOE on the selected contractor and upon completion an award will be made.

\section{COLLABORATION/TECHNOLOGY TRANSFER}

This technology will be directly applicable to essentially all environmental groups, whatever their environmental priorities. The prod- ucts of this project will effect all environmental work including site characterization, site remediation, and site restoration. DOE, Department of Defense (DoD), Department of Agriculture, Department of Interior, and the EPA are all potential users of the technology because time and cost will be significantly reduced, and the data collected more comprehensive and accurate. The private sector will also be included as potential users, as corporations begin to realize the need to collect more comprehensive and accurate data at the site characterization phase and speed up remediation of hazardous waste sites. As such, a considerable effort will be directed toward the transferring of information to the scientific community and private sector via literature publications, conferences, and on-site field demonstrations.

\section{For further information, please} contact:

\section{Candace M. Rose}

Argonne National Laboratory

ER203

9700 S. Cass Avenue

Argonne, IL 60439-4843

(708) 252-3499

\section{John Walker}

Argonne National Laboratory

ER203

9700 S. Cass Avenue

Argonne, IL 60439-4843

(708) 252-6803

\section{James Helt}

Technical Program Manager

(708) 252-7335

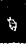




\subsection{TIME DOMAIN REFLECTOMETRY AND FIBER-OPTIC PROBES FOR THE CONE PENETROMETER}

\section{TASK DESCRIPTION}

Sandia National Laboratories (SNL) is fabricating, testing and evaluating a new cone penetrometer application for characterizing hydrogeologic parameters and subsurface contaminant concentrations with chemical specific fiber-optic probes and a Time Domain Reflectometry (TDR) sensor. This development work should help DOE meet some of their needs for characterization and monitor- ing technologies. Because this technology is based on a cone penetrometer system, its deployment is minimally intrusive, and therefore supplies needed subsurface information without waste products. The data collected with this system will meet critical needs for performing fate and transport modelling, as well as risk assessment analyses.

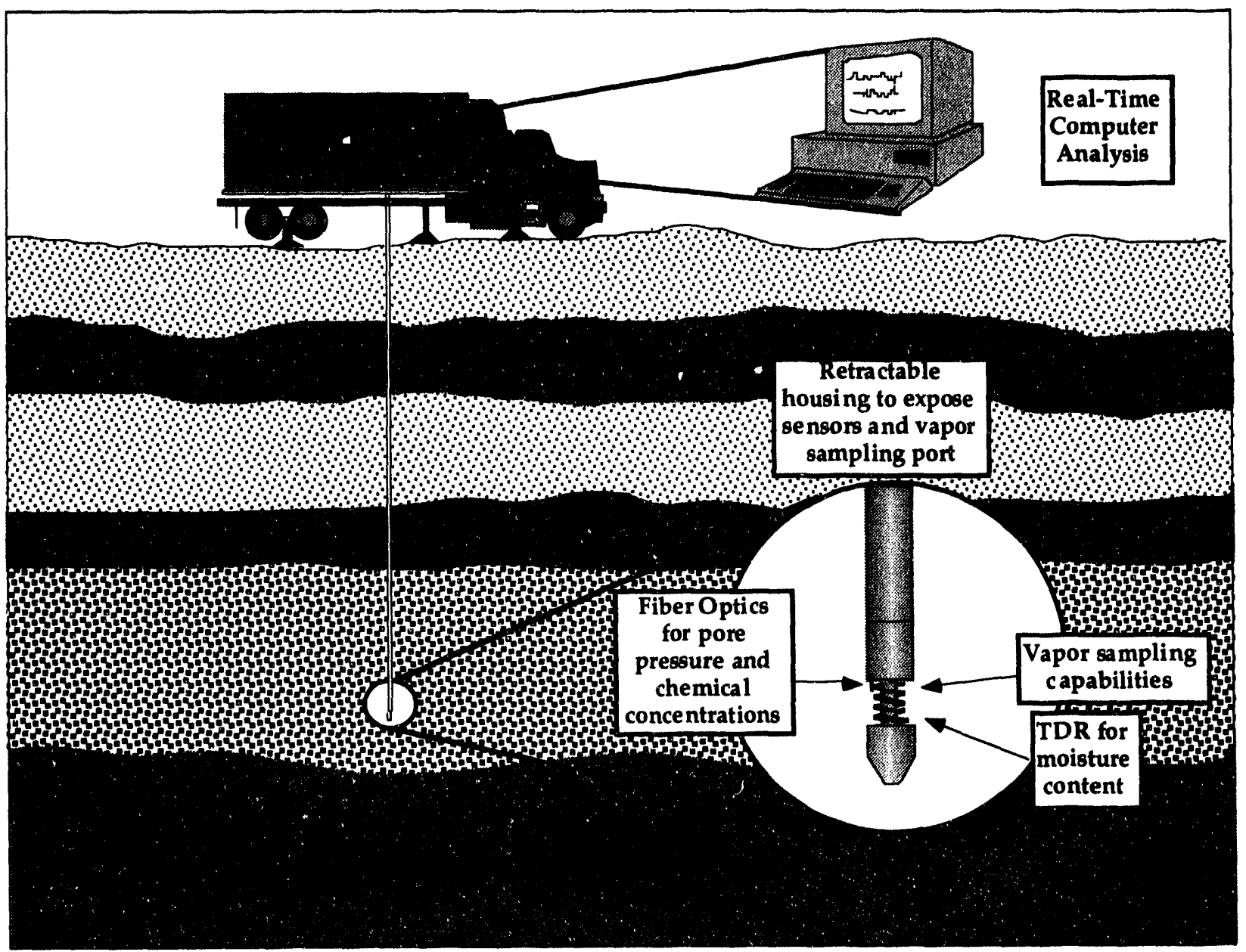

Figure 2.3. Cone Penetrometer Tip for Hydrologic Investigations. 
The basic work to be accomplished under this Task Plan is as follows:

- Complete testing of the fiber-optic probe for pore pressure determinations in unsaturated porous media;

- Design and fabricate a TDR probe to quantify soil-moisture content for downhole cone penetrometer deployment;

- Evaluate and test chemical-specific probes (e.g., fiber-optic) for possible inclusion in the cone penetrometer tip. This would include the evaluation of chemical-specific probes that might have adequate sensitivities for waste site characterization and/or monitoring purposes;

- Design and fabricate a cone penetrometer tip to incorporate the probes (see Figure 2.3); and

- Perform an in situ test of the new cone tip to evaluate its performance.

\section{TECHNOLOGY NEEDS}

As mentioned above, this technology will supply needed information to waste site investigators on hydrogeologic parameters and chemical specific concentrations in the subsurface. Moisture content and pore pressure measurements in unsaturated soils are critical parameters for inclusion in fate and transport modelling, and also in risk assessment evaluations. Whether a waste site poses a possible threat to human health and the environment is the ultimate driver for acceptability of a site or a remedial alternative. Risk assessment methods help to quantify whether a site poses a threat. Critical data needs for risk assessment are therefore critical characterization needs.
The nature and extent of contamination is also very important in the risk assessment analysis. This new cone penetrometer system will supply mainy critical needs to these modelling efforts.

\section{ACCOMPLISHMENTS}

This is the first year of funding for this project. The initial stages of this project will be focused on design and testing of the sensor packages. The TDR sensor for quantification of soil-moisture content is under design. Previous TDR designs have given sensitivities of $+/-1 \%$ moisture by volume. The fiber-optic pore pressure sensor is undergoing laboratory testing. This sensor should take the place of the conventional thermocouple psychrometer system for pore pressure measurements, which are quite cumbersome to apply. Other sensor packages are under investigation. Work is underway to define the applicable sensitivity levels desired for other chemical/radionuclide sensors for possible inclusion in the tip. It is preferable to have risk-based concentration thresholds driving the required sensitivities, and not the lowest achievable detection limit.

\section{COLLABORATION/TECHNOLOGY TRANSFER}

The opportunity for technology transfer and teaming with corporate entities is outstanding in this proposed work. First, the fiber-optic development of the capillary pressure sensor has been a collaborative effort to date between SNL and GeoCenters, Inc. GeoCenters will continue to support this development. The TDR probe may be solicited for technology transfer to the private sector. Also, the successful demonstration of chemical-specific 
probes would lead to increased commercialization of their product. Certainly, the procurement of the contract with a cone penetrometer logging company would facilitate the fabrication and use of this new cone penetrometer sensor tip. Given that there already exists a strong need for cone penetrometer applications, it would appear that the addition of sensor capabilities would greatly enhance the usefulness of the existing systems. Technology transfer would be quite welcome by all parties concerned in this project.

\section{For more information, please}

\section{contact:}

\section{Robert Knowlton}

Sandia National Laboratories

MS 1348

Albuquerque, New Mexico 87185-1348

(505) 848-0425

\section{George Allen}

Technical Program Manager

(505) 845-7015 


\subsection{AIRBORNE MINIATURE PLATFORMS}

\section{TASK DESCRIPTION}

Conventional aerial photography, airborne geophysics, and remote sensing techniques are too expensive to use when characterizing a small waste site, or when repeated flyovers are desired. The purpose of this project is to demonstrate that in such cases a radio-controlled airplane or helicopter can be used to collect high-quality data, quickly and cheaply (see Figure 2.4a).

For example, when new buildings or roads are constructed at an active disposal area the facility manager's existing aerial photographs become out of date, which hinders future planning. By using a small, radio-controlled airplane, equipped with an ordinary $35 \mathrm{~mm}$ camera, a new aerial photograph can be taken of the site eliminating the cost and inconvenience of hiring a helicopter or fixed-wing aircraft. At minimal cost, a whole series of aerial photographs could be taken to document activities at the burial ground.

Efforts are not limited to photography. A new generation of lightweight, lowpower sensors is being developed. These new sensors offer exciting new applications for airborne miniature platforms.

\section{TECHNOLOGY NEEDS}

The idea of using remotely-piloted vehicles for aerial photography and remote sensing is not new. But many of the current aerial platforms, most of which were developed for military applications, are complicated to operate and expensive to maintain, and consequently of little use in environmental restoration.

Ordinary, readily-available, model airplanes and helicopters that cost less than a thousand dollars, can be flown by any radio-control hobbyist, and can carry a 5-10 lb sensor payload are being adapted for environmental restoration purposes.
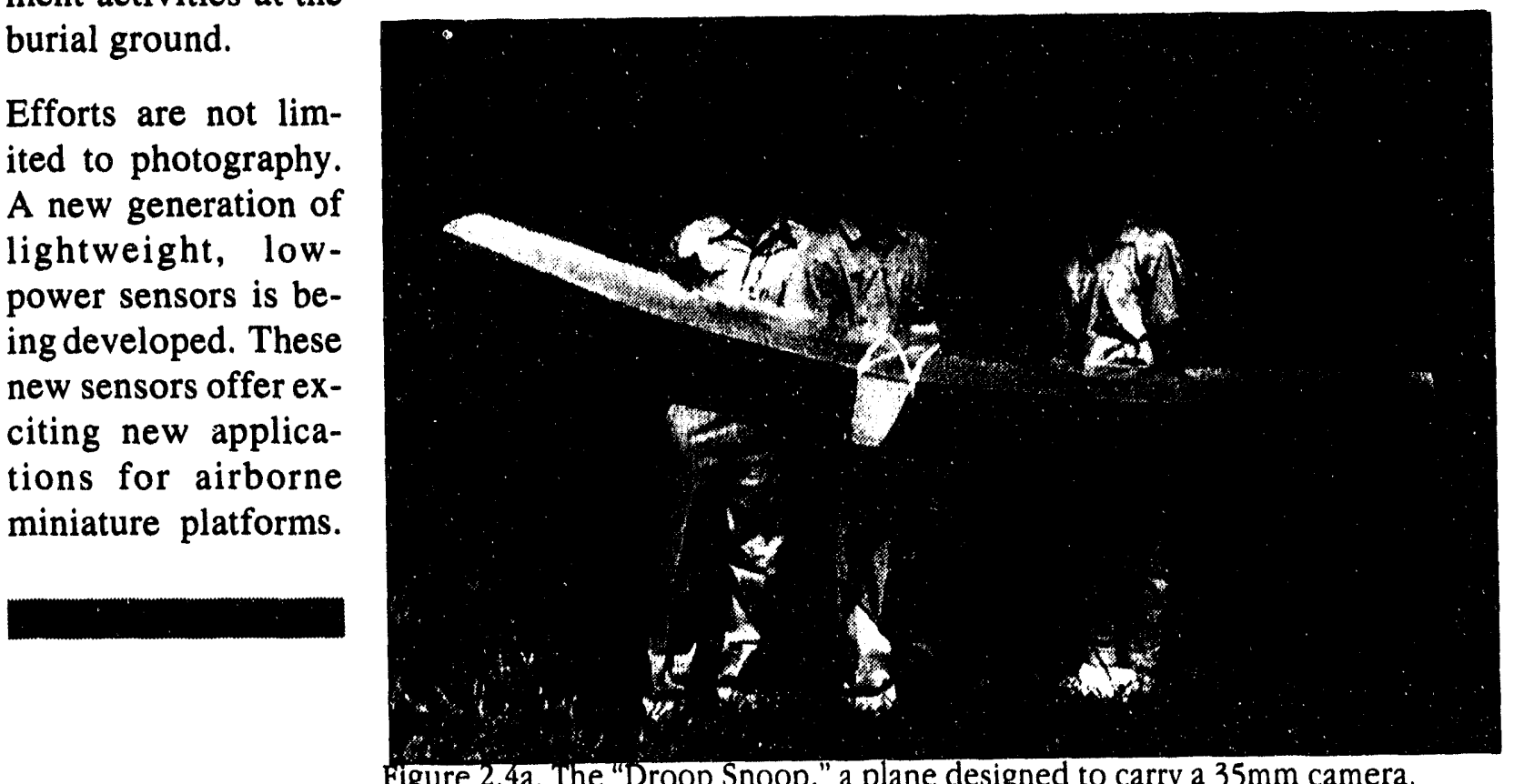

Figure 2.4a. The "Droop Snoop," a plane designed to carry a 35mm camera. 


\section{ACCOMPLISHMENTS}

Figure 2.4b shows an older aerial photograph of Solid Waste Storage Area 6, a burial ground on the Oak Ridge Reservation. Since then, a new building has been constructed, so this photograph is out of date. Using the "Droop Snoop", a model airplane designed and built by Brigham Young University, the boxed area was photographed. This newer image was then rectified and substituted into the digital version of the original aerial photograph. The results are seen in Figure 2.4c.

Current efforts are focused on equipping a model plane with a miniature 3-component magnetometer similar to those currently used by geophysicists in land-based surveys to look for buried drums and waste trenches. Radiation sensors, very low frequency electromag-

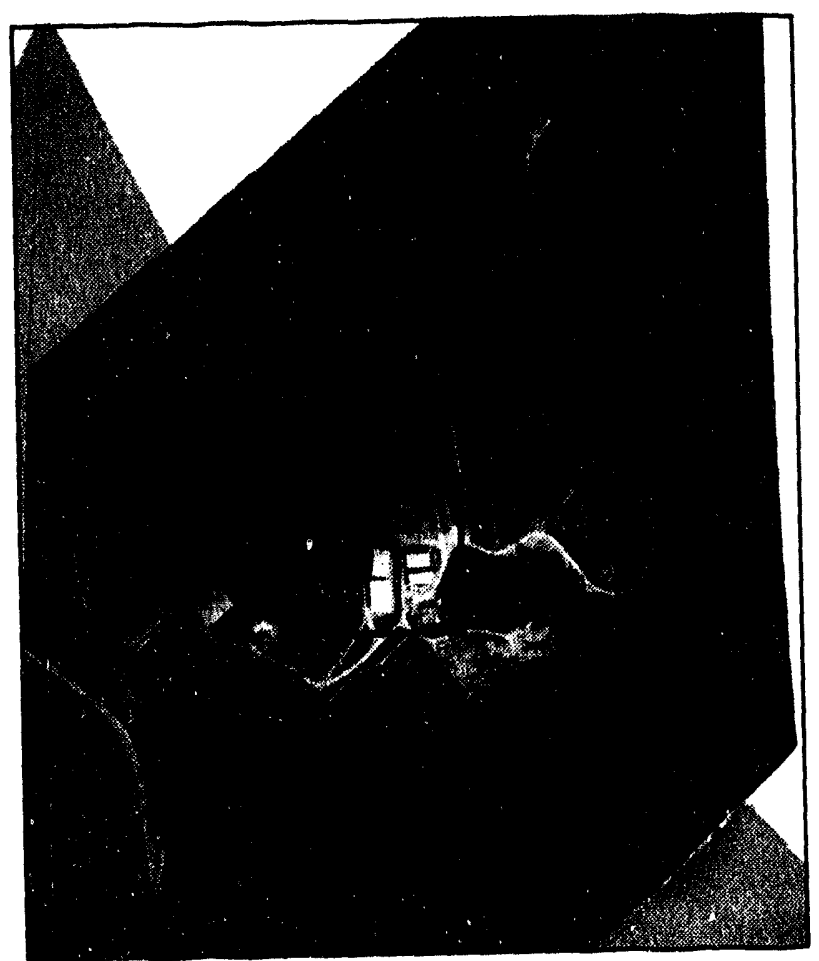

Figure 2.4b. Out-dated aerial photograph of Solid Waste Storage Area 6 on the Oak Ridge Reservation. netic sensors, and chemical vapor monitors are examples of other sensors that may be added in the future.

\section{COLLABORATION/TECHNOLOGY TRANSFER}

This project started in FY94, but already there has been considerable interest expressed by both environmental restoration workers and model aircraft manufacturers. As the geophysical applications are developed, inquiries from consulting companies and manufacturers of geophysical equipment are expected.

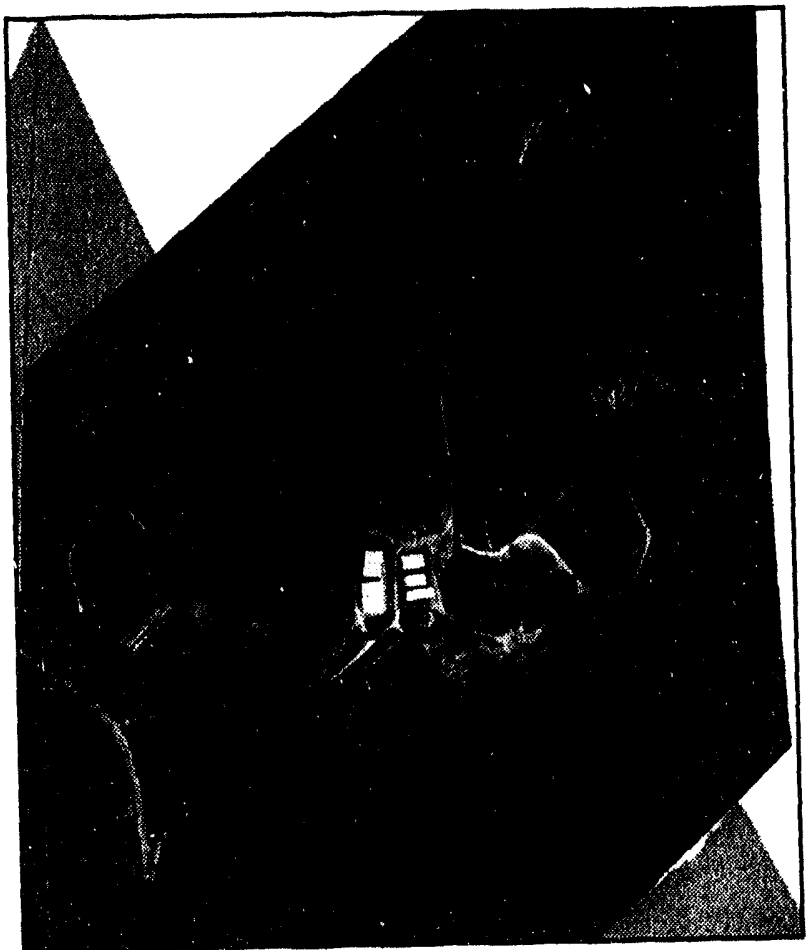

Figure 2.4c. Photograph taken from the "Droop Snoop," rectified and substituted for the same area in the out-dated photograph. 
For further information, please contact:

Jonathan E. Nyquist

Oak Ridge National Laboratory

P.O. Box 2008

Oak Ridge, TN 37831-6317

(615) 574-4646

Jan Pruit

Technical Program Office

(615) 574-4457 


\subsection{DEVELOPMENT OF SCREENING AND QUANTITATIVE FIELD METHODS COUPLED TO THE CONE PENETROMETER}

\section{TASK DESCRIPTION}

The overall goal of this investigation is to develop methods and technology that will couple a cone penetrometer (CPT) with fielddeployable gas chromatography/mass spectrometry (GC/MS) instrumentation to directly transfer volatile organic compounds (VOCs) and semi-volatile organic compounds (SVOCs) from subsurface material at depth to the analytical instrument in the field. Sampling, preconcentration, and analytical equipment will be directly coupled to a CPT to provide on-line, near-real-time analyses for VOCs (e.g., trichloroethylene, benzene) and SVOCs (e.g., polynuclear aromatic hydrocarbons, polychlorinated biphenyls) in subsurface materials. Preconcentration devices will be interfaced to GC/MS instrumentation and coupled to sampling devices housed in a CPT for in situ quantitative measurement of VOCs in soil gas and groundwater, and for screening of VOC and SVOC levels in the soil external to the penetrometer wall. The VOCs or SVOCs liberated from subsurface material will be carried to the surface by an inert, heated transfer line, preconcentrated, and analyzed by thermal desorption GC/MS.

\section{TECHNOLOGY NEEDS}

The projected costs for hazardous waste site assessment and cleanup in the United States are staggering. Environmental contaminants on DOE sites include radionuclides, toxic heavy metals (e.g., mercury), VOCs, SVOCs, and extractants, such as tributylphosphate. Decisions concerning remediation require reliable information about the presence and extent of contamination at the facilities. The most cost-efficient means of obtaining this information is use of minimally intrusive sampling techniques and on-site (field) analysis of samples. CPTs and in situ groundwater samplers provide a minimally intrusive, efficient, and cost-effective method for obtaining subsurface materials for analysis of contaminants. On-site analysis of samples has been shown to facilitate the characterization of sites by making real-time, interactive sampling decisions possible. Sampling techniques for VOCs in subsurface materials have been developed, and methods that are accepted by the EPA have been reported. These methods, although currently accepted, are cumbersome even when they are applied during on-site analyses. Consequently, there is a need to provide on-line, near-real-time methods of analyses for VOCs and SVOCs in subsurface materials that maintain sample integrity and improve the accuracy of the analytical results by eliminating the manipulation of samples during collection, transportation, and storage.

\section{ACCOMPLISHMENTS}

Tests have been initiated to determine the inertness of several different transfer line materials (stainless steel, nickel, Teflon ${ }^{\circledR}$ TFE, and Teflon ${ }^{\circledR}$ PFA) that will carry the VOCs from the CPT to the preconcentration device 
at the surface. A system has been designed to test transfer line materials in which the relative humidity and temperature of the gas stream carrying the VOCs can be controlled. A gas stream of a fixed relative humidity is generated by mixing dry zero-grade air with a humid air stream flowing from a gas washing bottle containing VOC-free water. The humid air stream is mixed in a stainless steel cylinder with the gas stream from a standard containing the VOCs and drawn through the transfer line with a personal sampling pump. VOCs in the sample steam are collected on graphite carbon and analyzed. Results are compared with the concentrations of VOCs in the mixing chamber to determine if they are retained by the transfer line.

A commercial Teflon ${ }^{\circledR}$ bailer has been purchased and is undergoing modification for incorporation into a CPT for in situ sparging of VOCs in groundwater. Methods are being developed to prepare aqueous standards of the VOCs for use in testing the device. A method will be developed to measure VOCs and SVOCs in soil. In this method, the compounds will be thermally desorbed from the soil adjacent to the CPT wall. The interface to the soil will consist of stainless steel mesh that will be inserted in the CPT in place of the membrane. Heater cartridges will be emplaced into the interface to heat the wall of the penetrometer to sufficient temperature to thermally desorb, but not pyrolyze, the VOCs and SVOCs. The desorbed organics will be swept through the mesh interface into the heated transfer line by an applied vacuum. Methods are being developed to prepare soil standards containing VOCs for use in testing the device.

\section{COLLABORATION/TECHNOLOGY TRANSFER}

The basic GC/MS systems to be used in this project are commercially-available, but are not widely applied in environmental characterization work. For this project to be considered successful in terms of providing better, faster, safer, and cheaper technology to EM40 and EM-30, information about the technology and these results must be made widely available to DOE site users. As part of the effort to gain acceptability, follow-on demonstration of the technology at an integrated demonstration has been proposed. Ames Laboratory is working with the commercial vendor to incorporate hardware and software changes into the instrument, to make the methods available to users as catalog items, and to market the whole package for use at DOE sites. Specific business relationships (e.g., a CRADA) and commercialization plans will be developed as part of this activity. Key to acceptance within the DOE community is acceptance by EPA of the data generated. A plan to gain EPA acceptance of both the field screening and the field quantitative methods will be developed. Results of this research and development will be presented at appropriate scientific meetings and DOE workshops, published in appropriate scientific journals, and published in DOE reports as needed. Distribution will be aimed at DOE site users. 
For further information, please contact:

\section{Paul V. Doskey}

Environmental Research Division

Argonne National Laboratory

9700 S. Cass Avenue

Argonne, IL 60439

(708) $252-7662$

James E. Helt

Technical Program Manager

(708) 252-7335 


\subsection{SECONDARY ION MASS SPECTROMETRY ANALYSIS: DEVELOPMENT AND EVALUATION}

\section{TASK DESCRIPTION}

Fast, inexpensive, and nonpolluting instrumentation for the detection of surface contaminants is being developed at the Idaho National Engineering Laboratory (INEL) using advanced secondary ion mass spectrometry (SIMS) technology. The attributes of this technology make it extremely attractive for waste and environmental characterization:

- no sample preparation is required;

- no waste is generated;

- analysis is rapid and simple;

- it is amenable to almost any sample type;

- it is amenable to nonvolatile organics, salts; and

- it is capable of fingerprinting and speciation.

SIMS has a simple principle of operation: surfaces are bombarded with high-energy particles, which sputter the contaminants into the gas-phase, where they can be detected as ions.

The objective of the SIMS Analysis Program is to develop instrumentation and chemical applications for the detection of nonvolatile or adsorbed contaminants on the surfaces of salts, rocks, minerals, soils, and other difficult to analyze samples. Three subtasks are being pursued to achieve this objective:

- demonstration of chemical analyses relevant to DOE problems using SIMS;
- development of SIMS instrumentation, which takes advantage of the most recent advances at INEL and in the mass spectrometer manufacturing industry; and

- transferring the advanced SIMS technology.

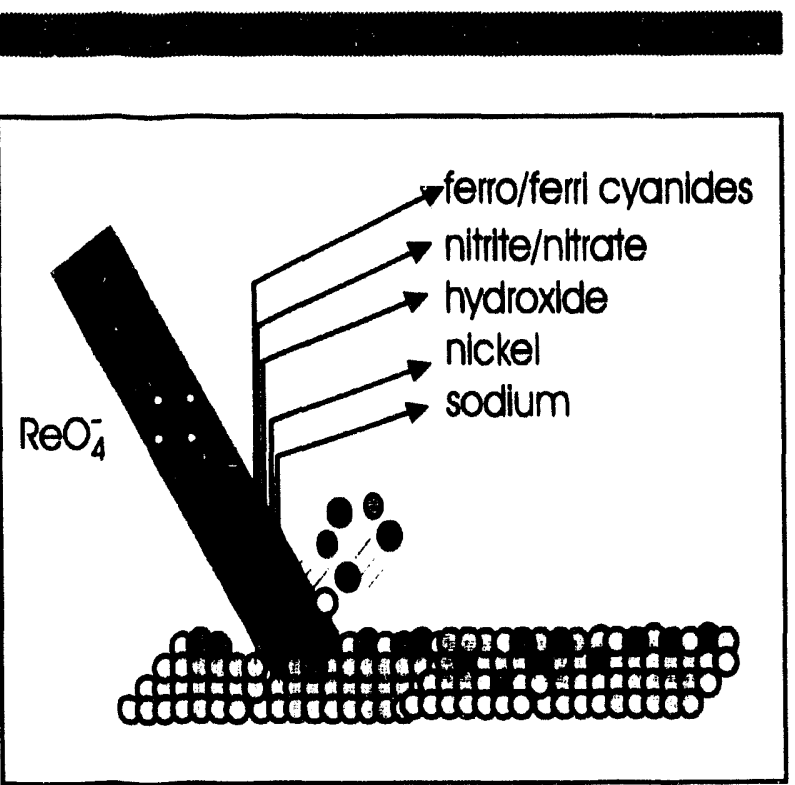

Figure 2.6a. Secondary ion mass spectrometry particle bombardment and sputtering of salt species from tank waste.

\section{TECHNOLOGY NEEDS}

DOE has many contamination problems that require the determination of contaminants that adhere tightly to waste, environmental, and industrial surfaces. There is a critical need in DOE and industry for characterization technologies that are fast, inexpensive, and can address surface contamination. An example of this need is characterization of core and 
particulate samples from high-level waste in underground storage tanks, which currently cost an average of $\$ 750,000$ /core analysis (see Figure 2.6b). Technologies capable of salt fingerprinting, and determining chemical speciation are needed to reduce the number of analyses needed, and to improve the estimation of tank energy content (critical for risk assessment associated with tank characterization and remediation activities).

Needs for technology for nonvolatile organics and salts persist in the In Situ Remediation Integrated Program and Decontamination and Decommissioning Integrated Demonstration. There are no easy ways to analyze for nonvolatile contamınants on the surfaces of minerals, soils or the surfaces of processing facilities. In both of these need areas, desirable attributes for candidate technology include ease of use, speed, sensitivity, and no waste generation. In all applications, technology that is transportable is needed. The advanced SIMS technology that has been developed at INEL has attributes that are a very close match with the technology development needs of high-level tank waste.

\section{ACCOMPLISHMENTS}

The rapid analysis of simulated salt cake samples was demonstrated using the laboratory-based SIMS instrument located at INEL. The analyses required no sample preparation, and hence required less than 10 minutes; in addition, no waste was generated. A unique attribute of the pulsed-extraction SIMS instrument is the ability to analyze cations and anions at the same time. This attribute is especially valuable for salt cake analyses because the salt samples contain both anion and cation species: nitrite, nitrate, cyanide, and hydroxide anions, and iron, sodium, potassium and nickel complexes were detected.

SIMS detection of tributyl phosphate (TBP), ethylenediamine tetraacetate (EDTA) and small organic acids has been demonstrated on significant DOE minerals, including basalt (see Figure 2.6c.). These compounds were used in nuclear material processing, and were disposed of with radioactive wastes. The TBP analysis produces information indicative of the mode of TBP-surface binding, in addition to identifying the presence of TBP. As little as 10 ng can be observed on a basalt chip.

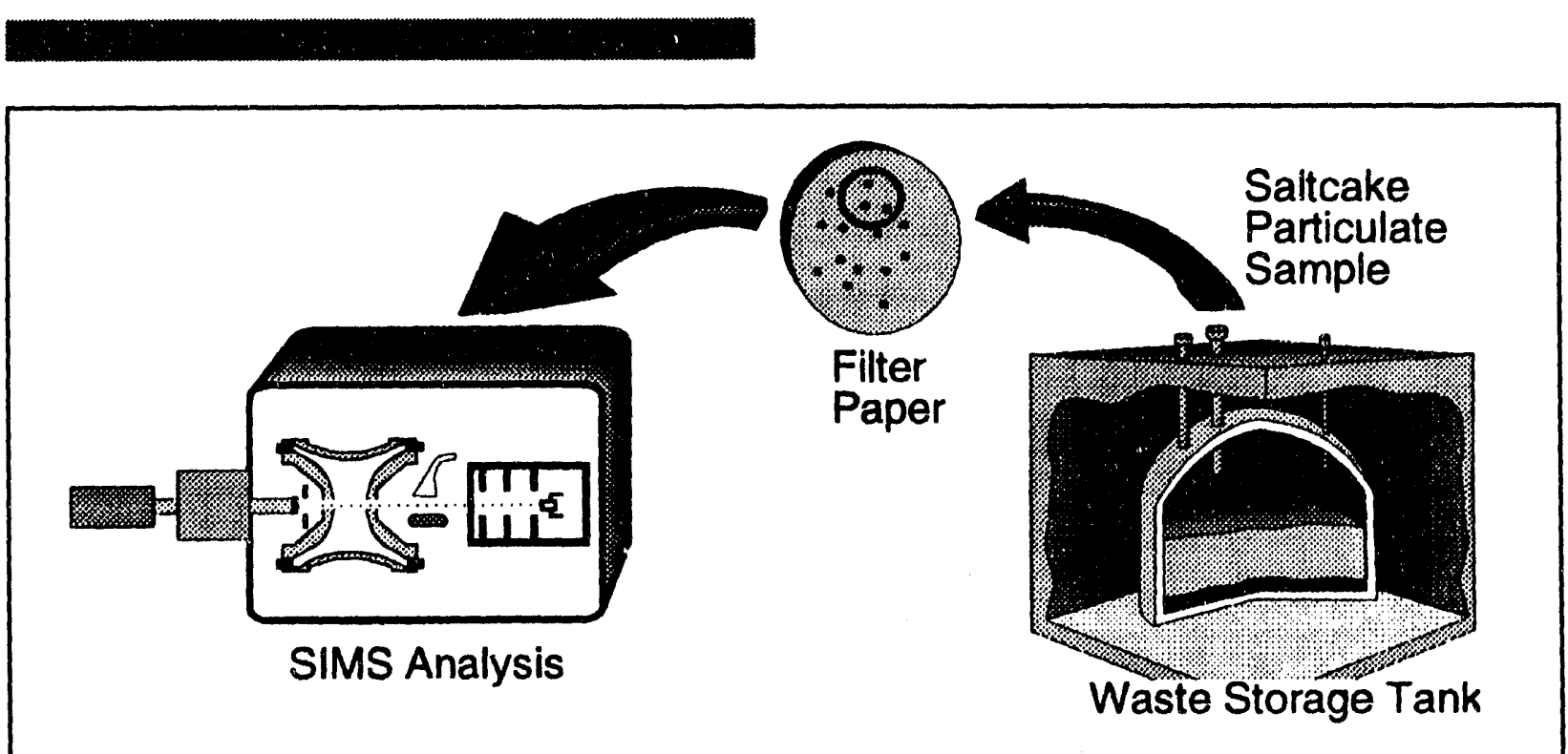

Figure 2.6b. Schematic diagram of transportable SIMS instrument applied to the analysis of salt particulate from underground storage tanks. 
Instrument transportability and improved sensitivity and selectivity are desired attributes of the instrumentation that will be constructed in this program. An ion trap mass spectrometer (ITMS) satisfies these requirements, and hence this type of instrument was selected for interfacing with the OTD SIMS technology: ITMS procurement will occur in 1994, and modification in 1995 . In addition to the technical offerings of the ITMS, new ITMS instruments will be on the market in early 1994, which opens opportunities for technology transfer.

\section{COLIABORATION/TECHNOLOGY \\ COLLABORATION/TECHNOLOGY TRANSFER}

New ion trap products are being introduced in early 1994, and hence an ion trap/SIMS instrument offers an excellent technology transfer opportunity. Contacts have been made with all ion trap vendors: Teledyne offers the best possibility for technology transfer, and negotiations with Teledyne have been initiated. The Teledyne ITMS product will be introduced at the Pittsburgh Conference in early March. Nondisclosure agreements and the procurement of a Teledyne ITMS are in progress.

\section{For further information, please contact:}

Gary S. Groenewold James E. Delmore

Idaho National Engineering Laboratory

P.O. Box 1625

Idaho Falls, ID 83415-2208

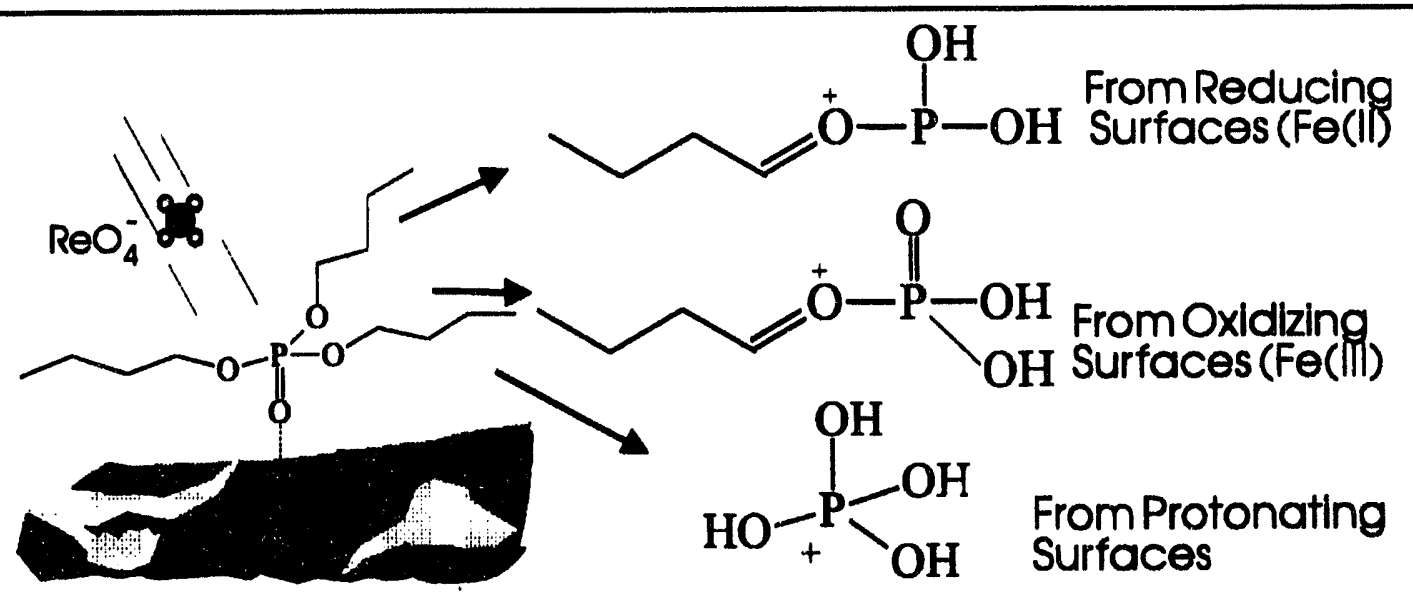

Figure 2.6c. Direct SIMS analysis of basalt chips contaminated with tributyl phosphate. 


\subsection{MINIATURIZED CHEMICAL FLOW PROBE SENSOR DEVELOPMENT}

\section{TASK DESCRIPTION}

A small, reconfigurable, and real-time chemical analysis instrument could provide field technicians performing screening operations with on-the-spot data to allow for smart field characterization studies. The flow probe will use a flowing reagent chemistry with fiberoptic-based detection and speciation enhanced by modern chemometric techniques. Goals are to develop an architecture that can encompass a large class of chemical speciation through the use of modular functional blocks, a flexible membrane sampling block, interchangeable reagents, and multiwavelength, multivariate (possibly second order) statistical methods. The specific field demonstration will include metals and VOCs in aqueous matrices.

\section{TECHNOLOGY NEEDS}

off-site method involves the long-time (up to months) delay of obtaining results. Flow probe research in the university environment has reached the point where the technology is ready to move into the commercial market. For this to happen however, significant engineering development is needed to produce a viable commercial instrument. This project provides the collaboration of the university scientist with the national laboratory engineer to perform this development in a pre-competitive setting.

\section{ACCOMPLISHMENTS}

Since the project's beginning in November 1993, performance specifications from a broad range of users have been received. The needs span the range from measuring trace organics in an organic matrix at $200^{\circ} \mathrm{C}$ to measuring trace metals in an aqueous matrix at room

Current methods for preliminary field analysis include: a) technicians taking samples, followed by transport to an off-site analytical laboratory for analysis, and b) technicians taking samples to an on-site mobile analytic laboratory. Both methods involve the high costs of analytic laboratory technicians and equipment, and the

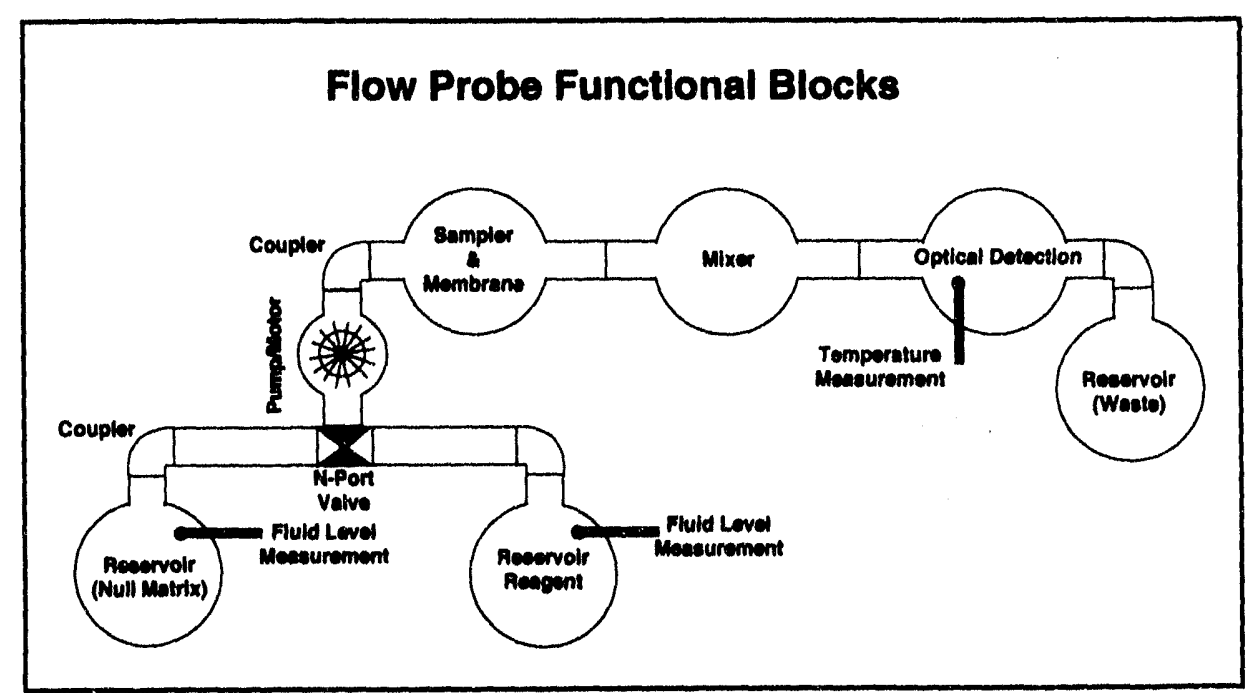

Figure 2.7. Schematic representation of functional blocks for the flow probe in a possible device arrangement. 
temperature. A system model of flow probe functional building blocks was üeveloped from these needs. The functional specifications for many of the functional building blocks needed for a generic instrument have been accomplished. A few of these functional blocks are shown in Figure 2.7a in one of many possible arrangements. The maximum size of the probe head and the minimum functions for this probe head were established. Two representations from the Center for Process Analytical Chemistry (CPAC) industry representatives attended a conceptual design meeting in January. Thus, the ideas and experience of the CPAC scientists, the SNL engineers, a LANL scientist and CPAC industrial members are working to produce a usable and commercially-viable flow probe.

Two functional constraints on the design are: 1) to maximize the chemometric information available for each analysis, and 2) to allow for additional reagent introduction into the analyte/ reagent mixture in downstream functional blocks. Two fluid moving implementations are being investigated: a pulsed flow type and a volume mover type. For the pulsed flow type, there is fluid in a pipeline at all parts of the flow probe head. Through the use of timed fluid pumping, localized fluid segments contain analytes for the various functional modules to operate on. For the volume mover type, a segment of fluid is captured in a physical cavity and then moved from one module to the next module. In this implementation, fluid is present only in one module at a time. These two implementations each have their manufacturing and field use advantages and disadvantages.

\section{COLLABORATION/TECHNOLOGY} TRANSFER

The project is a 50/50 collaboration with the CPAC at the University of Washington and Sandia National Laboratories. The analytical chemistry aspects are worked upon by the CPAC scientists and the engineering for a fieldable instrument is worked upon by SNL. The project consists of three phases. The initial phase includes obtaining performance requirements from the various CPAC-sponsored chemical companies (i.e., users) and working with the CPAC instrument companies (i.e., suppliers) early in the development of the instrument. The middle phase is to demonstrate in the field the instrument at both DOE and commercial sites. The final project phase is to include an instrument partner to make a pre-commercial prototype. Collaboration with all parties is well underway with representatives from Amoco and Sippican joining the design team discussions during a 3-day design review meeting in January 1994.

Letters of interest from many CPAC companies have been received, which include inkind support commitments that range from $\$ 200 \mathrm{k}$ (DOW USA) to $\$ 50 \mathrm{k}$ (Perkin-Elmer). Other companies expressing interest and inkind support commitments include Amoco, Calgon, Chevron, Sippican, Goodyear, Hewlett-Packard, Proctor \& Gamble, Shell, and ZymoGenetics. 
For further information, please contact:

\section{George R. Laguna}

Sandia National Laboratories

Department 2337

P.O. Box 5800

Albuquerque, NM 87185-0503

(505) 844-5273

\section{George Allen}

Technical Program Manager

(505) 845-7015 


\subsection{MULTI-ANALYTE, SINGLE-FIBER, OPTICAL SENSOR}

\section{TASK DESCRIPTION}

The objective of this task is to adapt Tufts University's unique optical fiber sensor technology to site-specific DOE needs. Multianalyte, sensitive, single-fiber, optic sensors will be prepared containing sensitivity to RCRA metals, anions and hydrocarbons. Indicator chemistries and prototype multianalyte fiber-optic sensors and readout instrumentation will be designed and constructed. Sensors will be delivered to Lawrence Livermore National Laboratory (LLNL), where a field-hardened instrumentation package will be used for testing and eventual transfer of technology to DOE remediation sites and industry. The successful completion of this project will require significant collaboration with Tufts University, which holds relevant patents and unique expertise in the chemical basis and design of multicomponent sensor arrays.

\section{TECHNOLOGY NEEDS}

Current methods for detecting nearly all priority contaminants require sampling and subsequent laboratory analysis. Sensors give the analyst the ability to measure contamination in situ, and in real time, thus saving time and expense. However, many DOE sites have a multitude of contaminants present that challenge the current state-of-the-art in sensor technology. This challenge is in both analyte specificity and sensitivity and in the complexity of instrumentation that would be required to measure many analytes simultaneously. The work described herein not only provides sen- sors for needed measurements, but also has the unique distinction of requiring only one sensor and instrument to make determinations of numerous analytes, thus greatly simplifying field applications.

\section{ACCOMPLISHMENTS}

The ability to place and read 12 individual $\mathrm{pH}$ sensors on a single-optical fiber terminus (see Figure 2.8) has been demonstrated. These results indicate the potential of placing as many as twenty sensors on one fiber.

The suite of target analytes $-\mathrm{Al}^{+3}, \mathrm{UO}_{2}{ }^{+2}$, hydrocarbon (nonspecific), and $\mathrm{pH}$ have been selected in collaboration with the Rocky Flats

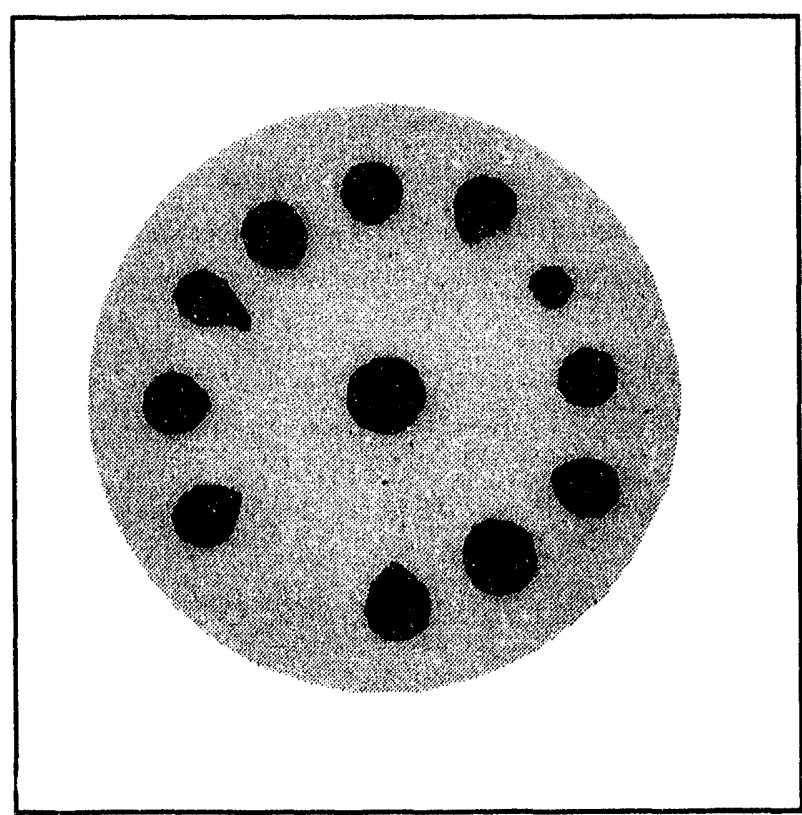

Figure 2.8. Photo-micrograph of the distal end of a single 500 micron diameter imaging fiber. 
facility as the initial multi-analyte sensor. Researchers at Tufts University have already demonstrated $\mathrm{pH}$ and aluminum ion sensors adequate for demonstration. Optical transduction schemes for hydrocarbon and the $\mathrm{UO}_{2}$ ion have also been identified. This project is on schedule for a laboratory demonstration of a four analyte sensor by late FY94 .

\section{FUTURE WORK/DIRECTION}

Initial success with measuring $\mathrm{pH}$ optically has opened up the possibility of an underground storage tank application. Here a wide range of $\mathrm{pH}$ sensors can be used to monitor for corrosive conditions, as well as a redundant number of individual sensors to mitigate the effects of the harsh environment. The potential application of a new concept recently demonstrated by Tufts University will also be explored. The combination of slow release polymer technologies with fluoroimmunoanalysis has the potential for a continuous reading antibody-based biosensor. Success would greatly increase the number of different analytes that could be measured with the multi-analyte sensor.

\section{COLLABORATION/TECHNOLOGY TRANSFER}

This project is a major collaboration among researchers at LLNL, the Chemistry Department at Tufts University, and the Hybridoma Center of the University of California at Ber- keley. Tufts University has received three patents covering the core technology. It is anticipated that application-specific technology developed under the collaboration will be available for field-use licensing. Informal collaborations with Princeton Instruments, Ames Laboratory, and Hamamatsu Corporation have also been established for various aspects of instrument component development.

\section{For further information, please contact:}

\section{Fred P. Milanovich}

Lawrence Livermore National Laboratory

P.O. Box 808, MS L-524

Livermore, CA 94550

(510) $422-6838$

\section{Ann Heywood}

Technical Program Manager

(510) 422-8203 


\section{TASK DESCRIPTION}

Sol-gel indicator (SGI) composites will be used by the Savannah River Technology Center to manufacture sensor elements to measure a variety of conditions and species of interest. The overall program includes SGIs for measuring solution $\mathrm{pH}$, and components, such as heavy metals (e.g. U, Hg) and selected halogenated organics. The technology is based on incorporation of indicator materials into specially prepared porous silica glass matrices. The SGIs change color in response to analyte concentration. The SGI composites are coated onto optical components, which will allow photometric measurements to be made.

The current task will involve the following:

- development of one $\mathrm{pH}$ sensor suitable for measuring selected environmental and process conditions;
- development of one uranium sensor for conducting measurements of soluble uranium;

- integration of a successful SGI uranium sensor as part of an integrated analytical measuring system and assessment of its use for field tests; and

- preliminary investigations of heavy metal SGI sensors.

\section{TECHNOLOGY NEEDS}

Increased emphasis in recent years on environmental analyses has fueled a need for fieldportable and remote monitoring instruments. An important contribution to this effort has been the development of portable fiber-optic diode array spectrophotometers (DAS) and associated fiber-optic probes. These probes

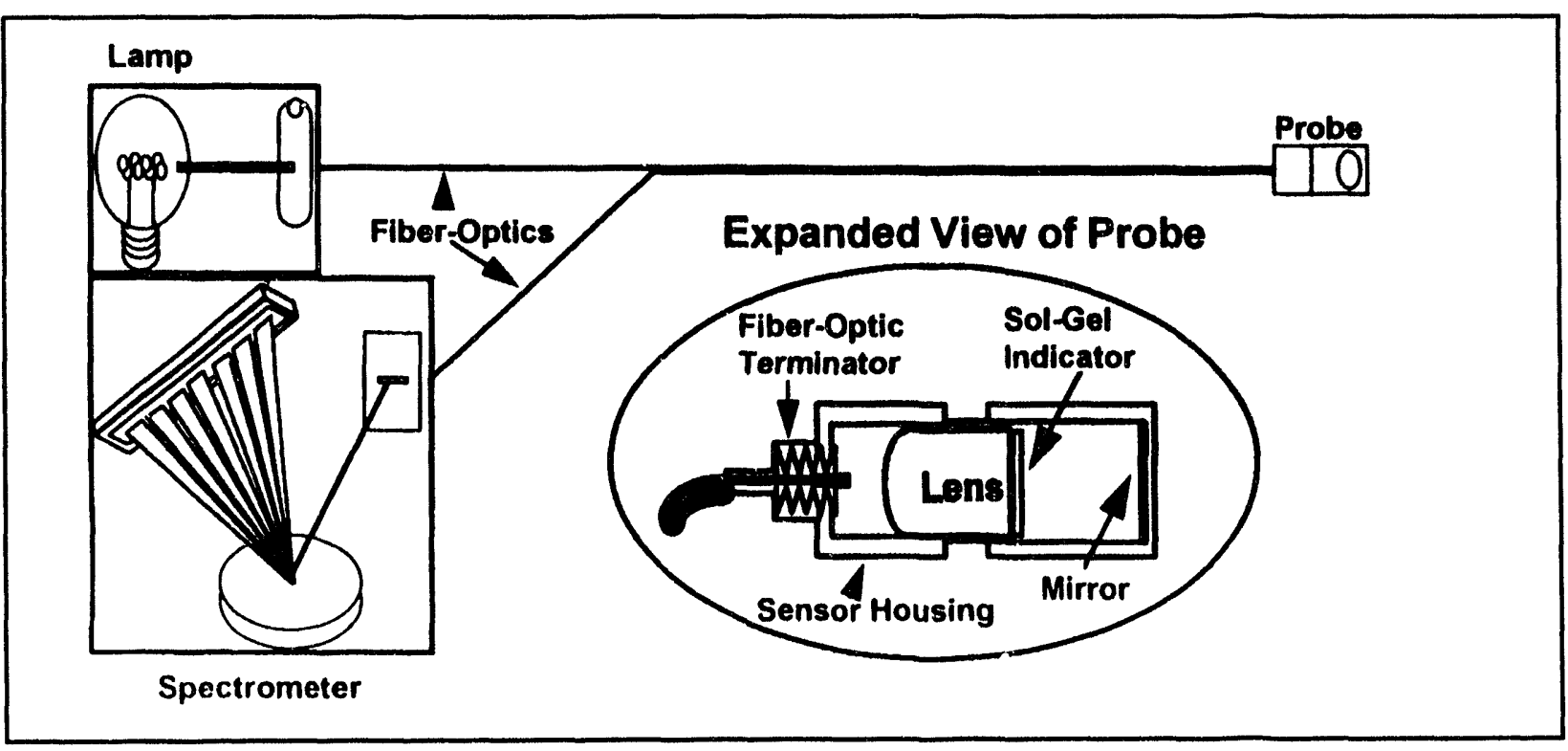

Figure 2.9a. Diagram of fiber optic diode array spectrophotometers system with sol-gel probe. 
contain the sensing element or function as a measurement cell, and are small, rugged and easily deployed.

Sol-gel technology has opened up a route to sensor element fabrication; the indicator may be trapped in a porous silica sol-gel matrix. Pore sizes of the sol gel can be controlled during synthesis to allow the desired analyte to react reversibly with the indicator molecule, while keeping the indicator trapped within the glass matrix. Sol-gel technology has the advantage of being able to distribute and incorporate the indicator in a chemically durable matrix at room temperature, and hence, avoid the high temperatures in conventional glass manufacture that degrade the organic indicator molecules. Figure 2.9a shows how the sol-gel sensor element is integrated into a fiber-optic DAS system.

\section{ACCOMPLISHMENTS}

A sol-gel sensor has been prepared with the $\mathrm{pH}$ indicator bromophenol blue. This sensor has been tested in buffers of $\mathrm{pH} 1-10$. The response of the bromophenol blue $\mathrm{pH}$ sensor is shown in Figure $2.9 \mathrm{~b}$. The response range of almost $4 \mathrm{pH}$ units is broader than seen in aqueous solutions of the indicator, where the response range is generally restricted to about $2 \mathrm{pH}$ units. The sol-gel pH sensor also responds to a more basic $\mathrm{pH}$ range than the aqueous solution of the indicator. The sensor in Figure $2.9 \mathrm{~b}$ is responsive over the $\mathrm{pH}$ range 3.9-7.7. $\mathrm{pH}$ differences as small as $0.1 \mathrm{pH}$ unit cause marked changes in the sensor spectrum. The $\mathrm{pH}$ sensor response time is on the order of a few seconds to half a minute. Sensor responses were modelled by multivariate techniques. For the bromophenol blue sensor, a principle component regression model based on a training set with intervals of $0.1 \mathrm{pH}$ units gave predictions accurate to $+0.3 \mathrm{pH}$ units on subsequent solutions.

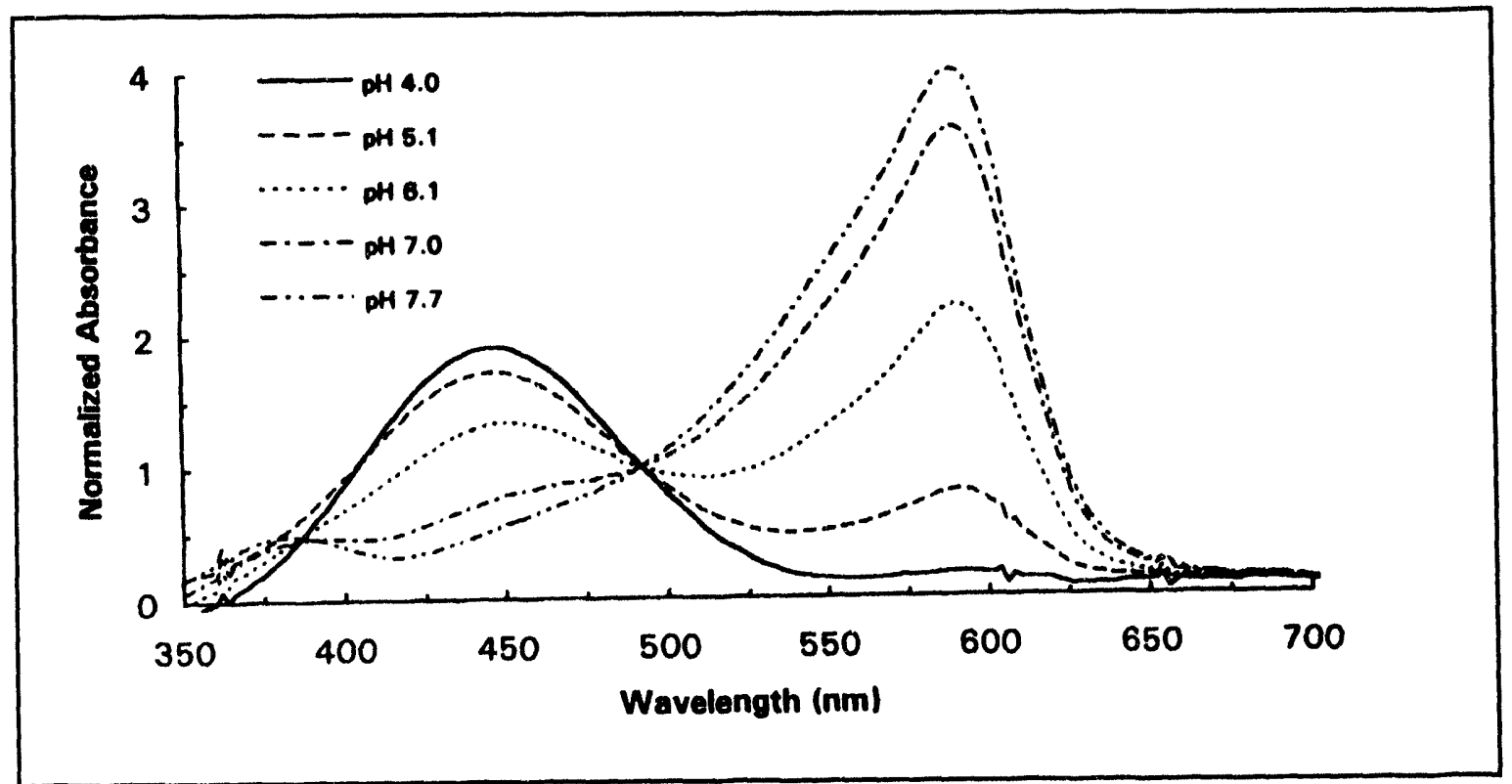

Figure 2.9b. Response of bromophenol blue sol-gel pH probe. 
A first generation uranium sol-gel sensor, based on the indicator arsenazo III, has been fabricated. The arsenazo III sol-gel product has been tested in dilute uranyl nitrate (97 ppm, $\mathrm{pH}=2$ ). Initial results have been encouraging, but sensor response time is slow. Modifications and optimization of the sol-gel formulation will be undertaken to improve the response time of the probe.

\section{COLLABORATION/TECHNOLOGY TRANSFER}

This technology will prove useful as a screening tool for in-field measurements (wells, lakes, streams, etc.) of properties, such as $\mathrm{pH}$ and dissolved heavy metals content. Measurements of this type are needed at many sites nationwide that require environmental remediation. Efforts towards technology transfer include the following:

- U.S. Patent \#796974 in process;

- one private sector company has already licensed this technology;

- presentations regarding SGI sensors have been made at:

- Sensors Expo West (Feb. 1994)

- TIE Meeting with Industry on Environmental Restoration Needs in the Northwest United States (Jan. 1994)

- Sensors Expo (Oct. 1993)

- Environmental Restoration'93 (Oct. 1993)

- Emerging Technologies in Hazardous Waste Management V (Sept. 1993)
- Sixth Annual National Conference on Federal Quality (July 1993)

- Fourth National TIE Workshop (May 1993)

- Westinghouse Savannah River Company Technology Transfer Meetings (May 1993 and Feb. 1994)

- Fifth Winter Conference on Flow Injection Analysis (Jan. 1993).

\section{For further information, please} contact:

\section{George Wicks}

Westinghouse Savannah River Company

Building 773-A

Aiken, SC 29808

(803) $725-3190$

John L. Steele

Technical Program Manager

(803) 725-1830 


\subsection{PORTABLE, REAL-TIME MONITORING SYSTEMS FOR VOLATILE ORGANICS}

\section{TASK DESCRIPTION}

The objective of this project is to develop, test, and demonstrate systems capable of realtime, on-line or in situ monitoring of volatile organic contaminants. As shown in Figure $2.10 \mathrm{a}$, these systems use surface acoustic wave (SAW) devices that are extremely sensitive to changes in thin film properties (can detect the mass of a single particle with a diameter onetenth that of the average human hair). This sensitivity enables them to be used for rapid chemical detection when they are coated with chemically-sensitive thin films. The portable acoustic wave sensor (PAWS) systems being developed need to provide long-term, continuous, and accurate monitoring of contaminant concentrations. They also need to be robust enough to detect high contaminant concentrations and to work in the presence of corrosive vapors. These systems should be automated, easy to set-up and use, and have little or no maintenance requirements. Down hole probes should use existing monitoring,

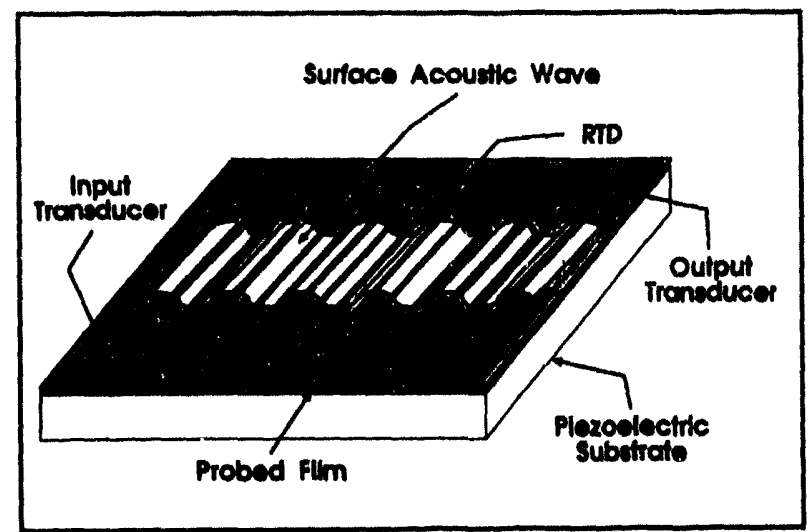

Figure 2.10a. Schematic of a surface acoustic wave sensor. while aboveground systems should be small and portable with battery power for remote operation.

\section{TECHNOLOGY NEEDS}

There are a significant number of DOE sites that have been previously contaminated with large amounts of volatile organic species including chlorinated hydrocarbons. One example is the Hanford site, which is contaminated mainly with carbon tetrachloride $\left(\mathrm{CCl}_{4}\right)$. One key need for these sites is to effectively characterize the distribution of contamination and to be able to provide ongoing monitoring of down hole concentration changes to evaluate the effectiveness of the remediation effort. This characterization and monitoring can best be accomplished by in situ analysis of contaminant concentrations using sensitive, accurate, and robust sensors that will not be overloaded by the high concentrations (tens of thousands of ppm) that may be present in some locations. The PAWS technology has demonstrated these basic requirements. Since a common and effective technique for removing volatile organics from soils is to pull them out using large vacuum pumps and wells into the contaminated site, another need is to be able to provide real-time, on-line monitoring of contaminant concentrations in off-gas streams from these soil vapor extraction systems. 


\section{ACCOMPLISHMENTS}

Efforts to date have resulted in the development and field demonstration of portable handcarried instruments about the size of a shoe box and down hole probes small enough to be placed underground in monitoring wells (see Figure 2.10b). These systems can continuously detect and measure isolated volatile organic compounds in the vapor phase from 10 to 100,000 parts per million (ppm). Accurate analysis has been demonstrated with rapid (seconds) and reversible responses. Based upon a patented technique to monitor both the speed and power of the wave, chemical identification of isolated species is possible.

The first PAWS field test demonstrated online monitoring of exhaust stack concentrations at a DOE production facility. This real-time chemical information was used to rapidly evaluate alternative cleaning processes resulting in a $96 \%$ reduction in emissions. For environmental clean up activities, PAWS systems were demonstrated for continuous, online monitoring of contaminant concentrations from soil vapor extraction systems at both Savannah River Site and Hanford. The systems were shown to be accurate and easy to transport, setup, and operate. Real-time analysis of gas samples pulled to the surface as a cone penetrometer probe is pushed into the soil at a contaminated site has also been demonstrated. Current development of these systems is focused on instruments for monitoring residual contaminants in treated off-gas streams containing corrosive chemicals and on systems containing multiple sensors and a pattern recognition routine to provide analysis of multiple species in mixtures.

The PAWS down hole probe was evaluated at the Hanford site as part of the VOC-Arid Integrated Demonstration. The probe was placed in six different wells with diameters

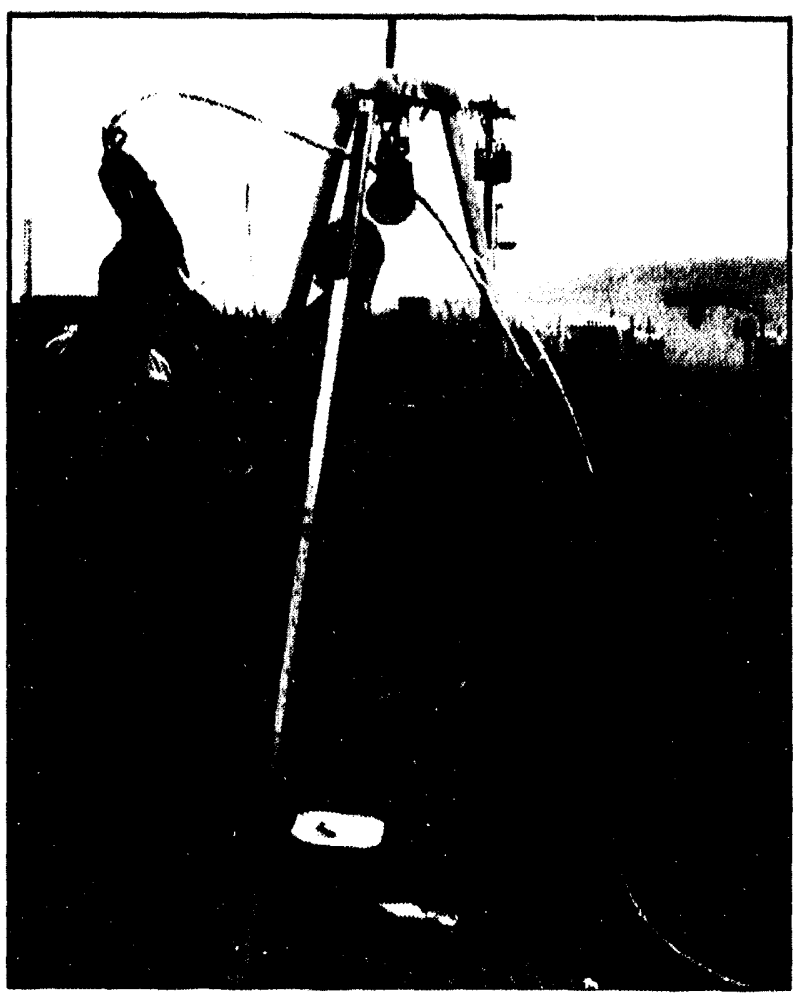

Figure 2.10b. Deployment of a down hole portable acoustic wave sensor system at the Hanford site in Washington State.

from $4 "$ to 8". Concentrations from below 10 ppm to over 20,000 ppm were observed during the demonstration, illustrating the wide range of concentrations these systems can monitor. The probe provided accurate and continuous monitoring of contaminant concentrations. An aboveground PAWS system provided comparison analysis of a sample pushed to the surface by the probe. As shown in Figure $2.10 \mathrm{c}$, agreement between the surface PAWS system and on-site analytical instrumentation was excellent (2\%); however, differences between the probe and the aboveground systems were observed. These differences were found to be due to contaminant addition or loss in the sample line to the surface, demonstrating the advantage of in situ analysis for site characterization. 


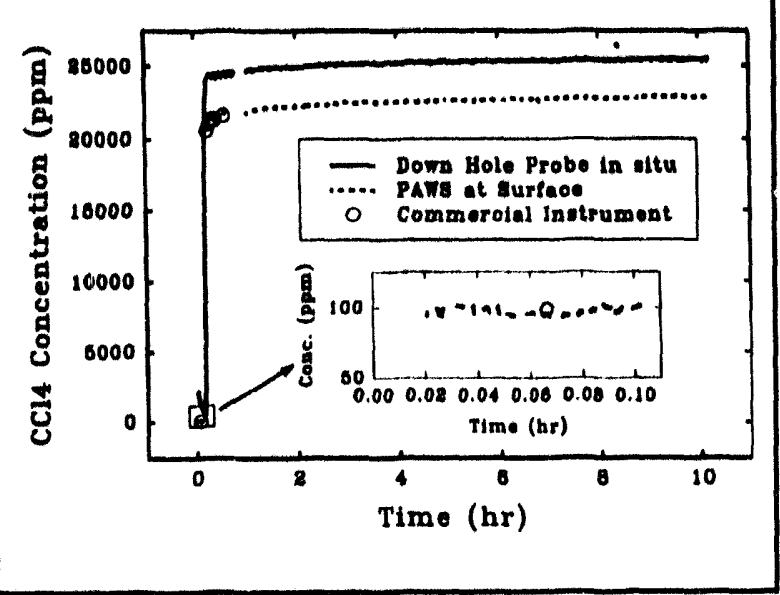

Figure 2.10c. Real-time monitoring of contamination at the Hanford site using a down hole portable acoustic wave sensor system for in situ analysis.

\section{COLLABORATION/TECHNOLOGY TRANSFER}

A key component of this program is transferring this monitoring technology to DOE environmental restoration and to industry. An above ground PAWS system has already been provided to Hanford Environmental Restoration for their ongoing use and a down hole system will also be transferred to Hanford following a second field demonstration. Regarding commercialization, announcement of the availability of this technology has been made by public presentations, publications, a Commerce Business Daily announcement, and representation at the Sensors Expo ' 93 and at a DOE-sponsored industrial workshop. A mailing was sent to 175 identified companies of which 13 responded with an initial questionnaire expressing interest and four responded with full business plans. Negotiations are underway with these four companies to identify the optimum relationships for maximizing the impact of this technology development work.
For further information, please contact:

Gregory C. Frye

Principal Investigator

Microsensor R\&D Department

1315, MS-0351

Sandia National Laboratories

Albuquerque, NM 87185-0351

(505) 844-0787 


\subsection{CHLORINATED AND AROMATIC HYDROCARBON THIN FILM CHEMICAL SENSORS}

\section{TASK DESCRIPTION}

This task aims to develop compact, inexpensive, and robust surface-acoustic-wave (SAW)-based chemical sensors for remote, real-time sensing in air, groundwater, and possibly soil of chlorinated and aromatic hydrocarbons. The sensors will be system-integrated through co-development with Motorola and with the University of California at Berkeley. The initial success of others who have demonstrated ppm sensitivity to specific chlorinated hydrocarbons using spin-cast cyclodextrin as the selective layer of a SAW-based mass sensor will be built upon. Cyclodextrins form inclusion complexes with chlorinated hydrocarbons and aromatics, thereby allowing for reversible binding of the analyte and near real-time sensing. This novel approach incorporates promising new technology:

- the use of surface modification techniques to covalently bond (via siloxane linkages) cyclodextrins directly to the SAW transducer substrate, thereby mitigating the ubiquitous spin-casted film problems of adhesion, leaching, swelling, and stability (see Figure 2.11a);

- subsequent molecular engineering to control access to the cyclodextrins and further enhance molecular specificity, sensitivity, and reversibility;

- employment of Lamb-wave transducers with advantages for sensing in aqueous and hostile environments; and
- the use of thermal desorption rates as an additional mechanism for species differentiation.

While the focus of this task is directed toward mass transduction sensors, the surface modification approach and chemistry employed is equally applicable to fiber-optic and electrochemical transduction devices, and can likely be extended to sensing other toxic organics, inorganics, or trace metals. Specific benefits include reduced cost, time, and worker risk associated with site characterization and monitoring; improved performance; and adaptability to a wider range of environmental conditions.

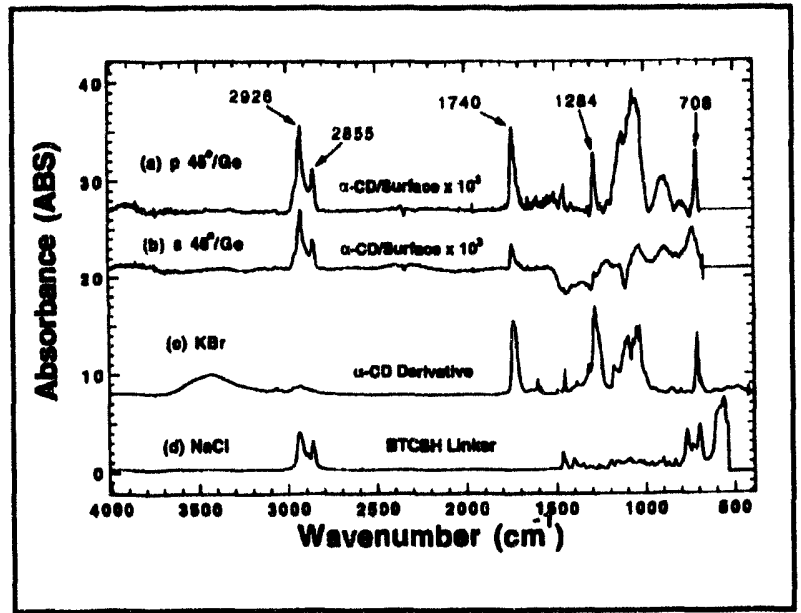

Figure 2.11a. Fourier-transform infraredattenuated total reflection (FTIR-ATR) spectra of (a) a-cyclodextrin monolayer covalently bound to the native oxide surface of $\mathrm{Si}<100\rangle$ with a $\mathrm{kGe}$ internal reflection element and $\mathrm{p}$ polarized light incident at 45o, 1024 scans, $2 \mathrm{~cm}-1$ resolution; (b) s-polarized; (c) bulk acyclodextrin derivative ( $\mathrm{KBr}$ disk), (d) neat linker on $\mathrm{NaCl}$ crystal. 


\section{TECHNOLOGY NEEDS}

Sensors for continuous real-time monitoring of ambient air, ground and surfacewater, and contaminant plume migration will be needed for compliance with state and Federal regulations (the Clean Air Act, the National Environmental Policy Act, and RCRA, to mention a few). Moreover, the specific needs of the environmental restoration and waste management programs require a new generation of sensors and advanced fieldable instrumentation. Present technology is simply inadequate to address the multitude of monitoring needs in site characterization, cleanup verification, post-closure monitoring, and process diagnostics and control. There is a specific highlevel need at a number of industrial sites for real-time sensors that will accommodate both air and down-hole aqueous phase sampling of chlorinated hydrocarbons (see Figure 2.11b).

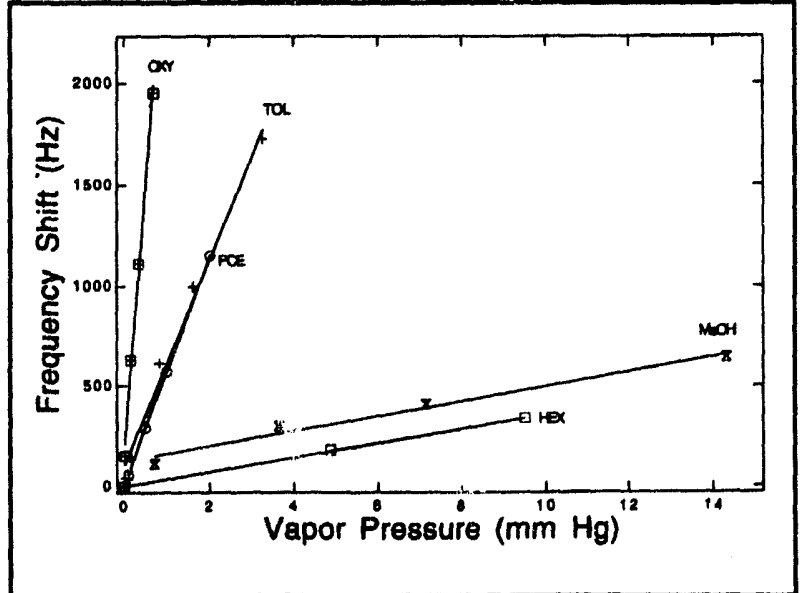

Figure $2.11 \mathrm{~b}$. Linear concentration dependent SAW response of various analytes to an acyclodextrin monolayer coated $200 \mathrm{HMz}$ resonator: perchloroethylene, toluene, oxylene, methanol, kand hexane.

\section{ACCOMPLISHMENTS}

Now beginning the second year of funding, a number of molecular surface building blocks have been synthesized covalently-bound selfassembled monolayer (CBSAM) thin films on various surfaces (e.g., Si wafers for infrared analysis, and SAW resonators for sensor evaluation have been fabricated), and the CBSAM thin films have been characterized via polarized variable-angle internal attenuated total reflection infrared (PVAI-ATR-IR) techniques and surface acoustic mass transduction. More specifically, asymmetric a-cyclodextrin20,30-dodecabenzoate and b-cyclodextrin20,30-tetradecabenzoate have been synthesized by first reacting dried and purified cyclodextrins with benzoyl chloride to form cyclodextrin perbenzoate, and then selectively hydrolyzing the benzoate groups on the primary side of the cyclodextrin rim using isopropoxide. The resulting mixture usually consists of a few other cyclodextrin benzoate derivatives, which were removed by chromatography using silica gel and benzene:ethanol as an eluted solvent. The final products (structure and purity) were characterized by ${ }^{1} \mathrm{H}$ NMR, FTIR, and TLC.

Monolayers of both asymmetric a- and bcyclodextrin benzoate derivatives can be successfully anchored on oxide surfaces through covalent bonds via a linker wbis(trichlorosilyl)alkane. To form the cyclodextrin monolayer, the substrate was first exposed to the vapor of the linker+1,6bis(trichlorosilyl)hexane, followed by binding subsequent cyclodextrin molecules through their primary hydroxyl groups. By blocking the secondary hydroxyl groups of a-cyclodextrin or b-cyclodextrin via functionalization of benzoate groups, these cyclodextrin surface building blocks can be easily linked to the surface with the cyclodextrin "bucket" facing upward. This desired molecular orientation 


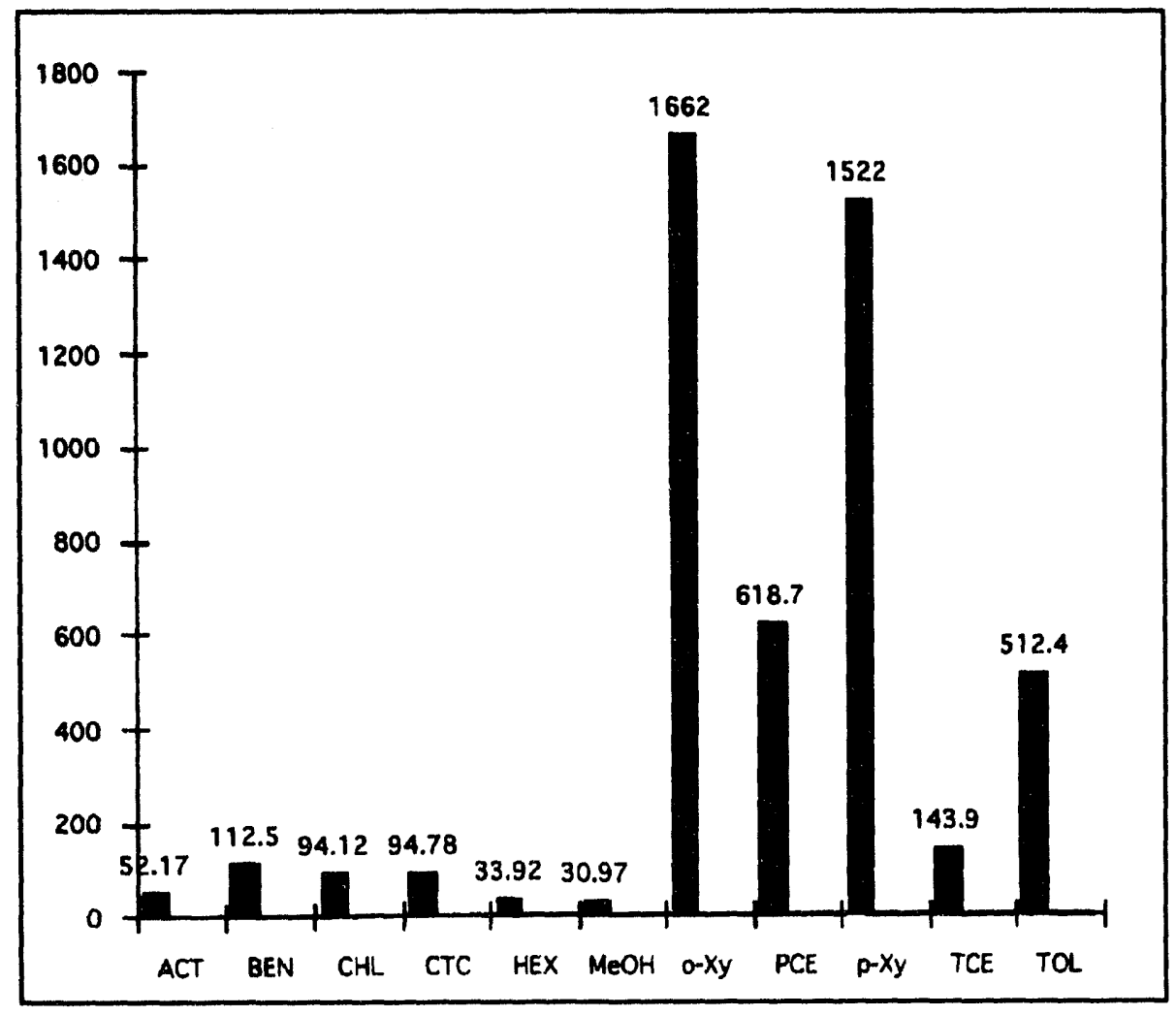

Figure 2.11c. Comparisons of the responses of the self-assembled acyclodextrin monolayer coated $200 \mathrm{MHz}$ SAW resonator microsensors to a variety of analytes at unit organic vapor concentration $(\mathrm{Hz} /$ $\mathrm{mmHg}$ ): Acetone, benzene, chloroform, carbon tetrachloride, hexanes, methanol, o-xylene (o-Xy, perchloroethylene, $\mathrm{p}$-xylene, trichloroethane, and toluene. Note the a-cyclodextrin coated monolayer thin film is very selective to xylenes, PCE, and toluene.
CBSAM thin films were analyzed by PVAIATR-IR techniques, and the results suggest successful monolayer formation of cyclodextrin derivatives on the Si wafer surfaces. The vibrations of cyclodextrin benzoates at $1740 \mathrm{~cm}^{-1}$, $1284 \mathrm{~cm}^{-1}$, and $708 \mathrm{~cm}^{-1}$ and its linker at 2926 $\mathrm{cm}^{-1}$ and $2855 \mathrm{~cm}^{-1}$, which are covalently attached to the Si surfaces, are clearly resolved. Monolayer thin films of both a- and b-cyclodextrin on actual surface acoustic wave devices have been fabricated. Results on $200 \mathrm{MHz}$ resonators indicate that the b-cyclodextrin thin films do show significant affinity to target chlorinated organic toxins such as PCE while acyclodextrin monolayer

results in an enhancement of the kinetic speed (i.e., response time) of the formation of inclusion complexes. Moreover, functionalities other than benzoates can be incorporated into the secondary hydroxyl group "tether" points. These functionalities include such alkyls as methyl, ethyl or aryl and serve to further control access to the cyclodextrin cavity by the analytes. In addition to covalent bonding to the oxide surface, this step-by-step supramolecular self-assembly technique offers molecular level manipulation of nano-structure such as cyclodextrin orientation. thin films prefer toluene and xylenes. Further experiments underway are aimed at maximizing monolayer coverage for construction of densely packed monolayer thin films. Sensing layer efforts into other synthetic host molecules have recently been expanded and the initial results are extremely encouraging.

The extreme outer rim of cyclodextrins can be further modified to achieve better selectivity and sensitivity by blocking the primary hydroxyl groups with t-butyldimethylchlorosilane followed by substitution reactions at the secondary hydroxyl groups (see Figure $2.11 \mathrm{c}$ ). This result opens up a number of opportunities to tailor the cyclodextrin-surface properties 
(hydrophilic versus hydrophobic) as well as its selectivity to various analytes. Cyclodextrins are also being synthesized for the construction of multilayer self-assembly using this step-by-step approach by alternating cyclodextrin layers and linker layers. Previous approaches have focused on linking host molecules via organic covalent bonds. A new inorganic approach that binds cyclodextrins or other synthetic hosts via a coordinative and/or ionic bond is being experimented with; to this end new molecular building blocks, such as a-cyclodextrin20,30-dodecabenzoate-60-hexaphosphate and other cyclodextrin phosphate compounds are being synthesized.

\section{COLLABORATION/TECHNOLOGY TRANSFER}

In the second fiscal year of this funding, Ames Laboratory and the University of California at Berkeley are collaborating to work on Lamb wave devices for aqueous sensing. A fulltime graduate student and part-time student will be supported by part of this funding $(\sim 50 \mathrm{k})$. Motorola is interested in sponsoring and establishing a test facility for sensor systems at their Phoenix plant for waste stream monitoring and downhole sensing in aqueous media. Motorola will provide a path to technology transfer and commercialization, via integration of our sensor elements into a remote, real-time monitoring system. A formal CRADA between Motorola and LANL is currently under development. A number of companies including Tektronix, Tanknology, Berkeley MicroInstrument, Amtex, Geocenter, and TPL have expressed interest in how variants of the base technology might meet their needs for sensor technology. For instance, Tanknology is interested in developing a pentane sensor with low ppm sensitivity for moni- toring the leaks of gasoline storage tanks. Tanknology has a great demand for these pentane sensors, as they currently sample around the tanks using a very expensive GCMS procedure. Ways to leverage efforts on related sensor technologies for benefit to all programs, DOE, and industrial partners are currently being pursued.

\section{For further information, please contact:}

\section{DeQuan Li}

Los Alamos National Laboratory

P.O. Box 1663

Los Alamos, MN 87545

(505) 665-1158

\section{Bruce Erdal}

Technical Program Manager

(505) 667-5338 


\subsection{AIR QUALITY SITE BOUNDARY MONITORING FOR VOLATILE ORGANIC COMPOUNDS}

\section{TASK DESCRIPTION}

This proposal describes a methodology in which a micromist air sampler (CMAS) developed at Los Alamos National Laboratory will be combined with a transportable gas chromatograph ion trap mass spectrometer ( $\mathrm{GC} /$ ITD) for the field collection and detection of airborne VOCs (see Figure 2.12). Membrane sampling technology, developed at Purdue University, will be used to introduce the preconcentrated VOCs to the GC/ITD. Each of these individual technologies has proven successful. Sensitivities can be tailored to quite easily surpass any existing or realistically anticipated regulatory requirements for the lower limits of detection. This technology can provide both primary (fast screening) and secondary (slower) legally defensible GC/MS data to verify air quality at and around DOE facilities and remediation sites. Sampling can be done in near-real time (minutes); additional samples can be easily collected for verification by independent off-line analysis.

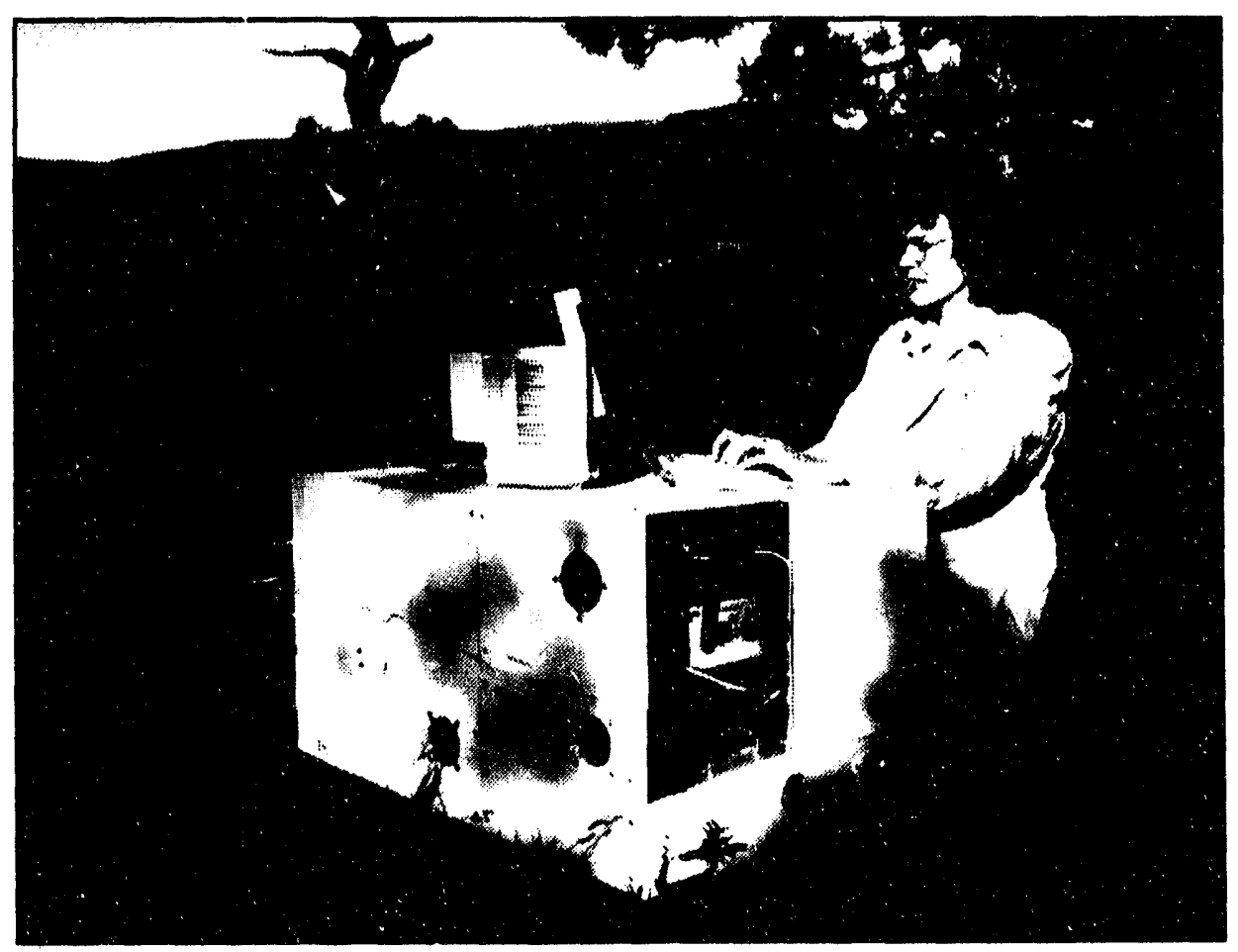

Figure 2.12. The Los Alamos transportable gas chromatograph ion trap mass spectrometer used for the field analysis of volatile organic compounds in the environment. 


\section{TECHNOLOGY NEEDS}

This technology is needed at every DOE facility to monitor air quality at site boundaries. There are many scenarios that require high sensitivity detection of atmospheric volatile organic compounds:

- routine monitoring to establish baseline air quality at site boundaries;

- response monitoring to characterize and document atmospheric distribution of volatile chemical solvents from accidental releases or spills; and

- waste site monitoring to ensure worker and public safety during remediation activities. Specific Integrated Demonstrations (ID) that could be supported by this technology include those where remediation of VOC-contaminated soil is planned or underway (Savannah River A-1, Hanford A-4, and SandiaAlbuquerque A-9). The instrument could provide monitoring for accidental releases during waste exhumation at the Buried Waste ID (B-I) at INEL.

The proposed technology can support many other activities in the environmental arena:

- air monitoring at hazardous or mixed waste storage sites;

- air monitoring at DOE and private industrial areas to ensure worker safety and to document exposure; and

- detection of atmospheric tracers to provide data for global modelling efforts.

Finally, the instrument could be used to monitor chemical emanations that are signatures of military operations, drug processing, and other illegal or aggressive activities.

\section{ACCOMPLISHMENTS}

Significant accomplishments were made in two key areas: (1) air sampling, and (2) membrane sample introduction. The collection of VOCs with the CMAS is problematic due largely to the poor partitioning of organics from air into the aqueous mist. Dilute surfactant solutions in the CMAS improved collection of certain compounds. With a prototype CMAS, detection limits for many VOCs in air are about a part-per-billion by volume (ppbv), with some in the high parts-per-trillion range. A new CMAS specifically for VOC collection was designed and built and is being tested. The development of the membrane interface at Purdue University was very successful. The efficiency of the membrane introduction system was improved by a factor of 100 . Organics in water can be detected at the low part-per-trillion by weight (pptw) level in nearreal time with linearity spanning a 2000 -fold concentration range. Although this system was designed as an interface between the CMAS air sampler and the ion trap mass spectrometer, the membrane sampling system could also be used for the direct analysis of VOCs in water, (e.g., as a waste stream monitoring technique).

\section{COLLABORATION/TECHNOLOGY TRANSFER}

This project is in collaboration with Purdue University. The Principal Investigators are remaining in close communication with Finnigan MAT, the commercial manufacturer of the ion trap mass spectrometer, and with the president of MIMS, a company founded to develop and market membrane separators for chemical analysis. In addition, a scientist from the National Center for Atmospheric Research is on sabbatical at the laboratory and 
will be working on improving the CMAS and developing new cryogenic methods of VOC collection.

\section{For further information, please}

contact:

\section{Phillip Hemberger}

Analytical Chemistry Group

Los Alamos National Laboratory

(505) 665-5735

\section{Bruce Erdal}

Technical Program Manager

Los Alamos National Laboratory

(505) 667-5338 


\section{TASK DESCRIPTION}

The purpose of this task is to develop and facilitate deployment of Direct Sampling Ion Trap Mass Spectrometry (DSITMS) instrumentation (see Figure 2.13a). Its focus is to provide fieldable instrumentation capable of the more-rapid and less-costly detection and measurement of organic chemical contaminants than is possible using currently employed technologies. DSITMS involves the continuous real-time monitoring of organic analytes as they are being introduced into an ion trap mass spectrometer (ITMS). Volatile organics in water and soil are introduced by purging the sample with helium and routing the purge stream to the ITMS. Volatile organics in air and water can be monitored in real time or may be collected on sorbent traps and analyzed by thermal desorption DSITMS. Thermally stable semi-volatile organics can also be determined by thermal desorption. No or minimal sample preparation or chromatographic separation is required. The result is that analyses are completed from real-time to three minutes, depending on the precision required.

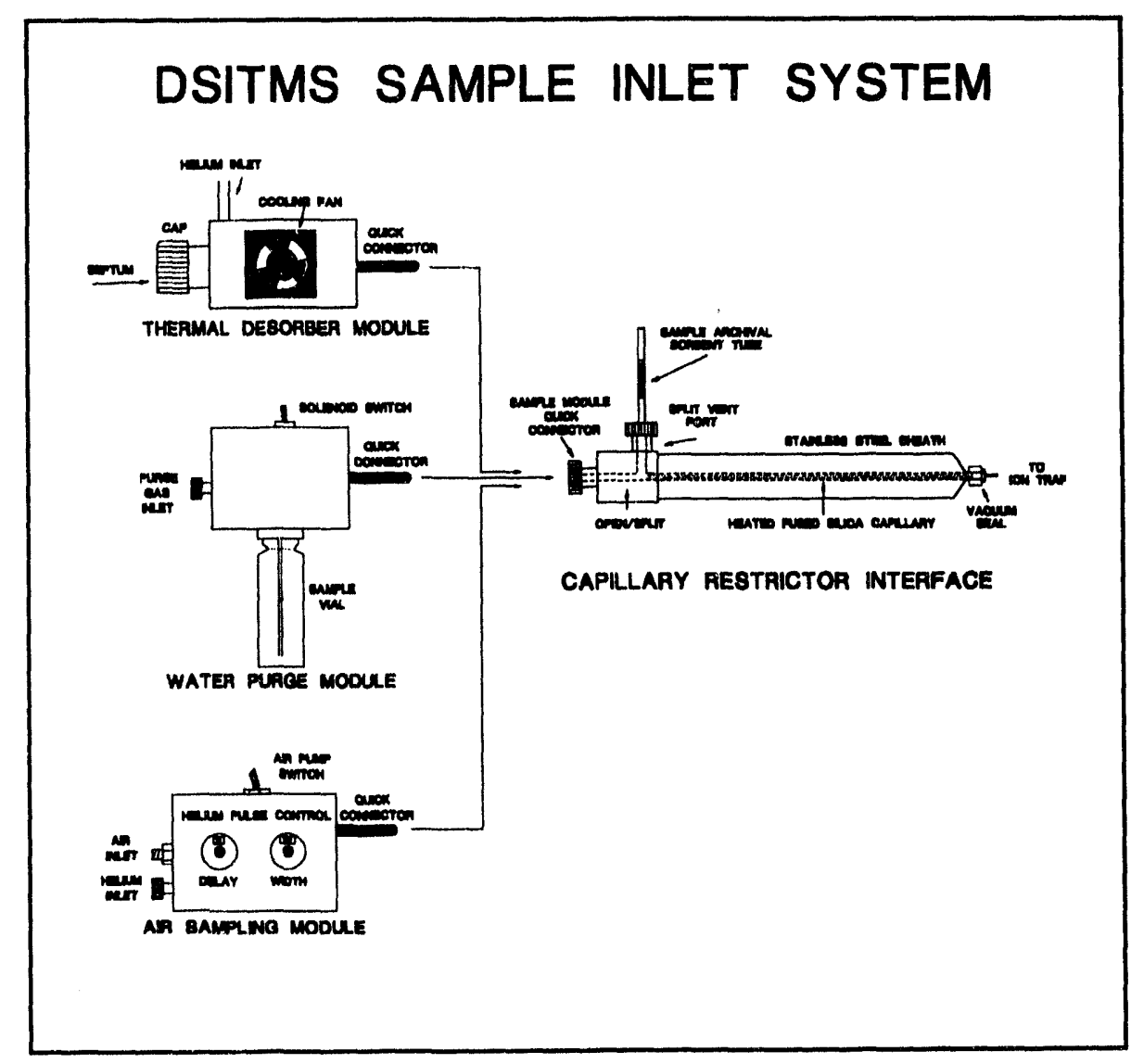

Figure 2.13a. Direct sampling ion trap mass spectrometry modular inlet system.
Commercially-available ion trap mass spectrometers have been modified and fitted with Oak Ridge National Laboratory-developed sample introduction modules. Both laboratory-based and fieldtransportable versions of the instrumentation are now available. Fullscan mass spectra are generated every approximately $100 \mathrm{msec}$ as the analytes are being introduced. Ions characteristic of the analyte(s) of interest are subsequently plotted as a function of time to produce purge profiles. The areas of the profiles are directly pro- 
portional to the quantity of the analyte(s) present. Multiplexed electron impact and chemical ionization mass spectra and multiple stage mass spectrometry are used to resolve many interferences. Excess purge stream material is collected on solid sorbent traps for analysis by traditional methods when interferences cannot be resolved directly. DSITMS instruments demonstrated to date are based on commercial ion trap mass spectrometers designed for other purposes. Neither the laboratory nor fieldable instrument are currently capable of the operator ease and on-line data processing inherent in the technology. The field instrument is not currently capable of multiplexed ionization nor multiple stage mass spectrometry. The purpose of this task is to facilitate commercialization and deployment of the existing technology, upgrade its operating and data processing routines, and develop an instrument optimized for DSITMS applications. Demonstration and commercialization are integral parts of this task.

\section{TECHNOLOGY NEEDS}

Current methods for the detection and measurement of organic contaminants most frequently involve the collection of samples, followed by expensive and time-consuming analyses at an off-site laboratory. Rapid, less costly field measurements fulfill needs for field screening of samples to be selected for laboratory analysis, the ability to analyze larger numbers of samples, a more nearly real-time monitoring of remedial actions, and rapid response to emergencies. DSITMS is especially attractive for such purposes because of its applicability to a large number of contaminants and its rapid reconfiguration for analyses of water, soil, and air. It also has shown promise as a truly continuous real-time moni- tor for air and aqueous streams, thus addressing needs for process and emissions monitoring.

\section{ACCOMPLISHMENTS}

A field-transportable DSITMS instrument based upon modifications to the commerciallyavailable Finnigan MAT Magnum/ITS 40 has been constructed and successfully demonstrated for multiple applications (see Figure 2.13b). Two instruments are in place at Oak Ridge National Laboratory for development and demonstration, one instrument is in routine use at the Savannah River Technology Center, and one instrument is at the Pacific Northwest Laboratory. The laboratory-based instrument has been used to document acceptable performance for the determination of VOCs in water and the data has been submitted to the EPA Office of Solid Waste for review. The field instrument has been demonstrated to be effective for the determination of

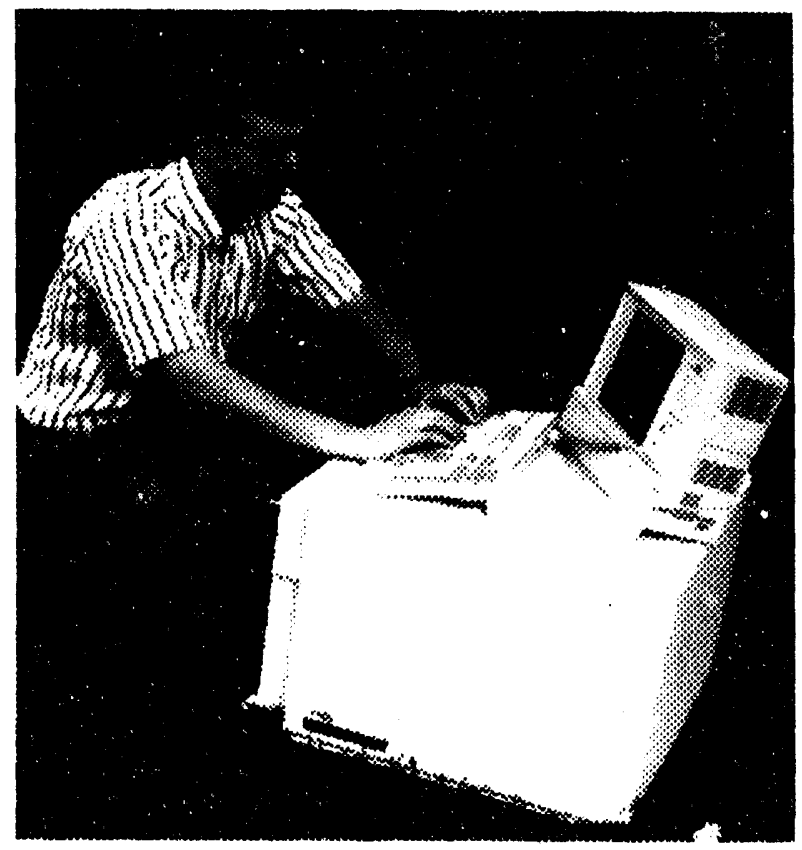

Figure 2.13b. Fieldable direct sampling ion trap mass spectrometry instrumentation. 
VOCs in water and/or soil at DOE facilities at the Portsmouth Gaseous Diffusion Plant, the Savannah River Technology Center, and the Oak Ridge K-25 Site. Regulatory agencymandated detection limits are readily achieved. DSITMS has also shown promising results for the continuous on-line monitoring of VOCs in an incinerator stack and in the stream of $a$ groundwater remediation process. An instrument was also successfully interfaced to a cone penetrometer sampling manifold as part of a demonstration of real-time VOC monitors at the DOE Hanford site. An instrument capable of operating while being transported has been developed. This was demonstrated by monitoring the exhaust of a van while it transported a marine battery-operated DSITMS. Both the laboratory-based and field instruments have performed well in studies of the applicability of DSITMS to the determination of pre-selected semivolatile organics using the thermal desorption sampling module. Progress has been made in software development to improve ease of operation and on-line data processing within the constraints of the commercial instrumentation. Partnerships are being formed to commercialize the existing instruments and to develop and commercialize an instrument optimized for user-friendly DSITMS applications.

\section{COLLABORATION/TECHNOLOGY} TRANSFER

This is a collaborative activity with the Army Environmental Center (AEC). DSITMS was developed under AEC support and DOE' OTD has taken the lead in developing field instrumentation for environmental applications. Current AEC work centers on interfacing DSITMS with the Army cone penetrometer system and on the determination of semivolatile organic contaminants. Collabo- rative studies have been performed with local and other investigators involved in demonstrations. Technology transfer is being pursued through the export of instrumentation to other DOE Laboratories, license agreements with Finnigan MAT and Teledyne Electronics, and contacts with small business firms interested in commercializing accessories to the Finnigan-based instrument. The Army Program Manager for Rocky Mountain Arsenal and a local EM-40 office have provided funding to construct and assist in deployment of DSITMS instruments at their sites. Representatives of the petroleum and automobile industries have expressed interest in testing the technology for its applicability to their needs.

For more information, please contact:

Marcus B. Wise

Michael R. Guerin

Oak Ridge National Laboratory

PO Box 2008, MS-6120

Oak Ridge, TN 37831-6120

615-574-4862 


\subsection{MULTISORBENT ARRAYED SAMPLER FOR COLLECTION OF VADOSE ZONE ORGANIC CONTAMINANTS}

\section{TASK DESCRIPTION}

The objective of the work is to develop, demonstrate, and deploy a novel sampling system for the multi-point collection of vadose zone soil gas samples (see Figure 2.14a). With this unique approach, samples are collected and concentrated at the point at which they emanate from the subsurface strata, not after having been transported through many 10's of feet of tubing. The sampler body consists of a cylindrical stainless steel assembly housing an array of thirteen micro-miniature solenoid valves in a mounting structure to accept six multi-sorbent traps connected into the system via standard 1/4" tube fittings. As mounted in the body, solenoid valves are connected to each end of each trap for isolation or sampling as desired. The outlet of each trap is connected (via a solenoid valve) to a common sample conduction manifold. A vacuum source at the surface draws an accurately metered sample of air through any selected trap via the manifold. An additional solenoid valve is used in the sampler head to provide for rapid direct evacuation of the residual air in the vicinity of the sampler prior to sampling through a trap, if such is deemed appropriate. The system may also be used to draw soil gas samples directly to the surface. Each end of the sampler body is fitted with an inflatable donut-shaped bladder, which acts as a packer to secure the body at any given vertical location in a well. The sampler body is connected to a control assembly at the surface by 160 feet of a composite cable. This assembly contains all of the necessary electrical and pneumatic circuitry to deploy and activate the sampler body. Combined with a sufficiently sensitive analytical system, the samples can be collected in sufficiently small quantities so as to not disrupt the subsurface equilibrium.

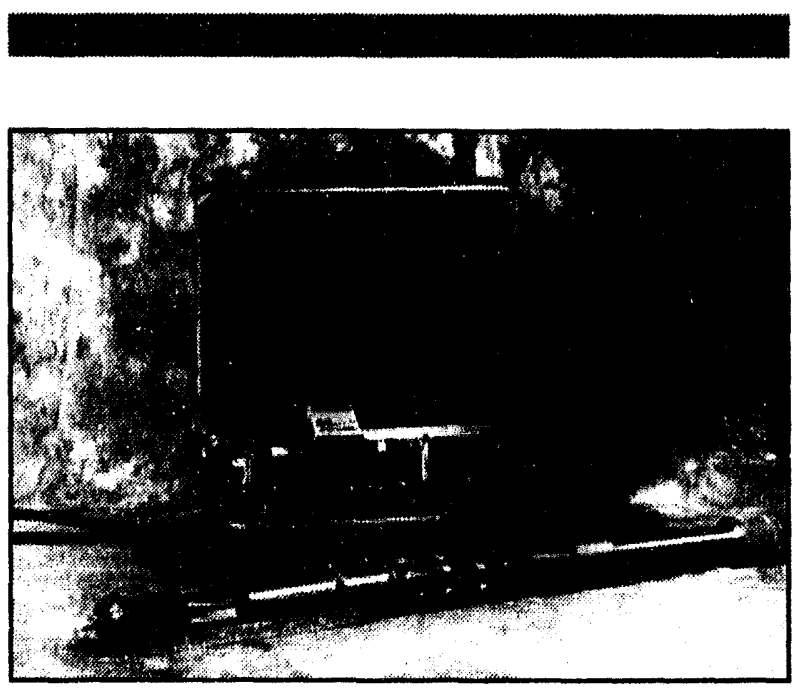

Figure 2.14a. Multisorbent arrayed sampler.

\section{TECHNOLOGY NEEDS}

There is a need for subsurface sampling in the vadose zone for a broad range of VOCs at contaminated sites, either during site characterization or remediation. Conventional approaches to the acquisition of a soil gas sample at depths of more than a few feet involve the implantation of a tube, and withdrawal of a soil gas sample to the surface. There are a number of potential problems with such an approach. First, in geologic strata with low porosity, the volume of gas that needs to be pulled to the surface may be greater than that which can be replenished by diffusion through the surrounding soil. Extraction of a large sample can disturb the subsurface equilibrium, and gas can be withdrawn that is not representative of that present in the soil. Sec- 
ondly, there can be significant losses of organic vapors through permeable tubing, such as Teflon, especially when the length of tubing involved is considerable. Even in nonporous tubing, organic vapors may adsorb on or react with tubing surfaces, or dissolve in water vapor condensed on the walls of the tubing. One alternative to drawing samples to the surface involves collection, stabilization, and concentration of the soil gas sample at the point at which it has been acquired. This can be accomplished by drawing the soil gas sample through a cartridge containing material capable of retaining a broad range of VOCs.

\section{ACCOMPLISHMENTS}

The sampler was fabricated and laboratory tested in FY91. Work in FY92 involved field testing of a prototype version of the sampler at the Savannah River Site (see Figure 2.14b.). Numerous vadose zone samples were collected, sampling soil gas volumes sufficiently small so as not to disturb the subsurface equilibrium, even in nonporous strata. Data acquired during the sampling yielded a wide range of apparent soil gas concentrations, from $5-130,000+\mathrm{g} / \mathrm{m}^{3}$ of trichloroethylene, as well as other co-contaminants. These tests demonstrated that the system could function in a realistic environment, and identified several modifications that could both simplify its use and enable it to sample from a more highly defined subsurface zone. The initial modifications were made to the sampler in FY93. Activities in FY94 are directed toward physical modification of the sampler so that it may interface more effectively with the long screened intervals at the Hanford Site, field evaluation trials at the VOC/Arid Integrated Demonstration Project, and initiation of the process of technology transfer.

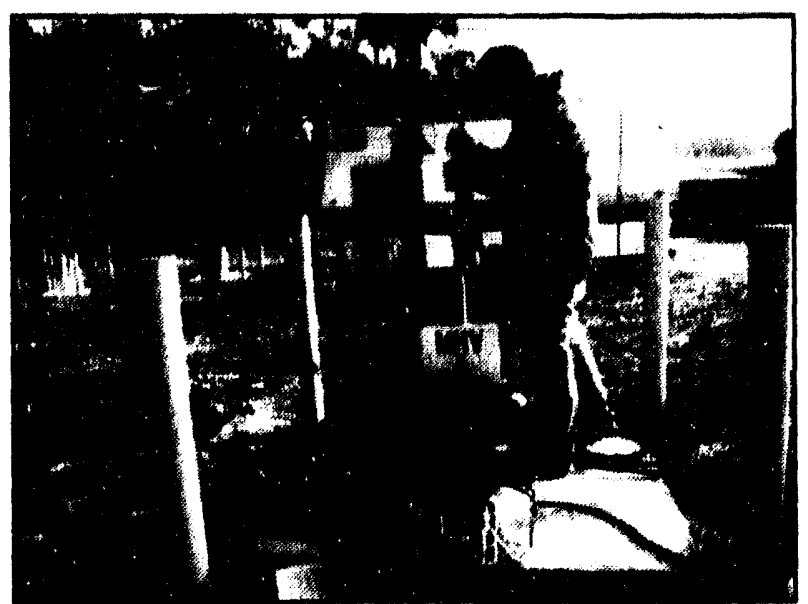

Figure 2.14b. Field deployment of prototype arrayed sampler at Savannah River Site.

\section{COLLABORATION/TECHNOLOGY TRANSFER}

Initial discussions have been held with a candidate commercial partner with interests in developing subsurface sampling and analytical systems. Multi-sorbent traps for sample collection have been shipped to the firm, to determine if such systems would be of use in its intended applications.

\section{For further information, please contact:}

\section{Roger A. Jenkins}

Oak Ridge National Laboratory

P.O. Box 2008, MS 6120

Oak Ridge, TN 37831-6120

(615) 576-8594

\section{Anthony P. Malinauskas}

Technical Program Manager

(615) 576-1092 


\subsection{MULTISPECTRAL NEUTRON LOGGING: A NEW GENERATION PULSED-NEUTRON INDUCED GAMMA-RAY MULTI-SPECTRA LOGGING SYSTEM FOR IN SITU MAPPING OF CONTAMINANTS}

\section{TASK DESCRIPTION}

This project addresses two nuclear borehole logging techniques that are capable of identifying and mapping numerous contaminants and are nuclide specific.

- Neutron-induced spectral gamma-ray logging measures gamma-ray energy spectra during and/or after irradiation of the borehole environment with energetic neutrons, and can positively identify many nuclides, including chlorine and a number of RCRA metals (see Figure 2.15a).

- Passive spectral gamma-ray logging positively identifies gamma-emitting contaminants and is quite sensitive, but needs work to be made quantitative.

In the neutron-induced spectral gamma-ray part of this project, a contaminant-doped concrete test facility has been designed and is now under construction at Grand Junction, Colorado (see Figure 2.15b). Assembled through collaboration with an industry partner (Environmental Measurements Corp., Denham, TX), a hybrid test instrument composed of the pulsed-neutron source section of the existing commercial instrument along with a laboratory-grade cryogenic detector and multichannel analyzer will be assembled. Experiments will be performed in the test facilities using the hybrid test instrument to make direct assessments of instrument sensitivity to the con- taminants in the test facilities. Ongoing computer simulations will allow extension of the experimental results to estimate detection thresholds for other contaminants of concern and determination of optimum design for a next-generation instrument.

In the passive spectral gamma-ray part of the project, experimental data provided by Westinghouse Hanford Company is being used, along with computer simulations to develop data correction and deconvolution algorithms to establish a quantitative basis for this tech-

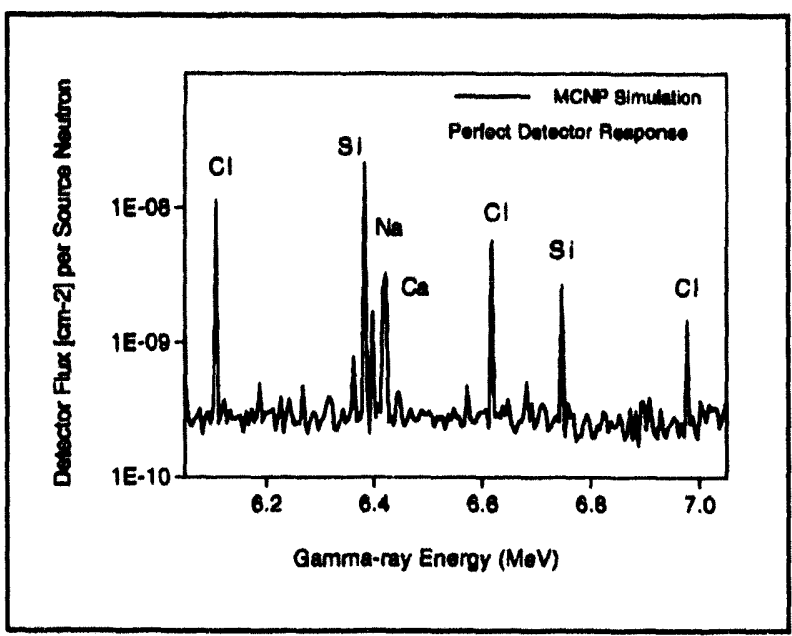

Figure 2.15a. Small portion of a simulated gamma-ray energy spectrum.

nique. The FY94 effort is to determine the response of an existing DOE instrument to many environmental variables and adapt existing data processing techniques, including linear inverse theory, to correct for those conditions. The FY95 effort is to generalize the data correction algorithms to less well-be- 
haved geologic conditions, where the assumption of linear system behavior is not valid. A more general statistical approach will be developed to assure data quality in such environments.

\section{TECHNOLOGY NEEDS}

This project responds to a number of needs identified by the CMST-IP:

- field analysis equipment for real-time results;

- significantly improved analytical methods or sensors;

- improved in situ measurements of subsurface properties;

- instrumentation for deployment by cone penetrometers; and
- statistically guided sampling and data quality assurance tools.

Letters of support for this project have been received from environmental restoration groups at Westinghouse Hanford Company, Sandia National Laboratories, Los Alamos National Laboratory, and Westinghouse Savannah River Company.

\section{ACCOMPLISHMENTS}

- Contaminant-doped concrete test facilities have been designed and are being constructed at Grand Junction, CO.

- Contract negotiations with an industrial collaborator are in the final stages for experiments using a hybrid commercial/experimental neutron-induced spectral borehole logging instrument.

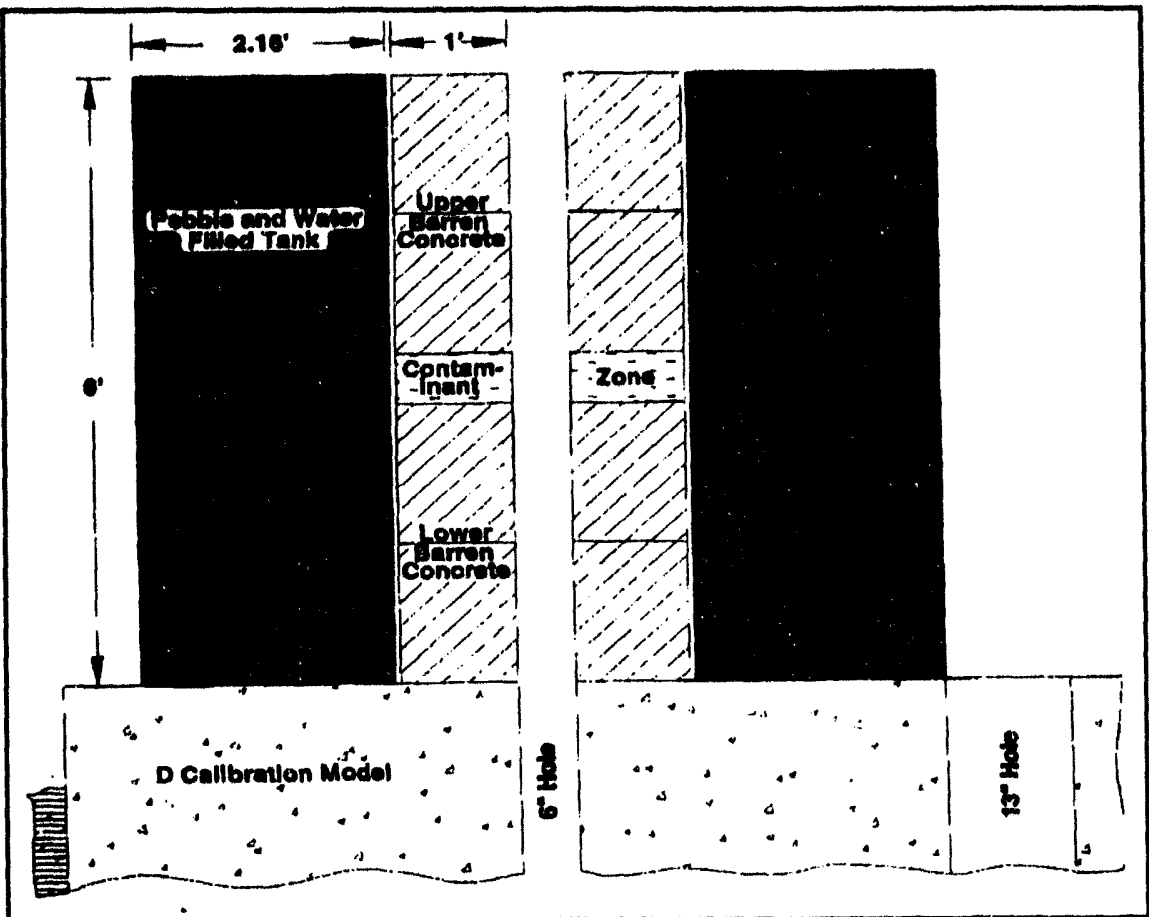

Figure 2.15b. Cross-section of contaminant-doped concrete test facility setting on an existing borehole calibration model at the Grand Junction Projects Office. 
- Computer codes for simulating neutron and gamma-ray transport problems have been installed and tested. Substantial improvements have been made to the codes for this project and other improvements are expected shortly that will greatly speed the simulation process. Simulations are now being performed successfully.

- For the passive spectral gamma-ray work, Westinghouse Hanford Company provided experimental data and details of their logging instrument. Simulation models are currently being tested.

- All work is on schedule and within budget.

\section{COLLABORATION/TECHNOLOGY TRANSFER}

This neutron-induced spectral gamma-ray work is being performed collaboratively by Los Alamos National Laboratory, RUST Geotech (site operator for the DOE Grand Junction Projects Office), and the U.S. Geological Survey, under separate Technical Task Plans. Westinghouse Hanford Co. is participating under EM-40 funding. Negotiations are in progress with a potential industry partner, Environmental Measurements Corp., who have been supportive and enthusiastic about collaborating on the project. The passive spectral gamma-ray work is primarily a Los Alamos project coilaborating with Westinghouse Hanford Company under their own EM40 funding. This part of the project is newer and the details of technology transfer are being worked out.
For further information, please contact:

John Conaway

Los Alamos National Laboratory

(505) 667-2683

David George

RUST Geotech

(303) 248-6699

Jon Mikesell

U.S. Geological Survey

(303) 236-1321 


\section{TASK DESCRIPTION}

This task will develop field-deployable instrumentation for rapid determination of hazardous metals in soils at hazardous and mixed wasie sites. The data quality is expected to be suitable for use of the instrumentation as a field analytical method during site characterization. Elements targeted specifically are those of primary concern at many DOE and industrial waste sites: $\mathrm{Cr}, \mathrm{Pb}, \mathrm{As}, \mathrm{Se}, \mathrm{Sb}, \mathrm{Cd}$, $\mathrm{Zr}, \mathrm{U}, \mathrm{Be}$, and $\mathrm{Th}$. The instrumentation will be based on laser-induced breakdown spectroscopy (LIBS). Using LIBS, it will be possible to determine rapidly both the concentration and location of elemental species in a waste site.

In LIBS, laser light is focused on a surface to vaporize a small amount of material. The vaporized material forms a short-lived plasma, which emits light that is collected, dispersed and analyzed. A schematic of a LIBS apparatus is shown in Figure 2.16a. LIBS instrumentation can be made quite compact and only requires line-of-sight access to a material. The method thereby lends itself to integration with other instruments and several instrument configurations. The working head of one portable instrument constructed at LANL is 4 inches in diameter and 8 inches long. Using a fiber-optic cable to guide the laser energy to soil will decrease the size requirements. Also, standoff analyses of at least fifty feet are anticipated to be achievable. The final form of the prototype instrumentation will either be designed to provide as general use as possible or will be determined by the instrument configuration and data requirements of any of a number of end-users.

Prototype instrumentation for hazardous waste sites will be available in mid-1995. Instrumentation for mixed-waste sites is planned for 1996. These programs all require a rapid field-screening method for site (or tank) characterization and real-time analysis for remediation and process monitoring.

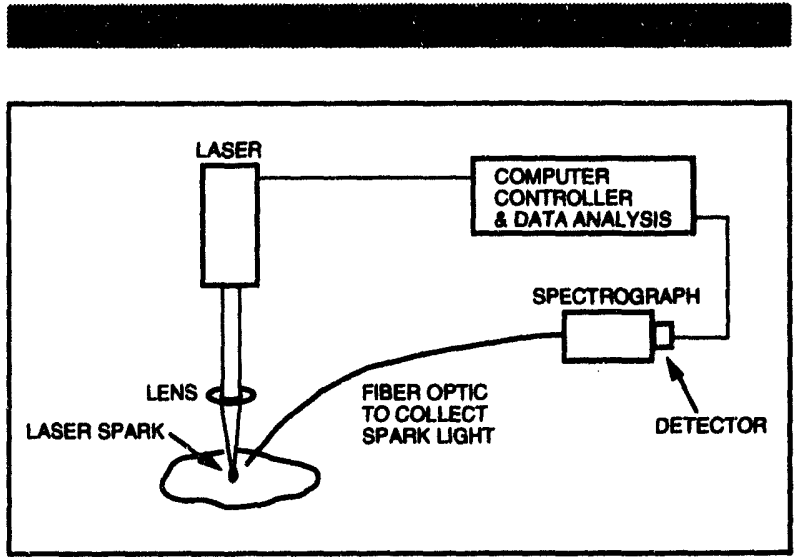

Figure 2.16a. Schematic representation of a basic laser-induced breakdown spectroscopy instrument.

\section{TECHNOLOGY NEEDS}

The need for a field method that can provide expedited site characterization of hazardous waste sites is critical. Site remediation often becomes mired in the site characterization step because of slow turn around time of sample analyses. In addition, once a sample is removed from a location, its chemical integrity is always of concern. A method that minimizes sample handling and transport is needed to better ensure data quality. The LIBS instrumentation to be developed and 
tested in this task is targeted to fulfill these needs for as many heavy metals as time permits.

In addition to increasing the speed and efficiency of analyses, this technology will decrease the costs associated with evaluating and remediating hazardous and mixed-waste sites. It is estimated that years will be saved in characterizing and remediating sites identified by EPA as falling under RCRA. Cost savings should include $80 \%$ of the sampling costs of using conventional laboratory techniques for all analyses as well as savings resulting from reduced crew downtime waiting for laboratory analyses. It is also anticipated that a reduction of $80-90 \%$ in transportation and $80-90 \%$ in the generation of new hazardous waste by sample analysis will occur. In addition, this instrumentation will eliminate the exposure of personnel to potentially hazardous wastes.

Another benefit is the larger number of samples that can be analyzed and the greater accuracy in determining the analyte distribution throughout a site. Analysis at a single position at a site should take one minute or less. Thus, a site can be surveyed in less time, with greater coverage, than achievable with conventional sample collection and analysis methods. Additionally, depth profiling by analysis of core samples is limited by the cost of analysis to one $10 \mathrm{~g}$ sample taken for every five foot section. This is a very small fraction of the entire core, and choosing a representative sample is a difficult but critical task. Using an instrument based on LIBS to scan the entire length of the core sample, in the field, will be a cost-effective solution to this sampling problem.

\section{ACCOMPLISHMENTS}

This is the first year of this task. As scheduled for the first few months of this year, laboratory experiments have been conducted to:

- identify spectral interferences from elements typically found in soils for the analytes of interest.

- determine the detection limit, sensitivity and precision of the best analytical line(s) in soils spiked with single elements of interest. Instrument parameters used are those that can be translated to fieldable instrumentation.

A typical calibration curve is shown in Figure 2.16b.

Complete details of the results for detection limits of soils spiked with single elements will be available in the report due at the end of March 1994.

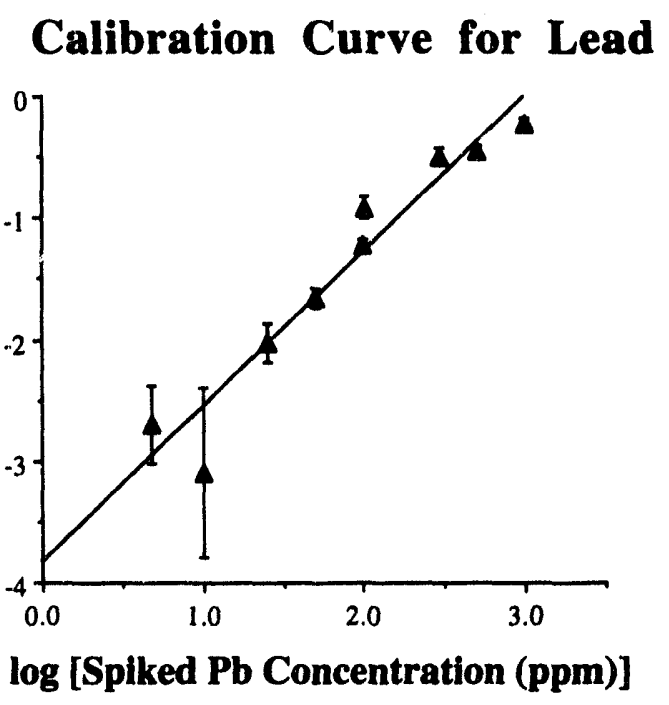

Figure 2.16b. Calibration curve for Los Alamos soil spiked with lead. 
COLLABORATION/TECHNOLOGY TRANSFER

Perkin-Elmer, Inc., one of the largest analytical instrumentation manufacturers in the world, is interested in developing LIBS technology for heavy metals analysis of soils in the field. The principal scientist from Perkin-Elmer involved in this project has conducted experiments in the LIBS labs at LANL on several occasions. They have provided funds for the construction of a laboratory LIBS instrument to be delivered to Perkin-Elmer for evaluation. Construction of that instrument has begun.
For more information, please contact:

Aaron Koskelo

Los Alamos National Laboratory

Los Alamos, NM 87545

(505) 665-4463

\section{David Cremers}

Los Alamos National Laboratory

Los Alamos, NM 87545

(505) 665-4180 


\subsection{AIR-QUALITY MONITORING FOR ALPHA CONTAMINATION - LONG-RANGE ALPHA DETECTION}

\section{TASK DESCRIPTION}

This project is developing detectors for airborne alpha contamination based on LongRange Alpha Detector (LRAD) technology. The goals are to demonstrate the effectiveness of this technology when applied specifically to monitoring air quality and to compare these results with those generated by more traditional detectors. LRAD-technology-based detectors should exhibit better performance, as indicated by greater resolution and faster response at a lower cost than existing baseline detectors.

Detection of alpha contamination in air samples has traditionally been limited by the short range of alpha particles and the relative insensitivity of fieldable alpha monitors. The best currently available technology uses continuous air monitor (CAM) detectors. These detectors must sample a given volume for several hours in order to achieve $\sim 0.1 \mathrm{pCi} /$ liter resolution.

The general design of LRAD-technologybased Air-Quality Monitors (AQMs) is shown in Figure 2.17a. Air is drawn through electrostatic and particulate filters into a sample enclosure. Ions produced by alpha decays within the sample enclosure are then collected on a grid and the current generated is measured using a sensitive electrometer. This current is directly proportional to the concentration of airborne alpha contamination.

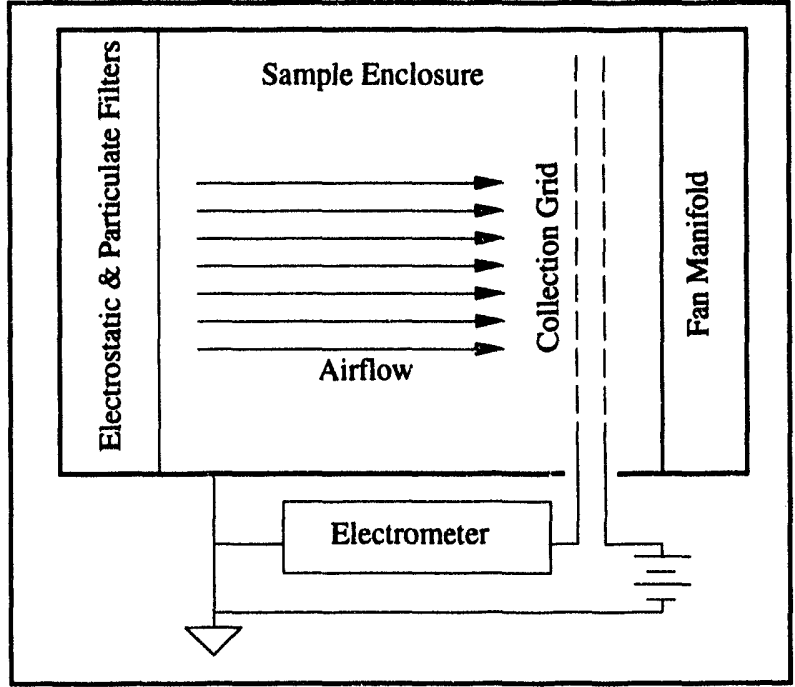

Figure 2.17a. Schematic of a long range alpha detector, technology-based air-quality monitor.

\section{TECHNOLOGY NEEDS}

In the Decontamination \& Decommissioning field, work involving sectioning and removing objects, such as walls, concrete floors, pipes and equipment, must be performed. Any alpha contamination attached to these objects can become airborne in the process. A realtime monitor capable of detecting alpha radiation levels ranging from the naturally occurring background of $\sim 1 \mathrm{pCi} / \mathrm{liter}$ up to $\sim 1000 \mathrm{pCi} /$ liter would improve worker safety. Continuous real-time monitoring in plutonium processing facilities, waste storage areas and other places where the potential for airborne alpha contamination exists is also desirable. 


\section{ACCOMPLISHMENTS}

Existing prototype LRAD detectors have been used to investigate whether the desired sensitivity to airborne alpha contamination can be achieved. Two detectors, originally designed as personnel hand monitors, were operated in the Radon/Radon Daughter Environmental Chamber operated by the Rust Geotech lab at the DOE Grand Junction Projects Office (GJPO). Concentrations spanning four decades, from $0.1 \mathrm{pCi} /$ liter up to $320 \mathrm{pCi} / \mathrm{Liter}$, were tested. Figure $2.17 \mathrm{~b}$ shows current measured by the two LRAD detectors (HM-1 \& HM-2) versus the chamber mean radon concentration as measured by 10 continuous radon monitors, including a commercially-

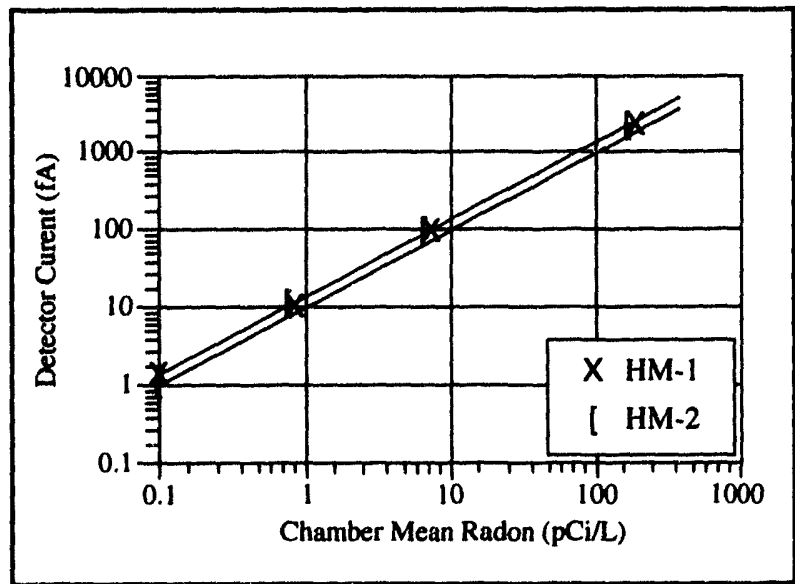

Figure $2.17 \mathrm{~b}$. Radon response of two long range alpha detector, technology-based detectors, HM-1 and HM-2.

available Eberline RGM-2 and two Pylon AB$5 \mathrm{~s}$, operated by the Grand Junction Project Office staff.

After subtracting a constant background produced by cosmic ray ionization in the sample enclosure and leakage currents in the electrometer and collection grid standoffs, linear calibration coefficients of 9.25 and $11.38 \mathrm{pCi} /$ L/fA were obtained for HM-1 and HM-2. Because detector HM-1 was equipped with a particulate filter while HM-2 was not, correlation coefficient for radon daughters attached to particulates were able to be measured. Figure $2.17 \mathrm{c}$ compares the GJPO data (10 detec-

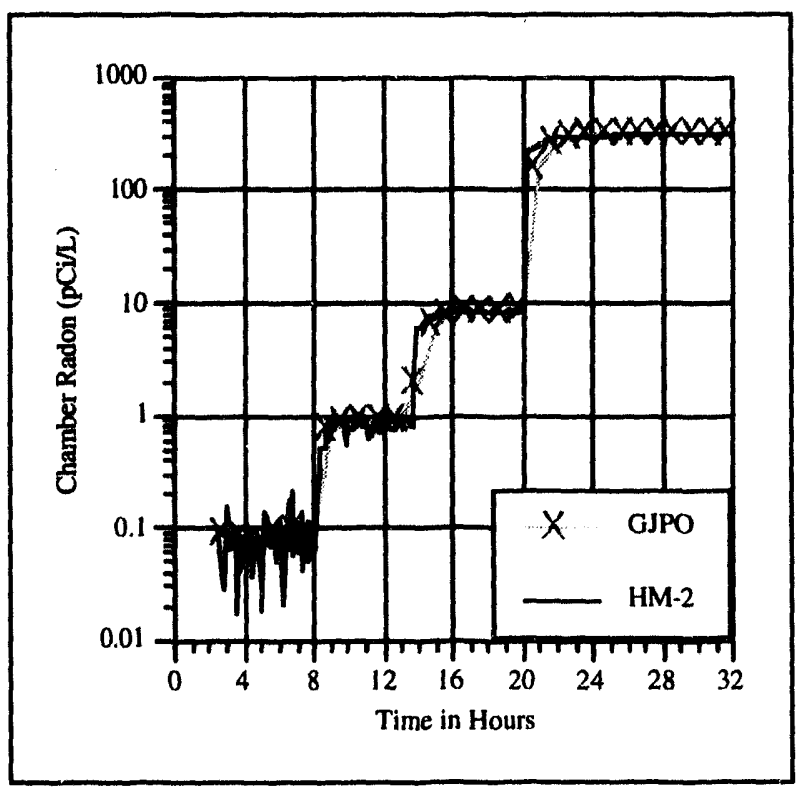

Figure $2.17 \mathrm{c}$. An overlay of the particulatecorrected HM-2 and Grand Junction Project Office data.

tors averaged over one hour intervals) to HM2 data (averaged over 6 minute intervals) after applying the calibration and particulate corrections.

These data show that LRAD-technology-based air-quality monitors will have a fast and linear response to airborne alpha contamination over the entire test range of $0.1 \mathrm{pCi} /$ liter to greater than $320 \mathrm{pCi} /$ liter. The speed of response to changes in concentration is determined by the rate of exchange between the sample enclosure and the surrounding air. This exchange rate is typically less than 10 seconds.

Rust Geotech Radon Laboratory has joined LANL personnel in analyzing and presenting these data as work in progress in a paper titled 
LRAD Radon Test Results at the Mid-Year Health Physics Society Meeting, Albany, NY (Feb. 13-16, 1994).

Two new prototype detectors (AQM-1 and AQM-2) have been fabricated in order to determine the optimum design for monitoring airborne contamination. While the HM detectors used airflow ion collection, these prototypes can easily be modified to operate in either the airflow or electrostatic ion collection mode.

Initial results obtained with the $A Q M$ prototypes indicate that the electrostatic ion collection method improves ion collection efficiency by $\sim 30 \%$. This increase in detection efficiency will translate into a smaller, more portable monitor.

Work is underway to optimize an electrometer for use with AQMs. All previous LRADtechnology-based detectors, including HM-1 and HM-2, used Keithley 617 electrometers. These cost $\sim \$ 3500$ each and are AC powered, large, heavy and subject to baseline fluctuations, due to temperature shifts, vibration or other environmental factors. In addition, since many of the potential applications of AQMs require operation outdoors or in facilities being decommissioned, battery operation is required. The current electrometer prototype has better performance than the Keithley unit, weighs only a few ounces, runs for $\sim 60$ days on a set of batteries and costs $\sim \$ 100$. Electrometers with additional improvements are under development.

\section{COLLABORATION/TECHNOLOGY TRANSFER}

Ames Laboratory is collaborating with personnel at the DOE GJPO and Rust Geotech Radon Laboratory on calibration and testing of LRAD-technology-based detectors. A second trip to this facility is planned for April, 1994 in order to calibrate and investigate the performance characteristics of the AQM prototypes.

A CRADA and licensing agreement between LANL and Eberline Instrument Corporation for the commercial development of LRADtechnology-based detectors already exists. Eberline has already commercially-produced an LRAD object monitor, the LRAD-1. As part of the technology transfer partnership, LANL continues to work with Eberline to evaluate and suggest incremental improvements to their existing design. LANL is working closely with Eberline and Commercialization Specialists to insure that transfer of the final $\mathrm{AQM}$ design and relevant technical information occurs at the appropriate moment. This transfer will most likely occur by mid- to late-summer. Once Eberline has a production unit available, based on the $\mathrm{AQM}$ design and technical input, the final part of this program, obtaining regulatory acceptance of AQMs as implemented by Eberline, can proceed.

\section{For more information, please contact:}

\section{Richard Bolton}

LANL, NIS-6, MS-J562

Los Alamos, NM 87544

(505) 667-8241

\section{Bruce Erdal}

Technical Program Manager

(505) 667-8914 


\subsection{DIRECT MEASUREMENT OF STRONTIUM-90 IN SURFACE SOILS IN REAL-TIME}

\section{TASK DESCRIPTION}

Strontium-90, with a half-life of 29 years, represents an extremely important radionuclide in waste cleanup processes. It is perhaps the fission product of greatest concern with regard to site remediation, but its analysis is difficult, time-consuming, and expensive, due to the need for radiochemical separations and ex situ monitoring technologies. Its decay involves the emission of a relatively lowenergy beta particle $(0.546 \mathrm{MeV}$ maximum) that is traditionally targeted; however, its daughter Y-90 (64.1-hour half-life) decays by emission of a $2.28-\mathrm{MeV}$ maximum-energy beta and this particle may be selectively measured in the presence of other synthetic and natural radionuclides in the soil (i.e., in situ) using new scintillating-fiber-based technology developed at the Pacific Northwest Laboratory.

It is the intent of this project to provide a compact, ruggedized, fieldable $\mathrm{Sr}-90$ analyzer with direct, instantaneous readout that can be used over a wide range of practical field situations, and serve as a basis for the thorough evaluation of the analyzer performance. The sensor is intended to be employed at various DOE sites where the characterization of strontium contamination in surface and exhumed/ treated soils is required.

\section{TECHNOLOGY NEEDS}

Current methods for the measurement of Sr90 in soils require the collection of myriad samples followed by expensive, laborious, and time-intensive radiochemical separations and subsequent beta counting. Sample turnaround often takes weeks to months when an outside laboratory is contracted to perform the analyses. To employ such techniques for large area site cleanup would be prohibitive from both a cost and time standpoint. Hence, new technologies must be developed to ensure the cheaper, faster, and safer monitoring of this radionuclide in the field, thereby supporting the expeditious characterization of those DOE sites requiring remedial action.

\section{ACCOMPLISHMENTS}

The latest version of the evolving sensor consists of stacked ribbons of $1.0-\mathrm{mm}$ and 0.5 $\mathrm{mm}$ plastic scintillating fibers and is optimized for the detection of high-energy beta particles. A unique feature of this sensor is the stacked configuration (see Figure 2.18a), which allows the discrimination between (a) unattenuated Y-90 betas that, when traveling at their "most probable" energies (roughly 0.8 $\mathrm{MeV}$ ), will penetrate nearly $3 \mathrm{~mm}$ of plastic, and (b) lower-energy beta particles arising from natural sources, such as $40 \mathrm{~K}, 232 \mathrm{Th}$ (and daughters), and 238U (and daughters). The improved multilayer design also affords additional discrimination against gamma rays and cosmic-induced species (compared to earlier versions) by observing and partially cancelling the contribution from these ubiquitous phenomena. The upgraded sensor establishes an electronic requisite for coincident signals from all layers (save the uppermost), thereby facilitating the detection of high-energy beta 
events (i.e., strontium activity) and effectively ignoring much of the gamma and cosmic contribution to the overall detector response.

Another critical improvement incorporated into the latest design of this sensor is the addition of improved electronic components that are sensitive enough to handle the rapid $(<10-n s)$ scintillation pulses originating from the excited fibers; these include custom-designed high-speed amplifiers, signal discriminators, and logic circuitry suitable for the specific technical requirements (see Figure $2.18 \mathrm{~b}$ ).

Current and projected efforts will concentrate on further miniaturization of the custom electronic package, improvement in the unit's minimum detectable activity level, and modularization of the sensor package. The latter task is intended to facilitate the development of individual "base units" or modules that may be connected together in unlimited orientations to allow the construction of larger sensors of any dimensions.

\section{COLLABORATION/TECHNOLOGY TRANSFER}

This novel technology is directly applicable to many existing nuclear waste and soil contamination problems throughout the industrial and DOE complexes as a means of establishing remedial protocols and verifying cleanup operations. Hence, considerable efforts have been directed toward transferring this technology to the scientific community and private sector via open literature publications and conference presentations. These include the paper "Characterization of Uranium Contamination in Surface and Subsurface Soils," accepted for publication in the Journal of

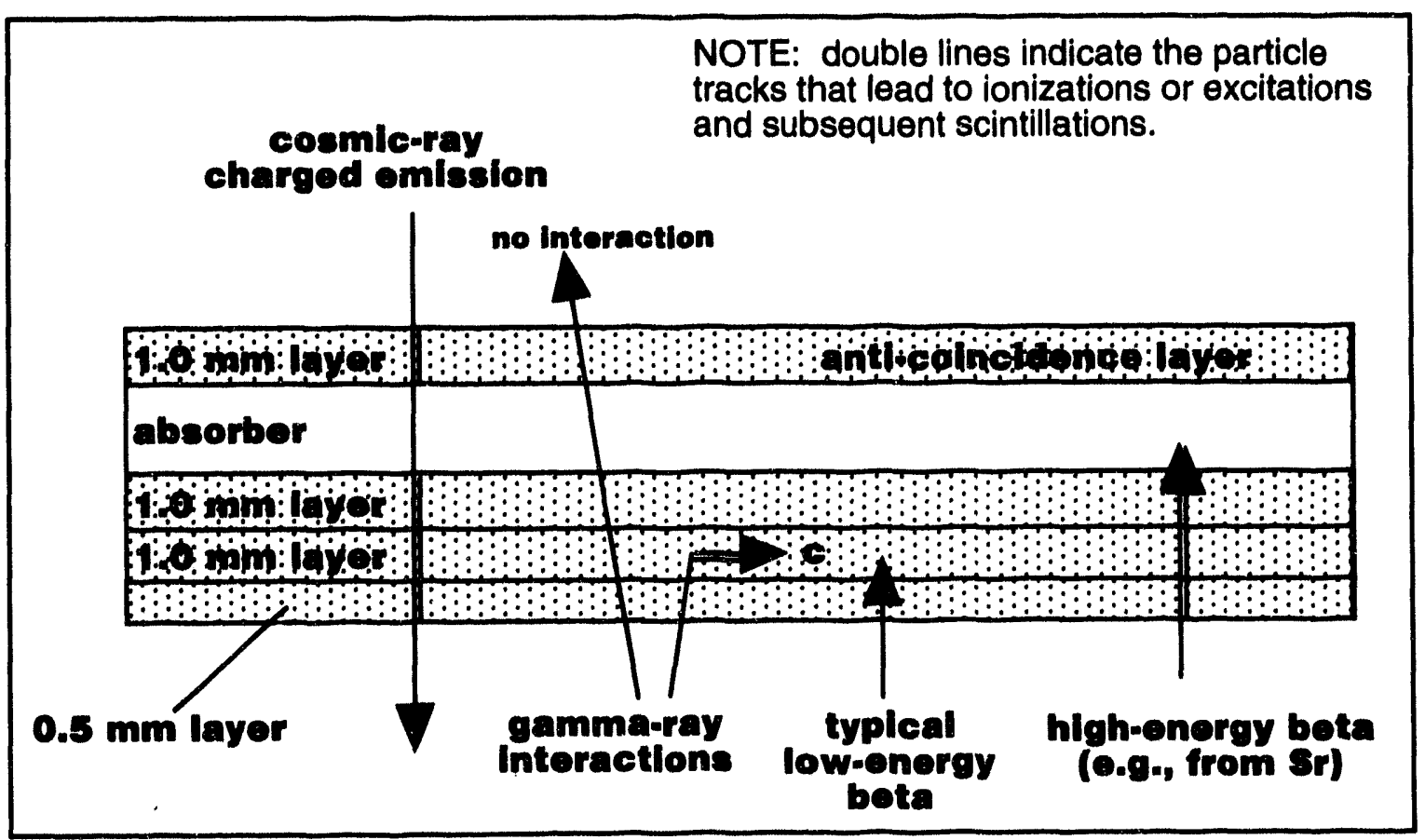

Figure 2.18a. Schematic cross-section of improved Strontium-90 sensor showing discrimination capabilities for (1) high-vs. low-energy beta particles and (2) beta particles vs. gamma rays and cosmic-induced species. 
Environmental Radioactivity, and presentations at the Electrical Power Research Institute International Low-Level Waste Conference (Monterey, California), the ER'93 Environmental Remediation Conference (Augusta, Georgia), the SCIFI93 Workshop on Scintillating Fiber Detectors (Notre Dame, Indiana), and the EM-40/50 Industry Outreach Meeting (Seattle, Washington). Commercialization and mass production is being actively pursued and the BICRONCorp. (Newbury, Ohio) has expressed strong interest in this technology; discussions with this potential industrial partner are currently ongoing.
For more information, please contact:

Dr. Alan J. Schilk

Pacific Northwest Laboratory

P.O. Box 999, MSIN P8-01

Richland, WA 99352

(509)376-9510

\section{Steven Slate}

Technical Program Manager

Pacific Northwest Laboratory

(509) 375-3903

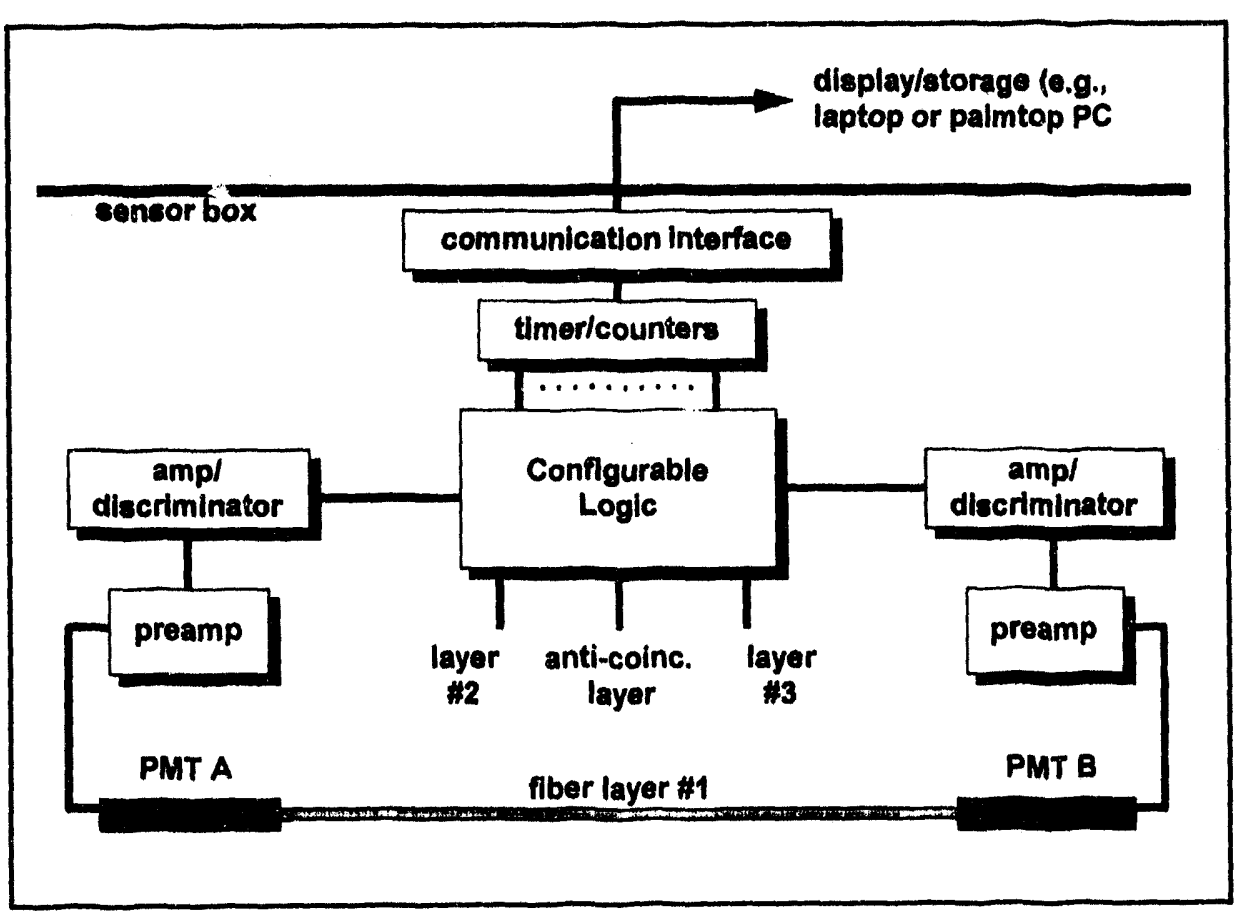

Figure $2.18 \mathrm{~b}$. Simplified diagram of the custom-designed sensor circuitry. 


\subsection{LA-ICP-AES USING A HIGH-RESOLUTION, FIBER-OPTIC INTERFEROMETER}

\section{TASK DESCRIPTION}

A high-resolution, compact, and portable interferometer system is being developed to provide isotopic and isobaric resolution and higher sensitivities for samples in complex matrices where detection limits are limited by low-level interferences. This system will be used in conjunction with environmental analysis by laser ablation - inductively coupled plasma - atomic emission spectroscopy (LAICP-AES). The technology being developed involves the use of an acousto-optic tunable filter (AOTF) and a high finesse fiber-optic Fabry-Perot interferometer (FFP), two devices developed by the communications industry for high bandwidth laser communications. The small size, extreme ruggedness, and spectral agility of these systems will make them well suited for use in a fieldable spectrometer system at a fraction of the cost, size, and weight of grating-based spectrometer systems. The AOTF will be used as a low-resolution filter to select spectral regions to be resolved by multiple FFP filiers (Figure 2.19a). The AOTF is capable of switching between spectral regions in microseconds with no mechanical moving parts and is also capable of simultaneous selection of several spectral regions.

\section{TECHNOLOGY NEEDS}

LA-ICP-AES has previously been shown to be a valuable tool for rapid, in situ environmental analysis. However, some limitations of this technique include sensitivity limited by the resolution of many emission lines for samples having complex matrices, lack of sufficient resolution to determine isotopic ratios for transuranic materials, and excessively large, expensive and temperamental spectrometer systems. The system under development addresses all of these shortcomings with commercially-available components developed for other uses.

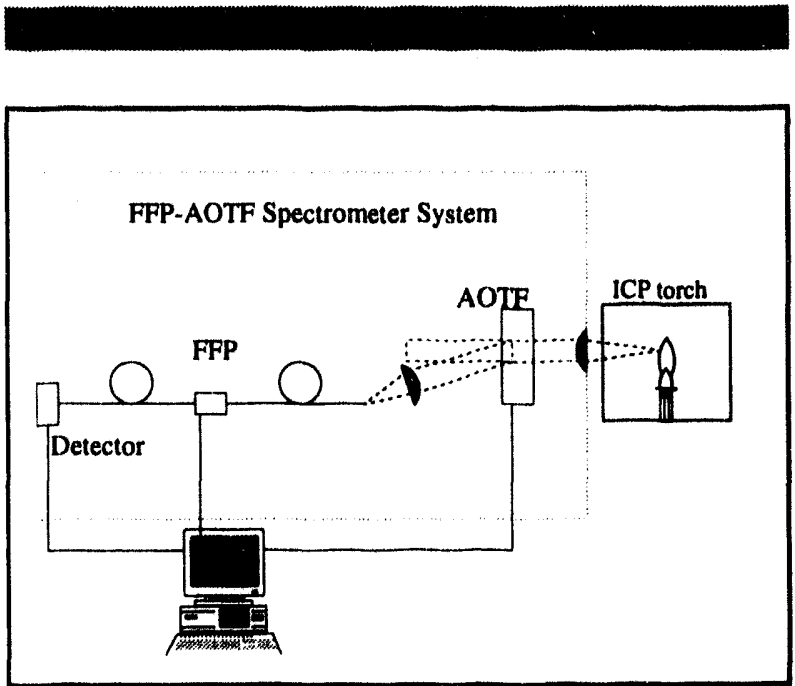

Figure 2.19a. Schematic of the acousto-optic tunable filter, fiber-optic Fabry-Perot interferometer system.

\section{ACCOMPLISHMENTS}

An AOTF has been obtained for use in this system and initial tests have been performed using a low-resolution (finesse $=100$ ) bulkoptics Fabry-Perot interferometer. A single AOTF accesses a $200 \mathrm{~nm}$ range of emission features. The bandwidth of the AOTF $(\sim 1,000$ $\mathrm{GHz})$ and the desired spectral resolution $(\sim 2$ $\mathrm{GHz}$ ) determine the specifications for the FFP (finesse $=500$ ) that must be developed to scan the spectral window defined by the AOTF (see Figure 2.19b). The optical coatings used in 
the FFP will not cover the entire region accessed by the AOTF. Therefore, a system with full access at high-resolution must utilize several FFPs, with a single AOTF for prefiltering and low-resolution survey scanning. The FFP technology to be used is already developed for red and NIR wavelengths, and development has begun for the blue and ultraviolet wavelengths required for this project. A spectrum of a sample containing natural abundances of $U 235$ and 238 (.7 and 99\%) was obtained using the bulk-optics Fabry-Perot (Figure 2.19c). The higher resolution of the FFP under development will greatly improve the obtainable spectra.
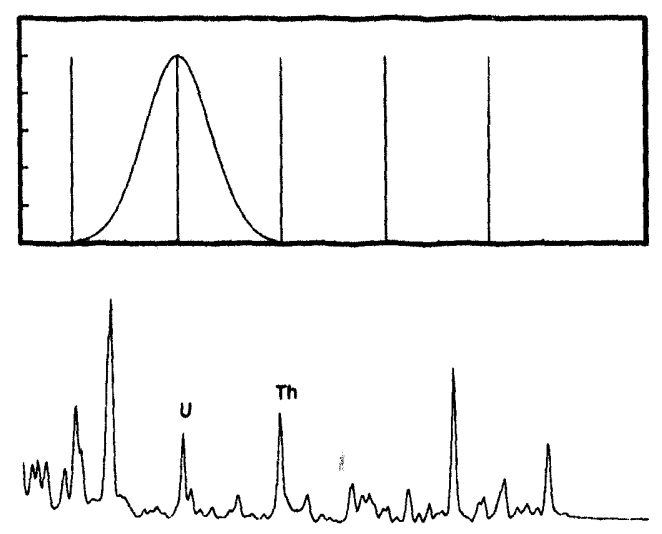

Figure $2.19 \mathrm{~b}$. Illustration of overlapping bandwidths of acousto-optic tunable filter and fiber-optic Fabry-Perot devices leading to high resolution of combined system.

\section{COLLABORATION/TECHNOLOGY} TRANSFER

This high-resolution interferometer system is capable of resolution comparable to that of commercial 3-meter spectrometer systems at considerably less cost, smaller package size, greater portability, and less sensitivity to external environmental factors. Its potential for use in portable spectrometric systems that require this combination of high-resolution and spectral agility should make this system highly marketable. The commercial developer of the fiber-optic Fabry-Perot interferometer has an established market in the communications industry and is exploring the spectroscopic industry through this collaborative work. Publication of the results of these investigations in spectroscopic and analytical chemistry journals will be the first step in widening interest in this technology. Further utilization of this system in future applications of the LA-ICP-AES and other spectroscopic applications within DOE will illustrate the usefulness of this system.

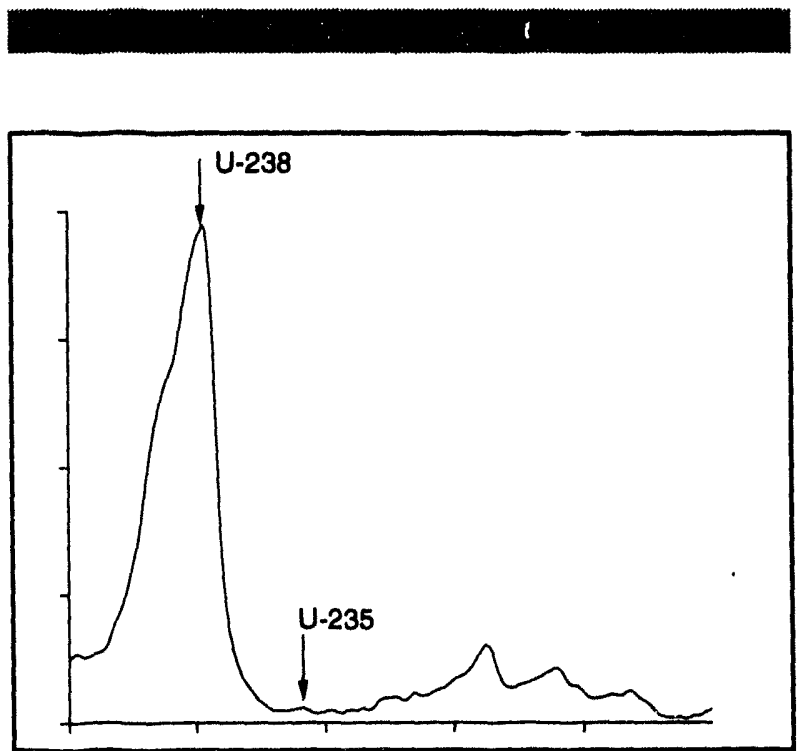

Figure 2.19c. Spectrum of uranium solution in an inductively coupled plasma, using the bulk optics Fabry-Perot. 
For more information, please contact:

David P. Baldwin

Ames Laboratory

8 Spedding Hall

Iowa State University

Ames, IA 50011

(515)294-2069

James P. Corones

Technical Program Manager

(515)294-9636 


\subsection{CHARACTERIZATION AND MONITORING SUPPORT FOR THE SAVANNAH RIVER INTEGRATED DEMONSTRATION PROGRAM}

\section{TASK DESCRIPTION}

The major objective of the Savannah River Site (SRS) Integrated Demonstration Program is to demonstrate and evaluate improved environmental restoration systems for the cleanup of volatile organic contaminants in soil and water. The primary purpose of characterization activities performed as part of this task was to document the physical, chemical, and biological characteristics of the remediation test sites. At each site a remediation system was demonstrated and appropriate geological, chemical, hydrological, and microbiological parameters were measured to evaluate the remediation systems. Pre- and post-test field characterization activities have been completed for demonstrations of in situ air stripping using horizontal wells, bioremediation using horizontal wells to deliver nutrients necessary for biodegradation, and in situ radio frequency-heating of contaminated clay units. Pretest characterization for the ohmic in situ heating demonstration was completed during this fiscal year and post-test activities are ongoing. Activities remaining on this task include completion of field and analytical activities in support of the ohmic heating demonstration as well as summary documentation.

Additional activities include analysis and documentation of field results of innovative technologies for environmental characterization and monitoring that were funded as part of the Integrated Demonstration and demonstrated at Savannah River. This task includes implementation of the ion trap mass spectrometer in support of Environmental Restoration activi- ties. This instrument developed by Oak Ridge National Laboratory is being used for screening of quarterly groundwater samples required as part of a regulatory monitoring program. If the program is implemented, uncontaminated samples will not be sent offsite for analysis. This activity will reduce analytical costs for the environmental monitoring program.

\section{TECHNOLOGY NEEDS}

A major task confronting DOE is management of wastes at facilities. Previous waste disposal practices, once considered state-of-theart, have proven inadequate and have resulted in significant soil and groundwater contamination. One of the most common environmental problems is contamination of soils and groundwater with volatile chemical solvents that were used as degreasers and cleaning agents by industry and many government facilities. DOE is committed to cleaning up contaminated sites to levels acceptable to state and Federal regulators. Present day technologies may not be capable of accomplishing these tasks within a reasonable period of time. A primary goal of the OTD is to develop innovative solutions to environmental restoration problems. The first integrated demonstration of innovative technologies for cleanup of soils and sediments contaminated with solvents was located at SRS where solvents (TCE and PCE) leaked from an underground process sewer line and contaminated underlying sediments and groundwater. 


\section{ACCOMPLISHMENTS}

Characterization of Demonstration Test Sites

Pretest characterization of the site where horizontal wells were used for the in situ air stripping demonstration was completed in 1990. Baseline characterization included sediment coring, depth-discrete sampling of both sediments and groundwater, geophysical logging of the boreholes, cone penetrometer (COE SCAPS), and installation of a variety of monitoring wells below the water table and in the vadose zone. The characterization reports for the in situ air stripping demonstration include images of the distribution of clay sediments, pre- and post-test distribution of TCE and PCE, estimation of contaminant inventories, results of geotechnical testing of undisturbed sediment cores, detailed cross sections of the ID site, and results of aquifer pumping test conducted at the site. The post-test in situ air stripping report serves as the pretest characterization report for the in situ bioremediation demonstration site.

The characterization report for the radio frequency Heating Demonstration documents pretest and post-test data collected in support of the Radio Frequency Heating Demonstration. The data presented and discussed in this report include a general description of the site including piezometer and sensor installation, stratigraphy, lithology, detailed geologic cross sections of the study site, tabulations of pretest and post-test moisture and VOC content of the sediments, sampling and analysis procedures for sediment samples, microbial abundance and diversity, and images of pretest and post test distribution of contaminants and volumetric calculations.

Field activities scheduled for this fiscal year include a demonstration of ohmic heating of clay-like material in the vadose zone to enhance recovery of solvents by researchers from
Pacific Northwest Laboratory. Pretest characterization activities for the six-phase ohmic heating demonstration included installation of the central vent well, electrodes, observation wells, electrode strings, and electrical resistance tomography sensors. Post-test characterization of the ohmic heating demonstration site was initiated in December soon after the power was turned off. Five continuous cores were collected directly adjacent to the locations of selected pretest borings. Samples were collected while the ground was still hot (approximately $80^{\circ} \mathrm{C}$ ) in order to collect samples that were representative of demonstration conditions. An additional two borings were collected in January after the ground had cooled $\left(50^{\circ} \mathrm{C}\right)$. Continuous cores were collected, and sediment samples are being analyzed for volumetric moisture content as well as VOC content.

Demonstration of Innovative Characterization and Monitoring Technologies

Innovative characterization technologies successfully demonstrated as part of the Integrated Demonstration include depth discrete sampling and sensing of groundwater, soil gas, and sediments; three-dimensional data imaging; video animation of contaminant plumes; innovative cone penetrometer applications; and high-resolution P- and S- wave seismic survey.

One of the systems installed for depth-discrete sampling was an in situ gas sampling system (SEAMIST ${ }^{\mathrm{TM}}$ ). The system can be used for initial characterization of contaminant plumes, characterization of intrinsic permeability, monitoring of contaminant migration, monitoring of restoration activities, and monitoring of tracer tests. Three SEAMIST $^{\mathrm{TM}}$ liners for depth-discrete sampling of the vadose zone were used to monitor the helium tracer test performed at the site. The tracer test was successfully completed, 
and the results were used to estimate consumption of methane in the subsurface during the bioremediation demonstration.

An ion trap mass spectrometer developed by ORNL was transferred to Savannah River Site for use at the Integrated Demonstration Site (IDS) and at ER waste sites at the beginning of FY93. Preliminary activities focused on calibration and optimization of the instrument for detection of TCE and PCE in groundwater at the various DOE IDs. Subsequent efforts resulted in development of appropriate analysis modules for data reduction. Duplicate samples were collected during biweekly groundwater sampling and were analyzed by both gas chromatography/mass spectrometry (GC-ECD) and the ion trap mass spectrometry (ITMS). A report on the use of the ITMS for analysis of groundwater from thoroughly characterized wells has been completed. Analytical results obtained with the ITMS are comparable with results obtained using baseline methods. The goal of this task is to validate the use of ITMS as a screening device for groundwater samples from thoroughly characterized wells. A presentation was made in January 1994 to DOE-SR, South Carolina Department of Health and Environmental Control, and EPA Region IV. The presentation was well received and discussions focused on use of the ITMS for sample minimization as well as use in future remedial investigations. If regulatory approval is obtained, the ITMS will be used instead of offsite labs for a selected suite of wells. This activity should result in a significant reduction in the number of samples sent off-site to commercial labs for analysis.

An overview report on monitoring technologies demonstrated at the ID was completed in December 1993. The report summarizes the results of field demonstrations of innovative characterization and monitoring technologies funded as part of the ID. Technologies for measurement of physical parameters include the in situ permeable flow sensors and the colloidal borescope for measurement of groundwater flow and seismic, electrical and electromagnetic tomography for three dimensional imaging of physical changes induced by the remedial process. New technologies for depth-discrete sampling include the passive multilayer groundwater sampler and the arrayed vadose zone sampler. Innovative technologies for chemical analysis include the fiber-optic TCE sensor for in situ detection of TCE and chloroform, both the portable acoustic wave sensor and the HaloSnif for continuous, on-line measurement of total chlorinated compounds over a wide dynamic range, and the direct sampling ion trap mass spectrometer for compound specific determination of organic analytes at concentrations down to ppb levels.

Comprehensive data evaluation and presentation is an essential component of cost effective environmental characterization and remediation. Throughout the characterization and monitoring activities completed as part of the ID, new computational techniques for digital imaging and video animation of environmental data have been developed and utilized (see Figure 2.20). This work has resulted in a new ability to communicate complex environmental issues and concepts in a format easily understood by individuals with a diverse range of technical abilities. These activities were synthesized in a video tape titled New Technologies for Clean Up of Solvents - The SRS Integrated Demonstration, completed in January 1994 . This video tape visually summarizes remedial activities completed during the in situ air stripping and bioremediation demonstrations. 


\section{COLLABORATION/TECHNOLOGY TRANSFER}

The demonstrations have provided timely transfer of new technologies to ER groups at SRS for use in full-scale remediation projects. The technologies for sampling and analysis of sediment cores and depth-discrete water sampling demonstrated were transferred to SRSEnvironmental Restoration and used in a number of waste site investigations. The support for deployment of the ITMS is in direct support of environmental activities at SRS. Commercialization plans for the ITMS will be prepared by the developers of the ITMS at Oak Ridge National Laboratory.

The characterization activities performed as part of this technical task plan in FY94 are in direct support of monitoring and remediation activities funded to principal investigators located at other DOE sites, including Pacific
Northwest Laboratory, Lawrence Livermore National Laboratory, Sandia National Laboratory, and Los Alamos National Laboratory.

\section{For more information, please contact:}

\section{C.A. Eddy-Dilek}

Westinghouse Savannah River Company (803) $725-2418$

\section{J. Rossabi}

Westinghouse Savannah River Company (803) $725-5220$

\section{J. L. Steele}

Technical Program Manager

Westinghouse Savannah River Company (803) $725-1830$

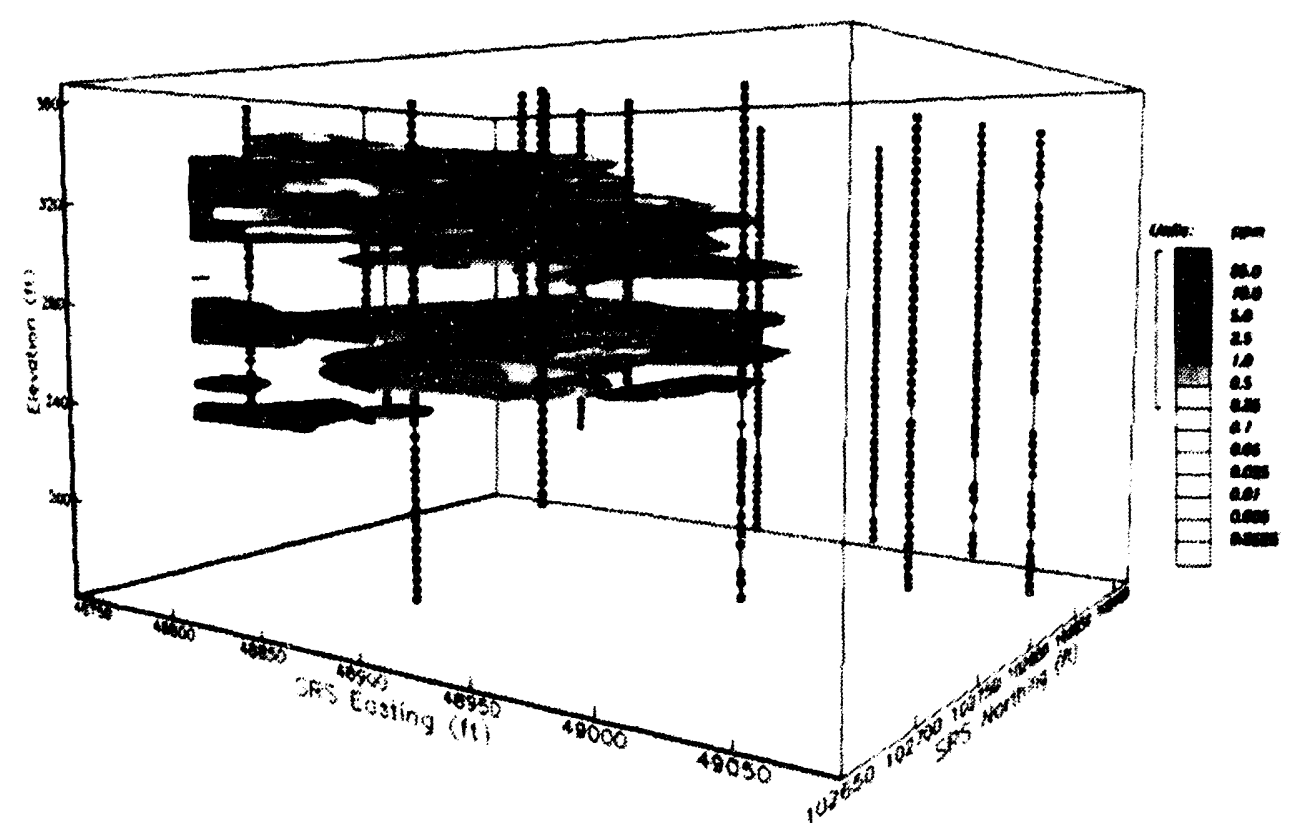

Figure 2.20. Three-dimensional image showing the distribution of tetrachloroethylene at concentrations of greater than $0.25 \mathrm{mg} / \mathrm{kg}$ in sediments at the Integrated Demonstration Site prior to the In Situ Air Stripping Demonstration. Sample locations are shown with small black squares. 


\section{TASK DESCRIPTION}

The objective of this activity is to identify those chemical, radiochemical, and physical sensors suitable for utilization on characterizing and monitoring hazardous, radiological, and mixed wastes at DOE sites nationwide. The literature search will focus on identifying those sensors presently available, those in the near-term development stages (1-2 years), and those in long-term development stages (3-5 years). More specifically, the task was to review, evaluate, and compile information on chemical sensors for potential use in the DOE environmental site characterization and monitoring programs. The scope of work was to cover fiber-optic characterization and monitoring programs. The scope has been broadened considerably since the first task assignment.

\section{TECHNOLOGY NEEDS}

Based on the extensive reviews conducted over the past 20 months or so, the following recommendations were made:

- Formation of several technical oversight panels to assist DOE in what course to follow in sensor research and development. These recommendations are spelled out in the Task 3 report, now widely distributed.

- Increased recognition and funding to those groups doing work in miniaturization of sensors and systems that have the potential for use in situ, for example in a cone penetrometer.

- Increased funding to those doing work in multisensor, multivariate data analysis, such as surface acoustic wave sensors, solid state sensors, and electrochemical sensors. The concept of single sensor/single analyte is largely wishful thinking. See the Task 5 report recommendations.

\section{ACCOMPLISHMENTS}

A series of reports have been issued from Advanced Sciences, INC., through HAZWRAP.

- Literature Search, Review, and Compilation of Data for Chemical and Radiochemical Sensors-Task 1 Report, DOE/HWP-130, Hazardous Waste Remedial Actions Program, Oak Ridge, TN, January 1993.

- Literature Search, Review, and Compilation of Data for Chemical and Radiochemical Sensors-Task 2 Report, DOE/HWP-133, Hazardous Waste Remedial Actions Program, Oak Ridge, TN, April 1993. (Completed March 1993).

- Chemical Sensor Research and Development Status Based on Research and Industrial Interviews-Task 3 Report, DOE/HWP-138, Hazardous Waste Remedial Actions Program, Oak Ridge, TN, October 1993. (Completed July 1993).

- Literature Search, Review, and Compilation of Data for Biosensors and Thermal SensorsTask 4 Report, DUE/HWP-144, Hazardous Waste Remedial Actions Program, Oak Ridge, TN, December 1993. (Completed October 1993).

- Literature Search, Review, and Compilation 
of Data for Gas Chromatography Sensors and Electrochemical Sensurs-Task 5 Report, Completed January 1994, submitted to HAZWRAP for publication 31 January 1994. Publication DOE/HWP-148.

Tasks underway, with expected completion dates, are:

- Review of Instrumentation and Sensors for Cone Penetrometer Applications-Task $6 \mathrm{Re}$ port, Completion end of March 1994.

- Report on Multisensor, Multivariate Analysis, title not yet assigned, completion expected end of April 1994.

\section{COLLABORATION/TECHNOLOGY} TRANSFER

Useful technology has been transferred through the distribution of the several reports. These have provided those doing research, development and commercialization of sensors with information about where research is being done, in what areas, what commercial organizations are involved, and so on.
For more information, please contact:

\section{Bill Roach}

Advanced Sciences, Inc. 6739 Academy Road NE

Albuquerque, NM 87109-3345

(505) 823-6869

\section{Fred Heacker}

Martin Marietta Energy System

(615) 435-3426 


\subsection{TECHNOLOGY PERFORMANCE SPECIFICATIONS}

\section{TASK DESCRIPTION}

This project will establish and implement technology performance specifications for $\mathrm{Re}$ search and Development and Demonstration, Testing, and Evaluation projects within the DOE Office of Technology Development (EM50). Technology performance specifications will be used to establish milestones, evaluate the status of ongoing projects and determine the success of completed projects. Preliminary performance specifications will be required in Technical Task Plans (TTPs) and will be evaluated as part of the TTP evaluation. In the first year, a pilot project will focus on chemical and radio-analytical measurement technologies for VOCs. The Principal Investigators will prepare a preliminary list of specification topics and values for chemical and radio-analytic measurement technologies. The list will be derived from available sources and resources. Evaluation criteria will address whether the list is complete, whether the values are within regulatory requirements, whether the values are reasonable, and whether the entire system will be workable.

The reviewers comments will be used to revise the specifications, which will then be applied to the three OTD-supported technologies selected by the Headquarters Managers, along with draft guidance to facilitate dissemination of specifications to the affected constituents (e.g., Principle Investigators, Technical Support Groups, etc.). In subsequent years, specifications will be prepared in other technical areas as directed by Headquarters.

\section{ACCOMPLISHMENTS}

A Performance Specifications Model has been prepared. The first step of the performance specifications process is to state the need of the environmental restoration or waste management customer. The general approach of the model is to document the baseline technologies that currently exist, or are nearing completion of their development, and to compare the baseline to the customers' needs in order to determine unmet requirements. The unmet requirements form the basis for further technology development. Investigators must be quantitative in assessing their proposed technology's reduction in the current cost of analysis or improvement in analyte detection over established measurement technologies.

A draft DOE report entitled Technology Baseline for VOC Characterization and Monitoring in the Environment has been prepared and distributed. The report reviews the following technologies: gas chromatography, mass spectrometry and gas chromatography, fiber-optic chemical sensors, infrared and Raman spectroscopy, electrochemical sensors and piezoelectric sensors. Included in the review are a description of the basic principles, applications and commercial-availability of instrumentation. In addition, the report also addresses the Performance Specifications Model referred to above. 
For more information, please

contact:

\section{Mitchell D. Erickson}

Argonne National Laboratory

Environmental Research Division ER/203

9700 South Cass Avenue

Argonne, IL 60439-4843

(708) 252-7772 


\section{Characterization Decision}

\section{Support Tools}

\section{Section 3.0}


1. 


\subsection{DATA FUSION FOR CHARACTERIZATION AND MONITORING}

\section{TASK DESCRIPTION}

The purpose of the this project is to successfully transfer Data Fusion technology developed for the Department of Defense (DoD) to the DOE environmental mission. Multi-sensor Data Fusion is a new discipline that seeks to combine data from multiple sensors to perform inferences that may not be possible from a single sensor alone. Most applications address military problems, such as automatic identification of targets, analysis of battlefield situations, and threat assessments (Hall 1992).

Coleman Research Company (CRC) is a developer of multi-sensor Data Fusion technology. Under DOE guidance, they have applied their DoD knowledge and experience to develop a Data Fusion workstation to combine environmental data sets. The technology is being demonstrated and tested for data collected at the Hanford site, in particular, at the Volatile Organic Compounds in Arid Soils Integrated Demonstration. During FY94, CRC collected multi-sensor data (surface geophysical data) and adapted their Data Fusion software. They transferred a Data Fusion workstation to Pacific Northwest Laboratory (PNL). This project will complete the adaptation of this technology, demonstrate its utility at the Hanford Site, and transfer the technology to the Westinghouse Hanford Company.

Initial efforts will be focused on insuring that the current software will perform efficiently. This task will focus on debugging the hardware and software, validating the results, and conducting sensitivity studies. The utility of the debugged software will be demonstrated through the development of a site conceptual model. Data Fusion technology will form the foundation of the site conceptual model. Transfer of the adapted workstation to Westinghouse Company will complete the task.

It is anticipated that Data Fusion technology can be used to maximize the utility of the data that has been collected at Hanford and other DOE environmental sites. The fusion of disparate data sets will permit a "unified" method for the interpretation of characterization and performance assessment data.

\section{TECHNOLOGY NEEDS}

A significant amount of effort and money has been expended by the DOE community to support its environmental mission. Much of that money has been spent in the collection of surface and subsurface data for the characterization of active and inactive waste sites. This data comprises many different types, and much of it has not been interpreted in a "unified" manner. That is, individual data sets are typically interpreted individually, or, at best, other da types are examined in a non-numerical manner to assist the interpretation. The high cost of data acquisition and the significant increase in computer capabilities promise to maximize the current investment in characterization data.

Data Fusion technology, as developed by DoD, is designed to mathematically merge or fuse different data types into the development of a 
single, coherent interpretation. This technology is capable of fulfilling the following technology needs:

- Multiple data sets can be fused simultaneously. The average scientist is hard-pressed to manually combine more than three or four data sets. The data fusion workstation should only be limited by the number of related data sets available.

- The fused interpretation is repeatable. The files necessary for fusion are stored, and they can be easily rerun.

- Residuals are calculated for the final fused interpretation. Thus, a statistical validity is assigned to all interpretations, and this value can be used to consistently judge the results.

- The fused results can be readily displayed using three-dimensional visualization software.

\section{ACCOMPLISHMENTS}

Effective use of the Data Fusion workstation hardware has been difficult, due to problems in system stability, reliability, and the lack of disk space. The stability problems have been common to the model of workstation delivered to PNL. The vendor solved the problems by replacing most of the boards in December 1993. Additional disk space was installed in January. Hardware problems have delayed the onset of this task by three months.

PNL has been actively debugging the software since the hardware problems were resolved. Collaboration with CRC to debug the data fusion software has occurred. CRC has provided multiple patches to the suftware, and will deliver a new version in the upcoming weeks. As part of this debugging process, PNL has generated a series of artificial data sets to test the sensitivity of the data fusion software to variations in inputs and data quality. In addition, an attempt to fuse surface resistivity data from another site to extend the capabilities of the fusion software has been made. The Hanford data collected by CRC in FY93 has been successfully fused.

All FY93 data from the Volatile Organic Compounds in Arid Soils Integrated Demonstration and additional data from Hanford Environmental Information System (HEIS) is currently being loaded into the workstation. PNL will use this data to develop an alternative site conceptual model. The loading is currently on hold while PNL works with CRC to determine whether the Data Fusion database should be rewritten. If it is rewritten, this subtask will be a collaborative effort between PNL and CRC.

\section{COLLABORATION/TECHNOLOGY TRANSFER}

The final step in the development of the Data Fusion Workstation will be the physical transfer of the workstation hardware to the user community at Westinghouse Hanford Company (WHC). PNL will provide partial support for training WHC personnel in the use of the workstation. PNL has provided funding, from an independent source, for the purchase of a replacement workstation. The replacement workstation will provide PNL the capability to support WHC after the transfer.

Because PNL is providing interim support between the development of the Data Fusion workstation at CRC and its use at the WHCER client, Ames Laboratory has been actively collaborating with scientists at both organizations. Currently, most of the dialogue has been 
with CRC to support the debugging effort and the exploration of new uses for data fusion technology.

\section{For more information, please}

\section{contact:}

\section{Stan Tomich}

Pacific Northwest Laboratory

(509) 376-9645

\section{Steven Slate}

Technical Program Manager

Pacific Northwest Laboratory

(509) 375-3903 
Geophysical and Hydrogeologic Measurements

\section{Section 4.0}



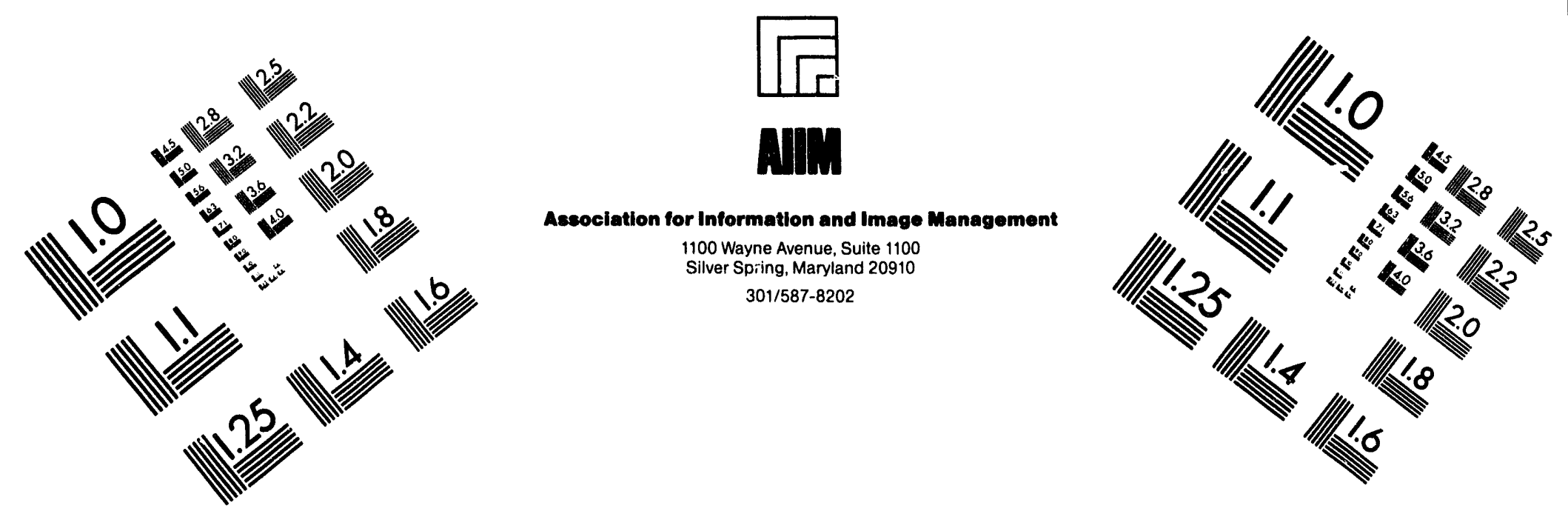

\section{Centimeter}

$\begin{array}{llllllllllllllll}1 & 2 & 3 & 4 & 5 & 6 & 7 & 8 & 9 & 10 & 11 & 12 & 13 & 14 & 15 & \mathrm{~mm}\end{array}$

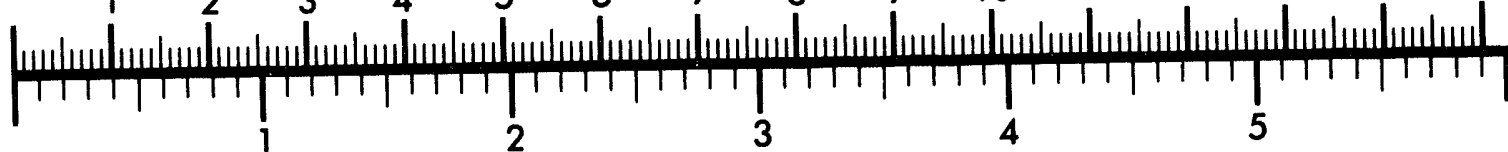
Inches
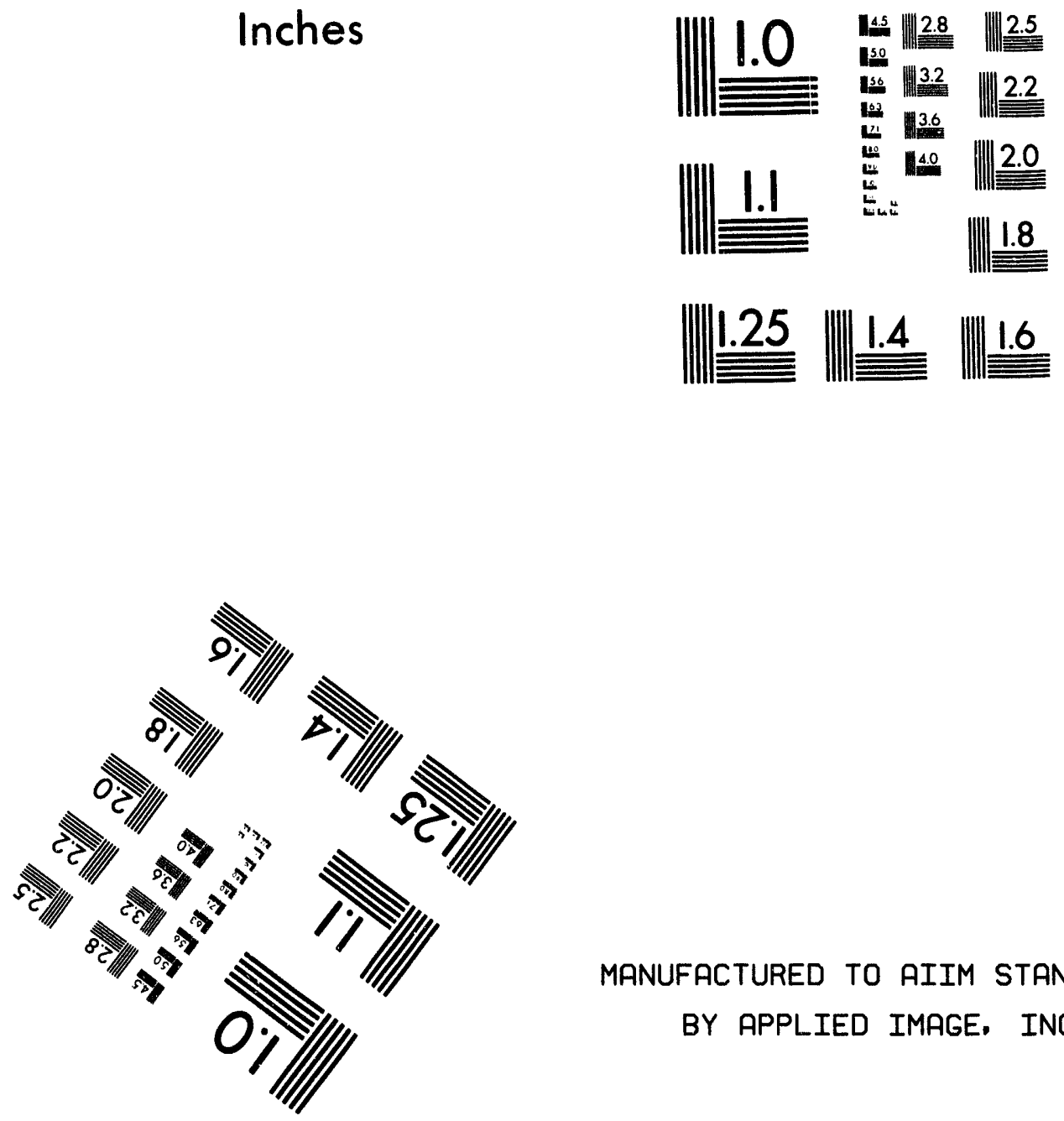

MANUFACTURED TO AIIM STANDARDS BY APPLIED IMAGE. INC.

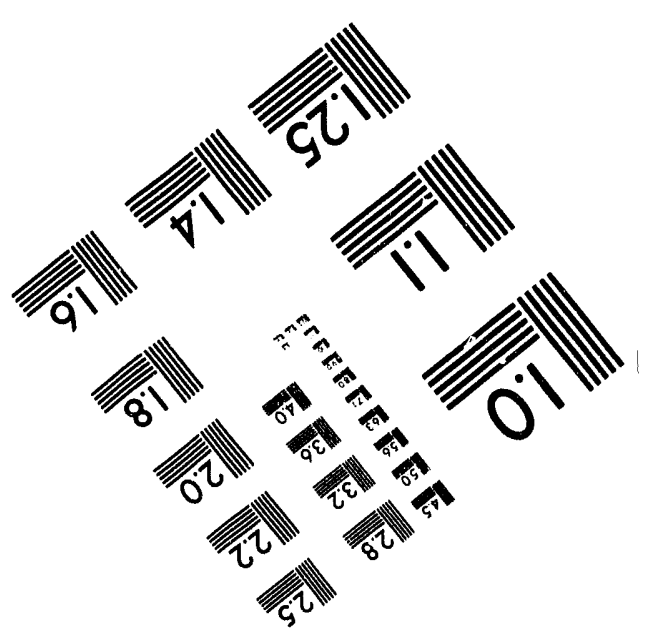



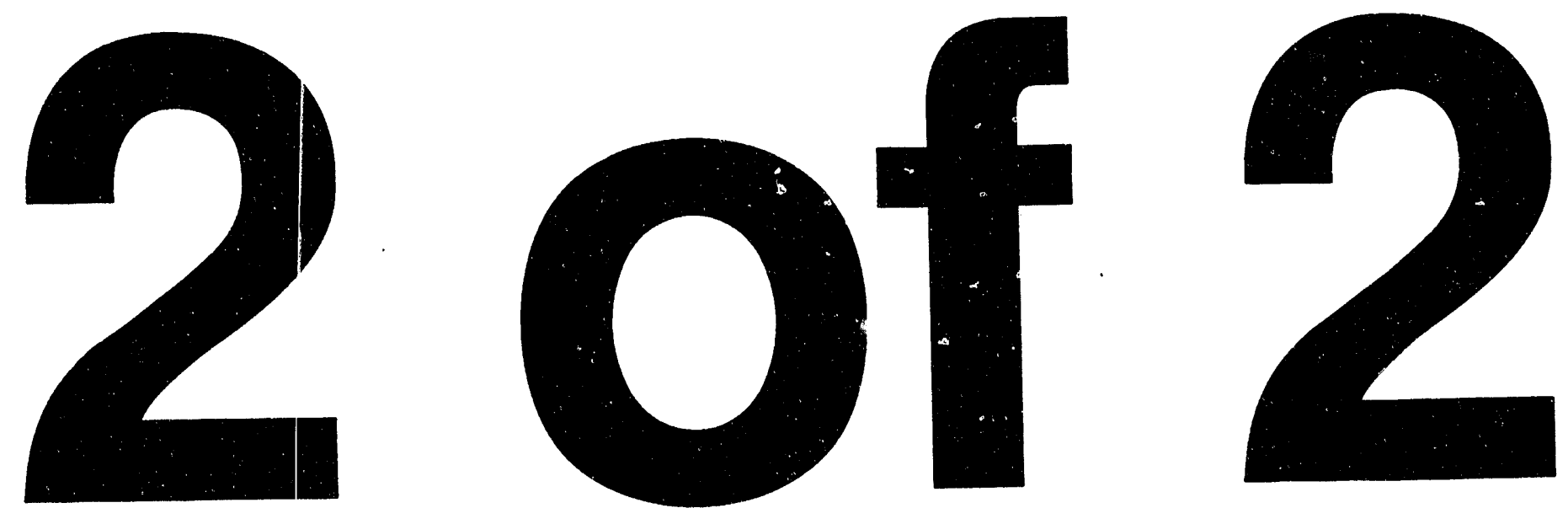


\section{TASK DESCRIPTION}

This task will investigate the near-surface earth in a uniform three-dimensional manner through the acquisition, processing, and interpretation of three-dimensional, three-component $(3 \mathrm{D} / 3 \mathrm{C})$ reflection seismic data. $3 \mathrm{D} / 3 \mathrm{C}$ seismic surveys record data in three-dimensions $(\mathrm{X}$ and $\mathrm{Y}$ along the ground surface, and depth Z) and three-components (vertical and 2 orthogonal horizontal directions. See figure 4.1a). Data will be acquired with available instrumentation, processed with existing, adapted and/or developed computer software, and interpreted by a combination of existing and developed methodologies.

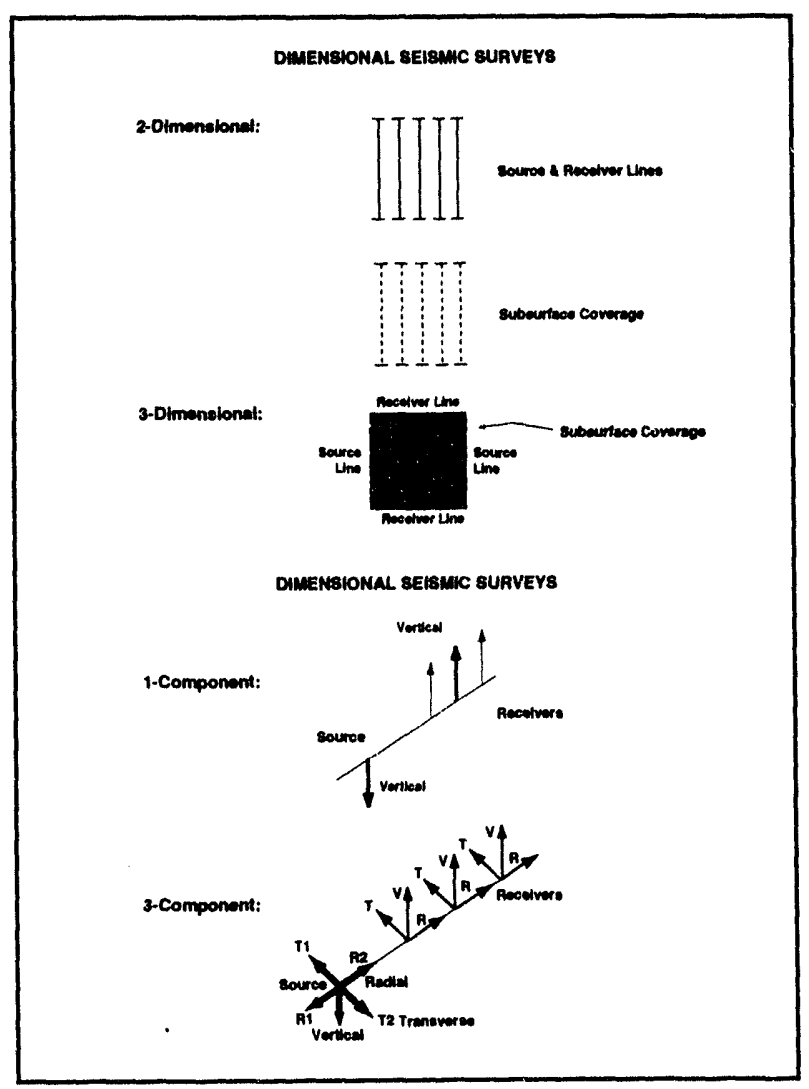

Figure 4.1a. Seismic survey definitions.
Seismic Survey Definitions. There are three primary objectives to this task. The shortterm objective will be the acquisition of threedimensional, one-component (3D/1C) and 3D/ $3 \mathrm{C}$ reflection seismic data sets of the highest quality given the local geologic conditions; the surveys will be designed such that data frequencies and spatial sampling are suitable for high-resolution of the shallow subsurface. The intermediate objective will be the processing and interpretation of the $3 \mathrm{D} / 1 \mathrm{C}$ data, which will serve as a baseline comparison for the $3 \mathrm{C}$ data and will allow for a direct indication of improvement in characterization between $1 \mathrm{C}$ and $3 \mathrm{C}$. All data processing will be designed to retain the high frequencies within the original data. The long-range objective will comprise the adaptation and/or development of software that will be used in the processing and interpretation of $3 \mathrm{D} / 3 \mathrm{C}$ data, and the submittal of draft and final reports detailing the acquisition, processing and interpretation of the $3 \mathrm{D} / 3 \mathrm{C}$ data. A Core Planning Group consisting of all the participants (RUST Geotech Inc., United States Geological Survey (USGS), Colorado School of Mines (CSM), and Resolution Resources , Inc.)) will be involved in all activities of this task.

\section{TECHNOLOGY NEEDS}

3D/3C seismic technology addresses the need to expedite site characterization by non-intrusive methods. The need may be divided into general depths of investigation from shallow, through intermediate, to deep, with inherent approximation of boundaries. The shallow 
need is primarily concerned with the definition/delineation of trench and pit boundaries, location of buried contaminants, and imaging of shallow structures. The intermediate need, while also concerned with those items of the shallow regime, concentrates more on hydrogeologic framework and subsurface geologic/physical properties measurement. The deep need is basically an extension of the intermediate with perhaps more emphasis on regional characteristics. Site-specific needs are detailed in the Technology Needs Assessment. In addition to DOE field sites, DoD, EPA and other government entities require technologies to conduct the best available characterization to produce data to be input into Records of Decision.

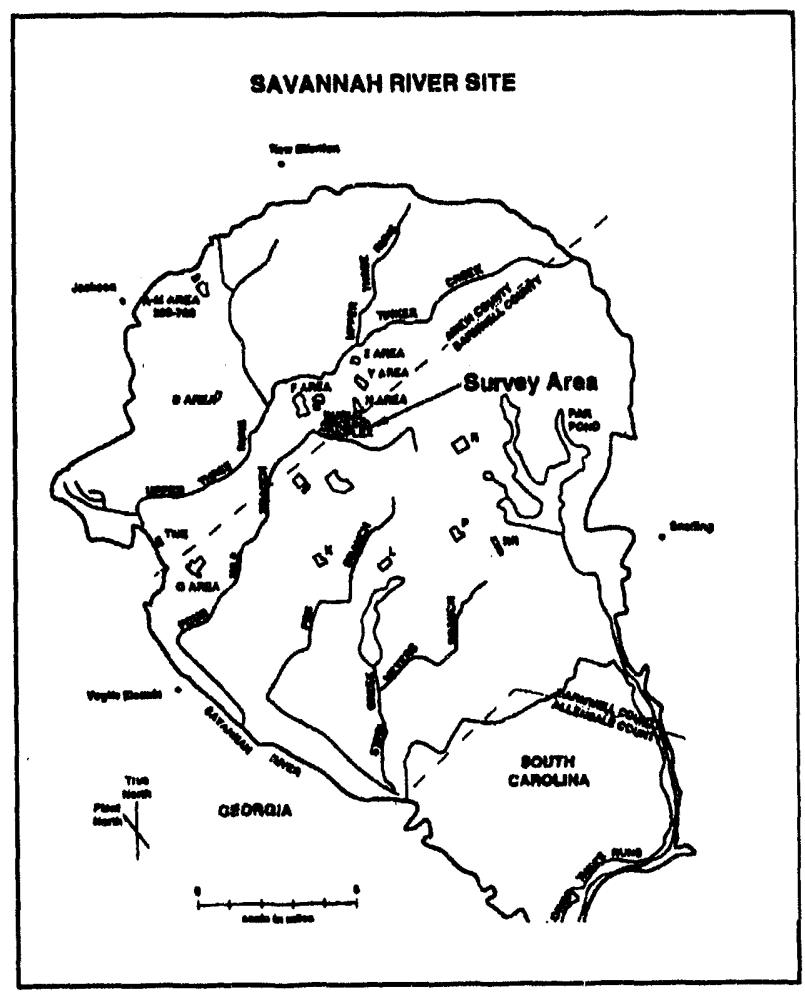

Figure $4.1 \mathrm{~b} .3 \mathrm{D} / 3 \mathrm{C}$ seismic survey location.

\section{ACCOMPLISHMENTS}

This is a newly funded project beginning in FY94. The field site selected for the demonstrations is south of the Old Burial Ground (OBG) in the F-Area Effluent Line (Creek) at the DOE Savannah River Site (SRS) (Figure 4.1b). This site was chosen in collaboration with EM-40 personnel at SRS. Three primary problems that will be addressed at this site with the $3 \mathrm{D} / 3 \mathrm{C}$ seismic technology include 1) definition and/or description of preferential pathways for contaminant migration; 2 ) location of faults and/or fractures; and 3) location and/or detection of plumes (primarily TCE, mercury and tritium).

The field demonstrations will be separated into two parts: namely, an initial $3 \mathrm{C}$ noise analysis survey and a subsequent azimuthal $3 \mathrm{D} / 3 \mathrm{C}$ survey. The results of the $3 \mathrm{C}$ noise analysis survey will be incorporated into the design of the azimuthal 3D/3C survey.

3D/3C Seismic Survey Location. The preliminary $3 \mathrm{C}$ noise analysis survey will consist of 2 lines also used for the azimuthal survey (tentatively the north-south and east-west lines) plus 1 or 2 lines within the "fill" area (perpendicular to the old stream channel). These surveys will be conducted by the USGS with assistance by other meinbers of the Core Planning Group. A sledgehammer source will be used for the surveys with 5 strikes (vertical, 2 radial and 2 transverse) into 3-components along a minimum of 6 spreads. Subsurface continuity, frequency content as a function of distance and anisotropy definition will be the primary objectives of these surveys. Processing and analysis of the data will be conducted primarily by the USGS, and by RUST Geotech to a lesser extent, using existing software.

The azimuthal surveys will consist of eight surface lines separated by $45^{\circ}$ and centered around a borehole. Three-component receivers will be located along the surface lines and 
within the borehole. A minimum of 20 stations (with 3-component receivers at each station) along the surface plus 20.3-component receivers within the borehole (at an unspecified interval) are planned. The $3 \mathrm{D} / 3 \mathrm{C}$ surveys will be conducted by Resolution Resources with assistance from other members of the Core Planning Group. Seismic sources may include the "mini-vibrator", sledgehammer and possibly the USGS "Rotator". An azimuthal array offers a multitude of angles and offsets, the inclusion of data from a borehole contributes to constraining solutions, and recording of all 3 components from a single source-impact reduces the number of variables within the experiment. Processing of the 3D/3C data will be conducted by CSM using Advance Geophysical Corporation's PROMAX software; it is envisioned that a subset of the data will be processed by RUST Geotech using Mercury International Technology or other software.

\section{COLLABORATION/TECHNOLOGY TRANSFER}

The joint participants within this task represent the DOE, private sector, academia and another government agency. The joint participants will collaborate towards the common goal to develop feasible near-surface 3D/ 3C seismic technology. Emphasis will be placed on providing technology to the private sector suitable for near-term application to specific EM programs. Resolution Resources, the private sector joint participant, will gain sufficient knowledge from this project to become a leader in the commercialization of the technology. The final reports will not only represent the work that has been done, but will be vehicles for the transfer of this technology.
For more information, please contact:

\section{James C. Hasbrouck}

RUST Geotech Inc.

P. O. Box 14000

Grand Junction, CO 81502

303-248-6714 (Voice)

\section{David Emilia}

Technical Program Manager

303-248-6417 


\subsection{CROSSHOLE COMPRESSIONAL AND SHEAR-WAVE SEISMIC TOMOGRAPHY}

\section{TASK DESCRIPTION}

For the geologic characterization and monitoring of environmental remediation sites, methods are needed for imaging of the geology and subsurface properties with a minimum of intrusion. Crosshole seismic tomography is a semi-intrusive method for such sites. The output of this method is an image of the seismic-wave velocity structure between the boreholes obtained by measuring the seismic-wave travel times between a large number of source and receiver locations at various depths within the wells. This velocity structure can be interpreted in terms of geology. In addition, by combining the use of compressional (P) and shear (S) waves, other rock properties, such as saturation level, can be imaged for identifying perched water zones and monitoring remediation processes that change saturation levels, for example, air sparging (see Figure 4.2a). This technology will be developed into a commercializable field and processing system through the development and improvement of existing downhole source and receiver technology. At the same time, the imaging and property determination capabilities of the technology will be demonstrated and improved through a series of surveys at the Hanford site using existing boreholes.

\section{TECHNOLOGY NEEDS}

At the present time, subsurface characterization is restricted to extrapolation of point information from wells, surface geophysical

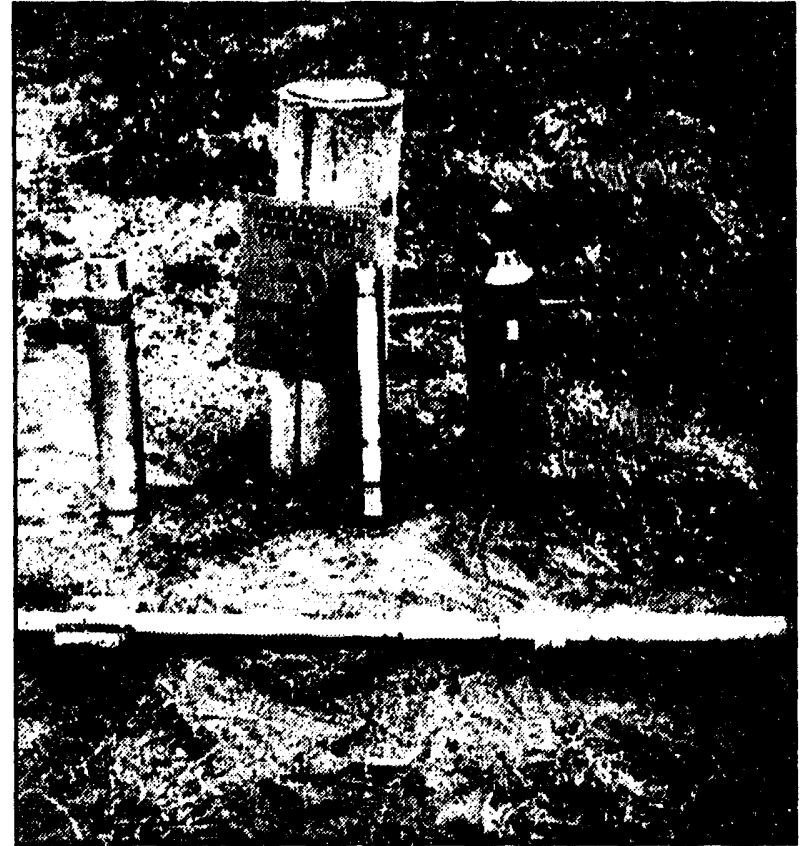

Figure 4.2a. Down hole equipment used in preliminary test at Hanford site. From left to right: Oyo-Conoco orbital vibrator, Bolt airgun, Oyo-Sandia downhole receiver. In front:

Sandia pneumatic vertical vibrator.

methods, and newly-developed crosshole electromagnetic imaging methods. Crosshole seismic imaging is needed to improve the subsurface geologic interpretation by providing information between the boreholes to help in extrapolating the borehole-determined properties. It has advantages over surface methods in that it does not depend on seismic energy returning to the surface via reflection or refraction, but relies on one-way transmitted energy, eliminating the need for reflectors in the subsurface. It also has the advantage of placing the source and receiver nearer to the zone of interest, resulting in less attenuation 
of the high-frequency, high-resolution information and avoiding the typically highly attenuative near-surface layers.

Finally, seismic imaging provides a complementary imaging method to crosshole electromagnetic methods in that they respond differently to changes in rock properties and, used together, can provide a much more complete picture of the subsurface. When limiting the methods to existing wells, seismic has the advantage of being able to work in steel-cased wells, unlike presently available EM methods.

\section{ACCOMPLISHMENTS}

Although funding for this project only began this fiscal year, an initial fielding at Hanford was performed in February (see Figure 4.2b.). This test was to examine three existing sources for their capabilities to transmit sufficient energy between existing boreholes at the Hanford site. Two sites were chosen, one in the Hanford formation of open-framework gravels and silts, and one in the more cemented gravels and sands of the Ringold formation. Both sites used locations above and below the water table to test coupling in the vadose zone as well as the saturated zone. The three sources used were a commercially-available airgun, which generates primarily $\mathrm{P}$ waves from a high pressure air pulse; a Sandia-developed pneumatically-powered vertical vibrator, which generates vertically-polarized $S$ waves; and a recently available eccentric mass orbital vibrator, which generates both $\mathrm{P}$ waves and horizontally-polarized $\mathrm{S}$ waves.

Preliminary results from this initial test showed that all three sources generated sufficient energy to be easily recorded in the geologic formations at Hanford in boreholes separated by up to $180 \mathrm{feet}$. In addition, surface geophones were recorded to test the possibility of recording reverse vertical seismic profiles (RVSP). Although these results are not as unambiguous as the crosshole data, significant amounts of energy were recorded on the surface geophones, indicating that RVSP may be a viable exploration technique in these areas. Although this preliminary test was not a full tomographic survey to determine seismic velocity structure, definite changes in velocity were noted at various depths in the hole and corresponded to changes in lithology determined from drilling information. This

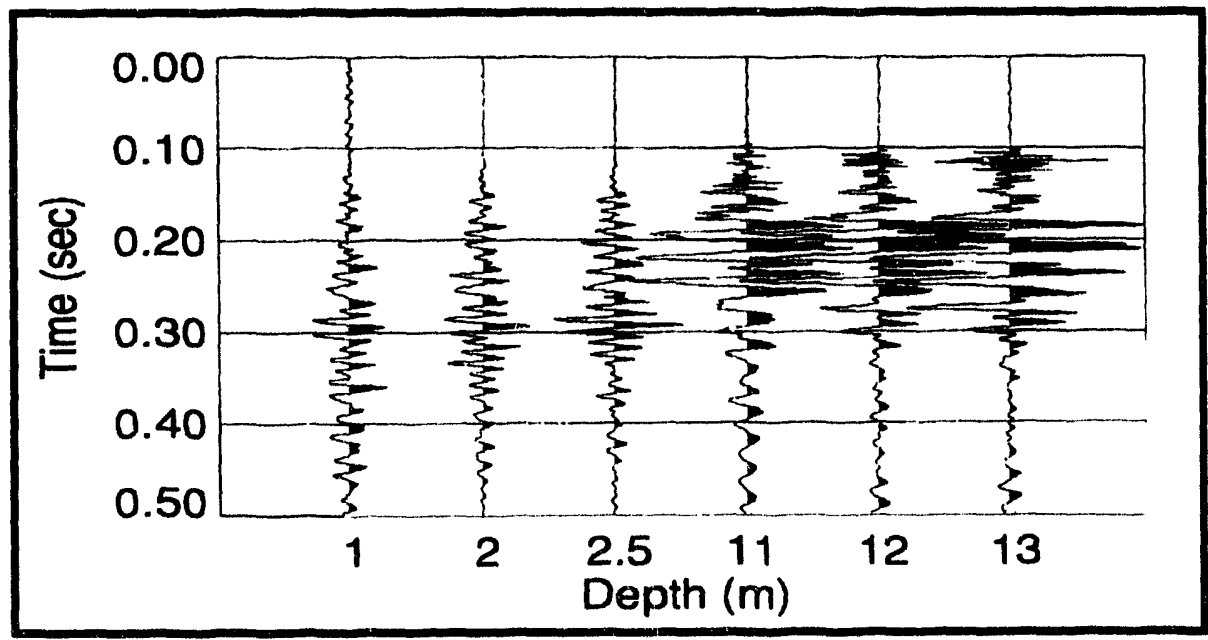

Figure 4.2b: Example of cross hole data collected with Bolt airgun at Hanford site. 
correspondence indicates that seismic tomography will be a useful method for imaging the geology between the wells.

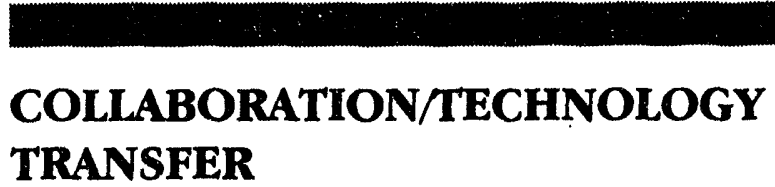

Negotiations have begun with Sandia Research Associates to enter into a cooperative agreement for the development of both new inversion processes for the seismic data and the development of a standard rapidly-deployable field system for collecting the seismic crosshole data. It is hoped that the final system will include both hardware and software for producing in-field preliminary velocity structure models. Sandia Research Associates is also actively pursuing additional industrial partners and plans to submit an SBIR proposal for additional funding next fiscal year.

Internal research funds through Sandia $\mathrm{Na-}$ tional Laboratory Directed Research and Development program have been used to develop a prototype of a new downhole source with higher frequency and energy output. It is hoped that FY95 funding for this project will allow the development of this source into a usable field tool to be employed at Hanford.

Finally, discussions have begun with Stanford University on the possibility of bringing one of their graduate students to Sandia at Stanford's expense to help out with the collection and processing of the data, as well as provide hydrogeologic input to the interpretation of the tomography results.
For more information, please contact:

Greg Elbring

Sandia National Laboratories

Division 6231 MS-0750

P. O. Box 5800

Albuquerque, NM 87185-0750

(505) 844-4904

\section{George Allen}

Technical Program Manager

505-845-7015 


\subsection{ZERO-TENSION LYSIMETERS: AN IMPROVED DESIGN TO MONITOR COLLOID-FACILITATED CONTAMINANT TRANSPORT IN THE VADOSE ZONE}

\section{TASK DESCRIPTION}

A lysimeter is a device installed in the soil to periodically sample groundwater. Zero-tension lysimeters (ZTLs) are especially appropriate for sampling water as it moves via preferential flow paths in saturated or unsaturated conditions. Because no ceramic barrier or fiberglass wick is involved to maintain tension on the water (as is the case with other lysimeters), particles suspended in the water, as well as dissolved species, may be sampled with ZTLs. A ZTL design is described to capture samples of suspended colloids as they move in the vadose zone.

The improved ZTL consists of a Teflon or polycarbonate cylinder placed below an undisturbed core of soil that has been initially withdrawn with an hydraulically-powered tube. The design has significant advantages over conventional designs with respect to simplicity and speed of installation. Because more ZTLs of this design can be installed to assess site variability, more accurate monitoring of contaminant transport before, during, and after remediation will be achieved. In addition, because of the improved spatial resolution in sampling and monitoring, if contaminants are mobilized, their source can be more easily identified than with piezometer-based monitoring methods.

The improved ZTL has been installed in 24 research plots near Ames, Iowa, to monitor potential transport of heavy metals applied to the soil in municipal sewage sludge. In 1993, four lysimeters were aiso installed at a site contaminated with americium and plutonium at the Rocky Flats Plant, Golden, Colorado.

\section{TECHNOLOGY NEEDS}

Zero-tension lysimeters are needed to monitor contaminant migration with mobile colloids (see Figure 4.3a.). They are particularly applicable where a site is undergoing in situ remediation treatment that leaves the soil physically undisturbed. They can also be used in other contexts where colloid-facilitated transport of contaminants is suspected or must be quantified in near-surface environments.

A zero-tension lysimeter that can be installed in much less time and with less site disturbance would allow more extensive and therefore more accurate monitoring of colloid transport in contaminated soils. In this project, a design that meets these needs is presented.

\section{ACCOMPLISHMENTS}

At the Ames site, turbidity in the soil water collected by the ZTLs was dependent upon the level of sludge addition to each plot. In both 1992 and 1993, the higher the rate of sludge addition, the less turbidity occurred in water that leached through the soil (see Figures $4.3 \mathrm{~b}$. and $4.3 \mathrm{c}$ ). Greater additions of sludge may be limiting colloid transport through the soil because of the abundance of salts added to the soil with the sludge. Greater 


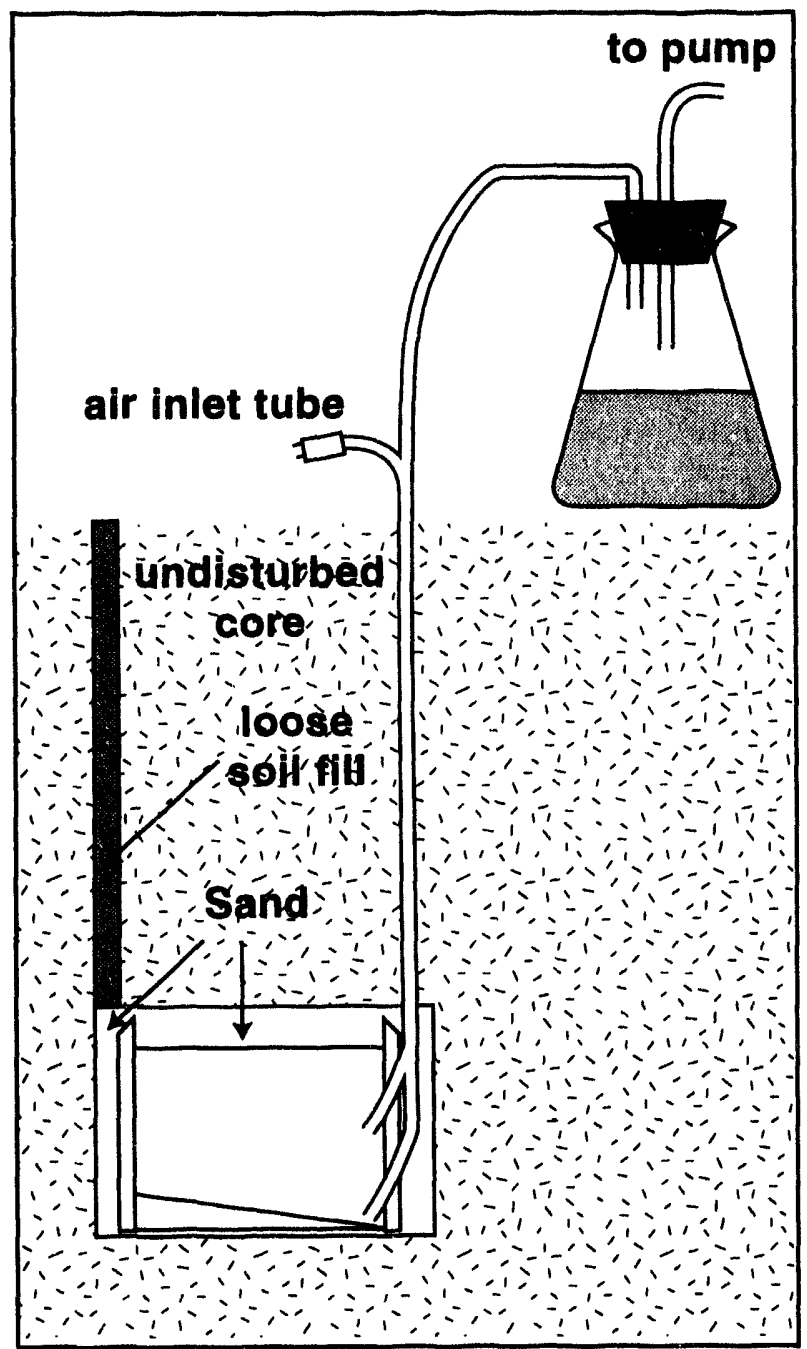

Figure 4.3a. Sampling and maintenance of the zero-tension lysimeter.

ionic strength in the soil solution tends to limit expansion of the diffuse layers of ions associated with soil colloids and to keep colloidal materials from dispersing.

This study is being conducted in the first years of sludge additions to the soil, and levels of heavy metals in the soil water were always low. In fact, it was rarely possible to detect cadmium in the water by the ICP-MS technique employed. Levels of zinc and nickel were typically in the ranges of $5-20 \mathrm{mg} / \mathrm{L}$, and these concentrations were not clearly correlated with any of the other parameters that were measured.
Copper occurred in concentrations that were low (also typically 5 - $20 \mathrm{mg} / \mathrm{L}$ ), but copper levels could be correlated both to treatment effects and to other soil water parameters. For example, significantly more copper leached into the ZTLs installed in plots receiving sludge treatment than in control plots. In addition, significantly more copper leached into the ZTLs under switchgrass than into ZTLs under trees. It is hypothesized that the trees are more effective at taking up copper and storing it in the biomass than is switchgrass.

Multiple linear regression analyses indicated a correlation of mobile copper with dissolved organic carbon, $\mathrm{pH}$, turbidity, and phosphorus, although the correlations varied between the two years of the study. These statistics suggest that copper moved through the soil in an organically complex form, consistent with laboratory studies that have demonstrated strong complexation of copper by soil organic matter. The correlation of copper movement in the soil with vegetation and rate of sludge amendment was only possible because an adequate number of ZTLs had been installed at the site to allow for meaningful statistical analyses. Otherwise, the soil's spatial variability and the relatively low levels of copper concentrations in the soil water would have made valid conclusions impossible. The ZTLs installed at the Rocky Flats Plant in 1993 will be tested by using simulated rainfall in the spring and summer of 1994.

\section{COLLABORATION/TECHNOLOGY TRANSFER}

The principal investigator works closely with an end user at EG\&G Rocky Flats in using the improved ZTLs to characterize the rate of actinide migration at the site. Successful field 
demonstrations will result in wide acceptability at other sites for monitoring contaminant migration in the vadose zone.

\section{For more information, please}

\section{contact:}

\section{Michael L. Thompson}

Ames Laboratory

2503 Agronomy

Iowa State University

Ames, IA 50011

515-294-2415

\section{James Corones}

Technical Program Manager

Ames Laboratory

515-294-9636
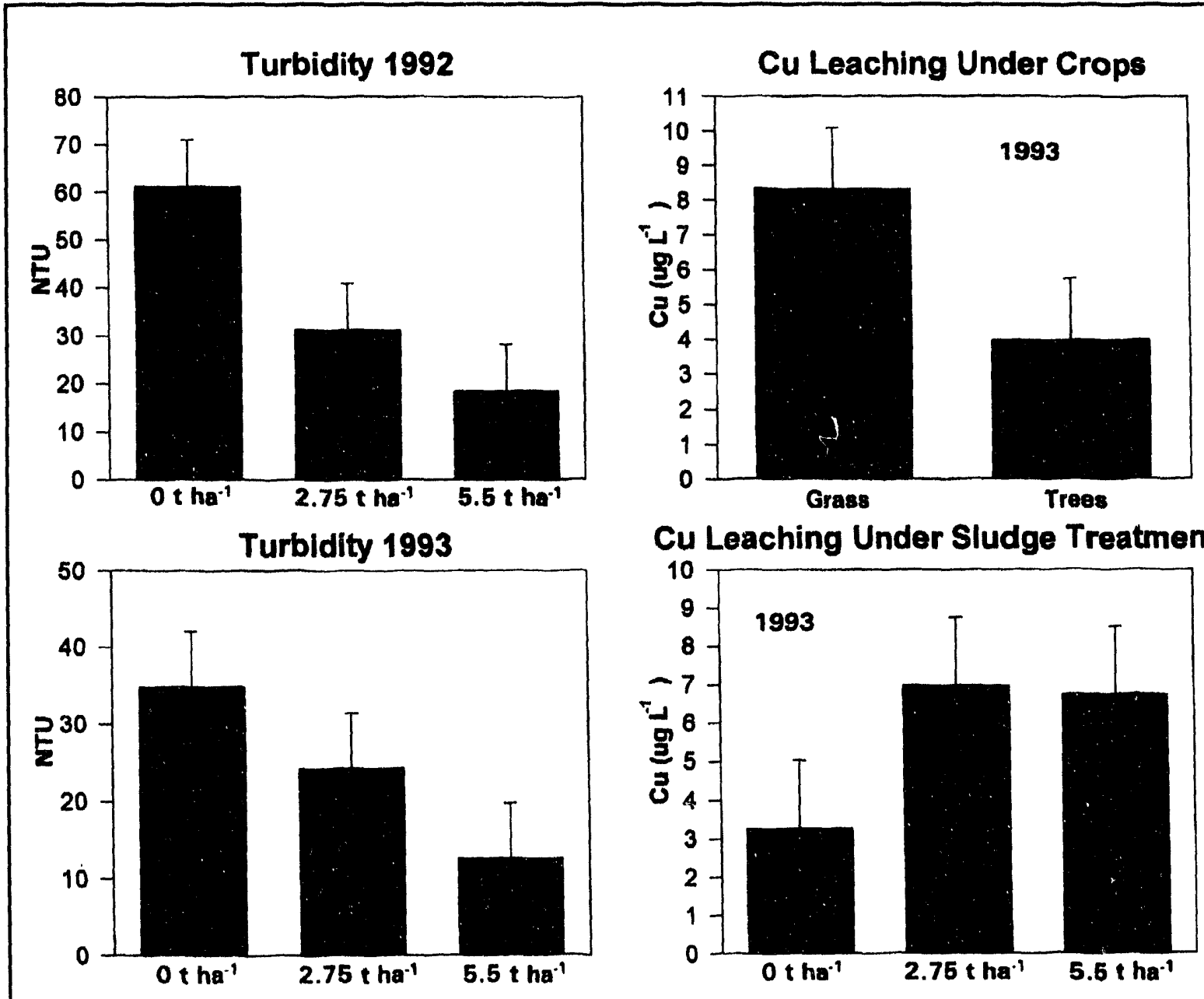

Cu Leaching Under Sludge Treatments

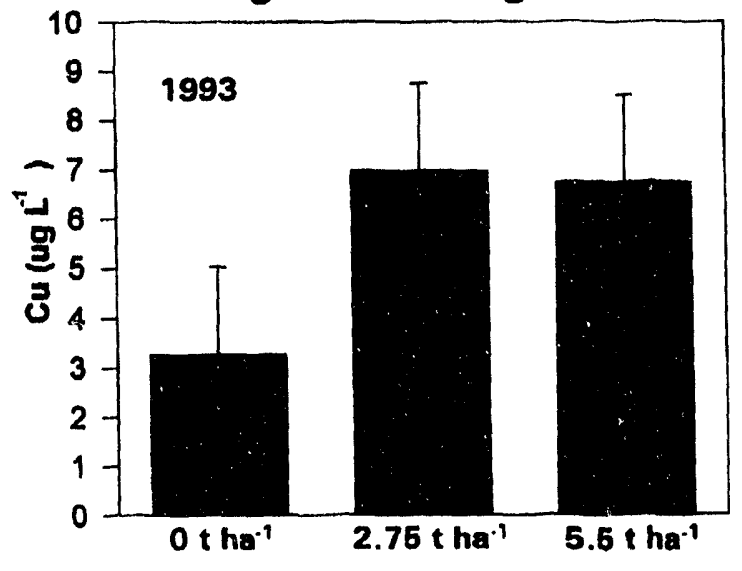

Figure 4.3b. Turbidity 1992.

Figure 4.3c. Copper leaching under crops. 


\subsection{ANALOG SITE FOR CHARACTERIZATION OF FRACTURED ROCK}

\section{TASK DESCRIPTION}

This project is designed to identify reliable tools and methodologies for characterizing the fractures that control flow and transport in specific geologic settings. Characterization tools will be used to predict the outcome of flow and transport experiments in fractured rock in order to assess the utility of these tools for characterizing important hydrologic features in similar contaminated sites.

At this proposed analog site two series of measurements would be performed. The first series would be designed to characterize the hydrology of the site. The second set would be a flow and transport experiment designed to test the predictive capability of the characterization methodology. For example, the characterization methodology at Stripa was confirmed by using the fracture zones identified in the characterization process as the basis of successful predictions of the measured fluid flow and transport in the block.

The characterization phase would begin with a geologic investigation designed to identify the style of fracturing and the likely fracture patterns. Then a suite of geophysical investigations would be performed that are expected to give indications of fractures that control permeability. Techniques such as seismic tomography, 3D seismic, electro magnetic tomography, radar reflection and tomography, hydraulic interference testing, etc., will be used. Any method judged to be useful at the particular site could be tried. The interpretation(s) of these measurements would consist of one or more estimates of the location of important hydrologic fractures. These features would then become the subject of a series of hydraulic tests designed to diagnose the hydrologic properties of the system. Tests would include fluid logging, interference testing and tracer tests. Conceptual models for flow and transport would be constructed based on this characterization.

The flow and transport tests would consist of tests designed to confirm the hydrologic flow paths. These might be tracer tests designed to prove the hydrologic connections between two or more points. In addition, a combination of hydrologic and geophysical monitoring tests will be performed. These could include radar tomography done during the progress of a saline tracer test, or perhaps seismic monitoring during the injection of a gas or fluid of different elastic properties than water. The idea here is to image the flow-through-flowinduced changes in geophysical properties. Comparison of the flow experiments with the flow patterns predicted in the first phase will provide a format for identifying those methods or combination of methods that successfully identify the fractures that control flow.

\section{TECHNOLOGY NEEDS}

Some contaminated sites have fractured rock. For example, the Oak Ridge National Laboratory has significant contamination in fractured shale. INEL and Hanford sites have problems in fractured basalt. The characterization of these sites in order to predict the transport of contaminants can be problematic. The location of fractures is often a mystery; their effect on flow can be dramatic. The 
fractures themselves may be leached by reactive waste material. Containment of the waste may require the sealing of fractures. Thus, the three key issues that influence remediation of these sites are:

- Finding the fractures that control fluid flow and transport.

- Analyzing fluid flow and transport in the fracture system.

- Predicting and controlling of induced or purposeful changes to the fracture system.

\section{ACCOMPLISHMENTS}

Field work should commence in FY95. Contacting of site offices to determine the extent of contamination problems in fractured rock has begun. A type of geology will be chosen for the analog site based on identifying a significant need as well as field site availability.

\section{COLLABORATION/TECHNOLOGY TRANSFER}

Partners are sought from traditional geophysical service companies and other geotechnical firms who might be interested in learning from this project, either by direct participation or through the results of the project.

Additional partners are sought from other national labs with expertise in fractured rock.

\section{For more information, please contact:}

Jane C.S. Long

Lawrence Berkeley Laboratory

Berkeley, CA 94720

510-486-6697 


\subsection{RABRIT VALLEY GEOPHYSICS PERFORMANCE EVALUATION RANGE}

\section{TASK DESCRIPTION}

Utilization of nonintrusive, investigative techniques represents a significant improvement over intrusive characterization methods, such as drilling or excavation, because there is no danger of exposing personnel to possible hazardous materials and no risk of releasing or spreading contamination through the characterization activity. Nonintrusive geophysical techniques provide the ability to infer nearsurface structure and waste characteristics from measurements of physical properties associated with those targets.

The DOE (GJPO) was tasked by the DOE Office of Technology Development to develop a geophysics performance evaluation range (GPER) in the high-desert terrain of Rabbit Valley, west of Grand Junction Colorado.

The purpose of the GPER is to provide:

- static physical models with fixed configurations to test geophysical instrument and method performance against baseline parameters; and

- dynamic physical models that can be reconfigured to simulate specific target parameters.

A subtask of this activity is to identify and catalog other geophysical test facilities within the DOE Complex and to solicit suggestions for test-cell design specifications for the Rabbit Valley GPER from the Offices of Waste Management, Environmental Restoration, and
Technology Development; DOE Operations Offices; other Government agencies; and the private sector.

\section{TECHNOLOGY NEEDS}

The Rabbit Valley GPER will provide known parameters against which the performance of geophysical instruments or methods can be assessed. Comparison of the response obtained over undisturbe. in with the responses observed after the test facilities have been constructed determines the response contribution of the materizis placed in the GPER cells. Quantification of this response contribution allows a direct assessment of precision and accuracy of geophysical instrumentation and provides performance criteria for development or adaptation of emerging geophysical methods and technologies.

\section{ACCOMPLISHMENTS}

GJPO solicited information on parameters of available geophysical test beds from DOE Program and Operations Offices, DOE contractors, National Laboratories, academia, and private industry. The results of the survey were presented in an initial report delivered in January 1994. The results of the survey will help catalog soil types, specific target parameters, measurement techniques, and instrumentation systems tested, as well as any lessons learned from successes and failures of equipment and techniques evaluated. 
Geophysical background data was collected from over 20 acres to be used for the Rabbit Valley GPER, using a $4 \mathrm{~m}$ by $4 \mathrm{~m}$ survey grid. Radiometric, frequency-domain electromagnetic, very-low-frequency electromagnetic, magnetic total field, time-domain electromagnetic, resistivity data, and multi-coil airborne electromagnetic survey data were acquired. Additional, magnetic data were collected by a private industry user who has made the data available to the GPER projectl.

\section{COLLABORATION/TECHNOLOGY TRANSFER}

The Rabbit Valley GPER is available to other Government agencies, universities, and private industry. To date, five organizations have utilized the site, including the DOE Special Technologies Laboratory in Santa Barbara, California, GeoCenters, in Boston, Massachusetts, Airborne Environmental Surveys, of Santa Maria, California, Coleman Researci Corporation in Orlando, Florida, and Dr. Bill Hasbrouck, of the U.S. Geological Survey.

The results of the geophysical measurements will be of interest to Federal agencies and private sector organizations conducting characterization or monitoring investigations of buried wastes. Transfer of the results of this task will be accomplished through public announcement of the Rabbit Valley GPER in trade publications and through presentations to professional forums and at conferences and workshops. A Rabbit Valley Geophysics Performance Evaluation Range User's Guide will be prepared and disseminated that provides range specifications, structure of the GPER database, numerical modelling results, and logistics, field, and dynamic model reconfiguration support available from the GJPO, as well as details of other geophysical test sites (see Figure 4.5.)

\section{For more information, please contact:}

\section{James W. Allen}

RUST Geotech Inc.

P.O. Box 14000

Grand Junction, Colorado 81503

(303) 248-6715

\section{Dan Varhus}

U.S. Department of Energy

Grand Junction Projects Office

(303) 248-7768 


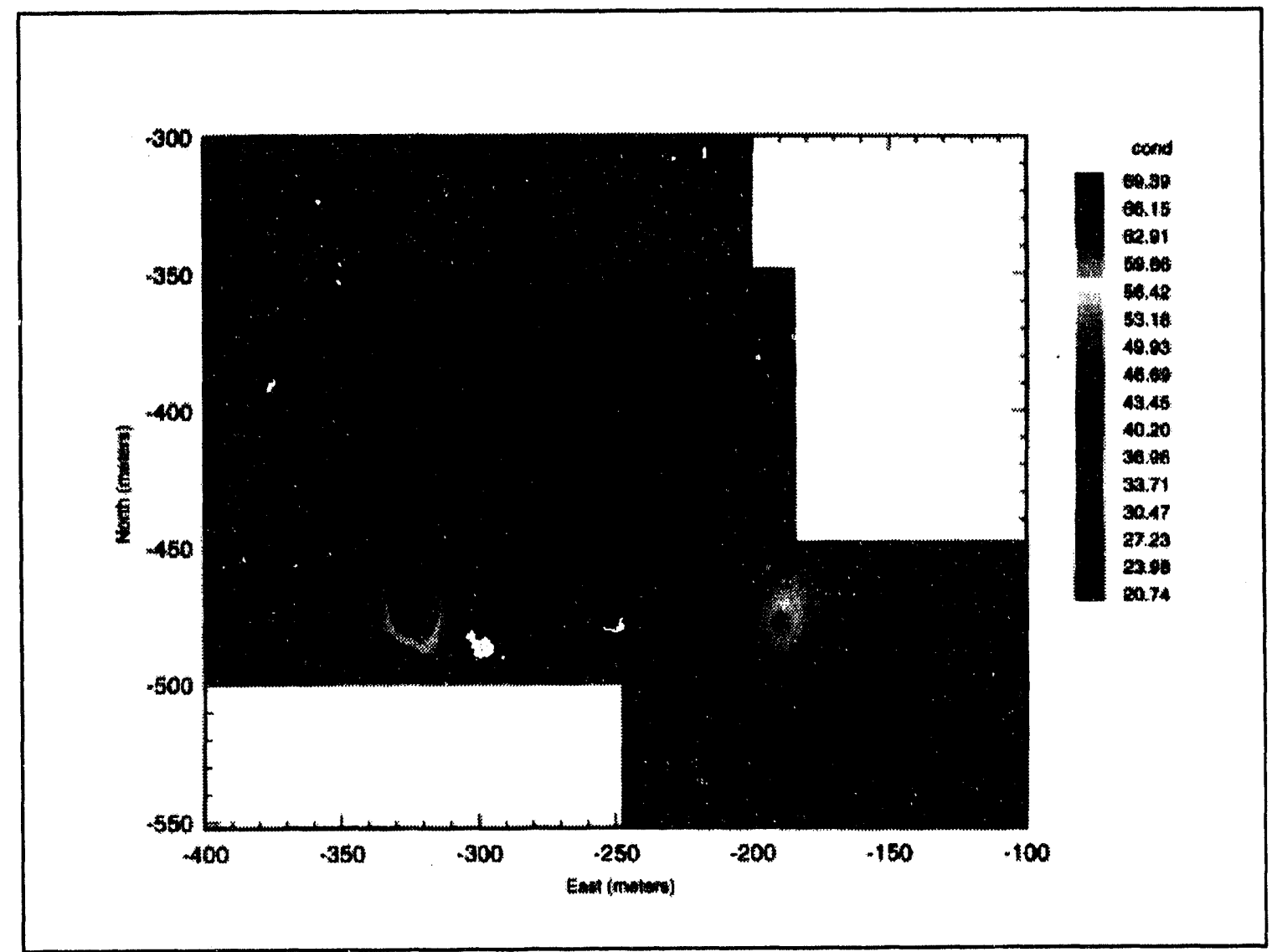

Figure 4.5. Contour presentation of electrical conductivity data collected over the Geophysics Performance Evaluation Range. 


\subsection{INTERNATIONAL ENVIRONMENTAL ASSESSMENT}

\section{TASK DESCRIPTION}

Defense and commercial nuclear production activities of the former Soviet Union (FSU) have resulted in massive contamination of the environment in western Siberia. Pacific Northwest Laboratory is developing three-dimensional numerical models of the hydrogeology and contaminant migration in the West Siberian Basin. The long-term goal is to help determine future environmental and human impacts, given the releases that have occurred to date and the current waste management practices. In FY93, the objectives were to (1) refine and implement the hydrogeologic conceptual models of the regional hydrogeology of western Siberia developed in FY92 and develop the detailed, spatially registered digital geologic and hydrologic databases to test thlem; (2) calibrate the computer implementation of the conceptual models developed in FY92; and (3) develop general geologic and hydrologic information and preliminary hydrogeologic conceptual models relevant to the more detailed models of contaminated site hydrogeology.

\section{TECHNOLOGY NEEDS}

Not applicable.

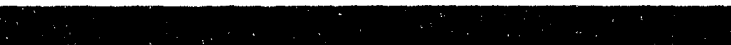

\section{ACCOMPLISHMENTS}

Initial characterization of the regional hydrogeology of western Siberia and successful calibration of single-layer and three-layer hydrogeologic models has been completed. Calibration studies using the regional

hydrogeologic computer model suggest that most precipitation entering the groundwater system moves in the near-surface part of the system and discharges to surfacewaters relatively near its point of infiltration. This suggests that deep injection of liquid wastes may not be an effective isolation mechanism if the injection wells are in areas where groundwaters are generally rising toward nearby surface-water discharge points. Beginning in FY94, more detailed local models will be developed to test assumptions concerning surfacewater/groundwater interactions and to explore the consequences of these assumptions with respect to contaminant migration in the West Siberian Basin.

\section{COLLABORATION/TECHNOLOGY TRANSFER}

Not applicable.

\section{For further information, please contact:}

\section{J. Bradley}

Pacific Northwest Laboratory

P.O. Box 999, MS K8-41

Richland, WA 99352

(509) $372-4161$

\section{Cheryl Thornhill}

Technical Program Manager

(509) 375-2532 


\subsection{CONTAMINANT TRANSPORT STUDIES OF RUSSIAN SITES}

\section{TASK DESCRIPTION}

The task is to perform cooperative RussianAmerican studies of Russian contamination sites, to evaluate site characterization and monitoring data from these sites, to carry out field measurements, and to develop approaches for site evaluation and remediation drawing upon Russian and American experience and technology.

Russia and the United States share a variety of environmental problems. Some have been caused by the operation of facilities supporting the production of nuclear weapons over the past 50 years. During this period, a large amount of radioactive and hazardous wastes have been produced and a significant quantity discharged into the environment. Much effort is being spent in both countries in cleaning up or controlling the contamination in the soil, surfacewater and groundwater systems. In the process, both countries have developed scientific expertise and databases or case histories in characterizing contaminated sites, modelling flow and transport phenomena, and designing optimal restoration or containment strategies.

In FY94, a selection of five to seven Russian scientists will be invited to stay in the U.S. for a duration of one to two months. They will participate in the project and add important Russian scientific inputs. Nomination of these scholars has been coordinated with the Russian Ministry of Atomic Energy (MINATOM), the Russian Academy of Sciences, and DOE, and their visits are jointly funded by DOE-ER and DOE-EM.
In FY94, it is planned to continue the work started in FY93 to make a careful study of contaminant transport at the Chelyabinsk site over the last forty years. The important physicochemical processes occurring in contaminant transport over kilometer distances and over long time periods will be identified. Some of these may not be observable in short-term experiments. The goal is to summarize these processes, describe their characteristics and understand their temporal and spatial properties. These will be of great importance to the environmental site characterization method development and optimal approaches to remediation.

Since the establishment of the connections with the Russian organizations involved in Chelyabinsk site-specific studies, much available data from Russian sources have been collected, reviewed, and are in the process of being published as ten reports in English. Based on this information, a plan will be developed to investigate important physicochemical processes in contaminant transport in the soil and groundwater system at Chelyabinsk. Part of this study will be a field measurement program, which will focus on a preliminary reconnaissance-level survey for radionuclides in Myshelyak riverbank soils and river water, and in soils between Lake Karachai. This field study is intended to confirm and complement Russian efforts. Also, such a survey will provide information to evaluate site characterization and monitoring methods. 
For FY94, a major field visit to the Chelyabinsk site will be proposed to the MINATOM. The proposed field study will be focused on several of the following possible topics:

- River Myshelyak survey: field radiometry along transects and sampling of water, soils, rock cuttings, and cores for laboratory analyses to identify sorption/desorption of radionuclides and rock/water interactions.

- Unsaturated zone sampling: collection of water and soil samples in the near-surface layers along rivers and near Lake Karachai.

- Vertical survey of geological structures, hydrological property variation, and plume migration with wells designed for detailed distribution sampling.

- Geophysical survey of the basement structures and deep geological structures with seismic and/or electromagnetic tomographic techniques to define the flow domains for contaminant containment and remediation.

This field visit will be carried out by approximately six U.S. scientists for one week to one month around July, 1994 in Chelyabinsk.

\section{TECHNOLOGY NEEDS}

The benefits to be derived from this project include the identification and assessment of a most comprehensive database and a real, largescale contaminated site to test current understanding and site characterization technologies that are used in evaluating contaminated sites. This is unique among current projects. The project will strive to test and demonstrate new field technologies and thereby lead to their rapid infusion into the DOE Environmental Restoration Program.

Other important benefits include the stimulation of increased collaboration among Russian and U.S. scientists on technology development for environmental studies. This will also facilitate identification of key resources for inclusion in the DOE Environmental Restoration Program.

\section{ACCOMPLISHMENTS}

The collaboration with Russian experts and institutions has been successfully established, including the government, research institutes, academia and commercial companies. Due to the established U.S./Russian partnership, it was possible to collect important data from Russian sources. Based upon this information, a field study plan has been developed to investigate important physicochemical processes in contaminant transport in the soil and groundwater system at Chelyabinsk and to test site characterization technologies.

So far ten reports have been produced due to this collaboration and these are now under the review process. These reports are listed below:

1. Drozhko,E.G., Mironenko, V.A.,Pozdniakov, S.P., Samsonova, L.M., Shestakov, V.M., Previous investigations and field hydrogeological data for Chelyabinsk region.

2. Drozhko, E.G., Mokrov, Yu.G., Glagolenko, Yu.V., Samsonova, L.M., Determination of hydrodynamic parameters of cleaved rock mass according to regime examination data in the Lake Karachai area.

3. Drozhko, E.G., Samsonova, L.M.,Zinin, A.I., Yinkin, V.P., Computer model of solutions to unsteady migration in groundwater. 
4. Mironenko, M.V., Y.G., Glagolenko, Drozhko, Eu.G., Khodakovsky, I.L., Mokrov, G.Yu., Polyakov, V.B., Smirnov, A.B., Spasennykh, M.Yu., The cascade of reservoirs of the RMAYAKS plant: case history and the first version of a computer simulator.

5. Mironenko, V.A., Rumynin, V.G., Analysis of hydrogeological consequences of hazardous accidents at designed nuclear reactors: forecast and field investigation.

6. Mironenko, V.A., Rumynin, V.G., Shestakov, V.M., Konosavsky, P.K., Pozdnyakov, S.P., Roshal, A.A., Development of analytical and numerical models for the assessment and interpretation of hydrogeological field tests at the key sites of the Lake Karachai area.

7. Pek, A.A., Malkovsky, V.I., Modelling of the fault-controlled hydrothermal ore-forming systems.

8. Malkovsky, V.I., Pek, A.A., Computer simulation of nuclear waste transport from the deep drill hole repository: thermal convection model.

9. Pek, A.A., Malkovsky, V.I., High-level nuclear waste geological disposal: utilization of HLW heat generation in the design of engineering barriers.

10.Pozdniakov, S.P., Shestakov, V.M., Quasi3D variable density flow model.

\section{COLLABORATION/TECHNOLOGY TRANSFER}

Through the Lawrence Berkeley Laboratory Russian-American Center for Contaminant Transport Studies, communications have been established with Bechtel, General Atomics' Environmental Technology Division, and other U.S. companies. The project will expedite the development, commercialization, and application of novel environmental technologies, thereby creating a major source of new business opportunities in both Russia and the United States. The project also aims at creating partnerships between industry, research and educational institutions, regulatory agencies and the central governments.

For more information, please contact:

Dr. Chin-Fu Tsang, Earth Sciences Division, Lawrence Berkeley Laboratory

1 Cyclotron Road, MS 50E

Berkeley, California 94720 (510) 486-5782 


\subsection{ELECTRICAL RESISTANCE TOMOGRAPHY FOR SUBSURFACE IMAGING}

\section{TASK DESCRIPTION}

The purpose of this task is to develop and demonstrate a system for detecting and locating leaks in the single-shell tanks at the Hanford site in Richland, Washington; develop very high-resolution imaging techniques for monitoring electrokinetic remediation, demonstrate the effectiveness of the technology at the Sandia testing of electrokinetic remediation; and transfer the basic electrical resistance tomography (ERT) technology to RIMTech, Inc., through formal training and by working in actual field applications of the technology.

\section{TECHNOLOGY NEEDS}

Detecting leaks from the Hanford single-shell tanks (SSTs): DOE has approximately 149 SSTs that have been used to store high-level mixed wastes. Many of these thanks are at the Hanford, Washington site. It is known that 60 to 70 (66 assumed) of these tanks are leaking and releasing their contents in the surrounding soil. Other tanks may be leaking, but the existing techniques for determining leakage prevents an accurate count. In line with the potential for danger such releases pose to site personnel, and the longer-term danger to the surrounding communities, environmental regulations require that even small volume releases from these tanks be reported. There is a clear need to be able to detect when a tank begins to leak so corrective measures can be taken before damage is great. There is also a need to be able to isolate the leak location in the event that tank repairs are practical.

Currently there are two methods for detecting leaks and neither is useful for locating the leak point. The simplest method is a careful inventory of tank contents. Unfortunately, the precision needed in level sensing is not simple due to the heterogeneities and chemical conditions of tank contents. Even level sensors are troublesome due to the "bergs" and the crusts in some tanks. The other approach is to drill beneath the tank and install sensors. This approach also has its problems, since it provides only point measurements under the tank,

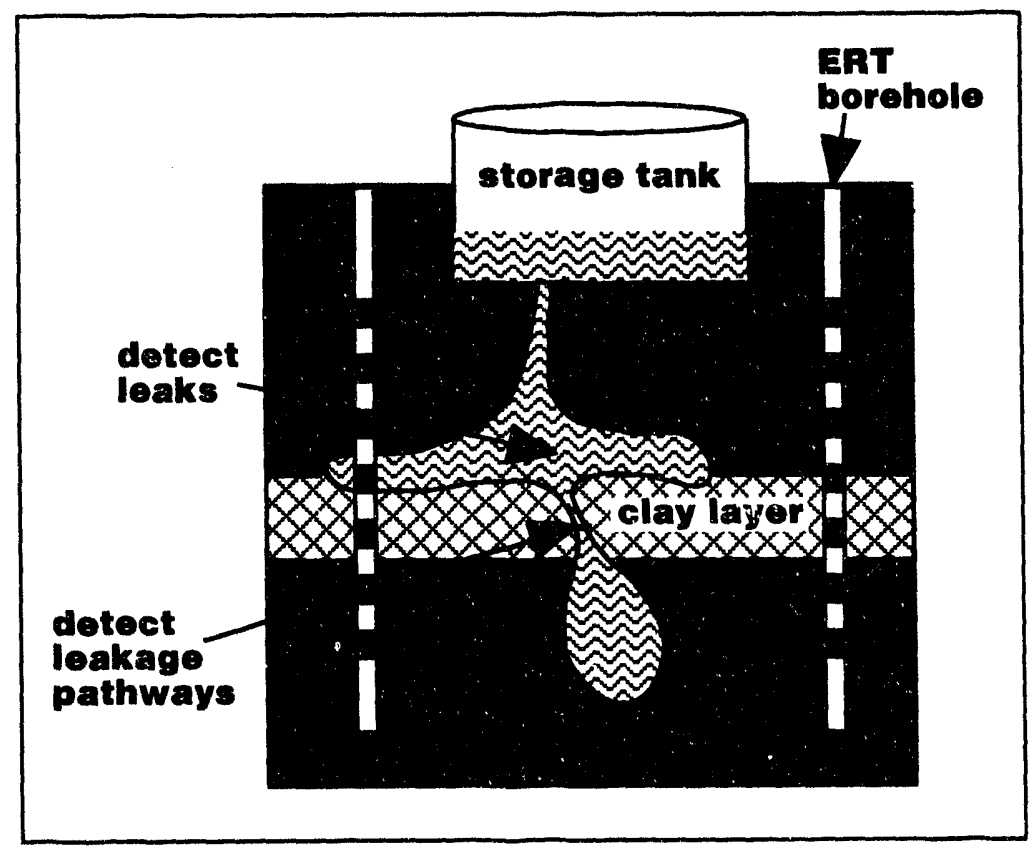

Figure 4.8a. Schematic representation of electrical resistance tomography to delineate leaks from an underground storage tank. 
and any leakage will probably be highly channeled due to the heterogeneous soil at Hanford, and therefore the leak will likely be missed.

Monitoring Electrokinetic processes. Electokinetic remediation of metals and other contaminants from soils is not a new idea. The technique is even commercialized in Europe. Unfortunately, much of the physićs, chemistry and influence of hydrogeology on the process is not well understood. As a result, it is likely that much electrokinetic remediation now practiced may be ineffective. The test to be performed at Sandia later this year is designed to provide the overdue basic research. To meet this goal, detailed information is needed of the test site and the process itself. Electrical resistance tomography is being done at the site before and during the test to help provide some of the needed detail. First, ERT will be used to obtain five high-resolution images to fill in borehole data about the site lithology (see Figures 4.8a and 4.8b). The hydraulic permeability distribution will be inferred from borehole cores and interpolated between holes using ERT and the fact that more permeable sands are resistive and less permeable clays are conductive. During the test, moisture content changes will be mapped in the test area from the well-documented correlation of electrical properties to soil water content. It is also planned to estimate the amount of water lost out the bottom of the system based on the images.

Technology Transfer. As prescribed by DOE, the accumulated experience and know-how of ERT will be given to RIMTech and the 2.5 D inversion code will be licensed by them.

\section{ACCOMPLISHMENTS}

(first six months of the project; this is a new project)

Detccting leaks from the Hanford single shell tanks. A fairly detailed test plan has been written and approved by Hanford personnel. Permitting for the test has begun. Hanford operations is doing the permitting for the site. After some negotiation, details of the test site have been settled and Hanford operations has agreed to start construction this spring.

Monitoring Electrokinetic processes. Many of the details of the test have been worked out with Sandia. Preliminary measurements at the test site have been made to set some of the parameters for later data acquisition. Experiments at the site have been performed using a method of placing ERT electrodes using SEAMIST $^{\mathrm{TM}}$. The technique worked, but was determined to be too expensive. An alternate method has been designed and a prototype is now being built to test in the laboratory before field deployment at Sandia.

Technology Transfer. Personnel from RIMTech have visited LLNL to become familiar with the operation of ERT data collection hardware and use of the inversion code OCC2D3D. Two more sessions are planned for later in the project to continue this training. Work is being planned with RIMTech personnel during each phase at Hanford and Sandia so they will be familiar with all aspects of planning and executing a project using ERT. The CRADA with RIMTech will be complete when signed by DOE Headquarters and the Oakland Operations Office. 


\section{COLLABORATION/TECHNOLOGY TRANSFER}

LLNL and Ames Laboratory are actively working with RIMTech, Inc., a Denver based geophysical service company, to transfer the basic ERT technology. That work will continue throughout FY94.

Collaboration is also occurring with the University of Arizona. The contribution is computer code development for the project. Collaboration with Westinghouse Hanford Company (EM-30) in the development of a test bed for the work at the site is occurring. They will do all site construction in accordance with the test plan.
For more information, please contact:

\section{William Daily}

Lawrence Livermore National Laboratory

L-156

Livermore, CA 94550

(510) $422-8623$

\section{Abe Ramirez}

Lawrence Livermore National Laboratory L-206 Livermore, CA 94550

(510) 422-6909

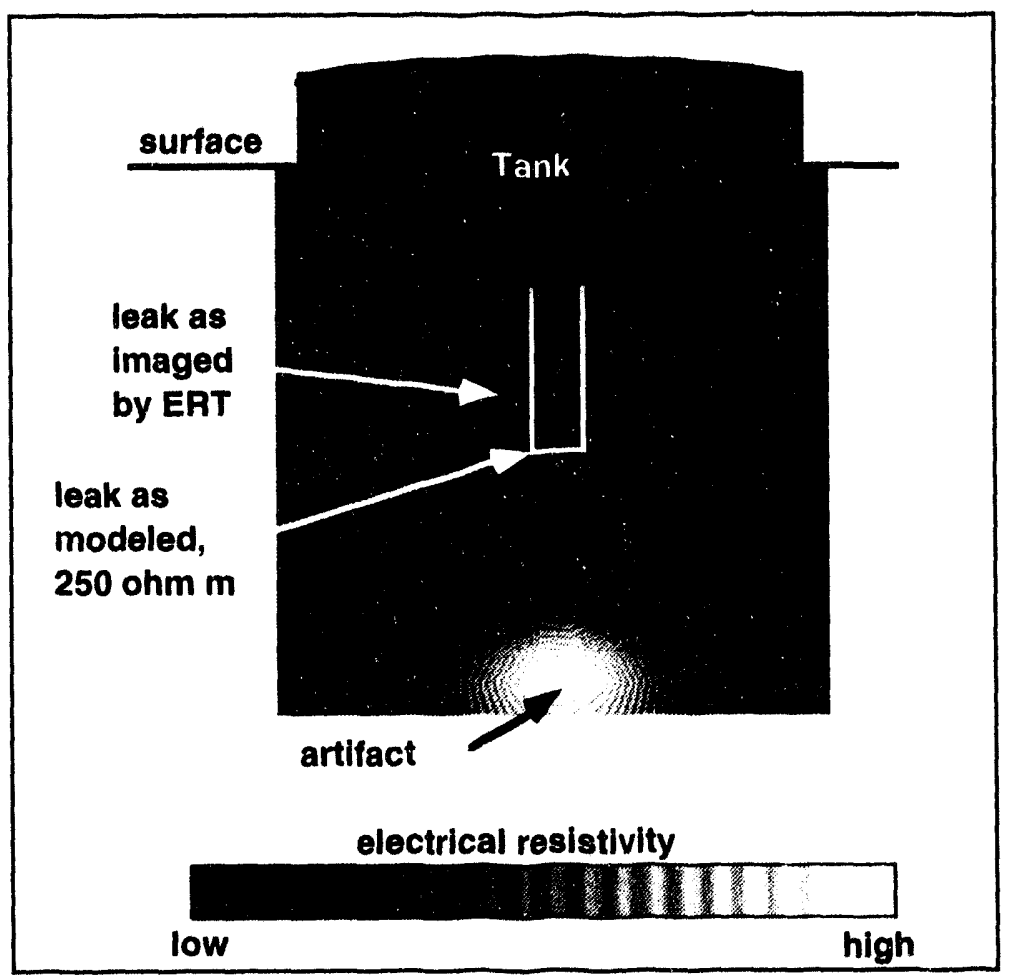

Figure $4.8 \mathrm{~b}$. Computer simulation of electrical resistance tomography below a steel tank with a conductive plume of $250 \mathrm{ohm}-\mathrm{m}$ beneath the tank center. 


$$
m^{-}
$$




\section{High-Level Waste Tanks}

Section 5.0 


\section{TASK DESCRIPTION}

Remote moisture measurement by electromagnetic induction has been successfully used in the wire-line logging industry for many years to measure water concentration and porosity in geologic formations. The objective for this task is to evaluate a similar electromagnetic induction method for monitoring moisture in the single-shell waste tanks at Hanford. Electromagnetic waves are transmitted into a waste material (typically a saturated salt solution containing 10 to 50 weight percent water) by placing a transmission coil at a selected location and exciting it with an alternating current. A receiver coil is placed at a nearby location. Monitoring the current applied to the transmitter and voltage developed in the receiver provide information about the electromagnetic properties of the material surrounding the two coils. The electromagnetic waves can penetrate into all materials to a depth controlled by their electrical conductivity, magnetic permeability and the frequency of the current exciting the transmission coil. By selecting different frequencies, water concentrations, and the many other variables expected to occur in a waste tank, experiments will be performed to demonstrate how this technology can be applied in a waste tank to monitor moisture.

First, stimulants must be verified electrically equivalent to the waste in the single-shell tanks. This is being accomplished by measuring the electrical properties of samples cored from a single-shell tank. The simulated waste presently in use will then be modified according to core sample measurements. A proto- type measurement system will be developed and calibrated in the laboratory and tested inside the Liquid Observation Well (LOW) of a waste tank. The moisture sensor, consisting of a transmitter and receiver coil, is expected to monitor the electrical conductivity (and hence the moisture) of the waste material surrounding the LOW out to a radius of about 60 inches, and identify liquid level to within one inch.

\section{$\cdot$}

\section{TECHNOLOGY NEEDS}

A major safety question exists for the HLW tanks at Hanford. The safety question results from the fact that the thermal stability of single-shell tanks containing ferrocyanide, or organics, in the presence of an oxidizer has been linked to the presence of sufficient water in the waste to quench any incipient explosive reaction. This makes it necessary to continuously monitor the HLW tanks for moisture to allow safe remediation activities to be executed. A safe water concentration is estimated to be somewhere between 20 and 30 weight percent. An active thermal neutron measurement technique deployed in a LOW is currently in use at Hanford to measure moisture. However, this method has a range of only a few centimeters. The electromagnetic method has a longer range, perhaps as long as 1.5 meters. If the electromagnetic method can provide even a relative measure of moisture, its measurements can be calibrated with an absolute measurement near the measurement point using the neutron probe. Combining the two methods would then yield absolute mea- 
surements at a distance up to 1.5 meters from the LOW. Absolute measurements of moisture may also be possible. Either way, such an advance in moisture measurement capability would provide a significant tank safety benefit.

\section{ACCOMPLISHMENTS}

The most important information needed to evaluate any kind of moisture sensor for this application is how sensitive it is to moisture variation and how well it can discriminate between moisture and the many other variables imagined to exist in a waste tank. Experiments have been designed to obtain this information and preliminary tests yielding insightful observations have been performed. Measurcments at the test-tube and $500 \mathrm{ml}$ beaker scale have shown how the electrical resistivity of ionic salt solutions and waste tank stimulants behave when their moisture content varies. Figure 5.1 shows the magnitude of the complex coil impedance measured as a function of moisture content for two stimulants', sodium $\iota$ chloride, sodium sulfate, and an equal mixture of the above with bismuth phosphate added. Error bars along the impedance axis are estimated from calibration tests performed on the experimental apparatus. This preliminary investigation shows that a strong correlation exists between the electrical resistivity of ionic solutions and their moisture content. From the limited data shown here, the solution/slurry composition appears to have a relatively small effect on the impedance measurement. Further work is needed to confirm this, but the results to date indicate that the electromagnetic method is a promising one for measuring moisture content of underground storage tank waste.
Experiments to determine how the electrical properties of the stimulants compare with samples cored from single-shell waste tanks are in progress. The core samples are contained in 4-ounce glass jars. The electrical impedance and moisture of the waste material in the glass jars will be measured in late February. The electrical impedance measurements will be performed without opening the jars; however, to obtain an accurate (and independent) measure of moisture, waste material must be removed from the jars, dried, and weighed.

\section{COLLABORATION/TECHNOLOGY TRANSFER}

Should application of this technology be developed into a successful measurement tool, the well-logging and waste management industry will have interests in commercializing it for waste-site assessment. Commercializa-

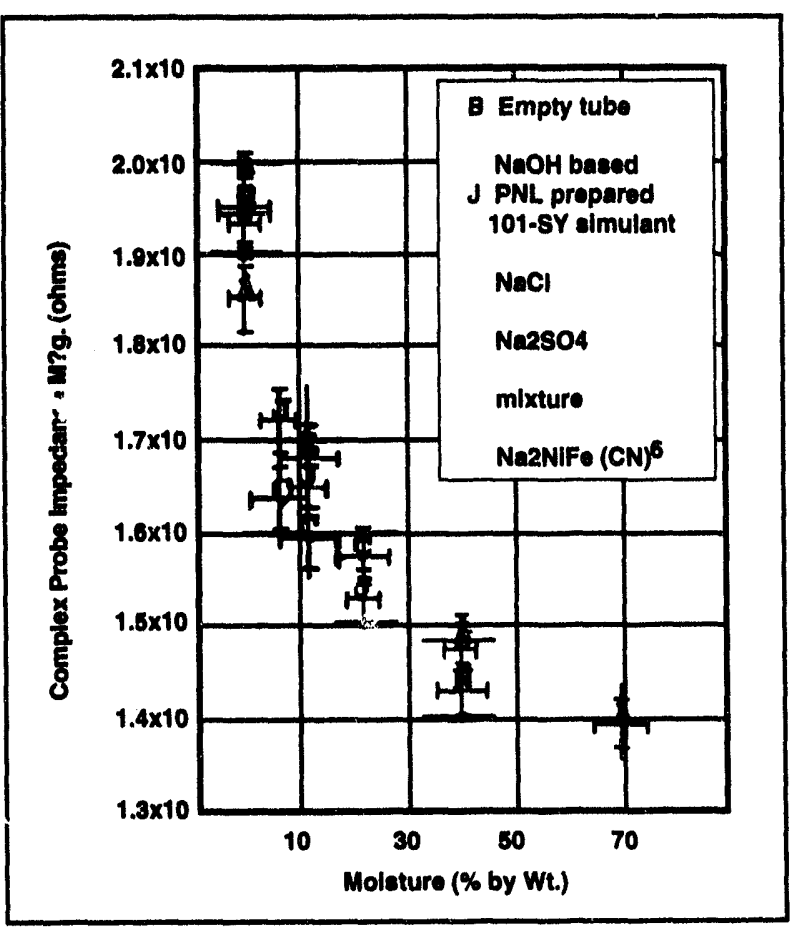

Figure 5.1. Magnitude of complex impedance plotted vs. percent moisture. 
tion partner interest, based on progress to date, is presently being sought and will be continued as more information becomes available.

For more information, please contact:

\section{Ronald L. Hockey}

Pacific Northwest Laboratory

P. O. Box 999, MS K5-26

Richland, WA 99352

(509) $375-2813$ 


\subsection{IN-TANK INTERFACE DETECTION USING TIME DOMAIN REFLECTOMETRY}

\section{TASK DESCRIPTION}

This project is developing Time Domain Reflectometry (TDR) as a cost-effective means of monitoring liquids in waste tanks at Hanford and Savannah River Site . The TDR systems will be able to monitor levels in liquid filled tanks as well as interstitial liquid in salt cake in tanks normally empty of liquid. Tests will also be made to determine the feasibility of detecting the interface between sludge and supernatant in tanks involved in in-tank-processing (ITP) of waste.

Present methods of liquid-level detection have not been satisfactory in the waste tank environment. The TDR probe is unaffected by radiation, temperature, pressure or liquid composition. The probe can function immersed in the liquid or inside LOWs present in the Hanford tanks.

Commercial TDR equipment made available by the shutdown of $\mathrm{K}$ Reactor at Savannah River Site is being used for all tests. The equipment is computer-controlled with a large amount of usable software already available. Also of use is site experience with another installed TDR system used to monitor the benzene/water interface in a decanter on the Precipitate Hydrolysis Environmental Facility Reactor at the TNX facility.

Some software development is being done to integrate computer-controlled microwave coaxial switches into the existing equipment. This will allow the multiplexing of several probes to one system of TDR electronics.
Most of the development work in this project will consist of probe design and tests in simulated liquid waste and salt cake.

\section{TECHNOLOGY NEEDS}

Accurate level detection inside waste tanks is of critical importance for environmental reasons. Of the 149 single-shell tanks at the Hanford site, 67 are assumed to be leaking with no sufficient level detection method being employed.

In-tank treatment of waste at Hanford, Savannah River Site and other DOE sites is planned as part of the waste solidification program. As a result of in-tank treatment, most of the Cs137 is precipitated out into a sludge that will settle to the bottom. This sludge will be pumped to facilities for solidification in glass. The supernatant will be sent to different facilities for treatment and disposal as low-level waste.

It is necessary to know where the sludge/ supernatant interface is located so as not to carryover one with the other during their respective transfers. This interface will change during transfer operations and any detection method must function over a range of several feet. The traditional means of detecting radioactive liquid-liquid interface has been to use fixed bubbler tubes to monitor density changes. This method has several disadvantages, such as the gradual plugging of the tubes, requirements for an air purge adding to off-gas levels, 
and the necessity of maintaining the interface between the bubbler tubes by feed flow control.

In addition to the need for level detection for waste processing and waste transfers, accurate level detection is important especially at Hanford, due to a significant number of known or assumed leaking tanks. When a tank is detected as leaking, an interim stabilization is performed in which as much liquid is removed (pumped out) of the tank as possible, leaving the more solid layers. Once a tank has been interim stabilized, there is no means of detecting if it is still leaking, since current level detection methods for the remaining liquid in the cake layer are not viable. Successful application of TDR level detection to this situation would be a significant accomplishment.
Tests with a laboratory twin lead probe in a LOW mock up have shown that this configuration can detect liquid outside the LOW with surprising accuracy (see Figure 5.2a). This finding is very encouraging to the possibility that interstitial water in salt cake can be monitored in the Hanford tanks using their LOW (see Figure 5.2b).

Since TDR, using a twin lead probe in a LOW, can detect water, the moisture content of salt cake may also be measurable.

\section{ACCOMPLISHMENTS}

A twin lead probe has been calibrated and is ready for demonstration in the Savannah River TNX Sludge Receipt and Adjustment Tank. The twin lead probe type is more appropriate for waste streams with heavy sludge that might

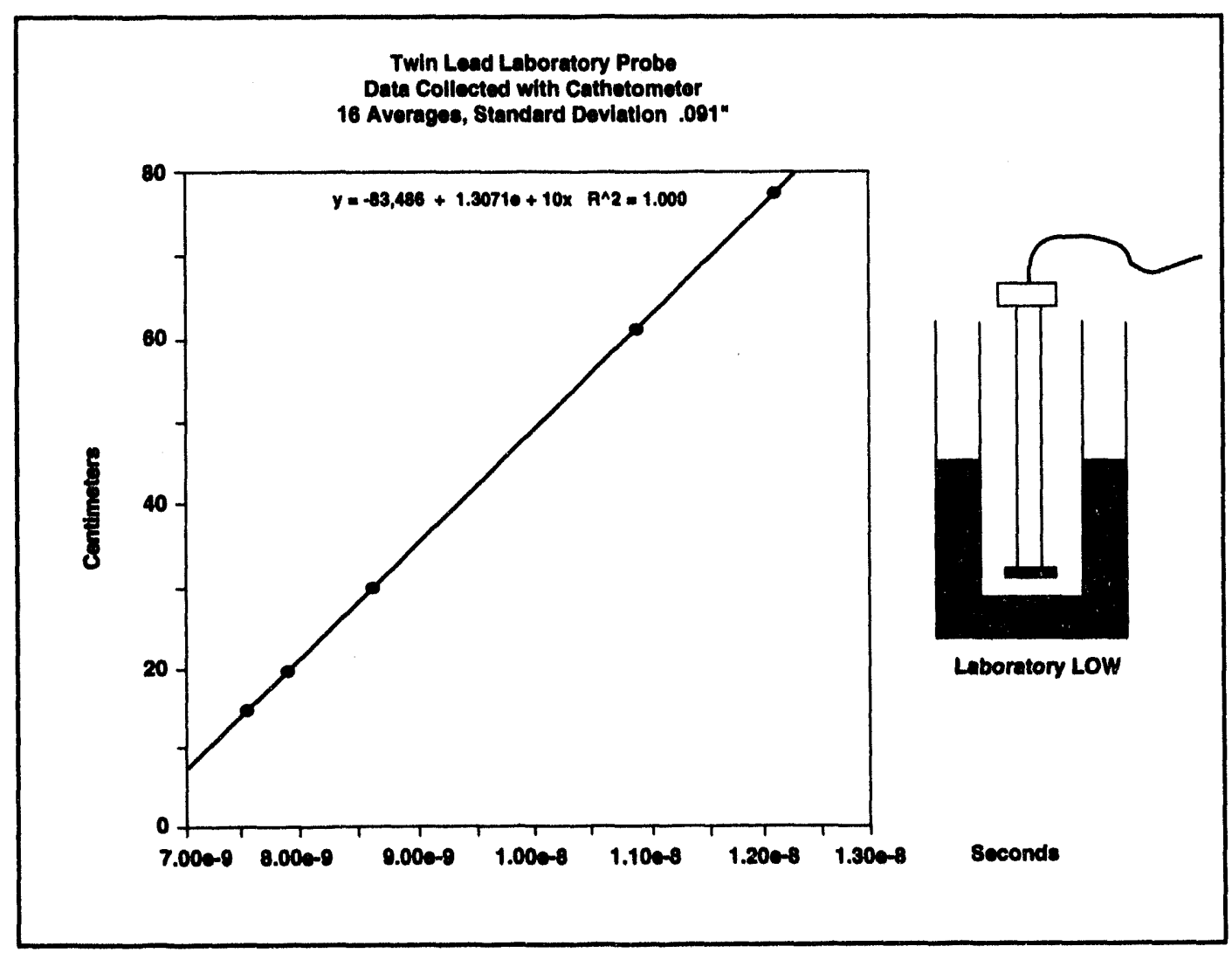

Figure 5.2a. Twin lead laboratory probe data collected with cathetometer. 
clog traditional coaxial probes. Laboratory calibration tests have shown the twin lead probe will have an accuracy of about plus/ minus . 1 ". In this demonstration the probe will be immersed in a waste simulant/glass frit slurry (see Figure 5.2c). The effect of caking on the probe will be examined.

The present method used to monitor interstitial water and salt cake moisture requires a neutron source/detector be lowered into the LOW. This method is expensive, time consuming, and non-continuous. If TDR is used on the Hanford tanks, several million dollars could be saved.
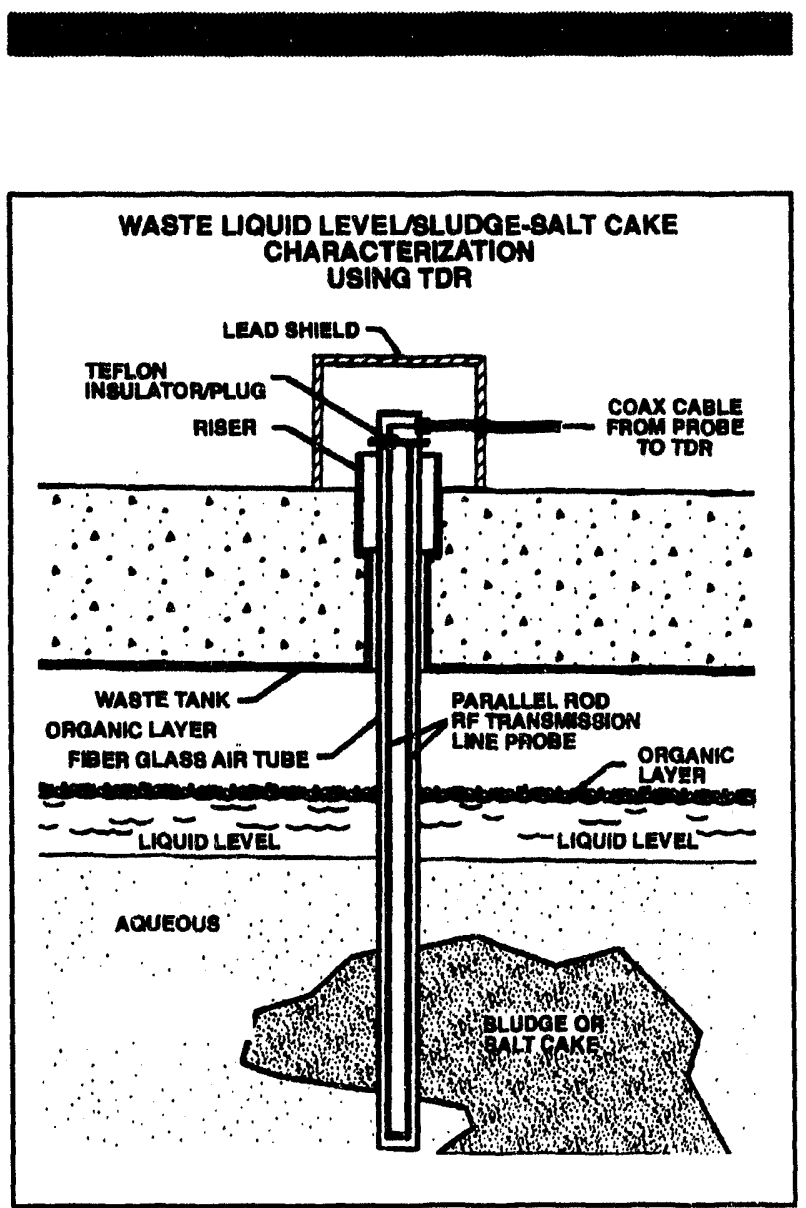

Figure 5.2b. Waste liquid level/sludge-salt cake characterization using time domain reflectometry.

\section{COLLABORATION/TECHNOLOGY TRANSFER}

This technology will be directly applicable to all existing nuclear waste tanks as well as many other commercial waste/chemical storage tanks. It will also be useful for liquid level monitoring in pressure/vacuum vessels. This information will be transferred via open literature publications. In terms of commercialization, a firm in Richland, WA, Mohr and Associates, has been contacted as a possible candidate for mass production of TDR systems.

\section{For more information, please contact:}

\section{Hilton R. Tilley, Sr.}

Westinghouse Savannah River Site

Bldg. 723-A

Aiken, SC 29808

(803) 725-1876

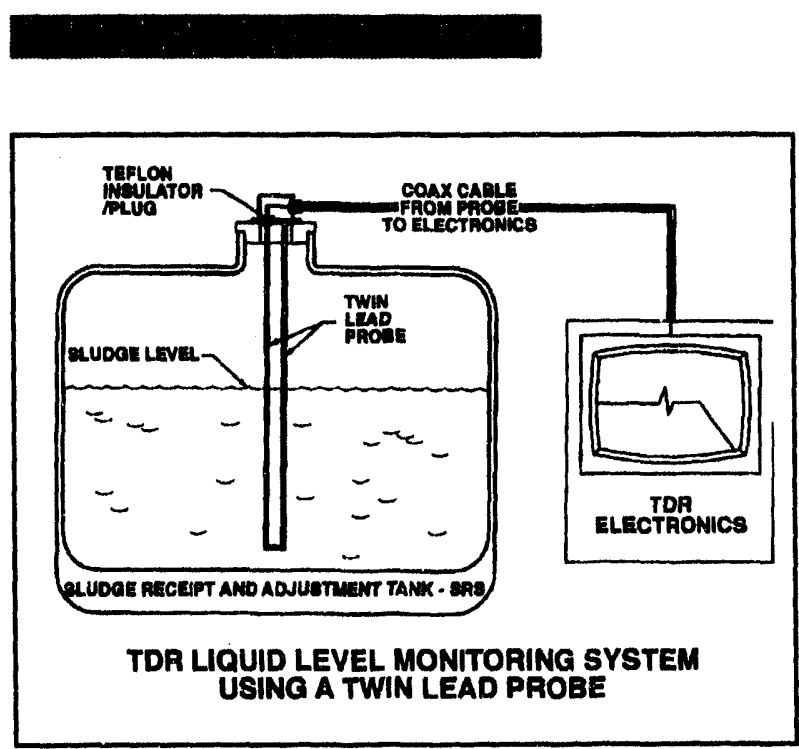

Figure $5.3 \mathrm{c}$. Time domain reflectometry liquid level monitoring system using a twin lead probe. 


\subsection{TRANSURANIC ELEMENTS AND MOISTURE MEASUREMENT IN HIGH-LEVEL WASTE TANKS BY NEUTRON ACTIVATION}

\section{TASK DESCRIPTION}

The purpose of this project is to adapt, calibrate and validate the well proven technique of relating the neutron activation of a metal (copper) to the neutron source strength; specifically in this case, to the quantity of transuranic elements in HLW tanks producing that neutron flux, and also to the amount of hydrogenous material (moisture) in the tanks providing thermalization of an introduced neutron flux. The long-range goal is to apply the technique, with the aid of a cone penetrometer, to assessing the moisture/transuranic (TRU) concentrations and distributions in all HLW tanks.

\section{TECHNOLOGY NEEDS}

The new technical strategy for the Tank Waste Remediation System (TWRS) activities at Hanford requires the mitigation of the potential hazards from the wastes in underground storage tanks that have unresolved safety questions (USQs). Mitigation requires initial characterization of the waste to resolve the USQ issues and/or to aid in the selection of treatment technologies to mitigate the USQ. Another key element of the TWRS strategy is to characterize all wastes prior to retrieval. As a result of this strategy, a high priority need has been identified for technologies to determine the moisture and the fissile-material content of these tanks to resolve safety questions and aid in making decisions regarding deployment of retrieval technologies. Excess quantities of fissile material could result in nuclear criticality concerns, while excessive dryness in certain tanks could potentially result in an unsafe storage situation. Currently, the only way to obtain this data is to retrieve the highly radioactive wastes from accessible locations in a tank and conduct expensive and timeconsuming analyses in a shielded analytical facility. Thus, another high priority need is for in situ techniques for obtaining this data in a rapid manner and permitting more extensive sampling of each waste tank than is currently possible.

\section{ACCOMPLISHMENTS}

This is a new project in FY94. Initial activities were directed towards confirming the use of copper as the activation metal for this technology. Analysis of copper samples was completed. The final results indicate that the material is acceptable. Half-life measurements were within $0.4 \%$ of the best published value, indicating that neutron activation of the sample copper probe material produced no conflicting emissions. Following completion of these activation tests, copper probes were fabricated (see Figure 5.3a). In addition, a mock-up calibration facility has been designed and the necessary equipment, including a large vessel for simulant containment (see Figure $5.3 \mathrm{~b}$ ), has been procured and installed. 


\section{COLLABORATION/TECHNOLOGY TRANSFER}

Besides characterizing HLW tanks at Hanford, the technology is directly applicable to similar wastes at Savannah River Site, Idaho Falls and other DOE sites. It is equally applicable to characterizing TRU and/or moisture in any inaccessible or hostile environment as may be required by a host of Federal agencies. This technology is closely coordinated with an ongoing activity at Westinghouse Hanford Company to develop a small bore cone penetrometer for deployment in the Hanford tanks.

For more information, please contact:

Ronald L. Brodzinski

Pacific Northwest Laboratory

P.O. Box 999, MS P8-07

Richland, WA 99352

(509) 376-3529

Steven C. Slate

Technical Program Manager

(509) 375-3903

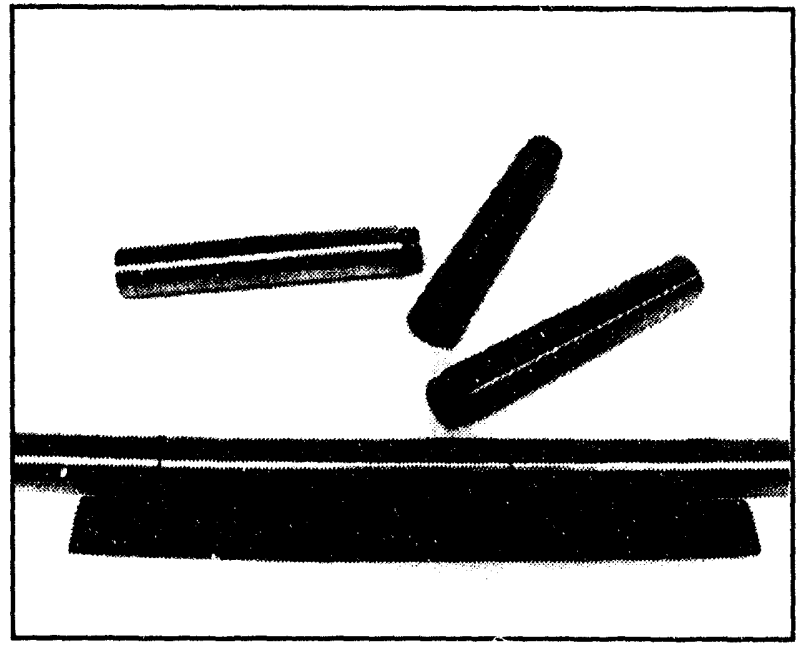

Figure 5.3a. Fabricated copper probes.

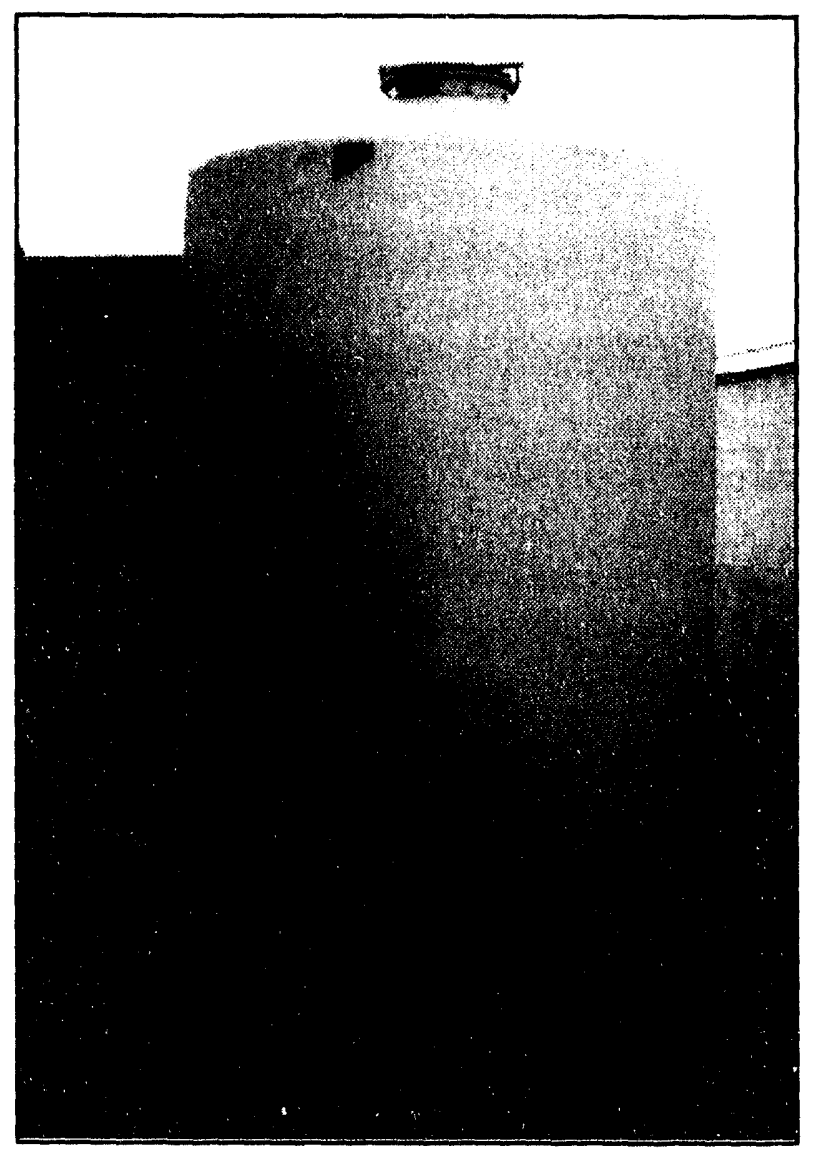

Figure 5.3b. Simulant containment vessel. 


\subsection{SENSING OF HEAD SPACE GASES: CONTINUOUS IN SITU MONITORING OF GASEOUS COMPONENTS IN UNDERGROUND STORAGE TANKS USING PIEZOELECTRIC THIN FILM RESONATOR SENSORS}

\section{TASK DESCRIPTION}

This task focuses on the development of semiconductor-device-sized, field-deployable gas sensors for use in the in situ monitoring of head space gases in underground storage tanks (USTs) and remediation sites. The gas sensor system will be comprised of arrays of cost effective, piezoelectric mass sensors and electronic readout instrumentation for the determination of the concentrations of several hazardous gases in the hostile environment of USTs (e.g., hydrogen, ammonia, nitrous oxide). Using integrated circuit technology and specially synthesized sensor surface coatings, small sensor systems capable of long-term, low-maintenance operation will be fabricated as manufacturable prototypes and field-tested to determine operational specifications.

The gas sensors will be developed from existing bulk acoustic-wave piezoelectric mass sensors that will be coated with materials that can selectively sorb the gases of interest. These highly sensitive mass sensors are thin film resonators (TFRs) consisting of thin piezoelectric aluminum nitride membranes in the shape of 400 micrometer squares that are supported by a silicon substrate (see Figure 5.4a). These sensors can detect surface mass loadings lower than 2 nanograms per square centimeter, which is much less than the loading for an adsorbed layer of a typical analyte. Coatings will be developed to withstand the harsh chemical and radiological environment of the USTs.

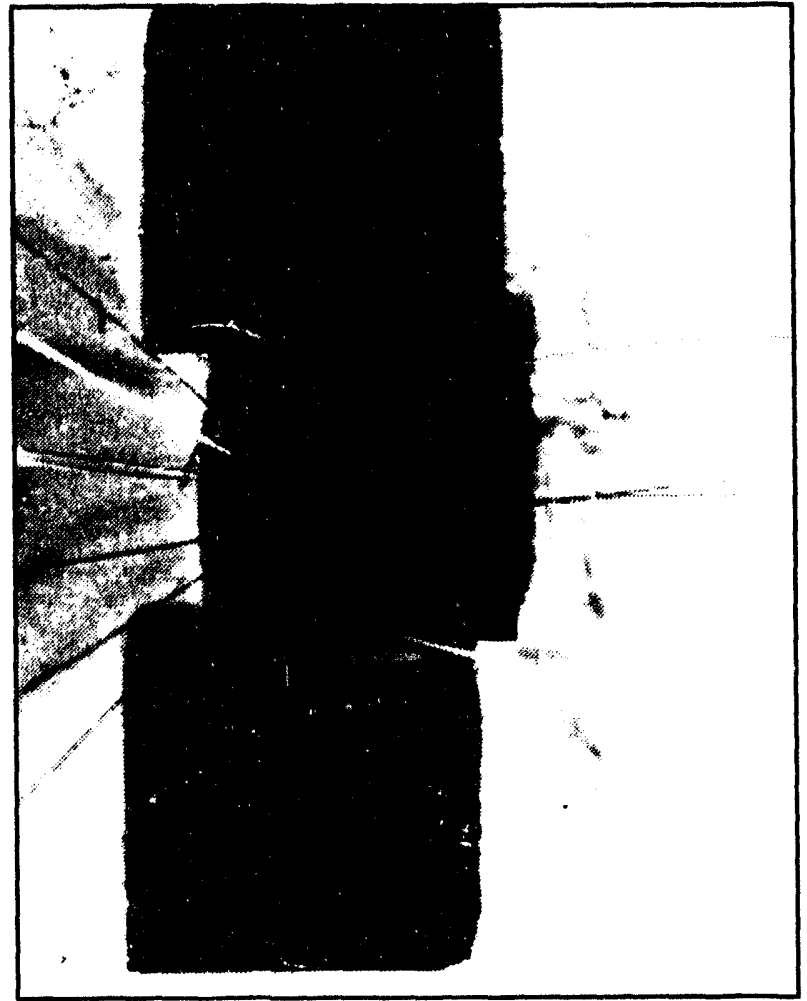

Figure 5.4a. T'wo thin film resonators and a custom integrated circuit epoxied to a chip carrier.

\section{TECHNOLOGY NEEDS}

The head spaces of USTs often contain explosive and toxic gases, such as hydrogen, nitrogen oxides, hydrocarbons, and ammonia. These gases are released from the viscous semi-solid tank content material to potentially provide locally high concentrations of the gases. Knowledge of water vapor content in head spaces is also useful to allow assessment of fire retardant potential. Thus, methods are needed to characterize the release and diffu- 
sion of gases within head spaces, and to monitor quantitatively the concentrations of these gases over extended periods of time at many tank sites, as well as at different locations within each tank. Any measurement devices placed inside the tank must not be a spark hazard and must be inherently safe in their operation. The monitoring need especially requires the development of cost effective, inherently safe, readily deployable gas sensors capable of long-term, unattended operation. Use of such devices at Hanford and Savannah River Site and other DOE sites would be especially helpful to field personnel from a safety and health perspective.

\section{ACCOMPLISHMENTS}

Work on this task was initiated in April 1993. The following summarizes the status of sensor coating development, integrated system design, and array implementation.

Initial prototype hydrogen sensors were created by depositing different palladium alloys and doped palladium coatings onto the surfaces of quartz crystal microbalances (QCMs) (Coatings are first tested on QCMs and then applied to TFRs). Responses proportional to the square root of the molar concentration of hydrogen can be obtained over two orders of magnitude with the concentration range dependent on the type of alloy or dopant combined in the palladium coating. An example is illustrated in Figure 5.4b. Thus, an array deployment using a selected subset of these coatings can be used to construct a sensor with

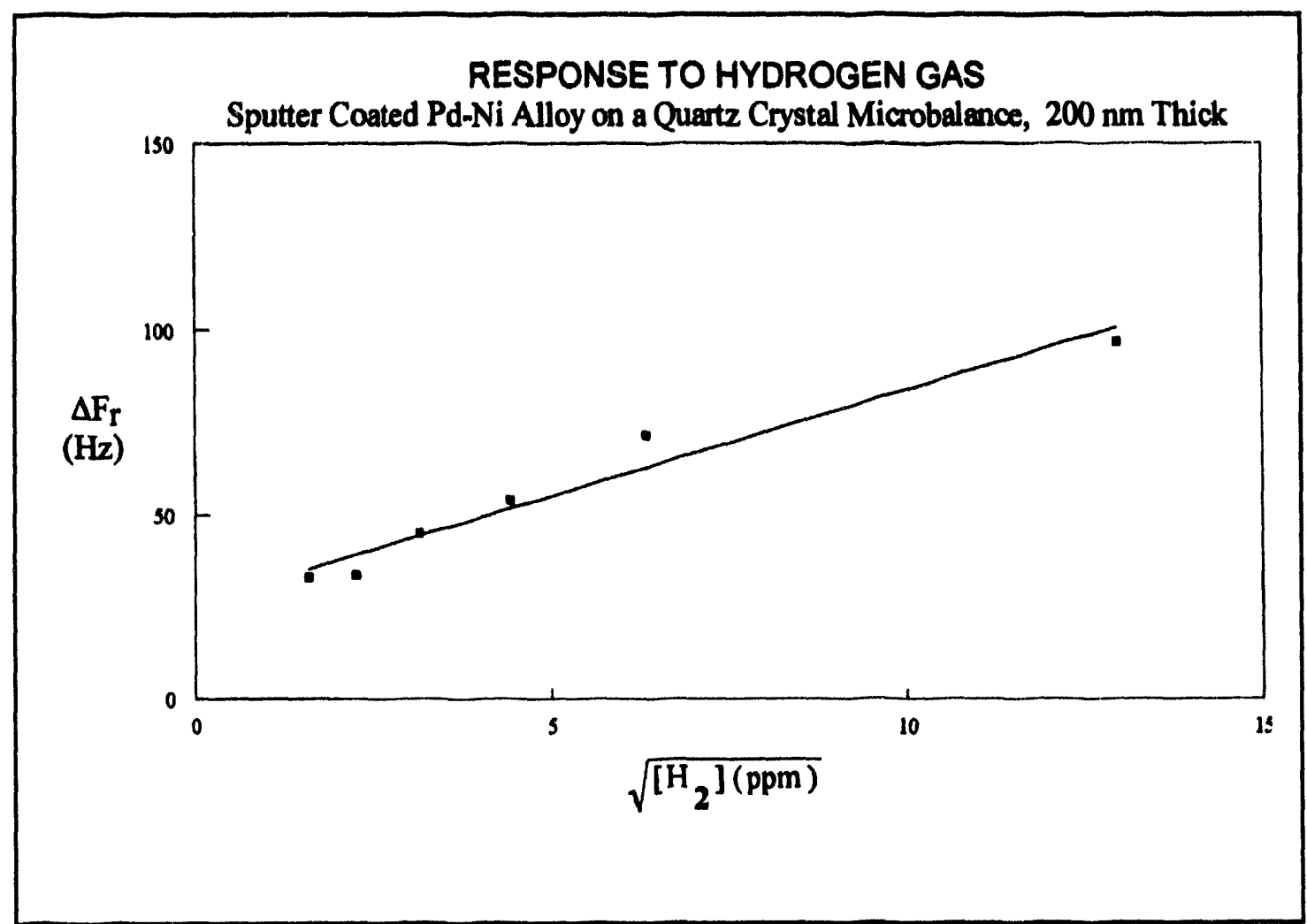

Figure 5.4b. Response of quartz crystal microbalances with a coating of nickel-palladium alloy as a function of hydrogen concentration. 
a large dynamic range. Testing of these sensors for possible interferences from other vapors found in USTs is underway.

A field deployable sensor system is under development. TFRs have been deployed as reference and indicator pairs with partial compensation of nonspecific effects, such as temperature, as indicated in Figure 5.4c. Electronic support circuitry has been successfully designed and implemented using two technologies: custom integrated circuits and discrete surface mount components. The design for a second generation custom integrated circuit to support operation of higher density arrays has been completed.

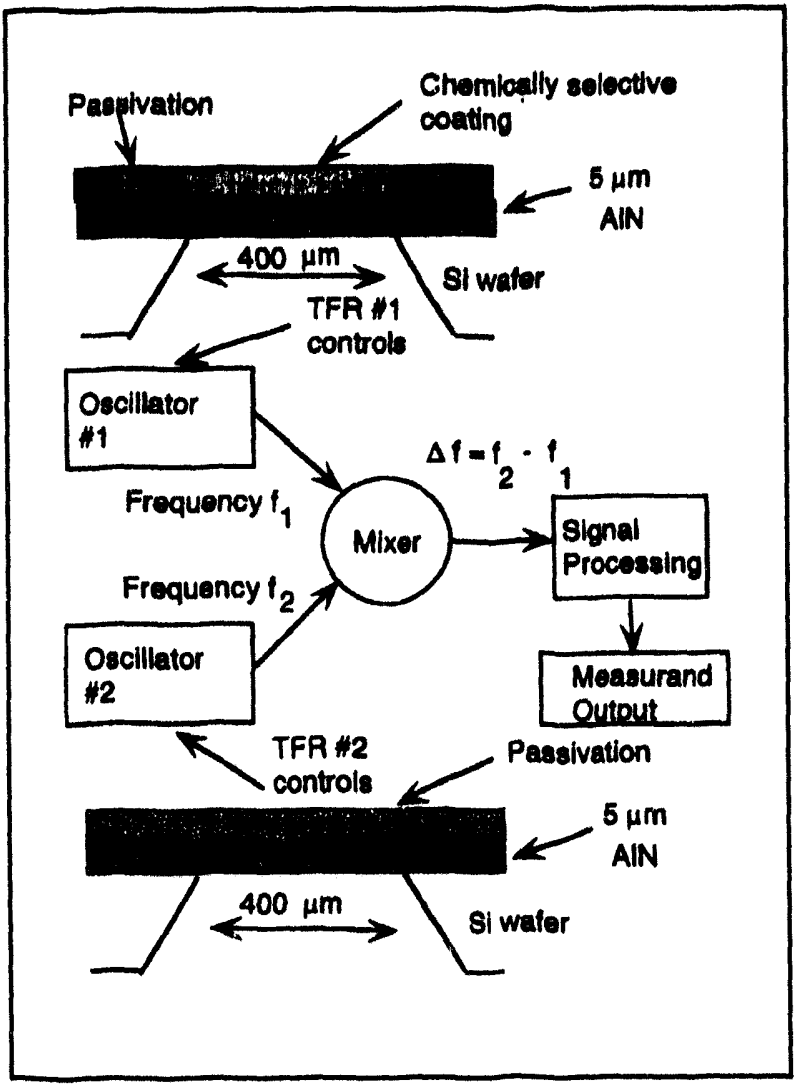

Figure 5.4c. Thin film resonators are used as the frequency control elements in oscillator

\section{COLLABORATION/TECHNOLOGY TRANSFER}

Upon completion, the field deployable gas sensor system will be useful for the characterization and long-term monitoring of hazardous and toxic gases within and near USTs. Many USTs exist at Hanford, and so preliminary discussions have taken place with Westinghouse Hanford Company and Richland Field Office personnel with respect to the gases and concentrations typically found in USTs, and with respect to making arrangements to field-test the sensor system. Field testing at this site will commence after satisfactory bench testing.

Commercialization of TFRs has been discussed with several corporations to find a partner for manufacturing and systems integration. An option for a license to patented TFR technology has been offered to one company for a portion of the environmental monitoring applications related to DOE needs. Discussions are continuing with other corporations for development of TFR sensors for commercial, as well as other DOE-related, areas.

\section{For further information, please contact:}

\section{Glenn Bastiaans}

Ames Laboratory

273 ASC II

Ames, IA 50011

(515) 294-3298

\section{James Corones}

Technical Program Manager

(515) 294-9636 


\subsection{RAMAN PROBE RADIATION STUDY}

\section{TASK DESCRIPTION}

The detection and identification of molecular and ionic species in the underground waste tanks at Hanford is required in order to provide information concerning the content of energetic compounds, including ferrocyanide, as well as compounds that will determine the success of pretreatment methods, such as organics and nitrates. There are very few options that allow such measurements to be made both in the hot cells and in the tanks. Raman spectroscopy can provide fingerprint identification of molecular and ionic species through detection of their unique vibrational spectra. This approach, using fiber-optic-based probes, has been selected as the technology most likely to succeed for these measurements. However, many uncertainties remain for application, especially for measurements made in the highly hostile environments of the waste tanks themselves. Included in these uncertainties are the effects of the high gamma radiation environment on the optical components of the remote Raman probe. This task will take prototype probes and examine changes in the quality of a Raman spectrum as a function of radiation dose. It will include real-time measurements in gamma fields in order to observe the effects of both short-lived and permanent darkening of the optical components on the signal quality of the Raman spectrum.

\section{TECHNOLOGY NEEDS}

The application of Raman spectroscopy to remote hostile environments will require a firm understanding of the expected lifetime and degradation of performance over the pe- riod during which the probe is in place. To that end, a method to monitor this performance in situ, with the probe in gamma radiation environments of known levels, must be developed. This will require standardized sources and controlled probe geometries. In addition, careful measurements of performance at different wavelengths will allow selection of the best laser source for the probes. These wavelength choices are visible, either at 514 or $488 \mathrm{~nm}$, and near-infrared, near $800 \mathrm{~nm}$. While radiation effects will be less pronounced in the near-infrared, source power and stability are better in the visible. However, such preference for a visible wavelength source may be supplanted by the loss of throughput associated with radiation darkening of optical components in this region. While the probe includes fiber-optics, the placement of other materials and optical elements in the radiation environments requires that total system performance be evaluated. Included in these other elements are filters, adhesives and index matching gels. Thus, the technclogy needs require total system performance evaluation.

\section{ACCOMPLISHMENTS}

To date, a portable Raman spectroscopy system has been constructed and coupled to fiberoptic probes provided by other investigators in the Raman spectroscopy project. Some filters were evaluated for performance in radiation fields before the integrated system was constructed, simply in order to gauge the anticipated degree of failure of the filter quality. This work is displayed in Figure 5.5. The exposure experiments are now being arranged with custodians of gamma sources at Los 
Alamos National Laboratory as well as at EG\&G in Las Vegas. The dose dependence of Raman signal will be measured by using a standard Raman scatterer, sodium nitrate, which is found both in solution and solid phases, in the Hanford tanks.

\section{COLLABORATION/TECHNOLOGY} TRANSFER

The transfer of the remote Raman probe technology will be pursued in other portions of the Raman development program. The measurements made as a function of irradiation will figure in the selection of possible industrial or government collaborators for this program.
For more information, please contact:

\section{Robert J. Donohoe}

Los Alamos National Laboratory

MS-C345

Los Alamos, NM 87545

(505) 665-6794

\section{Bruce Erdal}

Technical Program Manager

Los Alamos National Laboratory

(505) 667-5338

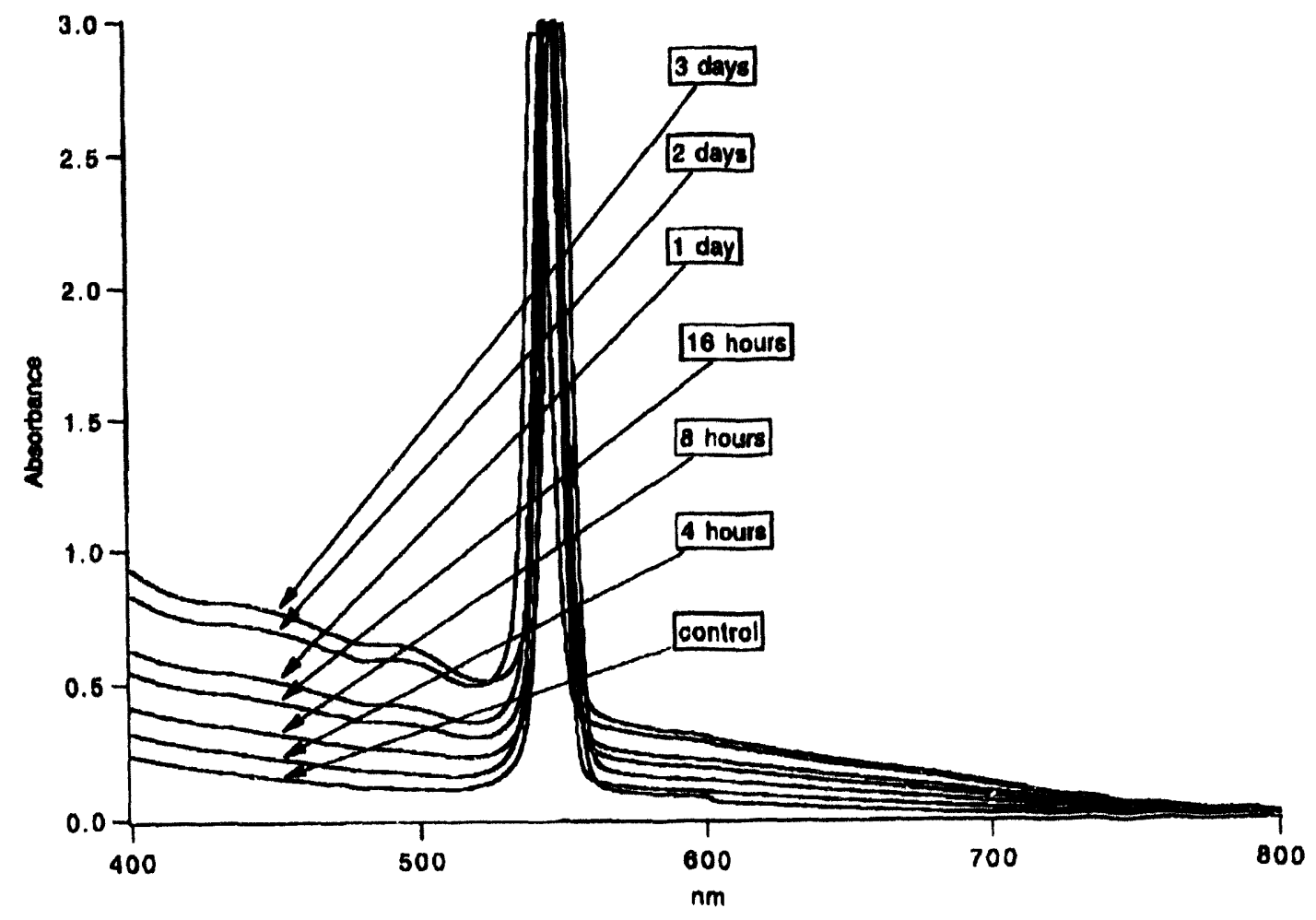

Figure 5.5. Absorption of holographic filters vs. exposure time at $435 \mathrm{Rad} / \mathrm{min}$. 


\section{INFRARED ANALYSIS OF WASTES: \\ NOVEL LAB AND ON-LINE MEASUREMENTS BY \\ PHOTOACOUSTIC AND TRANSIENT INFRARED \\ SPECTROSCOPIES}

\section{TASK DESCRIPTION}

This project consists of two different subtasks, which are developing technologies for separate environmental needs. One subtask is developing an analytical method for the sludges in large storage tanks at the Hanford Site. The other is producing a real-time processstream monitor for the polymer encapsulation of low-level rad waste salts. The Hanford waste-tank sludges are chemically active and physically heterogeneous, which makes them difficult to analyze by most methods, without extensive sample preparation. The project is developing laboratory methods using Fouriertransform infrared photoacoustic spectroscopy (FTIR-PAS) to quantitatively measure the molecular and multi-atom ionic components in these sludges. Methods have been worked out for the production of consistent samples and quantitative spectra. Calibration and component identification procedures are in preparation. The technology and need-specific methods will be transferred to Hanford personnel principally by training sessions held by project staff at Hanford, but also by providing guidance and advice whenever requested.

The second subtask is applying transient infrared spectroscopy (TIRS) as a real-time online monitor for the polymer encapsulation of low-level rad waste salt. Figure 5.6a shows how a TIRS unit will be applied to the waste processing operation. The TIRS monitor was originally developed for real-time analysis of process streams consisting of ambient temperature solid materials. It is being adapted in this project to the high temperature, viscous liquid process stream produced by the encapsulation process. The adapted monitor will be demonstrated in both cold and hot tests at both

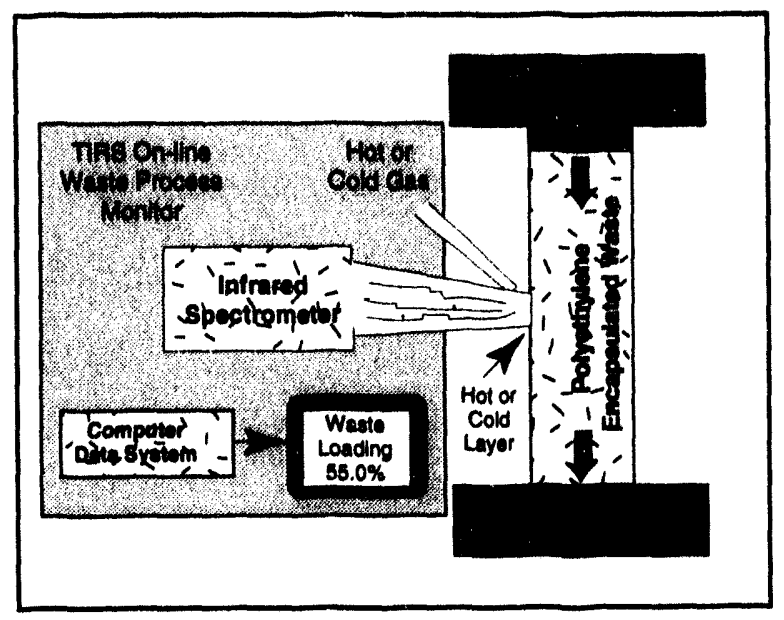

Figure 5.6a. Schematic of a transient infrared spectroscopy unit on the waste encapsulation line.

Rocky Flats Plant and Brookhaven National Laboratory with laboratory and pilot-scale waste processors.

\section{TECHNOLOGY NEEDS}

The waste-tank sludges and solids at Hanford present a uniquely challenging analytical problem. They are physically and chemically heterogeneous, chemically active, and radioactive. FTIR-PAS is exceptionally capable of handling such material. It can analyze milligram-sized samples with little or no sample handling. This increases efficiency, minimizes worker exposure, and reduces waste production. FTIR-PAS will provide a quanti- 
minimizes worker exposure, and reduces waste production. FTIR-PAS will provide a quantitative compositional analysis of the multiatomic ions and molecular species, which are the chemically active components in the sludges and solids. Brookhaven National Laboratory and Rocky Flats Plant are developing the polymer encapsulation process to immobilize radioactive salts and similar wastes for storage and disposal. TIRS appears to be the only technology available that can monitor

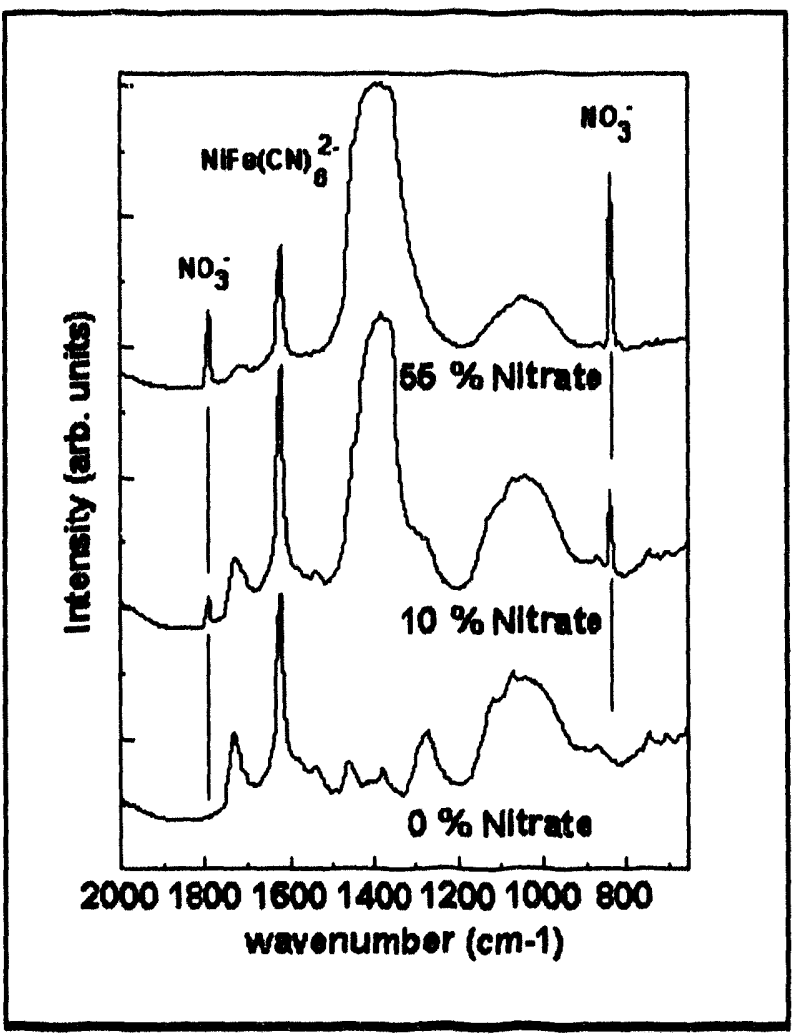

Figure 5.6b. Fourier-transform infrared photoacoustic spectroscopy spectra of three sludge surrogates containing differing amounts of nitrate.

the process stream in real time. It will provide data that will guide the waste process operators in their control of the encapsulation, certify the composition of the processed waste for regulators, and provide a record of the processed waste should questions or problems later arise.

\section{ACCOMPLISHMENTS}

FTIR-PAS is a widely used technique for analyzing normally intractable samples. A protocol has been worked out for acquiring reproducible spectra that can be reliably used for quantitative analysis. This includes freeze drying the material, which makes the water content reproducible and, more importantly, prevents migration of soluble components, which occurs during air drying. The migration problem had not previously been recognized by others working on tank material analysis. Figure 5.7b shows example spectra of sludges containing various known amounts of nitrate $\left[\mathrm{NO}_{3}^{-}\right]$. The sharp peaks at 1790 and $840 \mathrm{~cm}-$ ', as well as the broad feature at $1400 \mathrm{~cm}^{-1}$ and other small features are due to nitrate. The sharp peaks can be used to determine the amount of nitrate in a sample as exemplified by Figure 5.6c. It shows a typical correlation between peak sizes and the amount of nitrate

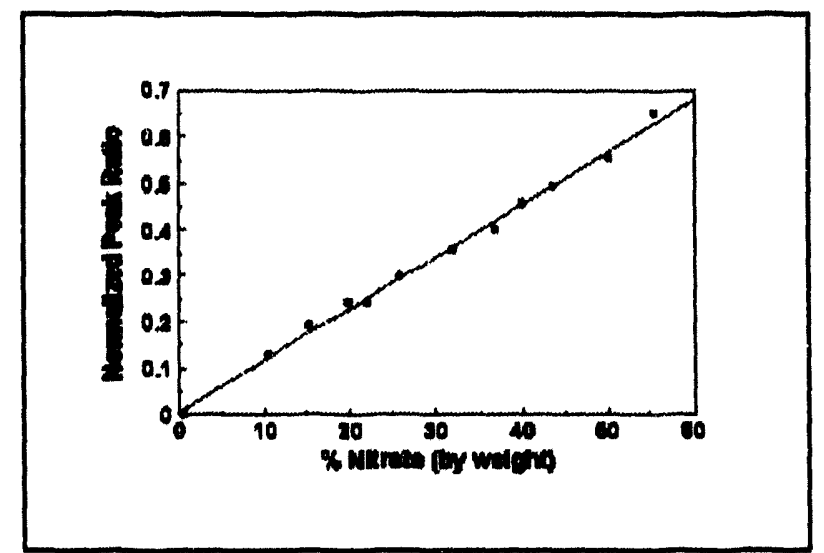

Figure 5.6c. Typical correlation between nitrate peak heights observed by Fourier-transform infrared photoacoustic spectroscopy and the actual nitrate concentration in the sample. 
present. Similar features exist for other important components, such as the sharp 1640 $\mathrm{cm}^{-1}$ peak for nickel ferrocyanide $\left[\mathrm{NiFe}(\mathrm{CN})_{6}{ }^{2-}\right]$ visible in Figure 5.7b. The first training session for transferring the technology to Hanford is scheduled for March.

The approach for using TIRS as a monitor for a molten polyethylene/salt stream has been developed. Figure 5.6d shows the excellent correlation between TIRS data and stream composition. Optimization for specific processing-line conditions is underway. A proofof-principle test has already been carried out at Brookhaven. The TIRS unit will be demonstrated as part of the pilot-scale test of polymer encapsulation planned for later this year at Erookhaven. At the request of Rocky Flats staff, both cold and hot demonstrations of TIRS on the laboratory scale are planned for that location beginning in April.

Y' gure 5.6d. Correlation between the actual nitrate content of a molten polyethylene/sodium nitrate process stream and the content predicted from transient infrared spectroscopy spectra.

\section{COLLABORATION/TECHNOLOGY TRANSFER}

Training sessions at Hanford are planned explicitly to transfer the technology to that site. Ames Laboratory has been collaborating with Hanford Site on relevant matters, such as e juipment specifications. The photoacoustic detectors used in FTIR-PAS have been commercialized by MTEC Photoacoustics, Inc.. MTEC is the principal producer of photoacoustic detectors worldwide. An MTEC detector was selected for an IR 100 Award in 1985. The project staff has extensive experience assisting end users in applying photoacoustic technology.
The application of TIRS as a waste-process monitor is closely tied to the development of polymer encapsulation occurring at other sites, as shown by the demonstrations discussed in the Accomplishments section. TIRS has also been successfully demonstrated as an on-line process monitor on the pilot and production lines of several manufacturers. It has been demonstrated in the laboratory for a wide range of solid and viscous liquid process stream properties, including chemical composition, cure level of paints and thermoset plastics, and oxidation level and mineral content of coal. The project principal investigators invented TIRS. Iowa State University has patented it, and it is available for licensing. TIRS received a 1992 R\&D 100 Award.

\section{For more information, please contact:}

\section{John McClelland}

Principal Investigator

Ames Laboratory

B27 Spedding Hall

Iowa State University

Ames, IA 50011-3020

(515) 294-7948

\section{James Corones}

Technical Program Manager

Ames Laboratory

329 Wilhelm Hall

Iowa State University

Ames, IA 50011-3020

(515) 294-7948 


\subsection{LASER ABLATION MASS SPECTROMETRY SCANNING OF WASTE TANK CORE SAMPLES}

\section{TASK DESCRIPTION}

The Laser-Ablation/Mass-Spectrometry (LA/ MS) method is being developed at Pacific Northwest Laboratories for analysis of waste tank core samples as part of a larger, jointly funded EM-50/EM-30 program to accelerate the characterization of the Hanford waste storage tanks, the Mobile Analysis Reconnaissance System (MARS) Program. The LA/MS method (see Figure 5.7a) relies upon three key steps:

- the ablation of solid material to form small particles;

- the entrainment of these particles in a carrier gas and their transport via a small tube to a low radiation area; and

- the chemical analysis of these particles by mass spectrometry.

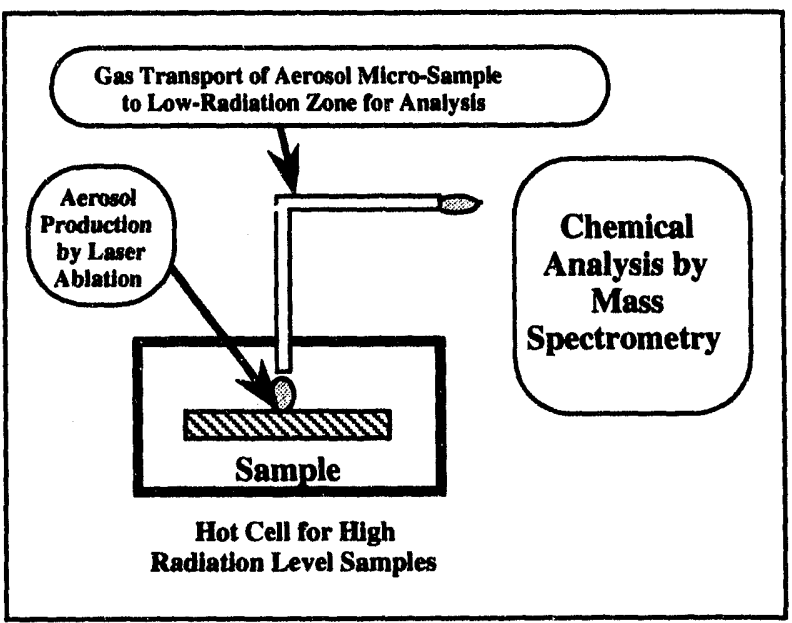

Figure 5.7a. Laser-ablation/mass spectrometry sampling analysis.
The challenge is to optimize this method to analyze for the chemical species present in the waste material; another MARS program team is working on elemental analysis. The ablated material is transported as small aerosol particles. Hence, the objectives are to optimize the production of representative aerosol particles and the chemical speciation analysis of these aerosol particles. Another element of the program is data analysis (of both the elemental and chemical speciation data) via chemometric methods to enhance LA/MS as a screening tool itself and when used in conjunction with other methods, such as Raman and infrared spectroscopies.

\section{TECHNOLOGY NEEDS}

Current chemical analysis of Hanford waste tank core samples relies heavily on traditional wet chemistry techniques. These techniques are very time consuming (up to six months for analysis and report) and expensive (often in excess of $\$ 500 \mathrm{~K}$ per core) and generate additional amounts of unwanted, mixed wastes. Hot cell chemical analysis process throughput is currently a major time/cost factor in meeting: 1) the schedule for characterization of Hanford tanks required for near-term tank safety assessment needs, and 2) the longer term waste processing needs.

The minimum criteria for success of the MARS program will be the reliable detection of a sufficient range of elements and compounds to guide the more detailed analysis of specific 
segments of core samples, dramatically increasing the throughput and reducing the costs (see Figure 5.7b).

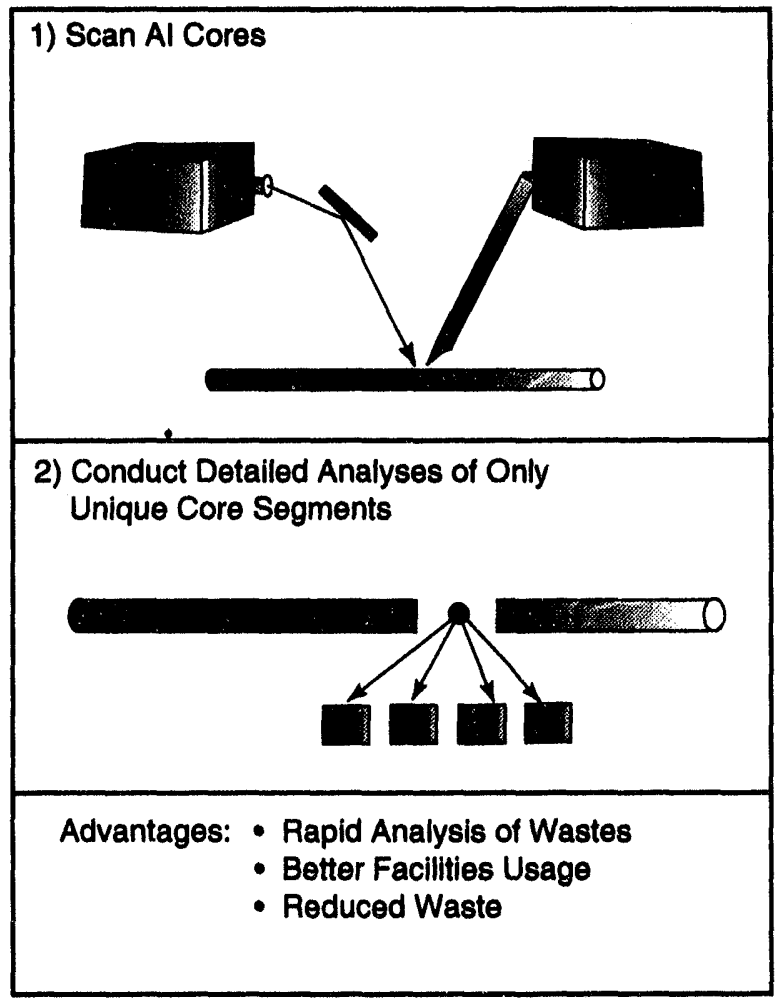

Figure $5.7 \mathrm{~b}$. Waste tank core scanning.

The optimal success will be finding that traditional analyses for certain species can be eliminated by this direct analysis technique, perhaps in combination with simultaneous application of other methods such Raman, infrared, or laser-induced emission scanning.

\section{ACCOMPLISHMENTS}

An existing LA/MS instrument at Pacific Northwest Laboratory (PNL) has been modified for use in selecting the best parameters for the production of aerosol particles. Of particular interest are: 1) the effects of cover gases on the ablation process, and 2) the most appropriate wavelengths and laser powers for use with the type of waste materials at the Hanford site. Key analytes (e.g. nitrates, cyanide complex ions, and organics) have been successfully detected in waste tank stimulants and the methods for their analyses are being refined.

A meeting of a working group on aerosol analysis methods was held at PNL on December 3-4, 1993. The general findings and recommendations of the working group were:

- chemical speciation analysis of aerosol particles is a very challenging task with high potential benefits going well beyond the scope of the Hanford waste tank characterization program;

- numerous potential methods of analysis should be evaluated in parallel through experiments at PNL and by having stimulants analyzed at industrial and other laboratories; and

- both on-line, direct aerosol analysis and off-line, captured aerosol analysis methods should be considered.

Several simulant samples have been sent to industrial and other laboratories for comparative analyses (with SIMS and other methods). These results are being compared to laser ablation and ion bombardment measurements being conducted to select the best technique for chemical speciation analysis of aerosol particles produced from waste tank stimulants.

LA/MS spectra produced by three waste glass samples of different compositions ware analyzed using a statistical cluster analysis technique (k-means clustering) and by principal components analysis (PCA). The objective of this effort was to determine the reproducibility of the technique and its potential usefulness for sample classification. It was found that the LA/MS spectra were consistent enough 
that data modelling techniques correctly grouped numerous replicate analyses of cach sample according to glass type. Thus, it appears that classification of wastes by LA/MS in conjunction with similar statistical techniques is also feasible.

\section{COLLABORATION/TECHNOLOGY TRANSFER}

The MARS program is managed under the guidance of the Richland DOE Field Office in collaboration with the primary contractors at the Hanford site. As such, it is focused on specific Hanford site needs; to provide working instruments directly to the tank characterization team at Hanford. The requirement for rapid development in the face of complex technical challenges has also led to collaboration with technical programs at other laboratories (i.e. INEL, NOAA, and NIST) and industry (e.g. Charles Evans and Perkin-Elmer) and universities (i.e. University of Washington and University of Delaware). This process will continue to evolve as the project comes closer to fruition. As a result, industrial partners have the opportunity to shape the development of the technology in ways that will optimize the likelihood that commercial instruments will make significant contributions to the final instrument packages.

\section{For more information, please contact:}

\author{
Steven D. Colson
}

Pacific Northwest Laboratory

P.O. Box 999, MS K2-14

Richland, WA 99352

(509) 375-6882

Steven C. Slate

Pacific Northwest Laboratory

(509) 375-3903 


\subsection{IMAGING THROUGH OBSCURATIONS DURING SLUICING OPERATIONS}

\section{TASK DESCRIPTION}

The purpose of this project is to evaluate candidate methods for viewing through obscurations, such as fog and water droplets, that can occur during waste tank remediation efforts. Candidate methods will be evaluated for their applicability for use during waste tank remediation efforts. A test chamber will be fabricated in which the size and salt concentration of the fog/water droplets can be varied in order to test several candidate methods for imaging through an environment that could occur during a sluicing operation. The results of this task will provide a basis for specifying and developing a system to meet the imaging needs of waste remediators.

\section{TECHNOLOGY NEEDS}

Waste remediators have identified that surveillance of waste remediation operations and periodic inspections of stored waste are required under very demanding and difficult viewing environments. In many cases, obscurations, such as dust or water vapor, are generated as part of the remediation activity and methods for viewing or imaging beyond the normal visual spectrum are needed. Workspace images guide the movement of remediation equipment, creating a need for rapidly updated, near real-time imaging capability. At present, because of the closed environment in which the remediation effort is conducted, a substantial amount of time is needed to clear the atmosphere, so that the effect of the remediation effort can be determined. During this time, labor costs continue

and equipment is being exposed to the hazardous environment. In addition, the safety of the operation could be jeopardized because of the lack of viewing the remediation operation in near real-time.

\section{ACCOMPLISHMENTS}

Potential methods for viewing through obscurations have been reviewed. Some of these methods include conventional video imaging with special lighting schemes, infrared sensors, acoustic sensors, laser rangefinding, and millimeter wave imaging. A test fixture has been fabricated (see Figure 5.8a) and testing has started. The test fixture has a three feet inside diameter and can be assembled to be up to 70 feet long. Interchangeable nozzles are used to obtain different droplet sizes. The test fixture is a closed-loop system in which the water will be recycled through the system. Hence, the conductivity of the water can be controlled to simulate suspended salt particles that will occur during a sluicing operation. Results similar to that shown in Figure 5.8b for several optical techniques have been observed.

Testing will continue over the next few months using different water droplet sizes, salt concentration of the water droplets, and acoustic and millimeter wave techniques. A final report will be written describing the test results and analysis. 


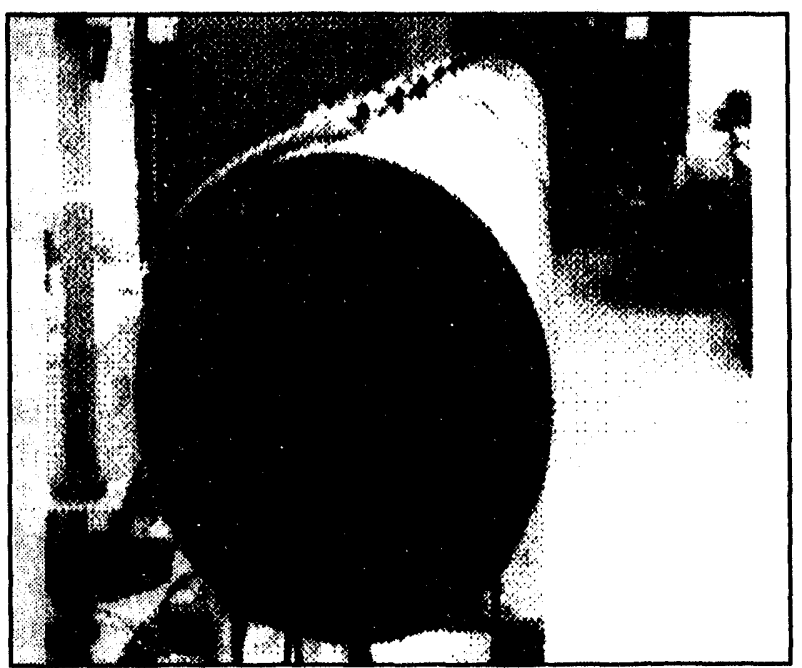

Figure 5.8a. Test Chamber. Three Feet Inside Diameter, Up to 70-Feet Long; Interchangeable Nozzles Produce Water Droplets from 25 - 1300 Microns in Diameter; and Open Ends for Easy Instrumentation Access.

\section{TECHNOLOGYTRANSFER}

The results of this study will be applicable to many waste remediation efforts. There is not very much information published about imaging through dense salty fog/water droplets for short distances (less than 75 feet). Most of the

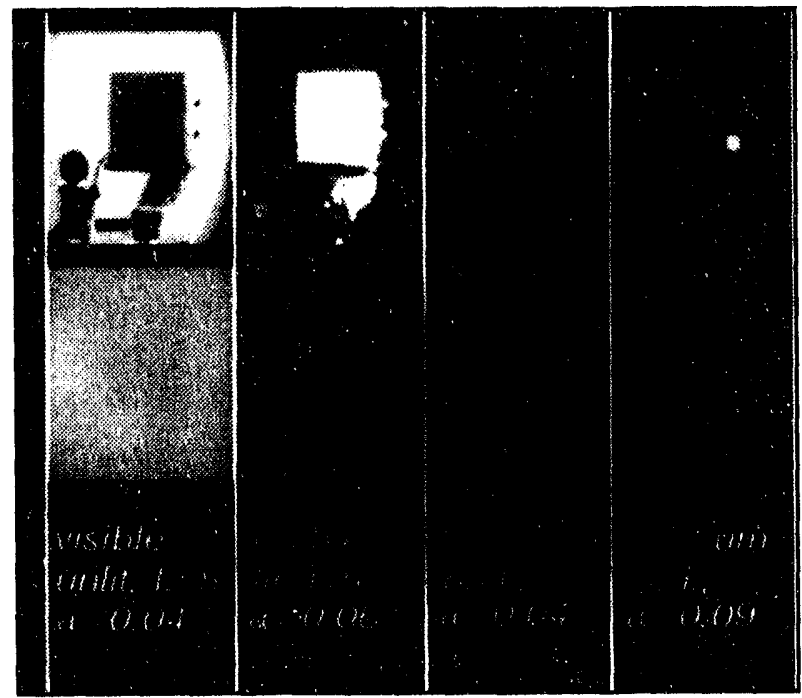

Figure 5.8b. Optical System Tests. Eighty-Foot Range; Top Images are with No Fog in the Test Chamber; Bottom Images are with 25 Micron Fog Particles in the Test Chamber; $a=$ Absorption ( $\mathrm{ft}-1$ ); Target Emissivity $=0.75$; Target Size: $7.5 \times 7.5$ inches. work of imaging through fog/water droplets has been for military applications in which the visibility and the range of viewing are defined using miles (or fractions thereof) as the unit of measurement. The waste tank work being conducted at the Hanford site will be used as a model for the requirements for a viewing system. Assuming promising results, the best performing method(s) would be developed for the specific applications and would be demonstrated and its function fully characterized for use by waste remediators.

\section{For more information, please contact:}

\section{Timothy Peters}

Pacific Northwest Laboratory

P. O. Box 999 MS K5-25

Richland, WA 99352

509-375-2101 


\section{TASK DESCRIPTION}

The overall objective of this work is to develop means for the rapid identification of unknown organic chemical releases to the occupational and ambient environment. The proposed work seeks to establish approaches, methodology, hardware, facilities, and expertise necessary to address such problems in a timely fashion, and to characterize unknown releases where required. Specific tasks in FY94 involve the development and validation of a split vent sample archival system for nonion trap based analytical technologies, consultation to other DOE sites, and the analysis and identification of constituents of samples acquired from unusual events.

\section{TECHNOLOGY NEEDS}

Throughout the DOE weapons complex and national laboratory system, there have been situations where unknown species have been encountered, and/or fugitive airborne releases of materials have occurred. Many times, the identity of these species have been difficult or impossible to confirm in a timely fashion. In some cases, these situations have resulted in undesirable occupational exposures. Examples include air releases in the vicinity of the Hanford underground storage tanks, off-gassing of noxious vapors from storage tanks associated with incinerators (e.g. Toxic Substances Control Act incinerator at the Oak Ridge K-25 site), particulates and vapors released from elevated temperature chemical processing operations, and terrestrial releases to the air of contaminant vapors during low pressure me- teorological conditions. Such leaks or releases have considerable impacts on facility operations. They raise health and safety questions, and may cause occupational exposures and negative public perception concerning DOE operations. Often, it is necessary to institute extremely conservative administrative or process control measures until the nature of the contamination is well understood. Such can sometimes result in suspensions of operations for weeks or months, until characterization studies have been completed. The development of a rapid characterization capability could serve to reduce the time required to identify unknowns and return to normal operations.

\section{ACCOMPLISHMENTS}

During FY93, efforts were directed toward the evaluation and validation of vapor sampling methodology employing sorbent media, in order to enhance the confidence by which a wide range of volatile and semi-volatile organic species could be collected and held for identification. The focus was on the collection and quantification of VOCs frequently encountered at DOE sites; including tri-and tetrachloroethylene, carbon tetrachloride, chloroform, benzene, and toluene. Studies designed to evaluate the degree of quantitative removal of target species from sorbent traps have indicated that temperature/gas flow profiles through the traps during desorption are more critical than previously anticipated. Also, scoping studies have suggested that the use of methanol as a carrier for calibration spiking solutions, the most commonly em- 
ployed approach, may radically alter retention characteristics of the media, and obfuscate and confound the interpretation of the data. A calibration and analysis method for the solid sorbent sampling and analysis of DOE-related VOCs in air has been developed and validated. The method is based on EPA methodology, but was validated for a much more versatile sampling trap. Use of profile libraries generated previously facilitated the identification of a class of alkyl nitrites present in the exhaust gas from one of the Hanford underground storage tanks, and the identity of a fuel spill at the X*10 site on the Oak Ridge Reservation. In addition, expedited characterization methodology was used to identify artifactual contamination at a radio frequency heating demonstration conducted at the Savannah River Site (see Figure 5.9).
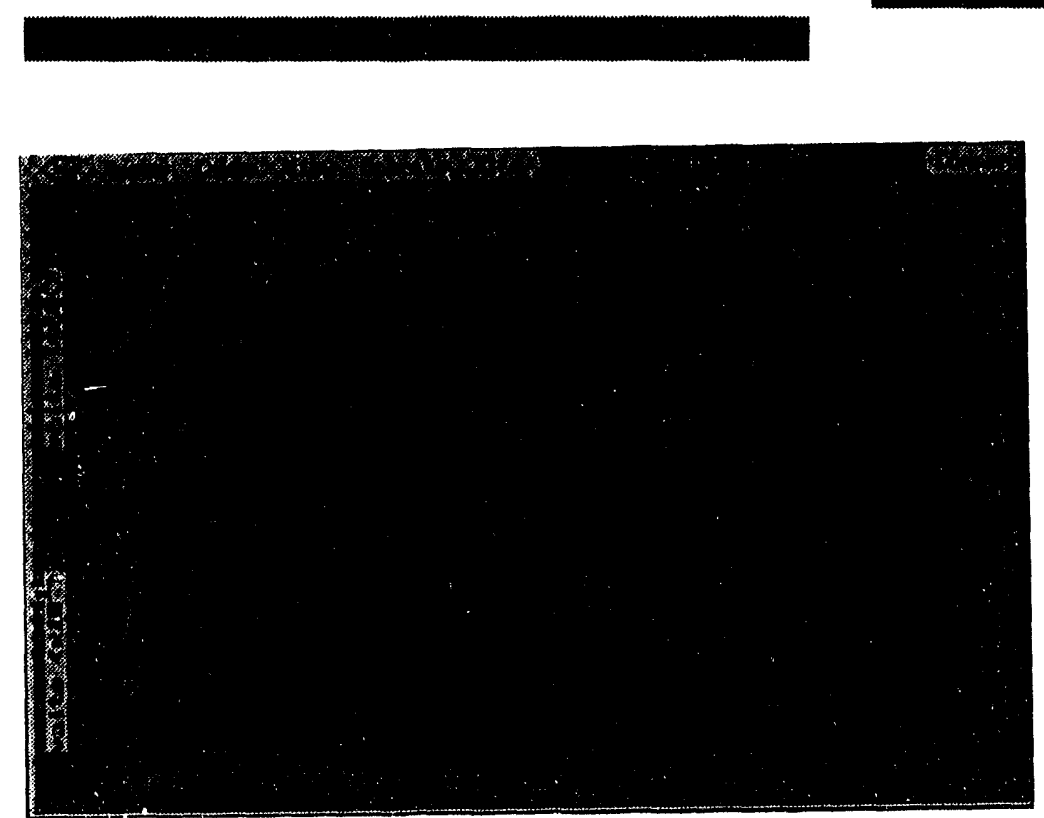

Figure 5.9. Comparison of chromatograms of extract of unknown fuel spill on Oak Ridge Reservation soil with standard diesel fuel, confirming that the unknown soil is actually diesel fuel from a ruptured storage drum.

\section{COLLABORATION/TECHNOLOGY TRANSFER}

Sampling and analysis technology is transferred to other DOE facilities. Those with which ORNL is in close collaboration are the Savannah River and Hanford Sites. Those sampling and analytical methodologies that are experimentally validated, and that appear potentially useful to other DOE sites are submitted for inclusion in the DOE Analytical Methods Compendium, the development of which is being sponsored by the Laboratory Management Division of the Office of Technology Development. In those cases in which the supported work results in particularly interesting or unique findings, such is reported in the open iiterature.

\section{For more information, please contact:}

Roger A. Jenkins

Oak Ridge National Laboratory

P.O. Box 2008

Bldg. 4500S

MS 6120

Oak Ridge, TN 37831-6120

(615) 576-8594

Anthony. P. Malinauskas

Technical Program Manager

(615) 576-1092 


\section{Characterization, Treatment, and Disposal of Mixed Waste}

\section{Section 6.0}




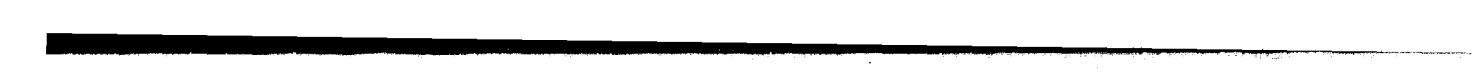




\subsection{CONTINUOUS EMISSION MONITOR FOR INCINERATORS}

\section{TASK DESCRIPTION}

This project addresses the need mandated by the Clean Air Act of 1990 to monitor air toxins. The objective is to develop a FTIR spectrometer combined with a heated longpath cell as a continuous emission monitor. The instrumentation will continuously monitor organic and selected inorganic stack emissions. The technology is applicable to incinerators, thermal treatment processes, and ambient air monitoring.

The primary benefit of an on-stream monitor for incinerator effluent is the near real-time determination of incinerator performance. Onstream analysis of the incinerator effluent would satisfy the requirements of the Clean Air Act of 1990 and address public concern about incinerator safety. Other benefits include elimination of the need for a trial burn and the expensive monitoring techniques currently used to characterize the effluent, such as VOST and MM5 sampling trains followed by GC/MS laboratory analysis. These methods are required under current procedures and provide a onetime analysis. Using these methods, monitoring is done only once every 18 months.

In the first year of this project, a laboratory incinerator and an FTIR spectrometer were assembled and tested. The lab incinerator was necessary so that closely controlled and reproducible incinerator conditions can be used to test the precision of the method. FTIR technology was advanced in four areas:

- testing cell materials for stability to hydrogen chloride;

- characterization of flue gas products of incomplete combustion;

- interpretation and evaluation of data quality; and

- development of automated analysis software.

In the second year, a field instrument was constructed and tested at the Toxic Substances Control Act (TSCA) incinerator at K-25 in Oak Ridge, Tennessee. Figure 6.1 a shows the field test site. Supporting data analysis and testing were performed using the laboratory incinerator. Data analysis was initiated and advanced algorithms were tested.

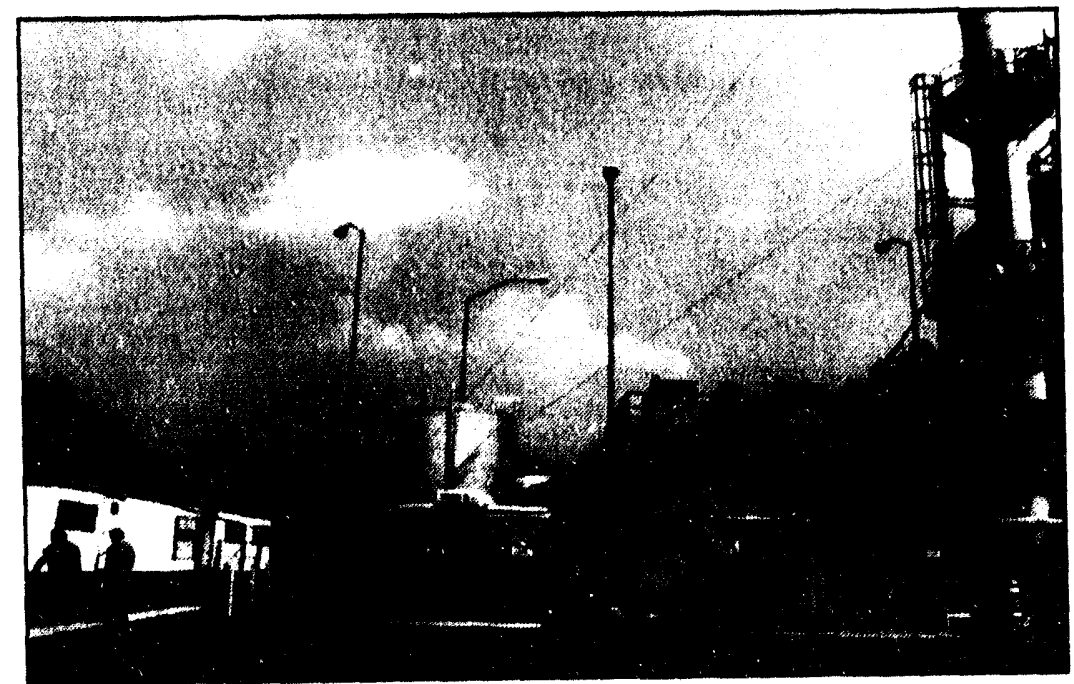

Figure 6.1a. The Toxic Substances Control Act Incinerator at K-25, Oak Ridge, Tennessee. 
The EPA has issued a protocol for an FTIR continuous emission monitor. This protocol was adapted into a standard operating procedure that was tested at $\mathrm{K}-25$. The objective is to meet all performance specifications required by the EPA so that the data will be considered compliant.

New data analysis methods are being developed to improve identification and detection levels. Multiple coprocessing of a single spectrum has improved quantitation by reducing noise. Time domain data analysis will also be initiated in combination with spectral analysis. This combined approach will enhance the ability to detect substances that have overlapping absorbances and allow for digital filtering of system noise.

During this year, the commercial instrument will be constructed and tested. A data package will be presented to the EPA as the first step for acceptance of this method. Advanced data analysis algorithms will be pursued and a combined time and spectral domain data analysis method will be field tested at K-25. Copies of the first field test report will be available upon request. An example of the ability of the FTIR monitor to detect emissions is shown in Figure 6.1b, where methane was detected in a single sample. The spectrum illustrated at the top is that of stack gas containing no methane. The middle spectrum shows the presence of methane in the stack sample. The library spectrum of methane is shown in the bottom spectrum.

\section{TECHNOLOGY NEEDS}

Title 3 of the Clean Air Act requires monitoring of air toxins from incinerators, stacks and fugitive emissions. This technology is applicable for these requirements and will result in EPA acceptance for FTIR monitoring data.
The method can be extended to cover thermal treatment, stack, and ambient air monitoring. Continuous monitoring will directly address issues of environmental safety, and the technology can be used to identify and quantify organic chemicals in the air. There is significant public concern about incineration. A continuous emission monitor addresses those concerns.

\section{ACCOMPLISHMENTS}

A laboratory incinerator has been constructed and integrated with an FTIR system. The operating conditions can be deliberately and reproducibly changed to simulate off-set conditions of an incinerator. Data obtained with this incinerator was used in the design of the prototype instrument. After laboratory testing was completed, the prototype instrument was field tested at the K-25 mixed waste (TSCA) incinerator at Oak Ridge. The initial testing was undertaken to ensure the technique will be EPA-compliant and follows the requirements of the EPA Protocol. EPA Performance Specifications Testing is in progress.

There have been significant advances in instrument design. The optics have been redesigned so the instrument can be moved easily and set up without disturbing optical alignment. The commercial instrument will consist of three modules that can be snapped together.

Data analysis will be much more sophisticated than found in conventional instruments. Data will be analyzed in both the time and spectral domains. Extensive use of coprocessors will provide rapid results and dramatically reduce the problem of spectral interferences. Digital filtering of the data will enhance detection levels. 


\section{COLLABORATION/TECHNOLOGY}

\section{TRANSFER}

A CRADA is currently under development with Clean Air Engineering (CAE) to advance the commercialization of the system. CAE will assist in testing the instrumentation and in developing stack sampling technology that is appropriate for this new technology.

For more information, please

\section{contact:}

\section{Jack Demirgian}

Argonne National Laboratory

9700 South Cass Ave

Argonne, Il 60439-4835

(708) 252-7335

\section{James Helt}

Technical Program Manager

Argonne National Laboratory

(708) 252-7335

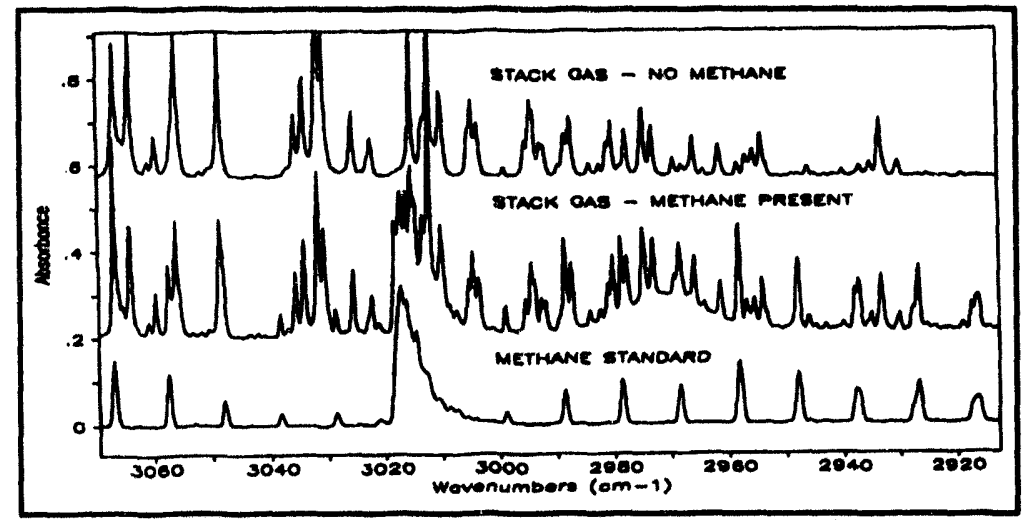

Figure 6.1b. Comparison of stack gas samples with and without methane present. 


\subsection{ASSOCIATED PARTICLE IMAGING}

\section{TASK DESCRIPTION}

The Associated Particle Imaging (API) system is an active, non-intrusive, single-sided, fast-neutron based system that will examine the interiors of sealed containers, display the locations, shapes, and sizes of their contents in three-dimensional image format, and identify their elemental compositions.

The general principles on which the API method is based are illustrated in Figure 6.1a. A sealed tube neutron generator (not shown in the figure) produces $14 \mathrm{MeV}$ neutrons and alpha particles via the collision of deuterium and tritium nuclei. The neutron/alpha pairs leave the collision site in opposite $\left(180^{\circ}\right) \mathrm{di}$ rections, as shown in the figure. The alpha particle hits a two dimensional position sensitive detector and starts the clock (labeled TAC). At the same time, the neutron heads off toward the region to be interrogated. If the neutron interacts with target material in the interrogation region, and if a gamma ray is produced and subsequently detected within a preset period of time, then the clock is stopped. Location of the alpha particle collision on the two dimensional detector gives the neutron direction of flight. The elapsed time between clock start and stop is proportional to the distance the neutron travelled before hitiing the target. These pieces of information ultimately give the $x, y, z$ location of the neutron-target interaction. Furthermore, the energy of the gamma ray is characteristic of the material that was hit. Thus the gamma spectrum allows one to identify the elemental composition of the material in the target region as a function of position.

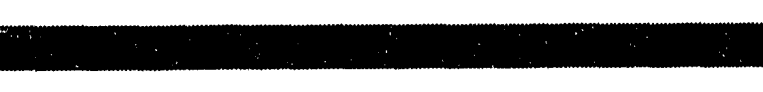

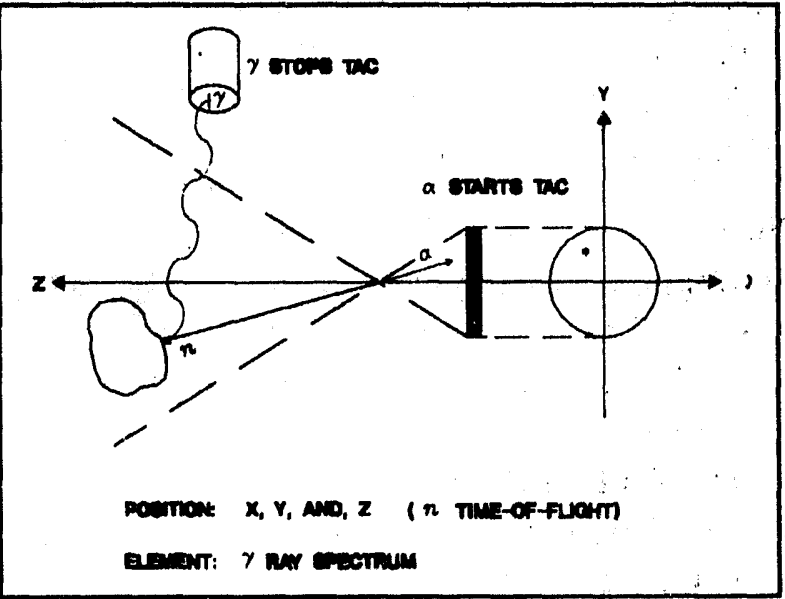

Figure 6.2a. Associated Particle Imaging schematic.

\section{ACCOMPLISHMENTS}

An example of API 3-D imaging capabilities is shown in Figure $6.2 \mathrm{~b}$. Although color information is missing due to the constraint of a black and white text format, the data images normally appear in colors corresponding to those selected for their gamma ray energies in

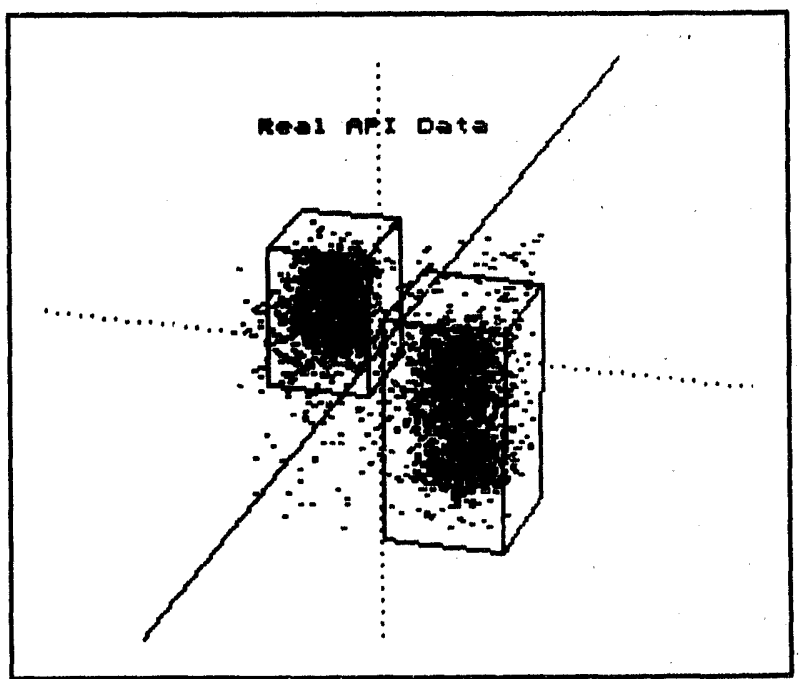

Figure 6.2b. Three-dimensional images of salt and water from real associate particle imaging data. 
the associated gamma ray spectra. In the figure, the accumulation to the left was produced by the $\mathrm{Na}$ and $\mathrm{Cl}$ gamma rays from a container of salt and is normally mostly green, while the accumulation to the right was produced by the $\mathrm{O}_{2}$ gamma rays from a container of water and is mostly blue. The boxes around the data aggregates were drawn by the user.

The real power of API lies in its ability to gain simultaneous elemental and positional information. This is illustrated in Table 6.2. The two left columns list the elemental information pertinent to salt $(\mathrm{Cl})$ and water $(\mathrm{O})$. The next two columns give information about each of these elements if the salt and water are measured together. However, if one is able to separate the salt from the water, as done in the boxes of Figure $6.1 \mathrm{~b}$, one can significantly reduce the signal to noise ratio. This is evidence by a comparison of the third and fifth columns of the table. In terms of NDE measurements, this means that the confidence level is many times improved over what it would be without the ability to spatially isolate the data. aggregates.

\begin{tabular}{|c|c|c|c|c|c|}
\hline \multirow{2}{*}{$\operatorname{ming}_{\operatorname{mon}}$} & \multirow{2}{*}{ anmers } & \multicolumn{2}{|c|}{ monorr eanu car } & \multicolumn{2}{|c|}{ 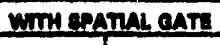 } \\
\hline & & & 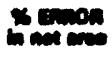 & nem & 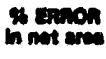 \\
\hline 1.72 & a & .11 & $17 \%$ & 43 & e.3n \\
\hline 211 & 9 & .12 & 104 & 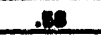 & E.1\% \\
\hline 25 & 0 & .80 & ext & 1.3 & $0.0 \%$ \\
\hline C.13 & 0 & .4 & $48 \%$ & .20 & $10 x$ \\
\hline
\end{tabular}

Table 6.2. Data showing how spatial gating improves signal to noise ratios.

The degree to which Monte Carlo calculations can be used to model API imaging is shown in Figure 6.2c, where the MCNP program has been used to simulate the same salt and water images as the real ones shown in Figure 6.2b. Computer simulation will aid significantly in the interpretation of data from waste drums and other containers.
An additional task under development in API is the neutron tomography program currently in progress at the University of California, Santa Barbara. The University of California, Santa Barbara has an extensive background in neutron tomography and believes that the STL neutron generator flux is sufficient for tomographic purposes.

\section{TECHNOLOGY NEEDS}

API addresses the need for the nondestructive evaluation of waste drums and other closed containers by single-sided, non-intrusive methods.

\section{COLLABORATION/TECHNOLOGY TRANSFER}

Preliminary discussions are in progress with Martin Marietta Energy Systems on the possible use of API to interrogate the piping in the $\mathrm{UF}_{6}$ cascade and with DOE Arms Control for possible use of API for weapons verification. However, as of yet, there has been no transfer of API technology.

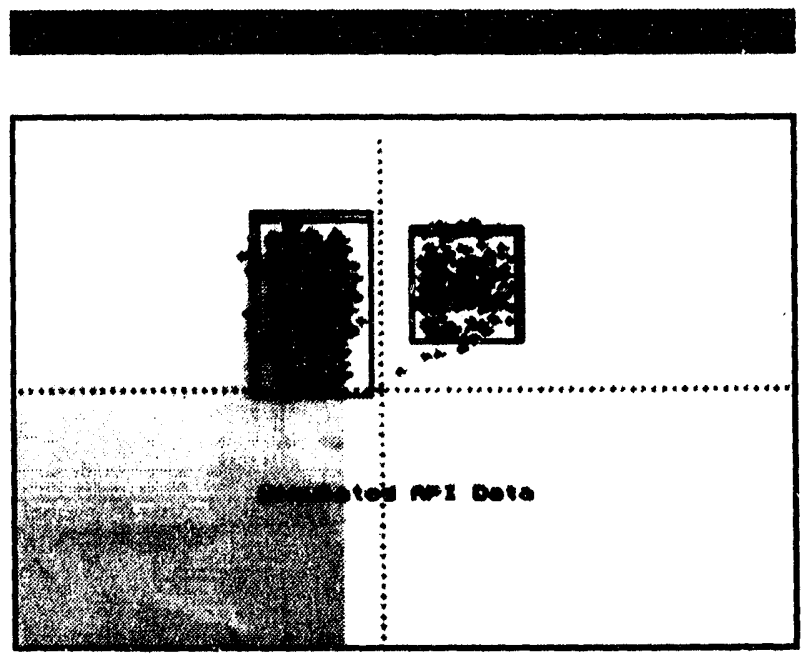

Figure 6.2c. Three-dimensional images of salt and water from simulated associated particle imaging data. 


\section{For more information, please}

contact:

\section{Paul Hurley}

Special Technologies Laboratory

5520 Ekwill Street, Suite B

Santa Barbara, CA 93111

(805) 681-2472

\section{Richard Lynn}

Technical Program Manager

(805) 681-2401 


\subsection{DEFINING REQUIREMENTS FOR EVALUATION AND TESTING OF CHARACTERIZATION TECHNOLOGIES}

\section{TASK DESCRIPTION}

This task will establish performance guidelines for, and monitor the progress of, selected OTD geophysical and remote-sensing programs in characterization, monitoring, and sensor technologies. Detailed sets of performance specifications will be written and used to review proposals for new projects and evaluate the progress of existing projects.

New project proposals will be examined for both technical and management content. Each experimental plan will be evaluated for overall technical merit by matching the proposed capabilities with the regulatory requirements to determine the probability of success in meeting those requirements. The sensors and their related instrumentation will be evaluated for performance expectation, while the data processing algorithms will be examined for technical merit and applicability. The proposed experimental plans, including schedules, milestones, cost estimates, and ultimate objectives in addition to the performance specifications, will be reviewed for reality and consistency. Similar proposals will also be screened to ensure complementarity and prevent duplication.

Serving OTD as a facilitator, the status and progress of existing programs will also be reviewed in cooperation with the principal investigators (PIs) for both technical and management content, and to advise and assist the PIs in meeting the performance goals and objectives of the programs. Low-profile, informal, on-site visits will be made, as appropriate, to selected laboratories to enhance the quality of technical assessments. Evaluation criteria for each of the programs will be established for the various measurement technologies to provide standards against which the performance of individual projects can be compared. These criteria will then be used to determine how the facilitator can work with the PI to ensure that the measured values meet the regulatory requirements, that the projected milestones have been reached, that the data are both reasonable and realistic, and that the system performed as proposed and anticipated.

The results of these evaluations will be transmitted to the Program Manager for appropriate action.

\section{ACCOMPLISHMENTS}

Selected programs involving ionizing radiation technologies continue, and are currently being monitored for technical content, status, and progress. Serving as a facilitator for scheduled on-site visits, the programs are reviewed as an on-going process with the appropriate PIs to assess the programs for technical content, and to assist in anticipating and resolving potential problems relating to scheduling and/or budgets. In this manner, the PI and the OTD representative (the facilitator), working as a team, will significantly contribute to the quality of the program and to its ultimate success in meeting the original performance goals and objectives. 


\section{TECHNOLOGY NEEDS}

The establishment of standards of quality (including performance specifications) of OTD programs will provide principal investigators, DOE customers, and DOE program reviewers with guidelines that can be used to evaluate existing and future OTD proposals for both quality and relevance.

\section{For more information, please}

contact:

\section{Paul Hurley}

Special Technologies Laboratory

5520 Ekwill Street, Suite B

Santa Barbara, CA 93111

(805) 681-2472

\section{Richard Lynn}

Technical Program Manager

(805) 681-2401 


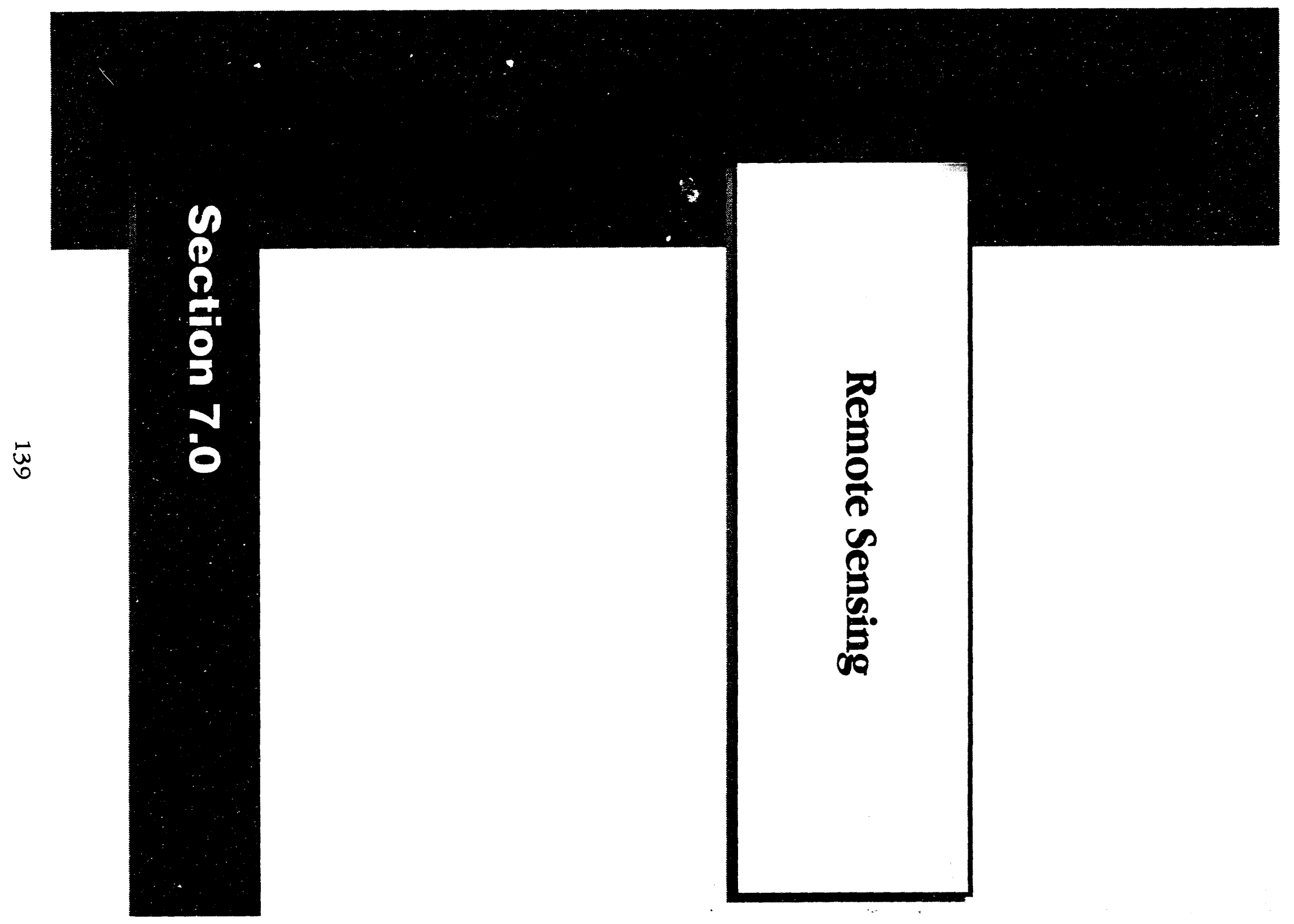




\subsection{REMOTE SENSING SYSTEMS DEVELOPMENT}

\section{TASK DESCRIPTION}

The focus of this project is the coordinated development and evaluation of existing sensor systems and new remote sensing technologies for environmental restoration and waste management efforts. The objective is to provide a methodology for applying current multispectral and next-generation hyperspectral remote sensing techniques to surface characterization studies. Multispectral and hyperspectral aircraft data will be acquired over various DOE sites. Targets that are representative of local needs will be specified by site personnel. Field data will be collected and used to remove solar, atmospheric, and instrument effects from selected aircraft data. The resulting apparent reflectance data sets will be useful for identifying surface materials and detecting changes in surface characteristics. Techniques for analyzing multispectral and hyperspectral data will be developed, tested and modified as necessary. A subtask to this work includes the development of algorithms for improved image registration, and also development of an image browse system to rapidly select suitable data for analysis.

\section{TECHNOLOGY NEEDS}

At many DOE sites, there is a need for noninvasive, in situ characterization of contaminants and resulting alteration of surface materials. The list of contaminants found on DOE sites includes a variety of organic and inorganic compounds, such as lubricants, fuels, solvents, and dense non-aqueous phase liquids. Multispectral and hyperspectral sensors will be evaluated on their usefulness for detecting and identifying contaminants exposed on the surface. Other needs include the delineation of burial sites, detection of vegetation stress caused by contamination, monitoring of site operations and remedial activities, and detection of geologic structures affecting water transport processes.

Given that airborne remote sensing imagery can be difficult to integrate with Geographic Information System databases, another task is to address the need for developing algorithms to more robustly correct for image distortions caused by viewing and target geometry, and aircraft roll, pitch, and yaw.

\section{ACCOMPLISHMENTS}

Three hyperspectral image processing software packages have been obtained and evaluated. These are the Hyperspectral Image Processing System (HIPS), the Spectral Image Processing System (SIPS), and the Environment for Visualization (ENVI). ENVI in particular represents state-of-the-art hyperspectral data processing. Ongoing collaboration with software developers is furthering the development of algorithms for performing subpixel analysis. Subpixel analysis involves the detection and identification of various materials occurring mixed within pixels (see Table 7.1).

Various chemicals occur as contaminants on DOE sites. Spectra of many of these compounds are being obtained from chemical companies and from the U.S. Geological Survey. Several spectral libraries have also been acquired from Brown University, the University 


\begin{tabular}{|l|}
\hline \multicolumn{2}{|c|}{ ALGORITHM CONPARISON } \\
Based on RSL helicopter scanner imagery (about \\
1000 lines) and aerial photo as a regiatration base \\
83 image control points \\
27 independent test points \\
Standard Polynomial (3rd order) \\
Finite Element (30x30 gridding) \\
Biharmonic Multiquadric
\end{tabular}

Table 7.1. Table comparing the root mean squared error of two standard image registration algorithms with the newly developed multiquadric algorithm. The registration error in the multiquadric method is less.

of Colorado, the Jet Propulsion Laboratory (NASA), Goddard Space Flight Center, the U.S. Army Corps of Engineers, and Johns Hopkins University.
In FY93, Daedalus Multispectral Scanner (MSS) data were collected over the LANL and the INEL (see Figure 7.1a). Analysis of these data is ongoing, but significant results have been produced thus far. In two areas, the limits of burial sites were discerned. Several geologic structures, likely controlling groundwater movement, were detected. Some features that site personnel were not aware of were discovered, including a series of shallow trenches possibly related to the removal of an aboveground pipeline. Perhaps the most interesting feature discovered in the data is a row of mostly unvegetated circles. LANL personnel were aware of a similar set of circles a few kilometers away. In the newly discovered set, there are eighteen circles, typically more than a meter in diameter. Site personnel were informed of the results of the data analysis and are using the results to direct ongoing characterization efforts. The analysis of the LANL and INEL MSS data is continuing. Data from

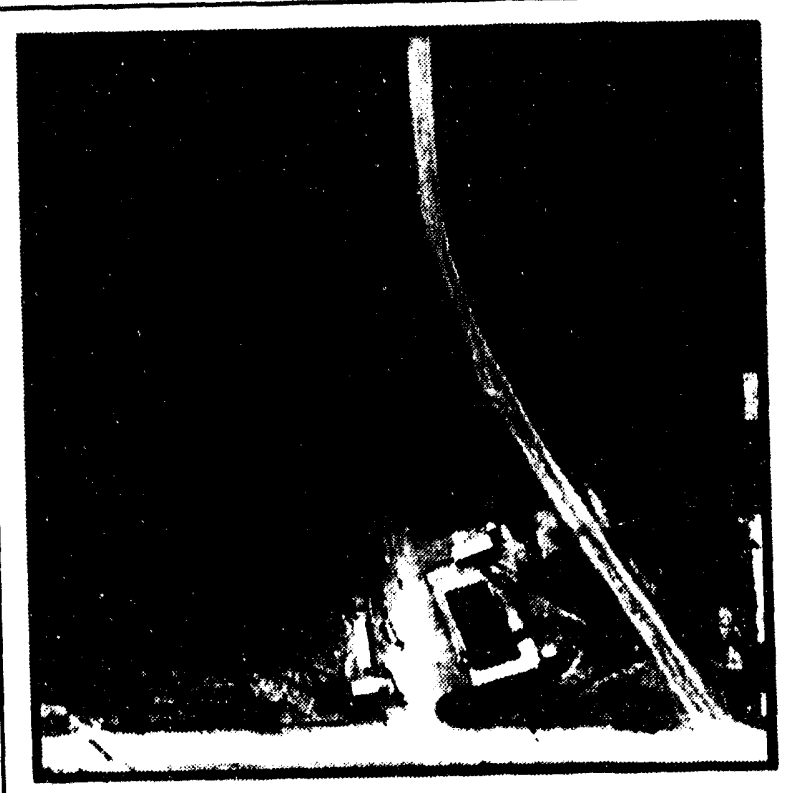

Arial Photo

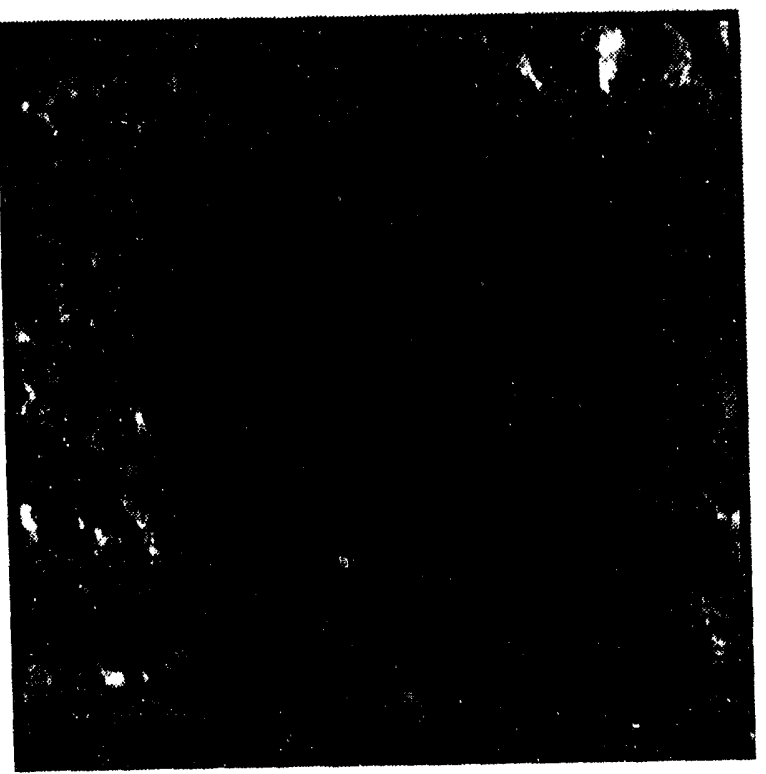

2.2 Micrometers

Figure 7.1. Comparison of aerial photo with Daedalus Multispectral Scanner channel 10. A row of anomalous white circles, discovered in the scanner image, are not readily apparent in the aerial photo. They are a series of unvegetated circles due to unknown causes. 
a hyperspectral instrument, the Airborne Visible/Infrared Imaging Spectrometer(AVIRIS), acquired over LANL, is also currently being analyzed.

Contacts were made with personnel operating hyperspectral airborne sensors. The AVIRIS and/or the Hyperspectral Digital Imagery Collection Experiment (HYDICE) will likely be flown over at least one DOE site in the coming year.

Meetings were held with Disney/EPCOT Center scientists to plan collaborative research on stressed vegetation. Reflectance spectra of stressed greenhouse plants will be used to determine the potential for remote sensors to evaluate vegetation health at DOE sites.

A new image registration multiquadric algorithm has been written and implemented with improved accuracy results. Automation of the control point selection process is underway.

\section{COLLABORATION/TECHNOLOGY TRANSFER}

Technologies developed for commercialization will likely involve techniques for calibrating and analyzing multi- and hyperspectral remote sensing data. Transfers of techniques developed and research results will be accomplished through discussions and meetings with DOE site personnel, as well as presentations at various national meetings. Several image processing vendors have expressed interest in incorporating the multiquadric registration algorithm into their software. A cooperative technology transfer effort will follow the publication of an article in a technical journal.
For more information, please contact:

Joe Zamudio EG\&G-RSL 2211 Hollywood Las Vegas, NV 89193 (702) 295-8811

Katie McWilliam Technical Program Manager (702) 295-1031 


\subsection{LASER INDUCED FLUORESCENCE IMAGING}

\section{TASK DESCRIPTION}

This task includes the development of hardware, software, and analysis methods for ground-based and airborne laser-induced fluorescence (LIF) systems. Applications for this technique include the detection of depleted uranium, VOCs, fuels, and vegetation stress.

Focus for the first half of this fiscal year has been in two major areas: (1) the development of an airborne gated line scan camera system, due to be flown for the first time in the third quarter of this year, and (2) fabrication of a portable, hand-held, fluorescence. imaging system.

\section{TECHNOLOGY NEEDS}

\section{Airborne Gated Line Scan Camera System.}

The airborne LIF Imaging (LIFI) system is being built around a multi-spectral gated line scan camera. This camera has been designed specifically for making LIFI measurements from an airborne platform. Critical building blocks of the camera include:

- A low-dispersion optically fast ( $\mathrm{f} / 2$ ) concave holographic grating;

- A 96x1024 pixel Dalsa camera, coupled to a micro-channel-plate image intensifier (MCPII) with an anamorphic optical system;

- An Alacron I-860 base image processing board. This board allows spectral features to be extracted from the data and processed in real-time; and

- A disk array provides up to 13 giga-bytes of raw data storage.
A layout of the airborne pallet, including the camera, is shown in figure 7.2a. A YAG and an excimer laser provide fluorescence excitation at two different wavelengths. The actual experimental plan for the upcoming fight test is to run the camera with three different light sources, each running at $60 \mathrm{hz}$., interleaved to produce a system repetition rate of $180 \mathrm{hz}$. The three different light sources include ultraviolet (UV) excimer excitation at $308 \mathrm{~nm}$, green YAG excitation at $532 \mathrm{~nm}$, and solar illumination. Dynamic control of the MCPII gate width adjusts the sensitivity of the detector for the solar illuminated experiment.

The three different illumination sources allows extraction of information contained in the excitation and UV-visible reflectance spectra of fluorescent materials. For uranium detection, the $308 \mathrm{~nm}$ excitation works well. Previous field work comparing UV and visible excitation of plants has shown that plant vigor information lies in the comparison of the two excitation band strengths. The UV excitation tends to primarily excite the cellulose, while the $532 \mathrm{~nm}$ excitation activates the chlorophyll bands directly. Ratios of these two bands have been correlated with stress in laboratory measurements. The solar channel is of interest in several ways: it will allow a direct

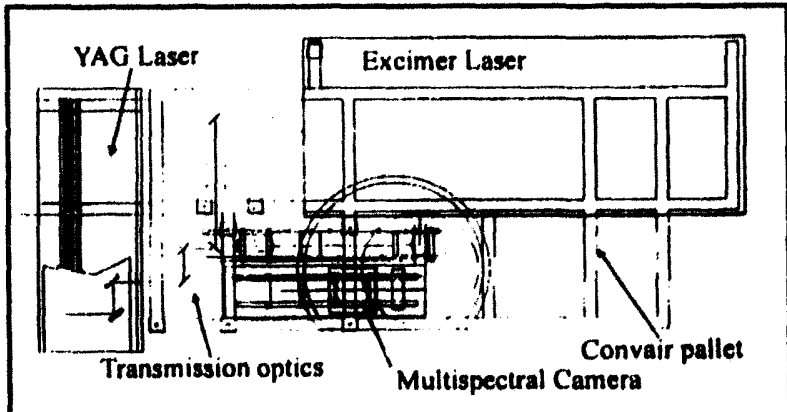

Figure 7.1a. Convair pallet layout. 
comparison of near hyper-spectral solar remote sensing results with LIFI; it will allow construction of a registered true color image of the target range in post processing; and, the UV sensitivity of the camera will enable analysis of reflectance bands near the solar blind.

\section{Portable Hand-held Laser Induced Fluores- cence Instrument.}

During last year's LIFI field tests at the Oak Ridge Gaseous Diffusion Plant (K-25), it became clear that laser induced fluorescence images from uranic compounds could be of great help to the D\&D efforts at that site. The field package that was assembled last year weighed over $1000 \mathrm{lbs}$. and required a small truck and several scientists for support. Data processing was accomplished on work stations at the home base. Final imagery was not available for some time. It was obvious that for this technique to be truly useful in the field, it must be made much lighter, easier to operate, and the processing must happen rapidly on site.

Figure 7.2b shows an artist's conception of a portable handheld LIFI instrument currently under development. The instrument will be housed on a one-man, portable cart and will be battery-powered. Light from a small flash

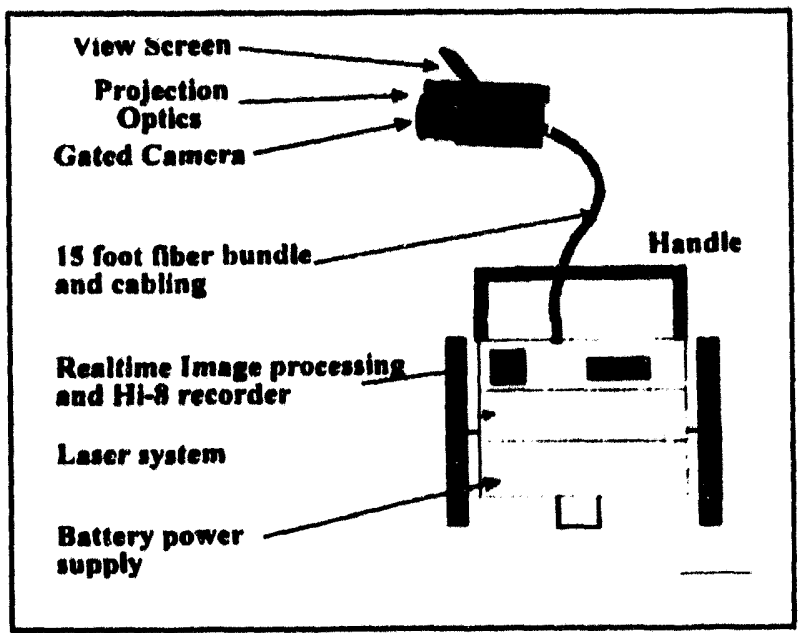

Figure 7.2b. Hand-held fluorescent instrument. lamp, fed by a YAG laser, will be fiberoptically coupled to a handheld pointing device. The detector will be a commerciallyavailable gated intensified video camera.

The detection algorithm developed last year requires control of the MCPII gate width and phase to detect the long-lived phosphorescence emanating from uranic compounds. This delayed gate image was colored red and overlaid upon an image resulting from either prompt fluorescence or ambient light.

The gate control and processing algorithm have been automated in the hand-held instrument. A low power computer and a custom video card, coupled with a small color LCD display, will enable the operator to see the location of the contamination in real-time, as well as record the signature for incorporation into a permanent database.

\section{ACCOMPLISHMENTS}

Assembly and fabrication of the airborne instrumentation is nearing completion. The system is being assembled in the laboratory for a final check out prior to installation in the DOE Convair 580 aircraft in March. The flight tests are scheduled to commence in April.

The preliminary design and specification of the hand-held instrument has been completed. The purchase orders for the major components, including the laser, the fiber-optic, and the video processing board have been placed. Demonstration is currently scheduled for the fourth quarter of this year. 
COLLARORATION/TECHNOLOGY TRANSFER

It is acknowledged that the portable fluorescence detector may have technology transfer potential, however, no contacts have been made to date.

For further information, please contact:

\section{John DiBenedetto}

EG\&G E/EM

130 Robin Hill Road

Goleta, CA 93117-3186

(805) 681-2240

Katie McWilliam

Technical Program Manager

(702) 295-1031 


\section{How To Get Involved}

\section{Section $\mathbf{8 . 0}$}


蓠 


\section{WORKING WITH THE DOE OFFICE OF ENVIRONMENTAL RESTORATION AND WASTE MANAGEMENT}

DOE provides a range of programs and services to assist universities, industry, and other private-sector organizations and individuals interested in developing or applying environmental technologies. Working with DOE Operations Offices and management and operating contractors, EM uses conventional and innovative mechanisms to identify, integrate, develop, and adapt promising emerging technologies. These mechanisms include contracting and collaborative arrangements, procurement provisions, licensing of technology, consulting arrangements, reimbursable work for industry, and special consideration for small business.

\section{COOPERATIVE RESEARCH AND DEVELOPMENT AGREEMENTS (CRADAS)}

EM will facilitate the development of subcontracts, $R \& D$ contracts, and cooperative agreements to work collaboratively with the private sector.

EM uses CRADAs as an incentive for collaborative R\&D. CRADAs are agreements between a DOE R\&D laboratory and any non-Federal source to conduct cooperative $R \& D$ that is consistent with the laboratory's mission. The partner may provide funds, facilities, people, or other resources. DOE provides the CRADA partner access to facilities and expertise; however, no Federal funds are provided to external participants. Rights to inventions and other intellectual property are negotiated between the laboratory and participant, and certain data that are generated may be protected for up to 5 years.

Consortia will also be considered for situations where several companies will be combining their resources to address a common technical problem. Leveraging of funds to implement a consortium can offer a synergism to overall program effectiveness.

\section{PROCUREMENT MECHANISMS}

DOE EM has developed an environmental management technology development acquisition policy and strategy that uses phased procurements to span the RDDT\&E continuum from applied R\&D concept feasibility through full-scale remediation. DOE EM phased procurements make provisions for unsolicited proposals, but formal solicitations are the preferred responses. The principle contractual mechanisms used by EM for industrial and academic response include Research Opportunity Announcements (ROAs) and Program R\&D Announcements (PRDAs). EM uses the ROA to solicit advanced research and technologies for a broad range of cleanup needs. The ROA supports applied research ranging from concept feasibility through full-scale demonstration. In addition, the ROA is open continuously for a full year 
following the date of issue and includes a partial procurement set aside for small businesses. Typically, ROAs are published annually in the Federal Register and the Commerce Business Daily, and multiple awards are made.

PRDAs are program announcements used to solicit a broad mix of R\&D and DT\&E proposals. Typically, a PRDA is used to solicit proposals for a wide-range of technical solutions to specific EM problem areas. PRDAs may be used to solicit proposals for contracts, grants, or cooperative agreements. Multiple awards, which may have dissimilar approaches or concepts, are generally made. Numerous PRDAs may be issued each year.

In addition to PRDAs and ROAs, EM uses financial assistance awards when the technology is developed for public purpose. Financial assistance awards are solicited through publication in the Federal Register. These announcements are called Program Rules. A Program Rule can either be a onetime solicitation or an open-ended, general solicitation with annual or more frequent announcements concerning specific funding availability and desired R\&D agreements. The Program Rule can also be used to award both grants and cooperative agreements.

EM awards grants and cooperative agreements if fifty-one percent or more of the overall value of the effort is related to a public interest goal. Such goals include possible non-DOE or other Federal agency participation and use, advancement of present and future U.S. capabilities in domestic and international environmental cleanup markets, technology transfer, advancement of scientific knowledge, and education and training of individuals and business entities to advance U.S. remediation capabilities.

\section{LICENSING OF TECHNOLOGY}

DOE contractor-operated laboratories can license DOE/EM-developed technology and software to which they elect to take title. In other situations where DOE owns title to the resultant inventions, DOE's Office of General Counsel will do the licensing. Licensing activities are done within existing DOE intellectual property provisions.

\section{TECHNICAL PERSONNEL EXCHANGE ASSIGNMENTS}

Personnel exchanges provide opportunities for industrial and laboratory scientists to work together at various sites on environmental restoration and waste management technical problems of mutual interest. Industry is expected to contribute substantial cost-sharing for these personnel exchanges. To encourage such collaboration, the rights to any resulting patents go to the private sector company. These exchanges, which can last from 3 to 6 months, are opportunities for the laboratories and industry to better understand the differing operating cultures, and are an ideal mechanism for transferring technical skills and knowledge.

\section{CONSULTING ARRANGEMENTS}

Laboratory scientists and engineers are available to consult in their areas of technical expertise. Most contractors operating laboratories have consulting provisions. Laboratory employees who wish to consult can sign non-disclosure agreements, and are encouraged to do so. 


\section{REIMBURSABLE WORK FOR INDUSTRY}

DOE laboratories are available to purform work for industry, or other Federal agencies, as long as the work pertains to the mission of a respective laboratory and does not compete with the private sector.

The special technical capabilities and unique facilities at DOE laboratories are an incentive for the private sector to use DOE's facilities and contractors expertise in this reimbursable work for industry mode. An advanced class patent waiver gives ownership of any inventions resulting from the research to the participating private sector company.

\section{EM SMALL BUSINESS TECHNOLOGY INTEGRATION PROGRAM}

The EM Small Business Technology Integration Program (SB-TIP) seeks the participation of small businesses in the EM Research, Development, Demonstration, Testing and Evaluation programs. Through workshops and frequent communication, the EM SB-TIP provides information on opportunities for funding and collaborative efforts relative to advancing technologies for DOE environmental restoration and waste management applications.

EM SB-TIP has established a special EM procurement set aside for small firms (500 employees or less) to be used for applied research projects, through its ROA. The program also serves as the EM liaison to the DOE Small Business Innovation Research Program Office, and interfaces with other DOE small business offices, as well.

\section{CONTACT}

\section{DAVID W. GEISER, ACTING DIRECTOR}

International Technology Exchange Division

EM-521

Environmental Restoration and Waste

Management Technology Development

U.S. Department of Energy

Washington, D.C. 20585

(301) $903-7940$ 


\section{EM CENTRAL POINT OF CONTACT}

The EM Central Point of Contact is designed to provide ready access to prospective research and business opportunities in waste management, environmental restoration, and decontamination and decommissioning activities, as well as information on EM-50 IPs and IDs. The EM Central Point of Contact can identify links between industry technologies and program needs, and provides potential partners with a connection to an extensive complex-wide network of DOE Headquarters and field program contacts.

The EM Central Point of Contact is the best single source of information for private-sector technology developers looking to collaborate with EM scientists and engineers. It provides a real-time information referral service to expedite and monitor private-sector interaction with EM.

To reach the EM Central Point of Contact, call 1-800-845-2096 during normal business hours (Eastern time).

\section{OFFICE OF RESEARCH AND TECHNOLOGY APPLICATIONS}

Office of Research and Technology Applications (ORTAs) serve as technology transfer agents at the Federal laboratories, and provide an internal coordination in the laboratory for technology transfer and an external point of contact for industry and universities. To fulfill this dual purpose, ORTAs license patents and coordinate technology transfer activities for the laboratory's scientific departments. They also facilitate one-on-one interactions between the laboratory's scientific personnel and technology recipients, and provide information on laboratory technologies with potential applications in private industry for state and local governments.

For more information about these programs and services, please contact:

Claire Sink, Director

Technology Integration Division

EM-521

Environmental Restoration and Waste

Management Technology Development

U.S. Department of Energy

Washington, D.C. 20585

(301) 903-7928 


\section{Acronyms}

\section{Section $\mathbf{9 . 0}$}




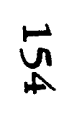


AEC

ANL

AOTF

API

AQMs

AVIRIS

CATD

CBSAM

CERCLA

CMAS

CMST-IP

CPAC

CPT

CRC

CSM

DAS

DNAPLS

DoD

DOE

DSITMS

EDTA

EM

ENVI

EPA
Army Environmental Center

Argonne National Laboratory

acousto-optic tunable filter

Associated Particle Imaging

Air-Quality Monitors

Airborne Visible/Infrared Imaging Spectrometer

Center for Advanced Technology Development

covalently bound self-assembled monolayer

Comprehensive Environmental Response, Compensation, and Liability Act

micromist air sampler

Characterization, Monitoring, and Sensor Technology Integrated Program

Center for Process Analytical Chemistry

cone penetrometer truck

Coleman Research Company

Colorado School of Mines

diode array spectrophotometers

Dense Non-Aqueous Phase Liquid

Department of Defense

Department of Energy

Direct Sampling Ion Trap Mass Spectrometry

Ethylenediamine Tetraacetate

Environmental Restoration and Waste Management

Environment for Visualization

U.S. Environmental Protection Agency 
ERT

ESC

ET

FFP

FSU

FTIR-ATR

FTIR-PAS

FUSRAP

GC

GC-ECD

GC/ITD

GPER

HEIS

HIPS

HYDICE

ICP-MS

ID

IDS

IP

ISU

ITMS

ITP

LA

LA-ICP-AES

LA/MS

LANL

LIBS electrical resistance tomography

\section{Expedited Site Characterization}

emerging technologies

finesse fiber-optic, or, Fabry-Perot interferometer

former Soviet Union

Fourier-transform infrared-attenuated total reflection

Fourier-transform infrared photoacoustic spectroscopy

Formerly Utilized Sites Remedial Action Program

gas chromatographic

gas chromatography/mass spectrometry

gas chromatograph/ion trap mass spectrometer

geophysics performance evaluation range

Hanford Environmental Information System

Hyperspectral Image Processing System

Hyperspectral Digital Imagery Collection Experiment

inductively coupled plasma-mass spectrometer

Integrated Demonstrations

Integrated Demonstration Site

Integrated Programs

Iowa State University

ion trap mass spectrometry

in-tank processing

laser ablation

laser ablation - inductively coupled plasma - atomic emission spectroscopy

Laser-Ablation/Mass-Spectrometry

Los Alamos National Laboratory

laser-induced breakdown spectroscopy 
Laser Induced Fluorescence (LIF)

LLNL

Lawrence Livermore National Laboratory

LOW

Liquid Observation Well

LRAD

Long Range Alpha Detector

MARS

Mobile Analysis Reconnaissance System

MCPII

micro-channel-plate image intensifier

MDLEST

MINATOM

mobile demonstration laboratory for environmental screening technologies

NRC

Russian Ministry of Atomic Energy

Nuclear Regulatory Commission

ORTAs

Office of Research and Technology Applications

OTD

Office of Technology Development (EM-50)

PAH

Polycyclic aromatic hydrocarbon

PAWS

portable acoustic wave sensor

PCE

tetrachloroethylene

PI

Principal Investigator

PNL

Pacific Northwest Laboratories

ppbv

part-per-billion by volume

pptw

part-per-trillion by weight

PRDAs

Program R\&D Announcements

PVAI-ATR-IR

polarized variable-angle internal attenuated total reflection infrared

QCMs

quartz crystal microbalances

RCRA

Resource and Recovery Act

RD/DT\&E

Research and Development/Demonstration, Testing, and Evaluation

ROA

Research Opportunity Announcement

RVS

Preverse vertical seismic profiles

SAWS

surface acoustic wave sensor 
SBIR

SB-TIP

SCAPS

SGI

SIMS

SIPS

SLAPS

SNL

SOPT

SSTs

SVOCs

TBP

TCE

TDR

$3 \mathrm{D} / 1 \mathrm{C}$

$3 \mathrm{D} / 3 \mathrm{C}$

TFRs

TIP

TIRS

TSCA

TTPs

TWRS
Small Business Innovative Research

Small Business Technology Integration Program

Site Characterization and Analysis Penetrometer System

Sol-gel indicator

Secondary ion mass spectrometry

Spectral Image Processing System

St. Louis Airport site

Sandia National Laboratory

state-of-the-practice technologies

single-shell tanks

semi-volatile organic compounds

tributyl phosphate

trichloroethylene

Time Domain Reflectometry

three-dimensional, one-component

three-dimensional, three-component

thin film resonators

Technology Integration Program

transient infrared spectroscopy

Toxic Substances Control Act

Technical Task Plans

Tank Waste Remediation System 

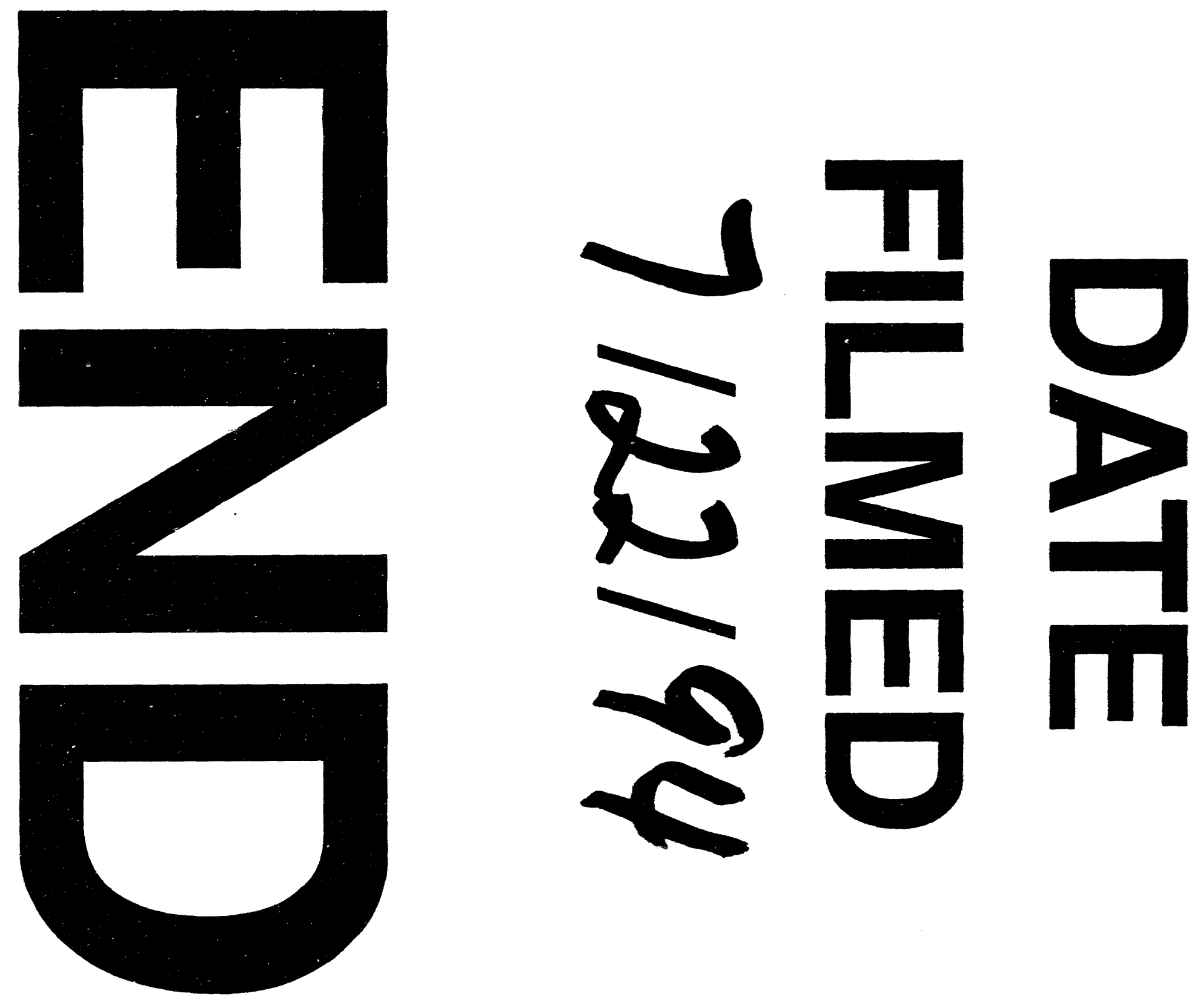
